


\title{
Der Hedgehog Rezeptor Patched bei der Tumorentstehung und in der Hämatopoese.
}

\author{
Dissertation \\ zur Erlangung des Doktorgrades \\ der Mathematisch-Naturwissenschaftlichen Fakultäten \\ der Georg-August-Universität zu Göttingen
}

\author{
vorgelegt von \\ Anja Uhmann \\ aus Erfurt
}

Göttingen 2006 
Referent:

Koreferentin:

Tag der mündlichen Prüfung:
Prof. Dr. W. Engel

PD Dr. S. Hoyer-Fender

06.07.06 
Die vorliegende Arbeit wurde in der Zeit von September 2002 bis April 2006 im Institut für Humangenetik der Universität Göttingen angefertigt.

Teile dieser Arbeit wurden veröffentlicht bzw. zum Druck eingereicht:

Uhmann A, Ferch U, Bauer R, Tauber S, Arzinam Z, Chen C, Hemmerlein B, Wojnowski L, Hahn H. A model for PTCH1/Ptch1-associated tumors comprising mutational inactivation and gene silencing. Int J Oncol, 2005 Dec; 27(6):1567-75.

Uhmann A, Dittmann K, Nitzki F, Kolova M, Frommhold A, Zibat A, Binder C, Adham I, T Heller, Armstrong V, Schulz-Schaeffer W, Wienands J, Hahn H. Specification and differentiation defects of the lymphoid lineage in conditional patched mutant mice. Nat. Immunol., 2006, eingereicht. 


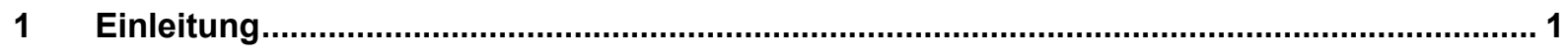

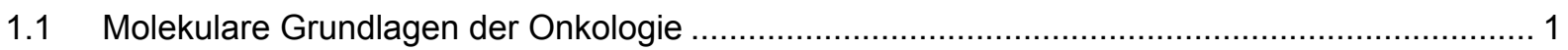

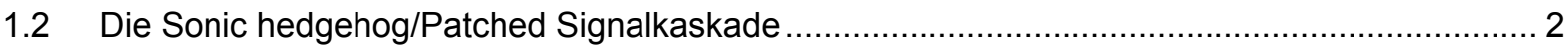

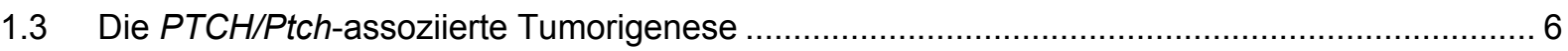

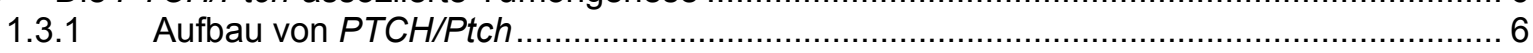

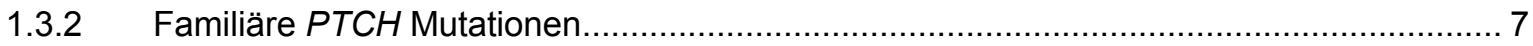

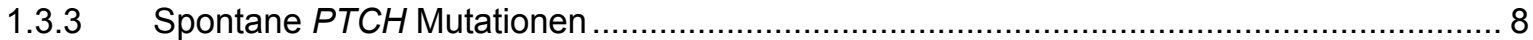

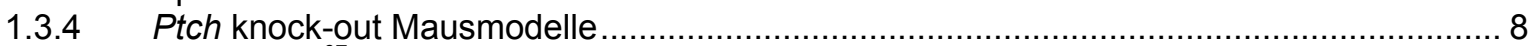

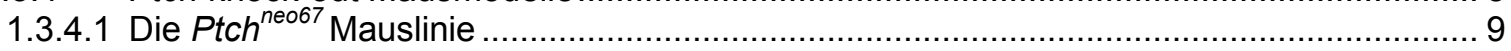

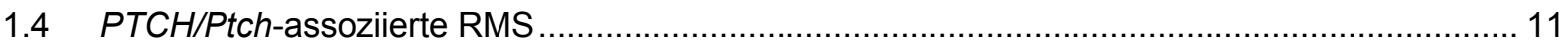

1.4.1 Entstehung von PTCH/Ptch-assoziierten RMS ….............................................. 12

1.4.1.1 Entstehungsmechanismus von humanen PTCH-assoziierten RMS .......................... 12

1.4.1.2 Entstehungsmechanismus von murinen Ptch-assoziierten RMS ............................... 12

1.4.1.3 Ursprungszelle von PTCH/Ptch-assoziierten RMS.................................................. 14

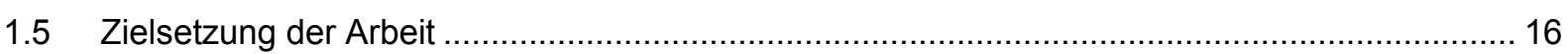

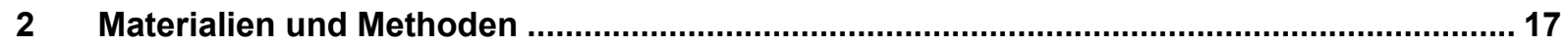

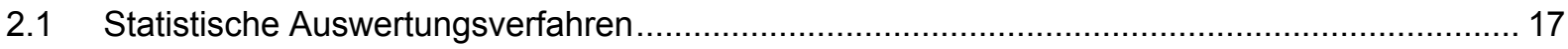

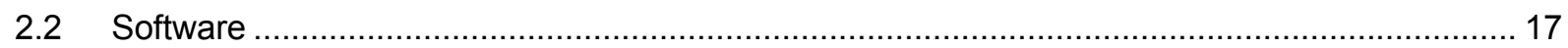

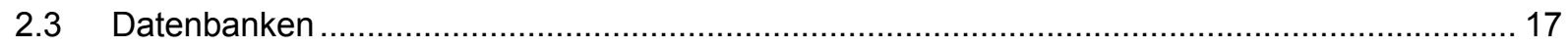

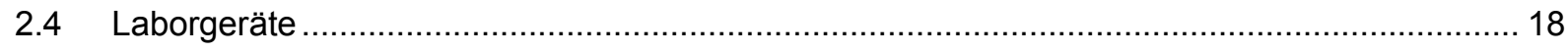

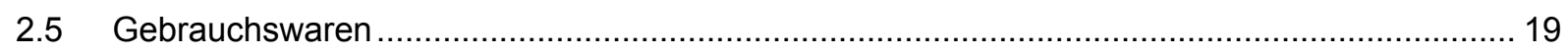

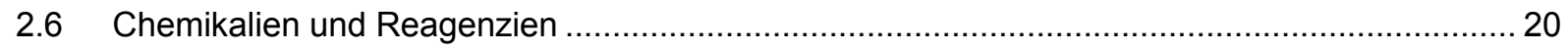

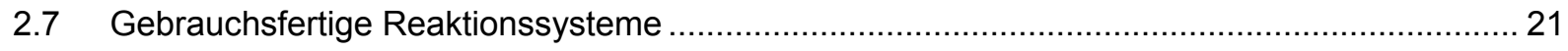

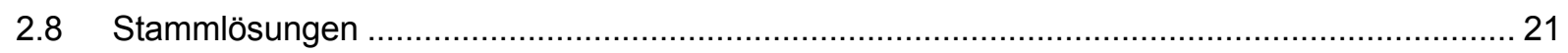

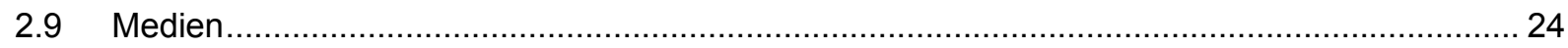

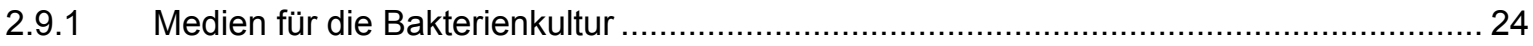

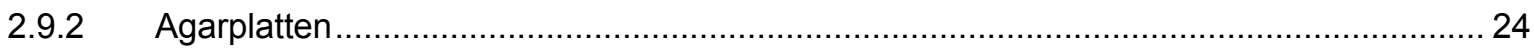

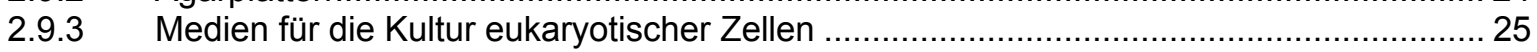

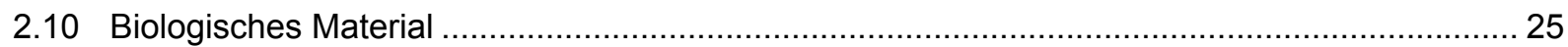

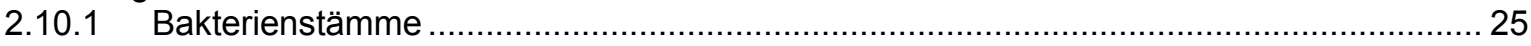

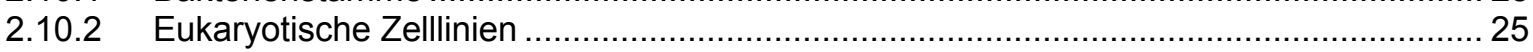

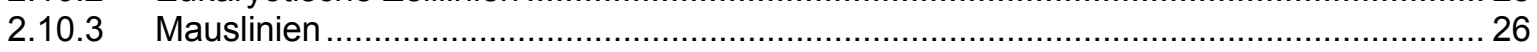

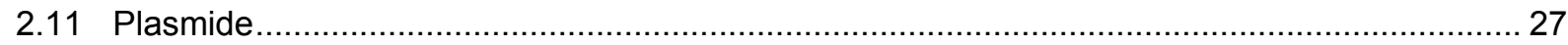

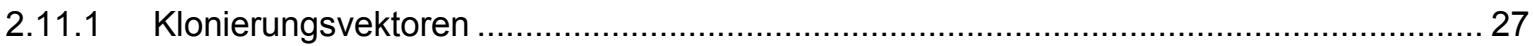

2.11.2 Eukaryotische Expressionsplasmide zur Analyse des Shh/Ptch-Signalweges .............. 27

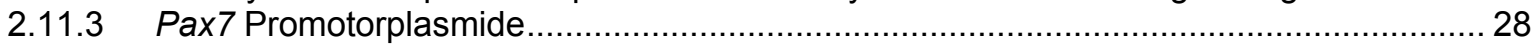

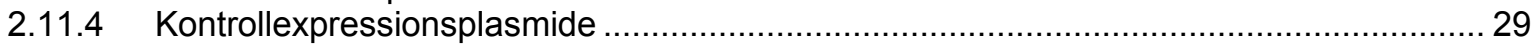

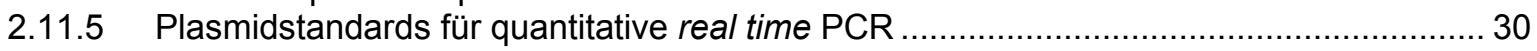

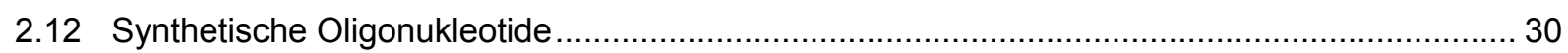

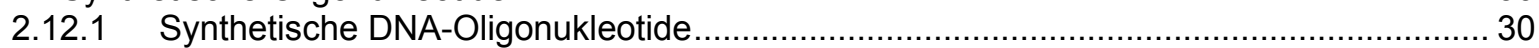

2.12.1.1 DNA-Oligonukleotide zur Genotypisierung von Mäusen ......................................... 30

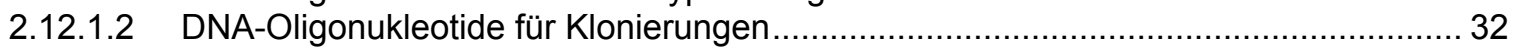

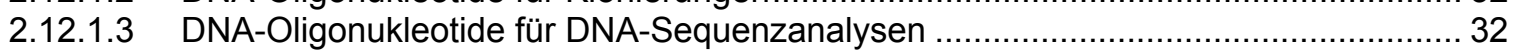

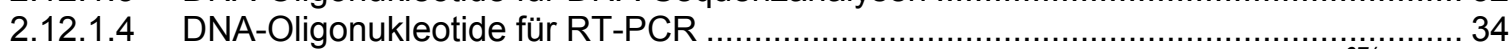

2.12.1.5 DNA-Oligonukleotide für den Transkript-spezifischen PCR-Assay in Ptch
Mäusen

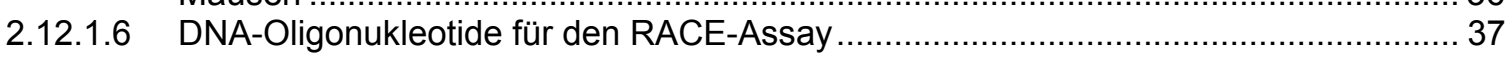

2.12.1.7 DNA-Oligonukleotide für die quantitative real time PCR ............................................. 37

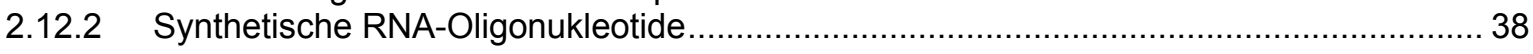

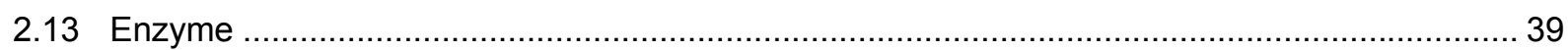




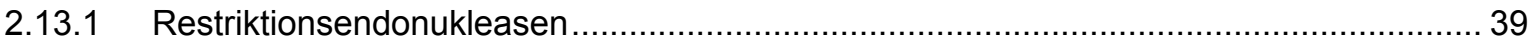

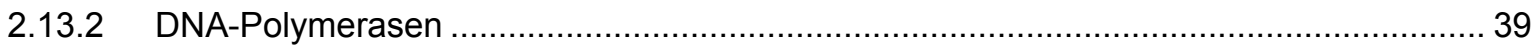

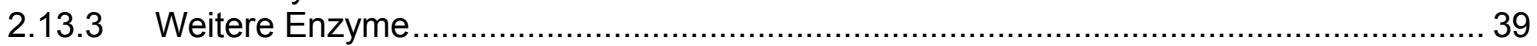

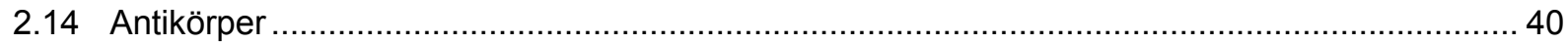

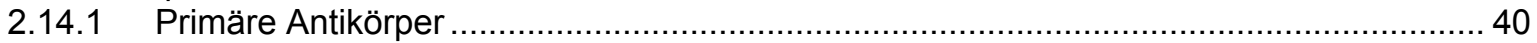

2.14.2 Sekundäre Antikörper und Fluorochrom-gekoppelte Streptavidin Reagenzien ............44 42

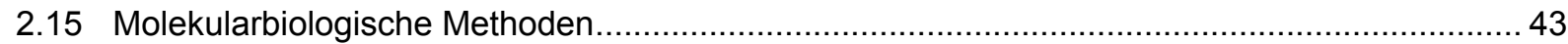

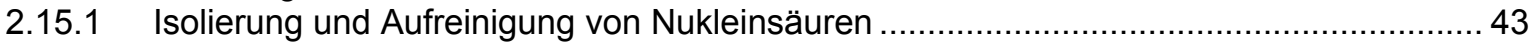

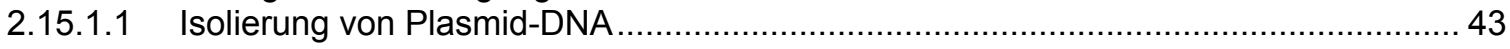

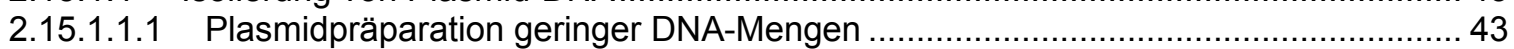

2.15.1.1.2 Plasmidpräparation geringer hochreiner DNA-Mengen ................................. 43

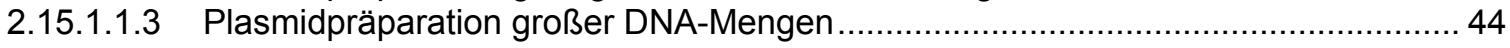

2.15.1.2 Ethanolfällung von DNA aus wässrigen Lösungen........................................ 44

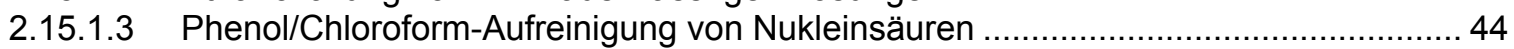

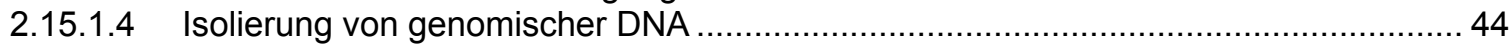

2.15.1.4.1 Isolierung von genomischer DNA aus eukaryotischer Zellkultur..........................44

2.15.1.4.2 Isolierung von genomischer DNA aus Gewebe (Schwanzbiopsie, Dottersack u. ä.) ..

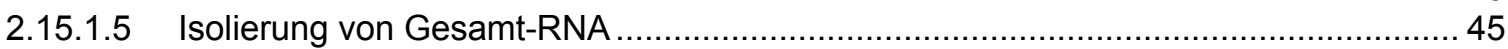

2.15.1.5.1 Isolierung von Gesamt-RNA aus eukaryotischer Zellkultur ................................45

2.15.1.5.2 Isolierung von Gesamt-RNA aus Geweben ............................................... 46

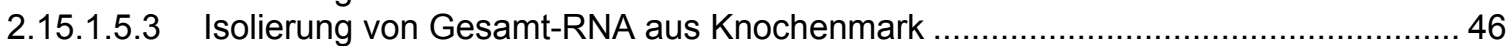

2.15.1.6 Isolierung von poly(A) ${ }^{+}$-RNA aus Gesamt-RNA ........................................... 46

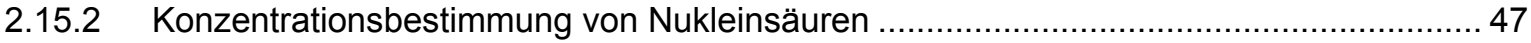

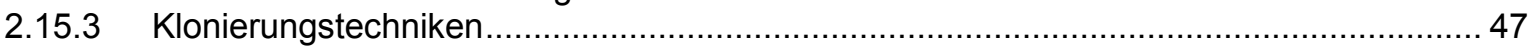

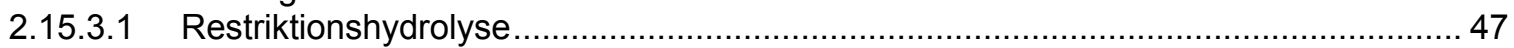

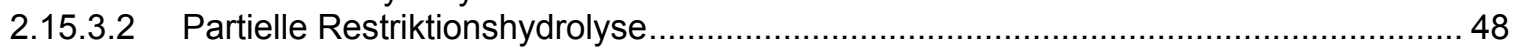

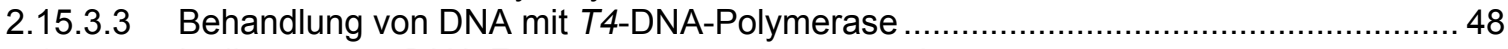

2.15.3.4 Isolierung von DNA-Fragmenten aus Agarosegelen ........................................ 48

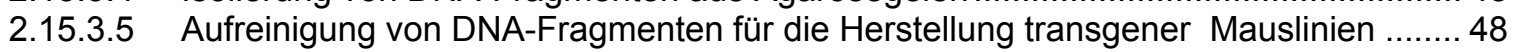

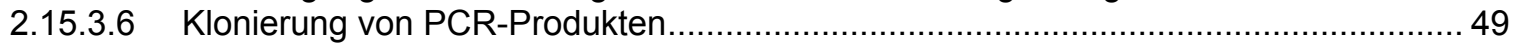

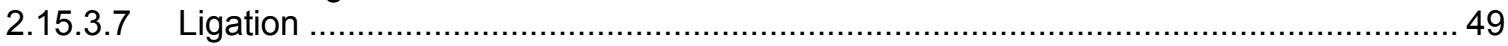

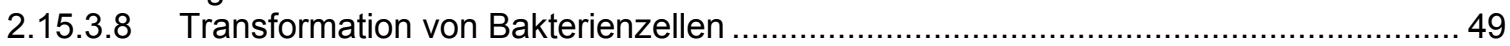

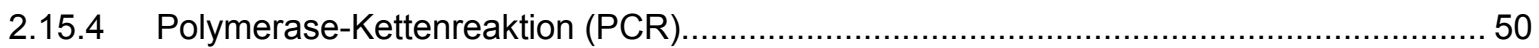

2.15.4.1 Polymerase-Kettenreaktion an Plasmid-DNA, cDNA und genomischer DNA ...........50

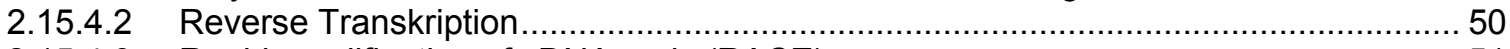

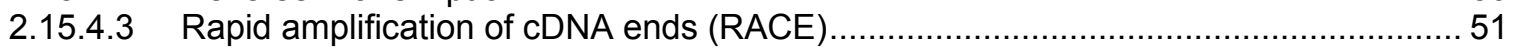

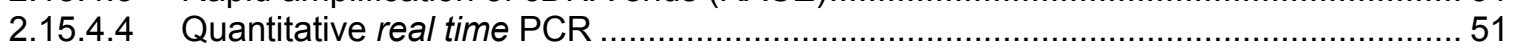

2.15.4.4.1 Aufbau und Auswertung der quantitativen real time PCR................................. 51

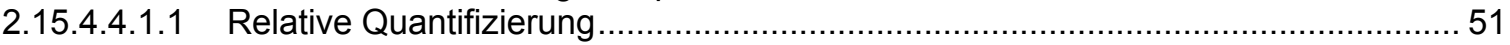

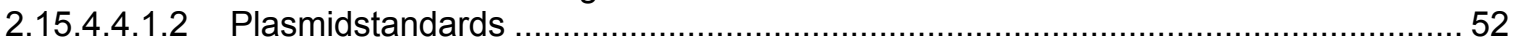

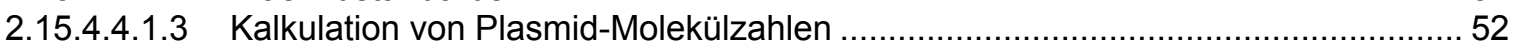

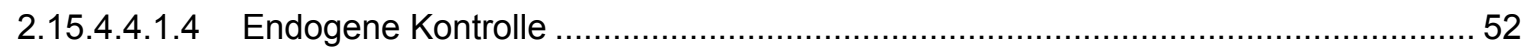

2.15.4.4.1.5 Durchführung und Aufbau der quantitativen real time PCR mit fluoreszenzmarkierten, sequenzspezifischen Sonden .................................... 53

2.15.4.4.1.6 Durchführung und Aufbau der quantitativen real time PCR mit SYBR green .......5 53

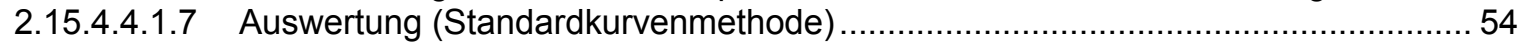

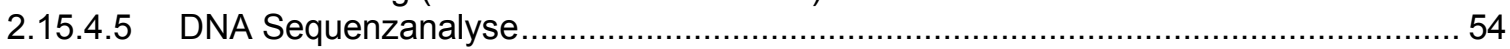

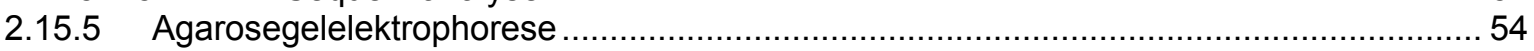

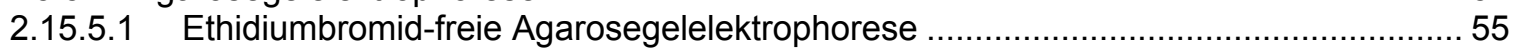

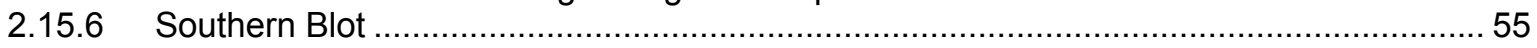

2.15.7 Klonierungen von eukaryotischen Expressionsplasmiden .................................... 57

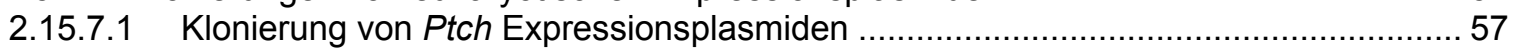

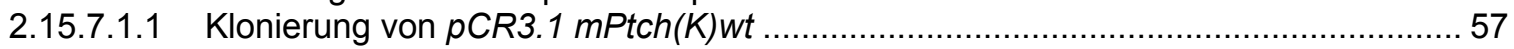

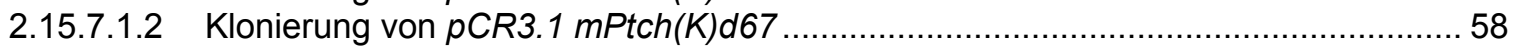

2.15.7.2 Klonierung der Pax7 Promotorplasmide ..................................................... 58

2.15.7.2.1 Klonierung der $p G L 3$ Pax7prom Reporterplasmide ....................................... 59

2.15.7.2.2 Klonierung des $p$ Pax7CreTM Plasmids ...................................................... 59

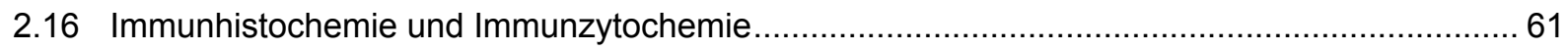

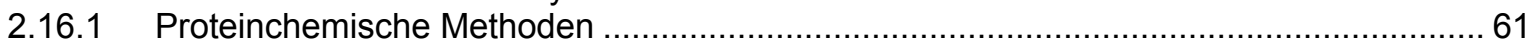




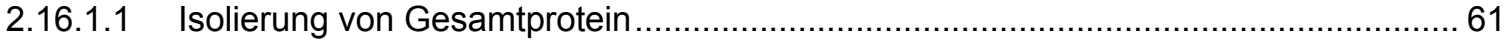

2.16.1.1.1 Isolierung von Gesamtprotein aus eukaryotischen Zellkulturen ............................61 61

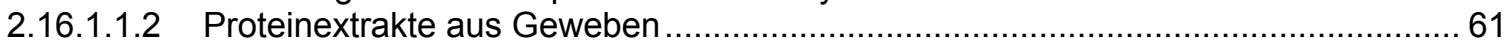

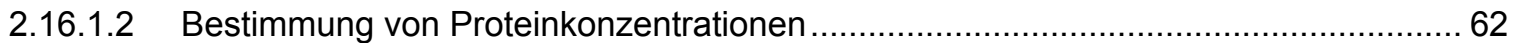

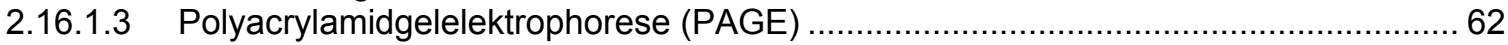

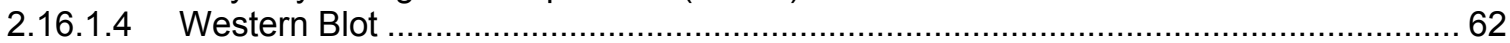

2.16.1.5 Aktivitätsnachweis des E. coli ß-Galaktosidase Proteins ........................................ 63

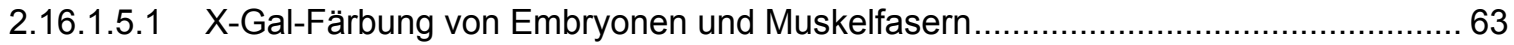

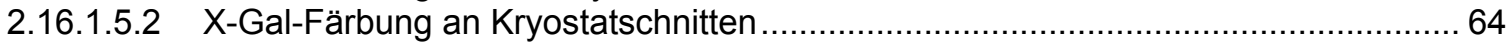

2.16.1.6 Quantitativer Aktivitätsnachweis der Luziferase (Dualer-Luziferase- Assay) und

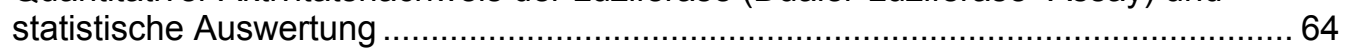

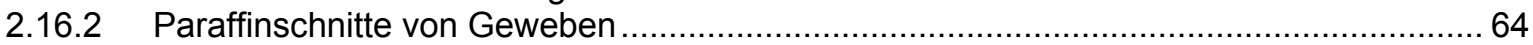

2.16.2.1 Gewebeeinbettung zum Anfertigen von Paraffinschnitten .......................................6 64

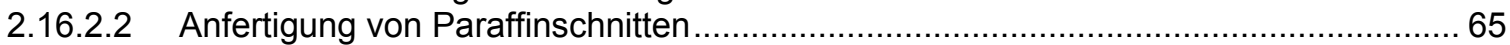

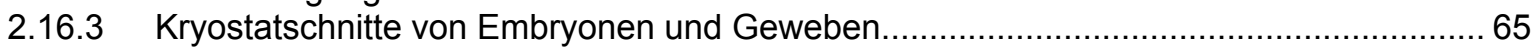

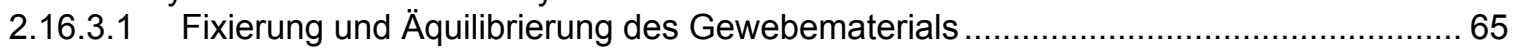

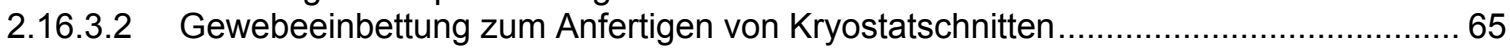

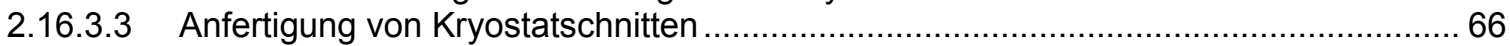

2.16.4 Hämatoxylin/Eosin (HE)-Färbung und Eindecken von Kryostat- und Paraffinschnitten.. 66

2.16.5 Immunhistologische Antikörperfärbungen an Paraffinschnitten ....................................6 66

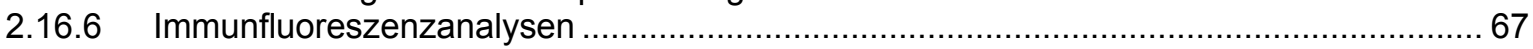

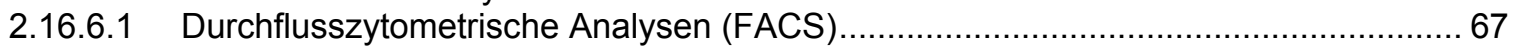

2.16.6.2 Immunfluoreszenzfärbungen an kultivierten Zellen, Muskelfasern und Kryostatschnitten...

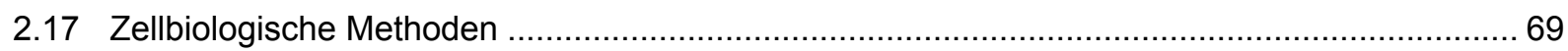

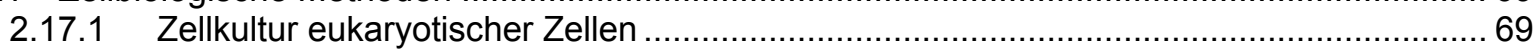

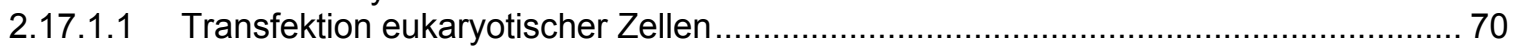

2.17.1.1.1 Transfektion eukaryotischer Zellen mit Expressionsplasmid-DNA .......................... 70

2.17.1.1.2 Transfektion eukaryotischer Zellen mit siRNA …............................................. 70

2.17.1.2 Stimulation des Shh/Ptch Signalweges durch Shh-N Protein ................................. 70

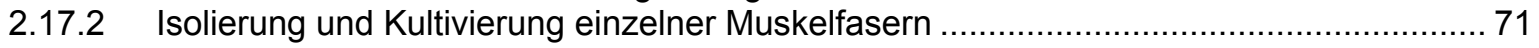

2.18 Zytologische und chemische Blut- und Knochenmarksanalysen ........................................ 71

2.18.1 Assay zur Bestimmung der kolonieformenden Aktivität von Stamm- und Vorläuferzellen

des Knochenmarks (Colony forming-unit Assay, CFU-Assay) ..................................... 71

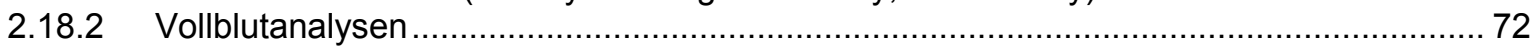

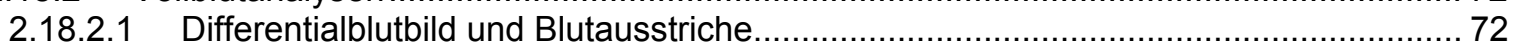

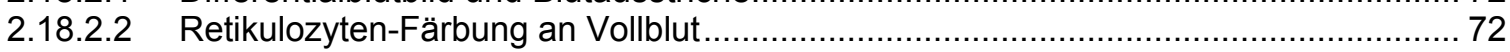

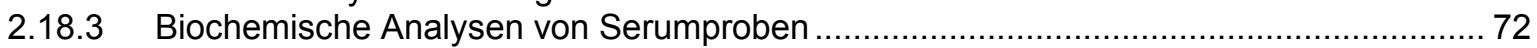

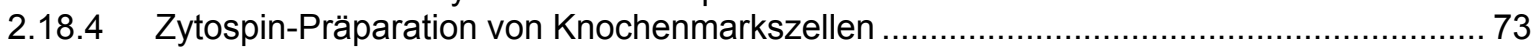

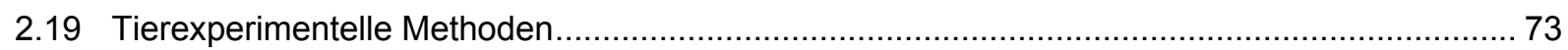

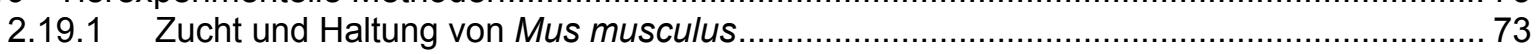

2.19.1.1 Schwanzbiopsie und Ohrlochmarkierung …...................................................... 73

2.19.1.2 Genotypisierung von Mäusen ........................................................................ 73

2.19.1.3 Herstellung von transgenen Mauslinien ........................................................... 74

2.19.2 Bestimmung des Kopulationszeitpunktes und der Trächtigkeit sowie Isolierung von

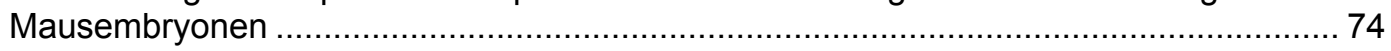

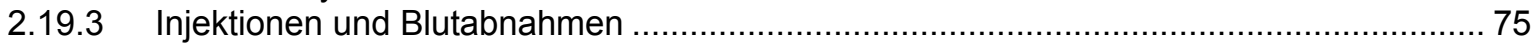

2.19.3.1 Intraperitoneale und intramuskuläre Injektion von Tamoxifen ................................. 75

2.19.3.2 Blutabnahme aus dem retroorbitalen Venenplexus und durch Herzpunktion ............... 75

2.19.4 Sichtung und Präparation von Tumoren .............................................................. 75

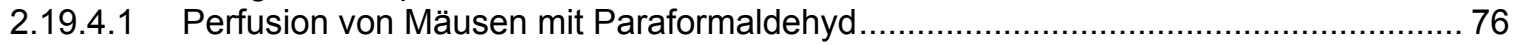

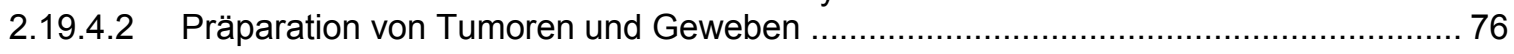

3 Ergebnisse.

3.1 Entstehung von RMS in konventionellen $P_{t c h}^{\text {neo67/4 }}$ knock-out Mäusen .................................. 78

3.1.1 Verminderte Expression von wt Ptch Transkripten und Überexpression mutanter Ptch ${ }^{\mathrm{d} 67}$

3.1.2 Verminderung der Expression von wt Ptch führt zur Aktivierung der Shh/Ptch Signalkaskade. 
3.1.3 Molekulare und funktionelle Analysen zur Expression des mutanten $\operatorname{Ptch}^{\text {neo67 }}$ Allels in Ptch-assozierten RMS

3.1.3.1 Exon 1a, 1b und 1c Ptch Spleissvarianten sind in murinen RMS überexprimiert ................ 85

3.1.3.2 Das murine Homolog von Exon 1e ist Teil des murinen Exon 2 .................................. 86

3.1.3.3 Überexpression von Exon 1b Ptch ${ }^{d 67}$ Transkripten in RMS......................................... 87

3.1.3.4 Das Ptch $^{d 67}$ Transkript wird zu einem Ptch ${ }^{d 67}$ Protein translatiert........................................ 89

3.1.3.4.1 Immunfluoreszenz-Nachweis von $\mathrm{Ptch}^{\mathrm{d} 67}$ in transient transfizierten NIH/3T3 Zellen . 90

3.1.3.4.2 Nachweis von Ptch ${ }^{\mathrm{d} 67}$ im Western Blot ................................................................ 91

3.1.3.5 Ptch $^{\mathrm{d} 67}$ Protein hat einen hemmenden Einfluss auf das Ptch wt Protein.............................. 92

3.2 Analyse der konditionellen Ptch knock-out Mäuse ................................................................... 94

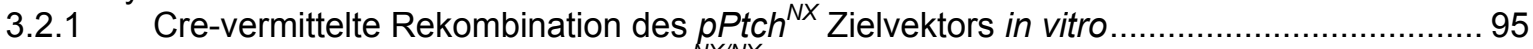

3.2.2 Etablierung von homozygoten Ptch ${ }^{N X / N X}$ Mäusen ............................................................... 96

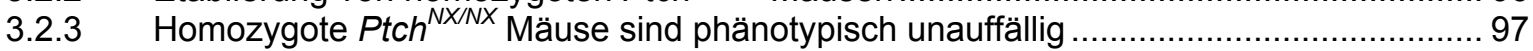

3.2.4 Cre-Rekombinase-vermittelte Deletion von Ptch in der Keimbahn ............................... 99

3.2.4.1 Heterozygote $P t c h^{\text {delNX/+ }}$ Mäuse entwickeln RMS und MB ........................................ 99

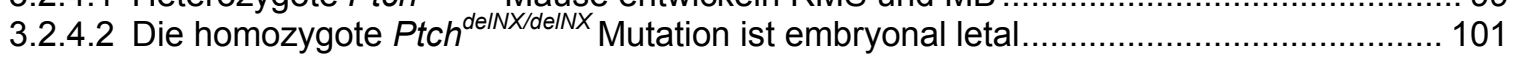

3.2.5 Deletion von Ptch in adulten Mäusen mittels einer Tamoxifen-induzierbaren Cre-

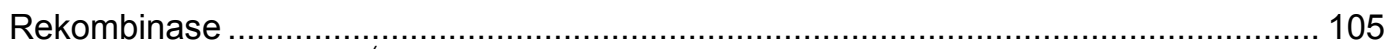

3.2.5.1 Phänotyp adulter $t$ Ptch $^{-/-}$Mäuse nach induzierter Inaktivierung von Ptch ...................... 105

3.2.5.1.1 In vivo Rekombinationseffizienz des Ptch ${ }^{N X}$ Lokus ................................................. 105

3.2.5.1.2 Hyperproliferative Organveränderungen in $\mathrm{PPtch}^{-/}$Mäusen.................................... 108

3.2.5.1.3 T Zelldefekte in Thymi von $\mathrm{Ptch}^{-/}$Mäusen ........................................................ 111

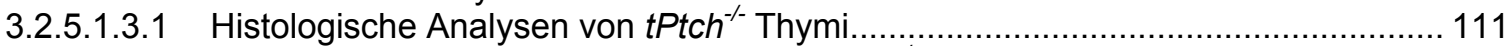

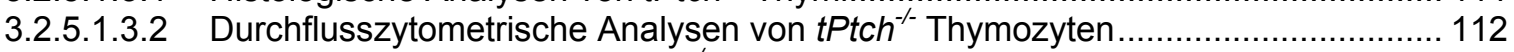

3.2.5.1.4 B Zelldefekte in Milzen von tPtch $^{-/}$Mäusen ....................................................... 117

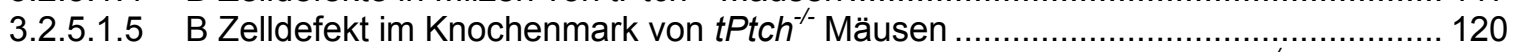

3.2.5.1.5.1 Entwicklungsdefekt früher B Zellvorläufer im Knochenmark von $t P t c h^{-/}$Mäusen.. 123

3.2.5.1.6 Differenzierungsdefekt der lymphoiden Linie im CLP-Stadium in $t P t c h^{-/}$Mäusen ... 125

3.2.5.1.7 Ungestörte Granulozyten- und Makrophagendifferenzierung und partieller Defekt der

Megakaryozyten- und Erythrozytenentwicklung in $\operatorname{Ptch}^{-/}$Mäusen .......................... 128

3.2.5.2 Versuch der Induktion von RMS in $P_{t c h}^{N X / N X} E R T^{\dagger+-}$ Mäusen ...................................... 131

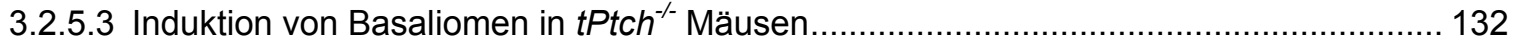

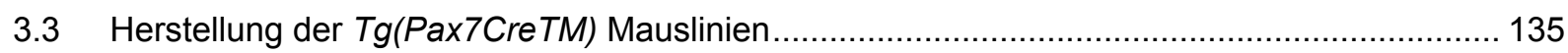

3.3.1 Pax7 spezifische Expression einer Tamoxifen-induzierbaren Cre-Rekombinase .......... 135

3.3.1.1 In vitro Analyse des murinen Pax7 Promotors...................................................... 137

3.3.1.1.1 Expression von Pax7 in der Zelllinie C2C12 .................................................. 137

3.3.1.1.2 In vitro Analyse der Pax7 Luziferase Reporterplasmide ..................................... 138

3.3.1.1.3 In vitro Analyse des pPax7CreTM Plasmids ........................................................ 139

3.3.1.2 Herstellung von $T g(P a x 7 C r e T M)$ transgenen Mäusen .......................................... 142

3.3.1.2.1 In vivo Analysen der CreTM-Rekombinaseexpression in Tg(Pax7CreTM) Mäusen 142

3.3.1.2.1.1 Keine Aktivität der CreTM-Rekombinase im Embryo .......................................... 143

3.3.1.2.1.2 Die CreTM-Rekombinase wird im adulten Muskel exprimiert.............................. 144

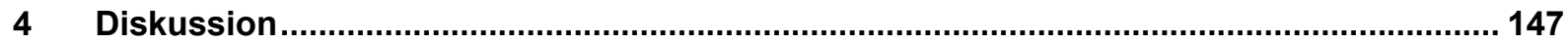

4.1 Analysen zur Entstehung von Ptch-assoziierten RMS.................................................... 147

4.1.1 Shh/Ptch Signalwegsaktivierung durch Reduktion von wt Ptch Transkripten .................... 148

4.1.2 Das Ptch ${ }^{\mathrm{d} 67}$ Protein kann den Shh/Ptch Signalweg nicht mehr hemmen .......................... 149

4.1.3 Ein modifiziertes Modell der Ptch-assoziierten Tumorigenese in Ptch ${ }^{\text {neo67/t }}$ Mäusen....... 151

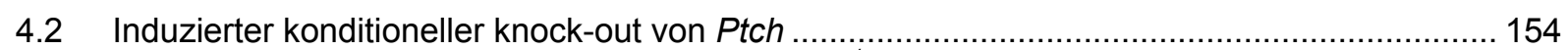

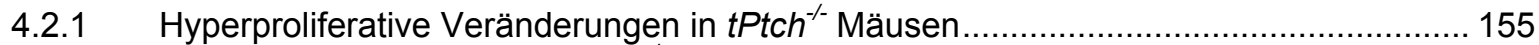

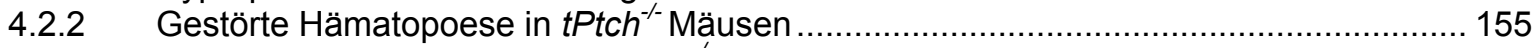

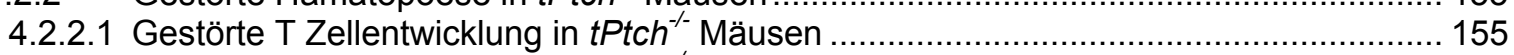

4.2.2.2 Gestörte B Zellentwicklung in $t^{2} t_{c h}{ }^{-/}$Mäusen .................................................................. 157

4.2.2.3 Entwicklungsdefekt der lymphoiden Linie im Knochenmark von $t P t c h^{--}$Mäusen ............ 158

4.2.2.4 Normale Entwicklung der myeloischen Linie in Ptch $^{-/}$Mäusen ................................... 159

4.2.2.5 Zusammenfassende Betrachtung der Funktion von Ptch bei der Lymphopoese............ 162

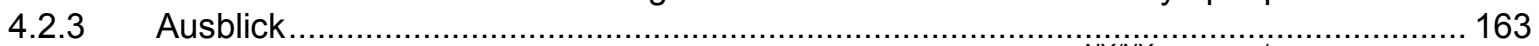

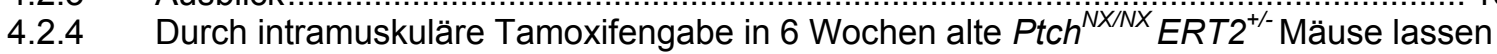

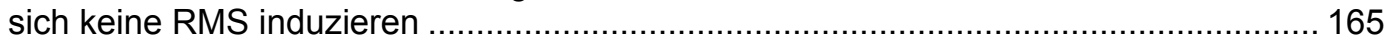


4.2.4.1 Induktion von Basaliomen durch intramuskuläre Tamoxifengabe in 6 Wochen alte

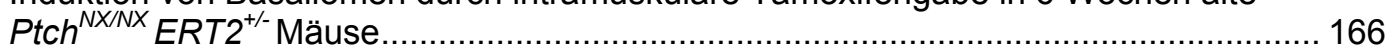

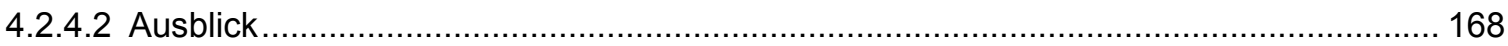

4.3 Versuch des Nachweises der Urspungszellen von Ptch-assoziierten RMS mit Hilfe von transgenen Tg(Pax7CreTM) Mauslinien ............................................................ 169

4.3.1 Keine Expression von Tg(Pax7CreTM) während der Embryonalentwicklung............... 171

4.3.2 $\mathrm{Tg}($ Pax7CreTM) wird im adulten Muskel in Nervenstrukturen, nicht aber in Satellitenzellen

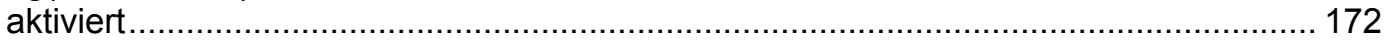

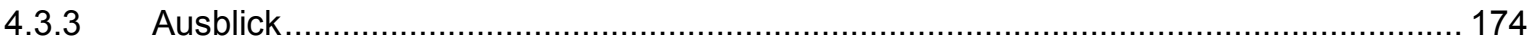

4.3.3.1 Sind Tg(Pax7CreTM) Mäuse für Studien zur Ursprungszelle des RMS geeignet?....... 174

4.3.3.2 Sind Tg(Pax7CreTM) Mäuse für Studien an adulten Nerven geeignet? ...................... 175

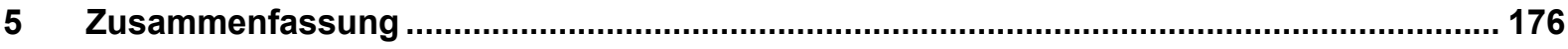

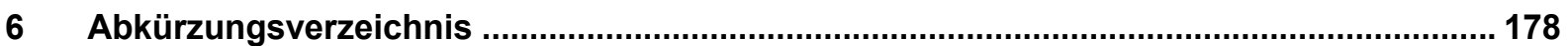

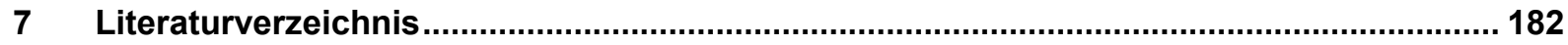

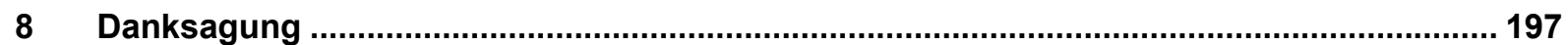

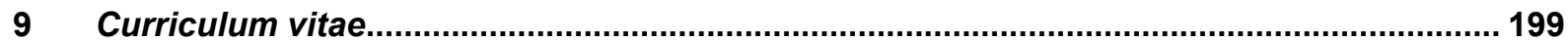




\section{Einleitung}

\subsection{Molekulare Grundlagen der Onkologie}

Die Entstehung von Tumoren wird seit jeher beobachtet. Schon Aristoteles (384 v. Chr. - 322 v. Chr.) verwendete den Begriff „Krebs“ (griech. "karkínos"), als er damit oberflächlich feststellbare, in benachbarte Organe infiltrierende und einwachsende Geschwülste beschrieb. Auch im ältesten bekannten Buch, dem „Papyrus Ebers“ (Ägypten; ca. 1550 v. Chr.; Zeit Amenhotep I/Anfang der 18.Dynastie/Neues Reich), sind Aufzeichnungen zur Behandlung von Tumoren zu finden (Nr.857-877 Lehrtexte gegen Geschwülste) (Ebers G, 1875; Wreszinski W, 1913; Ghalioungui P, 1987). Als Heilmittel wurden damals neben Arsen und Verbänden auch operative Eingriffe empfohlen. Die Ursachen der Tumorentstehung begann man jedoch erst seit dem Anfang des 20igsten Jahrhunderts besser zu verstehen. Ellermann und Bang beschrieben erstmals Viren als Auslöser von Tumoren (Ellermann $\mathrm{V}$ und Bang $\mathrm{O}$, 1908). Peyton Rous zeigte im Jahr 1911, dass Muskeltumoren durch den später nach inm benannten Rous Sarkom Virus (RSV) entstehen können (Rous P, 1911) und erhielt 1966 für diese Entdeckung den Nobelpreis. Mitte der 70iger Jahre gelang dann die Identifizierung von retroviralen Onkogenen als Tumorinduktoren. Es wurde gezeigt, dass diese retroviralen Onkogene relative Neuerwerbungen der Retroviren sind (Stehelin D et al., 1976). Onkogene entstehen durch Veränderungen von Gensequenzen (Mutationen), die für das normale Zellwachstum, die Zellteilung und die Zelldifferenzierung eine Rolle spielen. Die Vorstufen von Onkogenen sind die sogenannten Protoonkogene. Protoonkogene sind normale Bestandteile der Zelle und werden erst durch schädliche Einflüsse (Radioaktivität, chemische Substanzen oder Viren) in die krebserzeugenden Formen, die Onkogene, umgewandelt. Es sind heute mehr als 100 Protoonkogene (Stand von 2004) bekannt. Protoonkogene werden aufgrund der kodierten Proteine in mehrere Gruppen eingeteilt. Zu diesen gehören Peptid-Wachstumsfaktoren, Wachstumsfaktorrezeptoren, Proteinkinasen, G-Proteine und Transkriptionsfaktoren (Bishop JM, 1983; Cooper GM, 1987). Neue Dimensionen der Onkogen-Forschung wurden durch die Möglichkeit transgene Tiere herzustellen und durch die Technik der Inaktivierung von Genen in der Keimbahn (knock-out) eröffnet (Palmiter RD und Brinster RL, 1986; Sinn E et al., 1987; Mansour SL et al., 1988). Es konnten kausale Zusammenhänge zwischen mutierten bzw. ektopisch exprimierten Onkogenen und Krebsentstehung hergestellt werden, 
wobei häufig unerwartete Funktionen dieser Gene während der embryonalen Entwicklung und der Differenzierung erkannt wurden.

Nicht immer konnte die Tumorentstehung durch Mutationen eines Onkogens erklärt werden. 1971 stellte Alfred Knudson eine „Zwei Treffer“ Hypothese für die Entstehung von Retinoblastomen durch Tumorsuppressorgene vor. Er schlug vor, dass für die Entwicklung eines Retinoblastoms beide Allele des verantwortlichen Gens inaktiviert vorliegen müssen („two hit“ hypothesis, „zwei Treffer“ Hypothese) (Knudson AG, Jr., 1971). Dieses Modell erklärte erstmals die Tumorigenese durch Mutationen von Tumorsuppressorgenen. Sowohl das sporadische Auftreten von zwei somatischen Mutationen eines Tumorsuppressorgens innerhalb einer Zelle als auch die Mutation eines Allels in der Keimbahn und einer darauf folgenden somatischen Mutation des zweiten Allels (z. B. durch Verlust, welcher durch sogenanntes „loss of heterozygosity“ oder LOH erkennbar wird, oder durch inaktivierende Mutationen) können zur Tumorentwicklung führen. Heute ist bekannt, dass Tumorsuppressorgene als negative Regulatoren der Zellzyklusprogression (z. B. Rb1; retinoblastoma 1) (Stone JC et al., 1989) und als Initiatoren des programmierten Zelltodes (Apoptose, z. B. Trp53, transformation related protein 53) (Vogelstein B und Kinzler KW, 1992) wirken. Einige Tumorsuppressorgene spielen eine Rolle bei der Zelladhäsion, indem sie Kontaktinhibition bewirken (z. B. Cdh1; E-cadherin) (Nagafuchi A et al., 1987; Becker KF et al., 1994; Oda T et al., 1994).

Mutationen in Onkogenen bzw. Tumorsuppressorgenen führen somit zur Unabhängigkeit von Mitogenen oder Wachstumsfaktoren, zur Resistenz gegen Wachstumsinhibitoren oder Apoptose und zur Entwicklung von invasiven Kapazitäten und genomischer Instabilität (Hanahan D und Weinberg RA, 2000). Die Kenntnis dieser Eigenschaften von Tumorzellen ist fundamental für das Verständnis der Krebsentstehung und für die Entwicklung von Krebstherapien.

\subsection{Die Sonic hedgehog/Patched Signalkaskade}

Nüsslein-Volhard und Wieschaus beschrieben erstmals die während eines Mutationsscreenings gefundenen Gene Hedgehog $(H h)$ und Patched (Ptc) in D. melanogaster (Nusslein-Volhard C und Wieschaus E, 1980). Im Vergleich zu D. melanogaster wurden in Vertebraten drei zu Hh homologe und drei zu Ptc homologe Gene identifiziert. $\mathrm{Zu}$ den $\mathrm{Hh}$ Homologen zählen Desert hedgehog (Dhh), Indian 
Hedgehog (Ihh) und Sonic hedgehog (Shh). Zu den Ptc Homologen zählen Patched (Ptch), Patched 2 (Ptch2) und Translocation in renal carcinoma on chromosome 8 (Trc8). Die wichtigsten und in Vertebraten am besten untersuchten Homologen sind Shh und Ptch. Beide Gene sind in einen gemeinsamen Signalweg involviert, wobei Ptch der Rezeptor für Shh ist (Marigo V et al., 1996a; Stone DM et al., 1996).

In der signalsendenden Zelle wird das Shh Protein autokatalytisch gespalten und die aktivierende $\mathrm{N}$-terminale Signaldomäne $\mathrm{C}$-terminal mit Cholesterol sowie $\mathrm{N}$-terminal durch Palmitoylierung modifiziert (Porter JA et al., 1996; Pepinsky RB et al., 1998; Chamoun $Z$ et al., 2001). Die Freisetzung dieses aktiven Liganden in den extrazellulären Raum wird durch das Membranprotein Dispatched (Disp) bewirkt (Burke R et al., 1999).

In Abbildung 1 ist ein Modell der Shh/Ptch Signalkaskade innerhalb einer signalempfangenden somatischen Säugetierzelle dargestellt (links). Ohne die Bindung von Shh blockiert Ptch die Aktivität von Smoothened (Smo). Diese Blockade wird dabei nicht durch eine physikalische, sondern durch eine katalytische Interaktion zwischen Ptch und Smo hervorgerufen (Denef N et al., 2000; Ingham PW, 2000; Taipale J et al., 2002). Die Hemmung der Smo Aktivität bewirkt, dass die Transkriptionsfaktoren der Gli Familie über eine Reihe zytoplasmatischer Proteine (Cos2, Costal 2; Fu, Fused; Sufu, Suppressor of fused) im Zytoplasma gebunden bleiben und keine transkriptionelle Funktion ausüben können (Robbins DJ et al., 1997; Ruiz i Altaba A, 1997; Monnier V et al., 1998; Wang G et al., 2000; Ingham PW und McMahon AP, 2001; Mullor JL et al., 2002; Nybakken K und Perrimon N, 2002).

Durch die Bindung von Shh an seinen Rezeptor Ptch (Marigo V et al., 1996a; Stone DM et al., 1996) wird Ptch in seiner Funktion blockiert. Hierdurch wird die Aktivierung von Smo bewirkt, was die Freisetzung der zytoplasmatisch gebundenen Gli Proteine zur Folge hat. Daraufhin werden die Gli Transkriptionsfaktoren in den Nukleus transportiert, wo sie die Expression ihrer Zielgene aktivieren (Ptch; Wnt, Wingless; Bmp, bone morphogenic protein; siehe Kapitel 1.2) (Robbins DJ et al., 1997; Ruiz i Altaba A, 1997; Monnier V et al., 1998; Wang G et al., 2000; Ingham PW und McMahon AP, 2001; Mullor JL et al., 2002; Nybakken K und Perrimon N, 2002).

Die Gli-abhängige Transkription von Ptch bewirkt einen negativen Rückkopplungsmechanismus und damit die Inaktivierung des Signalweges nach Shh 
Stimulierung. So wird sichergestellt, dass nach erfolgter Signalwegsstimulierung die Kaskade wieder in ihren unstimulierten Zustand zurückversetzt wird.

Die Kontrolle der Signalkaskade ist also direkt an die Funktionalität des Rezeptors Ptch gekoppelt. Auf diese Weise wird sichergestellt, dass der Signalweg nur zu bestimmten Zeitpunkten und an bestimmten Orten durch Shh aktiviert wird (Ruiz i Altaba A et al., 2002).

Heute ist bekannt, dass die mutationsbedingte Inaktivierung von PTCH/Ptch oder aktivierende Mutationen anderer Komponenten des Signalweges (GLI/Gli, SHH/Shh, SMO/Smo) sowohl beim Meschen als auch in der Maus zur pathologischen Aktivierung der Signalkaskade führen (Roberts WM et al., 1989; Lam CW et al., 1999). In Folge dessen werden GLI/Gli Zielgene verstärkt exprimiert, und es wird angenommen, dass dies zur Entstehung von Tumoren führt. In Abbildung 1 (rechts) ist eine somatische Zelle gezeigt, welche durch eine PTCH/Ptch inaktivierende Mutation einen konstitutiv aktiven Signalweg aufweist.
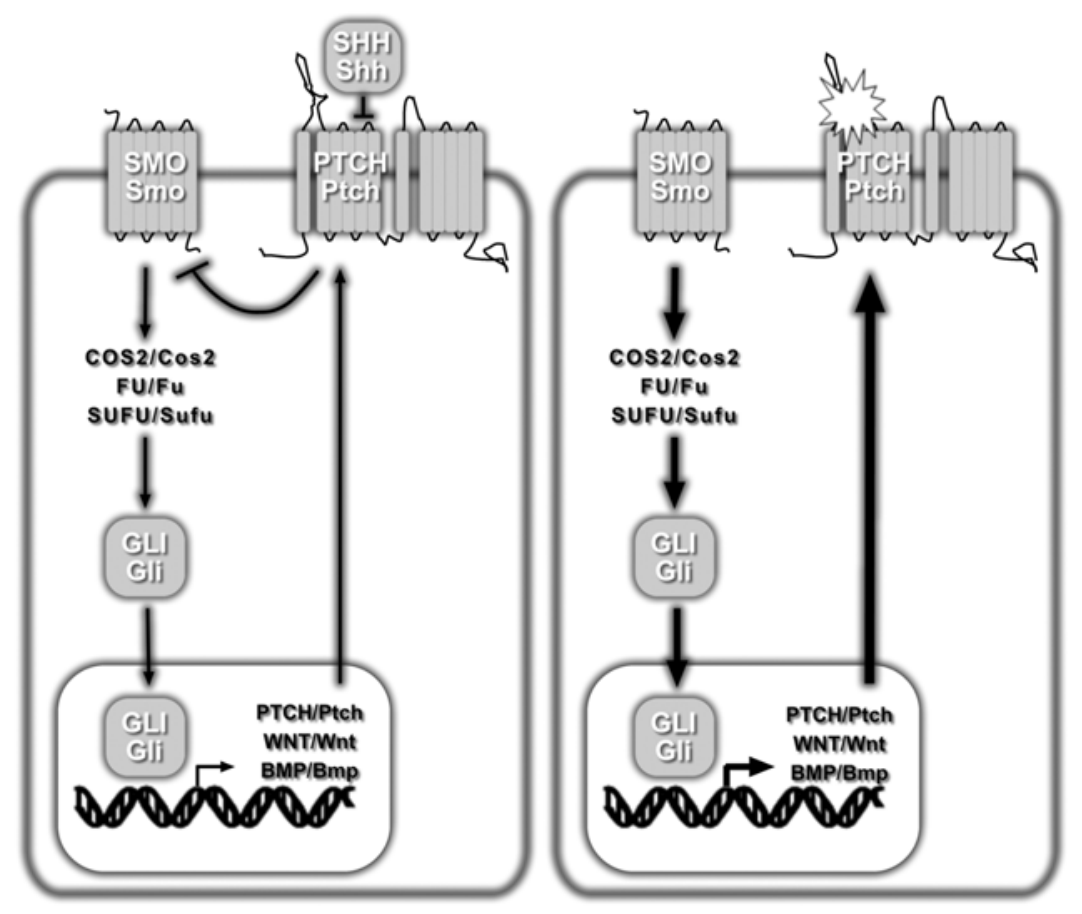

Abbildung 1: Schematische Darstellung des normalen und des pathologisch aktiven Shh/Ptch Signalweges. Dargestellt ist der Shh/Ptch Signalweg einer normalen somatischen Zelle (links) im Vergleich zu einer Zelle mit einem pathologisch aktiven Signalweg, ausgelöst durch inaktivierende PTCH/Ptch Mutationen. In der signalempfangenden Zelle (links) blockiert PTCH/Ptch, der natürliche Rezeptor des SHH/Shh Proteins, die Aktivität von SMO/Smo. Die Proteine Costal2 (COS2/Cos2), Fused (FU/Fu) und Suppressor of fused (SUFU/Sufu) vermitteln die zytoplasmatische Lokalisation von GLI/Gli. Durch die Bindung von SHH/Shh an seinen Rezeptor PTCH/Ptch wird die Aktivierung von SMO/Smo ausgelöst, und die GLI/Gli Transkriptionsfaktoren aktivieren im Nukleus die Transkription 
ihrer Zielgene (PTCH/Ptch; WNT/Wnt, Wingless; BMP/Bmp, bone morphogenic protein). Die GLI/Gliabhängige Expression von PTCH/Ptch bewirkt die negative Regulation der Signalwegsaktivierung. PTCH/Ptch inaktivierende Mutationen führen aufgrund der fehlenden Hemmung des Signalweges zur pathologischen Aktivierung von GLI/Gli Zielgenen und damit auch zur Überexpression von PTCH/Ptch selbst. In Großbuchstaben sind humane und in Kleinbuchstaben murine Homologe angegeben.

Die Aktivierung der Signalkaskade führt zur Transkription von verschiedenen Zielgenen. Diese wird durch die Familie der Gli Proteine vermittelt.

Die Familie der Gli Proteine der Vertebraten ist ortholog zum D. melanogaster Ci (cubitus interuptus) Protein (Kinzler KW et al., 1987; Kinzler KW et al., 1988; Kinzler KW und Vogelstein B, 1990) und umfasst 3 Proteine (Gli1, Gli2, Gli3), welche durch stark konservierte $\mathrm{C} 2 \mathrm{H} 2$ Zinkfingerdomänen gekennzeichnet sind (Ruppert JM et al., 1988). Während Gli2 sowohl als Transkriptionsaktivator als auch Transkriptionsrepressor wirken kann, aktiviert Gli1 nur die Expression seiner Zielgene (Ingham PW und McMahon AP, 2001). Nach seiner proteolytischen Prozessierung agiert auch das Gli3 Protein als Transkriptionsaktivator (Dai P et al., 1999; Wang B et al., 2000). Die Transkriptionsregulation der unterschiedlichen Gli Proteine erweitert zusätzlich die Regulation des Shh/Ptch Signalweges (Ingham PW und McMahon AP, 2001), vor allem, da die drei Gli Proteine synergistische oder redundante Wirkungsweisen besitzen (Ruiz i Altaba A, 1997; Ruiz i Altaba A, 1999; Aza-Blanc P et al., 2000).

Die Gli Zielgene der Shh/Ptch Signalkaskade, zu denen auch Ptch, Wnt, Dpp (Decapentaplegic) und Bmp zählen, sind essentiell während der Embryogenese und der Differenzierung adulter Gewebe (Wetmore C, 2003). So spielt die Wnt Genfamilie eine wichtige Rolle während der Zelldifferenzierung, der Ausbildung der Zellpolarität, der Zellmigration und der Zellproliferation. Die Fehlregulation der Expression von Wht Genen führt zu Entwicklungsdefekten und zur Tumorentstehung (Moon RT et al., 1997; Miller JR et al., 1999; Kuhl M et al., 2000; Taipale J und Beachy PA, 2001). Ebenso ist bekannt, dass Dpp von D. melanogaster (ein BMP Ortholog) für die normale Entwicklung des embryonalen Ektoderms und adulter Gewebe notwendig ist (Podos SD und Ferguson EL, 1999). Sowohl in D. melanogaster als auch in Säugetieren wird außerdem der Zellzyklus über den Shh/Ptch Signalweg reguliert. So wird die Expression von Cyclin D1 und D2 in Säugetieren direkt von Gli1 aktiviert (Duman-Scheel $\mathrm{M}$ et al., 2002; Mill $\mathrm{P}$ et al., 2003). Aber auch mittels direkter 
Interaktion von Ptch mit Cyclin B1 (Barnes EA et al., 2001) und durch Shh-regulierte p21-vermittelte Hemmung des Zellzyklusarrestes reguliert der Signalweg direkt die Aktivität von Cyclinen (Fan H und Khavari PA, 1999).

Weiterhin wird auch die Expression der Gli Genfamilie über den Shh/Ptch Signalweg reguliert. So wird die Expression von Gli1 durch die Aktivierung des Shh/Ptch Signalweges stimuliert (Bai CB et al., 2002; Bai CB et al., 2004), die Gli3 Trankription dagegen scheint negativ durch das Shh-Signal reguliert zu werden (Marigo $\mathrm{V}$ et al., 1996b). Durch eine pathologische Stimulierung des Signalweges wird somit auch eine Überexpression von Gli1 beobachtet (Dahmane N et al., 1997; Kappler R et al., 2003). Auch die Überexpression von Igf2 (insulin-like growth factor 2) in Ptchassoziierten Tumoren lässt auf einen Regulierungsmechanismus über die Shh/Ptch Signalkaskade schließen (Hahn H et al., 2000; Kappler R et al., 2003).

Nach erfolgter Stimulation des Shh/Ptch Signalweges durch Shh bewirkt die Gliabhängige Expression von Ptch eine negative Autoregulation der Signalwegsaktivität. Es ist bekannt, dass schon ein Ptch Molekül ausreicht, um eine fast 80 \%ige Aktivitätshemmung von 45 Smo Molekülen zu bewirken (Taipale J et al., 2002). Dies zeigt, wie wichtig die Expression von funktionellem Ptch für die Erhaltung der Balance und Regulierung des Shh/Ptch Signalweges ist.

\subsection{Die PTCH/Ptch-assozilerte Tumorigenese}

\subsubsection{Aufbau von PTCH/Ptch}

Das Ptch Gen kodiert für ein Transmembranprotein mit 12 hydrophoben membranständigen Domänen, intrazellulären carboxy- und aminoterminalen ( $\mathrm{C}$ - und N-terminal) Regionen und zwei großen extrazellulären Schleifen, die die Shh Ligandenbindung vermitteln (siehe Abbildung 1) (Hooper JE und Scott MP, 1989; Marigo V et al., 1996c). Bei Verlust der zweiten extrazellulären Schleife des Proteins geht die Fähigkeit zur Ligandenbindung verloren, während die Repression von Smo erhalten bleibt (Briscoe J et al., 2001). Wird der C-terminale Teil des Ptch Proteins deletiert, ist die Ligandenbindung weiterhin möglich, jedoch kann Smo nicht mehr durch Ptch inhibiert werden (Johnson RL et al., 2000).

Das Ptch Protein besitzt, wie auch Ptch2 und Trc8, eine „sterol sensing domain“ (SSD) von etwa 180 Aminosäuren, welche fünf membranspannende Domänen 
umfasst. Von weiteren SSD-Proteinen, z. B. denen der Cholesterol-Signalkaskade (HMGCR, 3-hydroxy-3-methylglutaryl-Coenzyme A reductase; SCAP, SREBP cleavage activating protein) ist bekannt, dass sie Fähigkeiten zum Kargotransport besitzen, und dass sie in ihrer Aktivität durch Sterol- und/oder Lipoproteinkonzentrationen modifiziert werden (Kuwabara PE und Labouesse M, 2002). Doch obwohl die SSD für die Aktivität von Ptch essentiell ist (Chen $Y$ und Struhl G, 1996; Marigo V et al., 1996c; Stone DM et al., 1996; Lewis PM et al., 2001) und bekannt ist, dass Ptc in D. melanogaster zwischen Zellmembran und endozytotischen Vesikeln pendelt (Incardona JP et al., 2000), ist die genaue Funktion der SSD von Ptch in Vertebraten bisher unklar. Im Mausmodell führt sowohl die Deletion eines Teils der SSD (Ptch ${ }^{\text {neo67) }}$ (Hahn $\mathrm{H}$ et al., 1998) als auch der komplette heterozygote Verlust eines Ptch Allels (Ptch ${ }^{\text {neo12 }}$ ) (Goodrich LV et al., 1997) zur Fehlregulation des Shh/Ptch Signalweges.

\subsubsection{Familiäre $P T C H$ Mutationen}

Erste Hinweise, dass es sich beim humanen PTCH um ein Tumorsuppressorgen handeln könnte, stammen aus Untersuchungen einer autosomal-dominanten Erkrankung, welche die betroffenen Patienten zu Entwicklungsdefekten und zu Tumoren prädisponiert. Diese Erkrankung ist als Gorlin-Goltz-Syndrom bekannt.

Das Gorlin-Goltz-Syndrom (auch Nevoid Basal Cell Carcinoma; NBCCS genannt) wurde erstmals 1960 von Gorlin und Goltz beschrieben (Gorlin RJ und Goltz RW, 1960). Diese Erkrankung wird mit hoher Penetranz und variabler Expressivität vererbt, wobei etwa $40 \%$ der Krankheitsfälle durch Neumutationen entstehen (Cohen MM, Jr., 2003). Das Syndrom ist durch eine Reihe von Entwicklungsstörungen (Hyperkeratose der Handflächen und Fußsohlen, Skelettanomalien, ektopische intrakraniale Verkalkungen, Gesichtsdysmorphien und Makrozephalie) sowie durch die Prädisposition zu verschiedenen Tumoren (Basaliome, Medulloblastome, MB; Rhabdomyosarkome, RMS) charakterisiert. Etwa $5 \%$ der Patienten sind geistig retardiert.

1996 wurden von zwei unabhängigen Forschergruppen heterozygote Keimbahnmutationen in $\mathrm{PTCH}$ (humane chromosomale Region 9q22.3) als Ursache für NBCCS identifiziert (Hahn H et al., 1996; Johnson RL et al., 1996). 


\subsubsection{Spontane PTCH Mutationen}

Gegenwärtig ist bekannt, dass auch sporadische Basaliome, MB (Unden AB et al., 1996) und RMS (Bridge JA et al., 2000; Tostar $U$ et al., 2006) durch somatische Mutationen in $P T C H$ entstehen.

Das Basaliom ist der häufigste Tumor des Menschen (Daya-Grosjean L und CouvePrivat S, 2005). Heute wird angenommen, dass PTCH bei dessen Entstehung die Funktion eines "Gatekeepers" spielt. Dies bedeutet, das Basaliome nur dann entstehen können, wenn eine Mutation in PTCH vorliegt (Sidransky D, 1996; Adolphe $C$ et al., 2006). Da vielfach ein biallelischer Ausfall von PTCH in Basaliomen entdeckt wurde, sollte es sich bei PTCH um ein Tumorsuppressorgen handeln.

Auch in sporadischen MB und RMS wurden PTCH Mutationen entdeckt (Pietsch T et al., 1997; Tostar U et al., 2006). MB zählen zu den häufigsten neuroepithelialen, rasch proliferierenden Tumoren der hinteren Schädelgrube im Kindes- und Jugendalter (Fletcher CDM, 1995; Scotting PJ et al., 2000). Das RMS ist ein Malignom des quergestreiften Skelettmuskels und ist das häufigste Weichteilsarkom im Kindesalter (Dagher R und Helman L, 1999).

Auch in vielen anderen Tumoren, wie beispielsweise in Tumoren der Brustdrüse (Kubo M et al., 2004) und der Harnblase (Hamed S et al., 2004), sind Mutationen in PTCH gefunden worden.

Zusätzlich ist heute bekannt, dass Fehlregulationen des Signalweges, welche durch Mutationen in anderen Genen der SHH/PTCH Signalkaskade oder auch durch Überexpression von SHH oder GLI ausgelöst werden, zu den oben genannten Tumoren, sowie zusätzlich zu Tumoren des Verdauungstraktes, des Pankreas und der Lunge führen können (Dahmane N et al., 1997; Oro AE et al., 1997; Berman DM et al., 2003; Thayer SP et al., 2003; Watkins DN et al., 2003).

\subsubsection{Ptch knock-out Mausmodelle}

Goodrich et al. untersuchten 1997 erstmals die Funktion von Ptch durch Inaktivierung des Gens in Mäusen (Goodrich LV et al., 1997). Es konnte gezeigt werden, dass homozygote Ptch ${ }^{\text {ne012/neo12 }}$ mutante Mäuse während der Embryogenese aufgrund von Neuralrohr- und Herzdefekten sterben (siehe auch Abbildung 3). Heterozygote Mäuse dagegen weisen Symptome auf, welche auch bei NBCCS-Patienten 
diagnostiziert werden. So wird eine Anzahl von Entwicklungsdefekten der Extremitäten (Syndaktylie, Polydaktylie) und eine hohe Inzidenz für das Auftreten von MB in diesen Mäusen beobachtet (Goodrich LV und Scott MP, 1998). 1998 wurde durch Analyse eines zweiten Ptch knock-out Mausmodells (Abbildung 2, Abbildung 3) (Hahn $\mathrm{H}$ et al., 1998) gezeigt, dass heterozygot mutante Ptch ${ }^{\text {neo67/+ }}$ Mäuse nicht nur die von NBCCS-Patienten bekannten Symptome aufweisen, sondern auch mit hoher Inzidenz RMS entwickeln.

Wie bereits erläutert wurde, sind MB kindliche Hirntumore und RMS die häufigsten Weichteilsarkome im Kindesalter. Ptch knock-out Mäuse sind daher nicht nur ein geeignetes Modell zur Untersuchung der Funktion von Ptch, sondern auch ein hervorragendes Modell zur Überprüfung der Pathogenese dieser beiden kindlichen Tumore. Außerdem können anhand dieses Tiermodells neue Therapieansätze zur Behandlung dieser Tumoren überprüft werden.

\subsubsection{Die Ptch ${ }^{\text {neo67 }}$ Mauslinie}

In der Ptch knock-out Mauslinie Ptch ${ }^{\text {neo67 }}$ sind die Exone 6 und 7 von Ptch durch eine Neomycin-Resistenzkassette (Ptch ${ }^{\text {neo67 }}$ Allel) ausgetauscht worden. In Abbildung 2 ist der Ptch ${ }^{\text {neo67 }}$ Lokus im Vergleich zum Wildtyp (wt) Ptch Lokus der Ptch ${ }^{\text {neo67/+ }}$ Mauslinie dargestellt (Hahn $\mathrm{H}$ et al., 1998).

Die Mauslinie weist den bereits beschriebenen Ptch knock-out Phänotyp auf (siehe

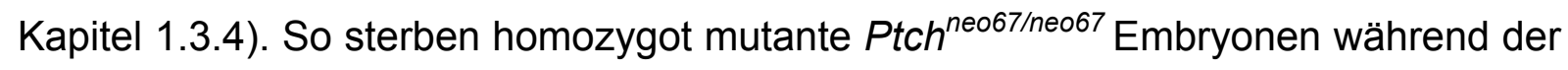
Embryogenese aufgrund von Neuralrohr- und Herzdefekten (Abbildung 3, links). Heterozygote Ptch ${ }^{\text {neo67/+ }}$ Mäuse können Entwicklungsdefekte aufweisen (Abbildung 3, Mitte) und entwickeln mit hoher Wahrscheinlichkeit RMS und MB (Abbildung 4, links und Mitte) (Hahn $\mathrm{H}$ et al., 1998). Außerdem wird durch UV-Bestrahlung heterozygoter Ptch $^{\text {neo67/+ }}$ Tiere die Entstehung von Basaliomen ausgelöst (Abbildung 4, rechts) (Aszterbaum M et al., 1999). 


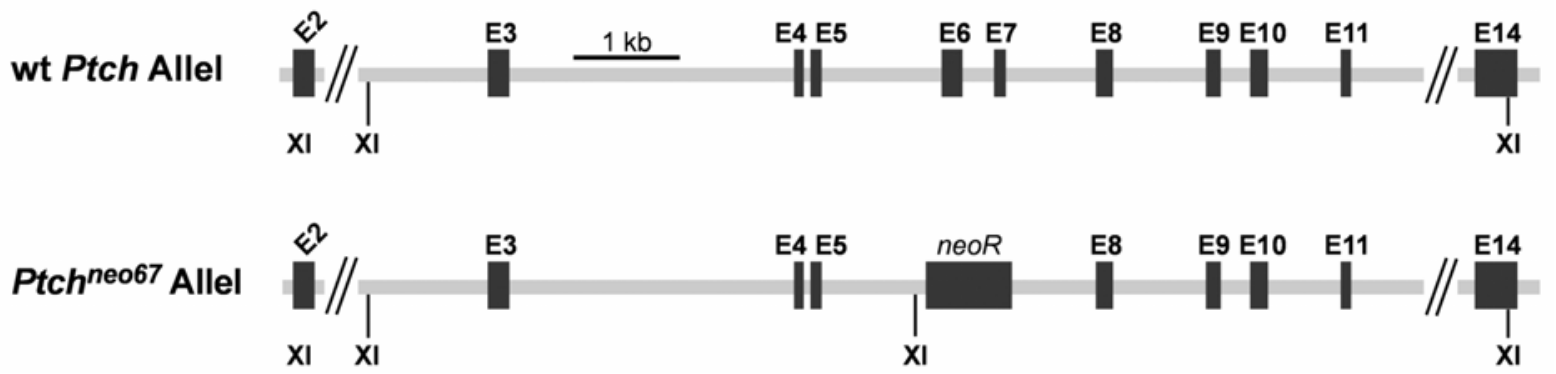

Abbildung 2: Schematische Darstellung des Ptch $^{\text {neo67 }}$ Lokus. Dargestellt sind die Exon- und Introngrenzen von Exon 2 bis Exon 14 (E2 bis E14) des wt Ptch Allels (wt Ptch Allel) und des mutanten Ptch $^{\text {neo67 }}$ Allels von Ptch ${ }^{\text {neo67/+ }}$ Mäusen. Das Ptch ${ }^{\text {neo67 }}$ Allel enthält anstelle von Exon 6 und 7 eine Neomycin-Resistenzkassette (neoR) (Hahn $\mathrm{H}$ et al., 1998).
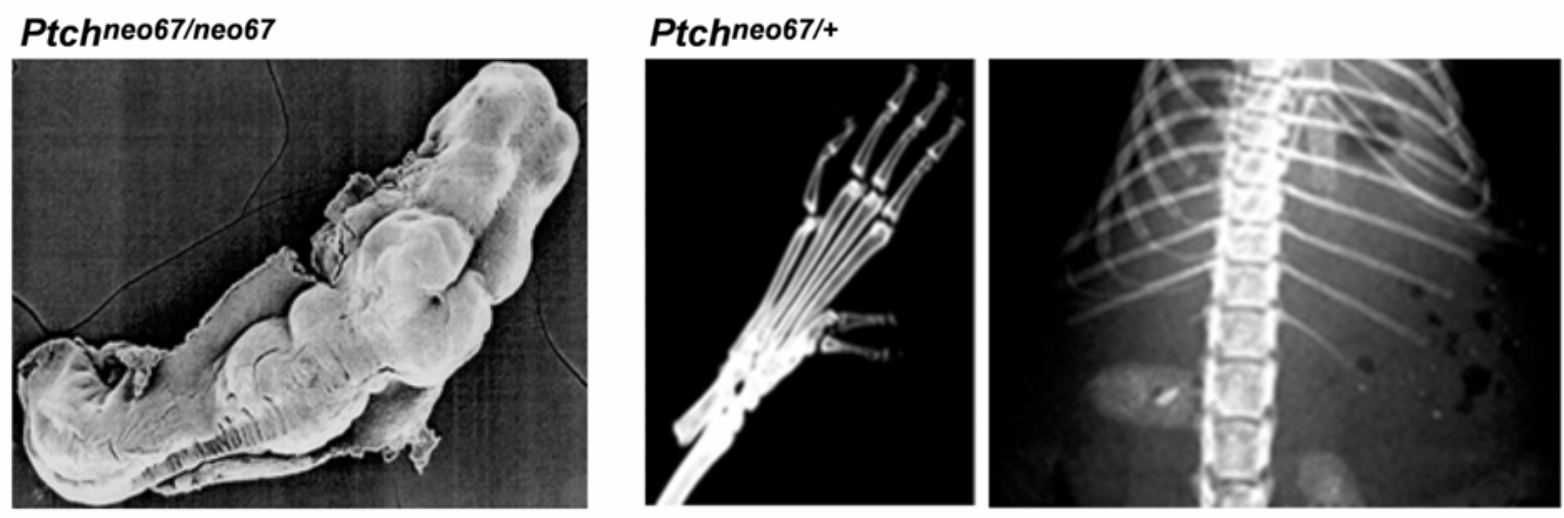

Abbildung 3: Entwicklungsdefekte der $\boldsymbol{P t c h}^{\text {neo67 }}$ Mauslinie. Dargestellt sind eine

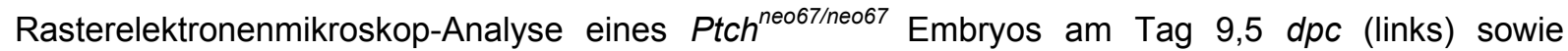
radiologische Analysen der Skelettanomalien von $\mathrm{Ptch}^{\text {neo67/+ }}$ Mäusen (Polydaktylie, Mitte und fehlende Rippe, rechts) (Hahn H et al., 1998).

\section{Ptchneo67/+}
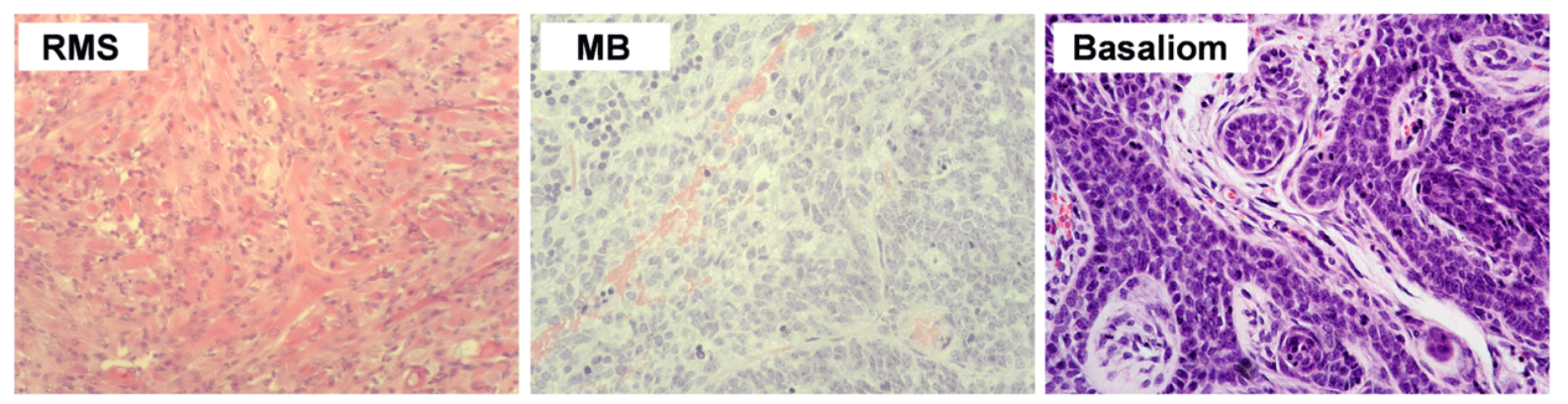

Abbildung 4: Tumoren von Ptch ${ }^{\text {neo67/+ }}$ Mäusen. Dargestellt sind Hämatoxylin/Eosin (HE) gefärbte Paraffinschnitte eines Rhabdomyosarkoms (RMS, links), eines Medulloblastoms (MB, Mitte) und eines Basalioms (rechts). 


\subsection{PTCH/Ptch-assoziierte RMS}

Alle Skelettmuskeln, mit Ausnahme der Kopfmuskulatur, entwickeln sich aus den embryonalen Somiten. Die Myoblastenentwicklung aus den Somiten wird dabei Shhabhängig reguliert. Die Zellproliferation und das Überleben der Zellen während der embryonalen Entwicklung der Muskulatur ist somit stark an den Shh/Ptch Signalweg gekoppelt (Cossu G und Borello U, 1999). Im adulten Organismus ist der Shh/Ptch Signalweg meist inaktiv, jedoch scheint auch hier die Proliferation und Differenzierung von sich aktiv teilenden Zellen Shh-abhängig reguliert zu sein.

Wie bereits beschrieben, werden in Vertebraten bestimmte Tumoren einschliesslich RMS durch Mutationen im Shh/Ptch Signalweg hervorgerufen. Man nimmt an, dass dies aufgrund einer pathologischen Aktivierung der Signaltransduktion geschieht. Das Auftreten von sporadischen RMS aufgrund somatischer PTCH Mutationen (Bridge JA et al., 2000; Tostar U et al., 2006) sowie die Prädisposition für RMS bei Gorlin-Goltz-Patienten (Gorlin RJ, 1987) zeigt den Einfluss der Shh/Ptch Signalkaskade bei der Entstehung von RMS im kindlichen oder adulten Organismus.

RMS sind Tumore des quergestreiften Skelettmuskels. Sie gehören zur Kategorie der klein-, blau- und rundzelligen Tumoren und sind die häufigsten Weichteilsarkome im Kindesalter. In zwei Drittel der Fälle treten RMS in einem Lebensalter unter sechs Jahren mit einer Mortalität von 40 \% auf (Dagher R und Helman L, 1999).

Wahrscheinlich entstehen RMS aus primitiven mesenchymalen Zellen und nicht aus differenziertem Muskelgewebe. Die immunologische Diagnose erfolgt über den Nachweis von Muskelproteinen wie $\alpha$-Aktin, der schweren Myosinkette, Desmin, Myoglobin, Z-Banden Protein und MyoD (myogenic differentiation 1).

Es können zwei RMS Subtypen unterschieden werden. Charakteristisch für den embryonalen Subtyp (ERMS) sind spindelförmige, stromareiche Zellen. ERMS unterscheiden sich damit vom alveolären Subtyp (ARMS), der aus kleinen, runden, dicht gepackten Zellen besteht. ARMS entstehen häufig durch die Translokation des Pax3 oder Pax7 Gens mit dem FKHR (fork head box 01) Genlokus (Galili N et al., 1993; Davis RJ und Barr FG, 1997; Barr FG, 1999; Keller C et al., 2004). ERMS zeigen dagegen häufig den Verlust der Heterozygotie (LOH) am 11p15 Lokus (Merlino G und Helman LJ, 1999) und in einigen Fällen auch den Verlust von genomischem Material am PTCH Lokus auf Chromosom 9q22 (Bridge JA et al., 2000) (siehe Kapitel 1.4.1.1). Obwohl ERMS nicht mit Pax-FKHR Fusionsproteinen in 
Verbindung gebracht werden, wird in vielen ERMS Pax7 überexprimiert (Tiffin $\mathrm{N}$ et al., 2003).

\subsubsection{Entstehung von PTCH/Ptch-assoziierten RMS}

\subsubsection{Entstehungsmechanismus von humanen $P T C H$-assoziierten RMS}

Interessanterweise ist bei einigen Fällen von ERMS der Verlust von genomischem Material am PTCH Lokus auf Chromosom 9q22 nachgewiesen worden (Bridge JA et al., 2000).

In einer kürzlich durchgeführten Studie konnte gezeigt werden, dass der SHH/PTCH Signalweg sehr häufig in humanen RMS dereguliert ist und LOH am PTCH Lokus ein häufiges Ereignis bei ERMS ist (Tostar U et al., 2006).

Bisherige Untersuchungen an Ptch knock-out Mäusen (siehe Kapitel 1.4.1.2) weisen darauf hin, dass die monoallelische Mutation von Ptch ausreichend für die Entwicklung von RMS ist (Wetmore C et al., 2000; Calzada-Wack J et al., 2002).

Daher wird heute davon ausgegangen, dass Haploinsuffizienz von PTCH die Entwicklung von $\mathrm{PTCH}$-assoziierten Tumoren begünstigt. Jedoch ist bisher nicht geklärt, ob eine biallelische Inaktivierung von $P T C H$ tatsächlich notwendig ist, um die Entwicklung von humanen RMS auszulösen. Des Weiteren ist nicht bekannt, aus welchen Zellen sich diese Tumoren entwickeln.

\subsubsection{Entstehungsmechanismus von murinen Ptch-assoziierten RMS}

Die meisten Erkenntnisse über die molekularen Vorgänge, die durch Ptch Mutationen ausgelöst werden und letztendlich in RMS resultieren, stammen aus Analysen der heterozygoten Ptch $^{\text {neo67/+ }}$ Mäuse. Die Inzidenz für die Entwicklung von RMS ist bei diesen Tieren stark vom genetischen Hintergrund abhängig. So entwickeln 10 bis $15 \%$ der heterozygoten Ptch mutanten Mäuse auf einem genetischen CD1 Hintergrund RMS (Hahn $\mathrm{H}$ et al., 1998). Zusätzlich erhöhen dominante Allele des Balb/c genetischen Hintergrundes diese Prädisposition für die Entwicklung von RMS, wogegen rezessive C57BL/6N Allele die Inzidenz erniedrigen (Hahn $\mathrm{H}$ et al., 2004).

Durch vergleichende Array-Analysen wurde gezeigt, dass sich das Expressionsprofil Ptch-assoziierter RMS deutlich von den aggressiven, undifferenzierten Trp53- 
assoziierten RMS unterscheidet (Kappler R et al., 2004). RMS von Ptch ${ }^{\text {neo67/+ }}$ Mäusen sind stark differenziert, wenig aggressiv und ähneln histologisch eher den ERMS als den ARMS. Auf einen ERMS Subtyp weist auch die starke lgf2 Expression dieser Tumore hin (Hahn H et al., 2000; Kappler R et al., 2003). Ptch ${ }^{\text {neo67/+ }}$ Tiere auf einem Igf2-defizienten Hintergrund entwickeln keine RMS, was auf eine enge Kopplung zwischen RMS Entstehung in $\mathrm{Ptch}^{\text {neo67/+ }}$ Mäusen und Igf2 schliessen lässt (Hahn $\mathrm{H}$ et al., 2000).

Weiterhin sind Ptch-assoziierte RMS durch die starke Expression von Zielgenen des aktiven Shh/Ptch Signalweges, wie Ptch und Gli1, gekennzeichnet (Dahmane N et al., 1997; Kappler $\mathrm{R}$ et al., 2003).

Auch Gene antiapoptotischer Signalwege (z. B. Bcl2, B cell leukemia/lymphoma 2) sowie der Zellzyklus-Inhibitor p27 ${ }^{\text {kip1 }}$ (Cdkn1b, cyclin-dependent kinase inhibitor 1b (p27)) und der Wachstumsinhibitor Gadd45 $\alpha$ (growth arrest and DNA-damageinducible 45 alpha) werden im Tumorgewebe stark exprimiert (Kappler $\mathrm{R}$ et al., 2003). Da PTCH/Ptch ohne den Einfluss seines Liganden SHH/Shh den apoptotischen Zelltod über die Aktivierung von Caspasen bewirkt, wurde eine zusätzliche Funktion von PTCH/Ptch als pro-apoptotischer "dependence“-Rezeptor postuliert (Thibert C et al., 2003). „Dependence“-Rezeptoren vermitteln in Anwesenheit ihrer Liganden proliferative Signale, sind jedoch ohne Ligandenbindung für die Induktion des programmierten Zelltodes verantwortlich (Mehlen $\mathrm{P}$ und Bredesen DE, 2004). Dies läßt vermuten, dass die Entstehung von RMS in Ptch ${ }^{\text {neo67/+ }}$ Mäusen neben der Induktion der Proliferation auch eng an die Hemmung der Apoptose gekoppelt ist.

Trotz der Einstufung von Ptch als Tumorsuppressorgen, wurde in RMS aus $P t c h^{\text {neo67/+ }}$ Mäusen keine biallelische Inaktivierung von Ptch gefunden. So konnten weder inaktivierende Mutationen im wt Allel noch der Verlust des wt Allels detektiert werden. Es wurde jedoch gezeigt, dass die starke Ptch Expression im Tumor durch die vermehrte Expression des mutanten Allels verursacht wird (Calzada-Wack $\mathrm{J}$ et al., 2002). Gleichzeitig wird im Tumorgewebe die verminderte Expression von wt Ptch Transkripten beobachtet (Uhmann A et al., 2005). Dies läßt darauf schließen, dass RMS von Ptch ${ }^{\text {neo67/+ }}$ Mäusen aufgrund eines Expressionsungleichgewichts der Ptch Allele entstehen könnten. Bisher war aber nicht geklärt, wodurch dieses Ungleichgewicht erzeugt wird. Auch war nicht bekannt, ob das mutante Transkript 
translatiert wird. Daher konnte bisher keine Aussage darüber getroffen werden, ob die verminderte Expression von wt Transkripten oder ein nicht funktionelles mutantes Protein zur Tumorigenese führt.

PTCH Transkripte können 5 unterschiedliche alternative erste Exone enthalten (Kogerman P et al., 2002; Nagao K et al., 2005a; Nagao K et al., 2005b). Obwohl in vitro alle beschriebenen PTCH Isoformen zur Interaktion mit SMO befähigt sind, wurde gezeigt, dass nur die Expression von Exon 1b-enthaltenden PTCH Transkripten zur vollständigen Inaktivierung des SHH/PTCH Signalweges führt.

Da humane Exon 1b-enthaltende $\mathrm{PTCH}$ Transkripte in humanen Basaliomen überexprimiert sind (Kogerman $\mathrm{P}$ et al., 2002), wurde die Hypothese aufgestellt, dass in humanen Basaliomen mit biallelischer PTCH Inaktivierung ein spezifischer PTCH Promotor aktiviert wird. In der Maus war bis zum Zeitpunkt der Arbeit nichts über Ptch Spleissvarianten oder deren Überexpression in Tumoren bekannt.

\subsubsection{Ursprungszelle von PTCH/Ptch-assoziierten RMS}

Aufgrund der Tatsache, dass eine Aktivierung des Shh/Ptch Signalweges eine unkontrollierte Expansion von Stammzellen bewirkt (Zhang $Y$ und Kalderon D, 2001), könnte es durchaus sein, dass RMS durch eine unkontrollierte Proliferation von Vorläuferzellen des Skelettmuskels entstehen. Diese Hyperproliferation könnte dabei durch die konstitutive Aktivierung des Shh/Ptch Signalweges und damit durch ein Ungleichgewicht zwischen Proliferation und Differenzierung der myogenen Vorläuferzellen hervorgerufen werden. In Folge dessen könnten diese Zellen dabei zum Ziel von vermehrter Mutagenese werden, was schließlich in der Tumorentstehung resultiert.

Eine Möglichkeit um zu beweisen, dass Ptch-assoziierte RMS aus Muskelstammzellen entstehen, bietet die Methode des konditionellen knock-outs. Dabei wird neben der konditionellen Ptch knock-out Maus noch eine weitere Mauslinie benötigt, mit deren Hilfe Ptch gezielt in Muskelstammzellen deletiert werden kann. Um eine solche Cre-Rekombinase-vermittelte Rekombination zu ermöglichen, muß die Cre-Rekombinase unter der Kontrolle eines spezifischen Muskelstammzell-Promotors exprimiert werden und darüberhinaus induzierbar sein. 
Alle bisher untersuchten ERMS und ARMS exprimieren Pax7 (Galili N et al., 1993; Davis RJ und Barr FG, 1997; Barr FG, 1999; Keller C et al., 2004). Dies trifft auch für Ptch-assoziierte RMS zu (Abbildung 48) (Barr FG, 2001; Tiffin N et al., 2003).

Heute ist bekannt, dass Pax7 in Satellitenzellen des Skelettmuskels exprimiert wird und für die Entstehung dieser Zellen notwendig ist (Sharp $\mathrm{R}$ et al., 2002; Tiffin $\mathrm{N}$ et al., 2003). Satellitenzellen sind eine Gruppe von Muskelstammzellen des adulten Skelettmuskels, die in der Lage sind, nach entsprechendem Stimulus zu proliferieren und neue Muskelfasern zu bilden.

Da RMS Pax7 exprimieren, die adulten Stammzellen des Muskels, die Satellitenzellen, ebenfalls Pax7 exprimieren und angenommen wird, dass sich RMS aus Muskelstammzellen entwickeln, könnte die Satellitenzelle die Ursprungszelle für die Entstehung von RMS darstellen.

Aus diesen Gründen wurde zur Herstellung der oben genannten Cre-exprimierenden Maus der Pax7-Promotor gewählt, der eine Satellitenzell-spezifische Expression der Cre-Rekombinase gewährleisten sollte. Da Pax7 jedoch auch noch in anderen Geweben exprimiert wird und während der Embyronalentwicklung eine wichtige Rolle spielt, wurde eine induzierbare Cre-Rekombinase verwendet. 


\subsection{Zielsetzung der Arbeit}

Ziel dieser Arbeit war es, die Pathogenese von Ptch-assoziierten RMS besser zu verstehen. Des Weiteren sollte der Versuch unternommen werden, die Ausgangszelle dieser Tumoren zu identifizieren. Hierzu wurden Mausmodelle verwendet.

Mit Hilfe von konventionell-hergestellten $P t c h^{\text {neo67/+ }}$ Mäusen sollte zunächst geklärt werden, welche Ptch Transkripte vom mutierten als auch von wt Lokus gebildet werden. Dann sollten die Funktionen der entsprechenden Proteine untersucht werden. Aufbauend auf diesen Untersuchungen sollte ein Modell zur Entstehung von Ptch-assoziierten RMS in Ptch ${ }^{\text {neo67/+ }}$ Mäusen erstellt werden.

Um zu klären, ob RMS aus den adulten Stammzellen des Muskels, den Satellitenzellen, entstehen, wurde im Rahmen dieser Arbeit eine transgene Maus generiert, welche eine Tamoxifen-induzierbare Cre-Rekombinase unter dem Pax7 Promotor exprimiert. Mit Hilfe dieser Mäuse sollte es möglich sein, Ptch in konditionellen $\operatorname{Ptch}^{N X / N X}$ Mäusen gezielt in Satellitenzellen auszuschalten und zu untersuchen, ob sich Tumoren aus diesen Zellen entwickeln.

$P_{t c h}^{N X / N X}$ Mäuse waren zum Beginn dieser Arbeit im Labor bereits generiert worden. Die Mäuse waren jedoch noch nicht charakterisiert. Daher wurde zunächst untersucht, ob die Einführung der loxP-Sequenzen oder der NeomycinRestistenzkassette eine negative Auswirkung auf Expression oder Funktion von Ptch hat. Daher wurde Ptch durch die Kreuzung mit der Tg(EllaCre) Maus in der Keimbahn deletiert. Der entsprechende Phänotyp wurde mit dem der konventionellen knock-out Mäuse verglichen. Weiterhin wurde die Ptch Funktion im adulten Tier untersucht. Hierzu wurde die ROSA26CreERT2 Mauslinie verwendet, welche eine Tamoxifen-induzierbare Cre-Rekombinase unter dem ROSA26 Promotor exprimiert. Nach Induktion der Cre-Rekombinase in 6 und 8 Wochen alten tch $^{N X / N X}$ ROSA26CreERT2 ${ }^{+/}$Mäusen wurden der Phänotyp als auch molekulare Veränderungen untersucht. 


\section{Materialien und Methoden}

\subsection{Statistische Auswertungsverfahren}

Statistische Auswertungen von Dualen-Luziferase-Assays (siehe Kapitel 2.16.1.6) und quantitativen real time PCR Assays (siehe Kapitel 2.15.4.4) wurden mit Hilfe der Software Statistica durchgeführt. Die statistischen Graphiken wurden in Box-WhiskerPlots dargestellt, um zentrale Tendenz, Streuung, Steigung und Spannweite einer Verteilung inklusive möglicher Ausreißer in einem Bild zusammenzufassen. Die Box umfasst die mittleren $50 \%$ der Verteilung und reicht daher vom unteren bis zum oberen Quartil. Der Median (Zentralwert) wird durch einen senkrechten Strich an der entsprechenden Stelle in der Box deutlich gemacht.

Die Signifikanz von Unterschieden und Gleichheit der einzelnen Gruppen wurde mit Hilfe eines t-Tests für unabhängige Gruppen (Mann-Whitney-U-Test) getestet. Wobei $P$ Werte von $P<0,05$ als signifikant und $P$ Werte $P>0,05$ als nicht-signifikant bezeichnet werden.

\subsection{Software}

ABI 3100 genetic analyser data collection 1.0
BD FacsDiva ${ }^{\mathrm{TM}}$
EXEL
FlowJo
FreeHand MX
Intas GDS
Photoshop 6.0
SDS 2.1
Sequencher
Simplicity 2.1
Statistica
WORD

Applied Biosystems, Darmstadt BD Biosciences, Heidelberg Microsoft Co., Redmond, USA Treestar, Inc., Ashland, USA Adobe Systems Incorporated, San Jose, USA Intas, Göttingen Adobe Systems Incorporated, San Jose, USA Applied Biosystems, Darmstadt Applied Biosystems, Darmstadt Berthold detection systems $\mathrm{GmbH}$, Pforzheim StatSoft $\mathrm{GmbH}$, Hamburg Microsoft Co., Redmond, USA

\subsection{Datenbanken}

MGI_3.43-mouse genome informatics

National Center for Biotechnology Information (NCBI)

European Bioinformatics Institute (EBI)

Ensembl

MatInspector http://www.informatics.jax.org/

http://www.ncbi.nlm.nih.gov/

http://www.ebi.ac.uk/Information/

http://www.ensembl.org/index.html

http://www.genomatix.de/online/matinspector/matinspector.html 


\subsection{Laborgeräte}

$-80^{\circ} \mathrm{C}$ Schrank (MDF-U71V)

AcT 5 hematology analyzer

Agarosegelelektrophorese-Kammern

Autoklav

Automat zur biechemischen Serumanalyse (MODULAR P)

BD LSR || flow cytometer

Blotsystem (Turboblotter)

Brutschränke; Begasungsbrutschränke (6000, BBD 6220)

Crosslinker (Crosslinker CL-1)

Digitale Photokamera (PowerShot G2)

Einkanal-Pipetten

Entwicklermaschine (Curix 60)

Feinwaagen (Satorius Basic plus)

Filmkassetten

Gasbrenner (Gasprofi 2 scs)

Geiger-Zähler

Gewebeeinbett-und -entwässerungsautomat (TP 1020)

Heizblöcke (Thermomixer)

Heizrührer (MR 3000/3001)

Homogenisator (Miccra D-1)

Hybrdisierungsofen (HB-1000 Hybridizer)

Inverses Mikroskop mit Fluoreszenzfilter (Axiovert 25, Filter set $43,01,09$ )

Kaltlichtquelle (KL 200)

Kryostat (Model CM 1900-1-1)

Luminometer (MPL-3 (2 Injektoren))

MilliQ-Anlage

Multipette

PAGE-Kammer (PerfectBlue S)

PA-Gelgießkammer (45-V10-SC2)

Paraffinspender, Ausgießstation (Dispenser PAG 12)

PCR-Gerät (PrimusHT)

PCR-Gerät (Robocycler Gradient 96 Combo)

pH-Meter (inoLab pH Level 1)

Photometer, Thermodrucker (Biophotometer 6131 Thermodrucker DPU-414)

Pipettierhilfe (Accu-jet)

Quecksilber-Kurzbogenlampe (HBO 50W/AC)

Schlittenmikrotom (HN 40)

Schüttelbrutschrank

Schüttelwasserbad (1083)

Sequenziergerät (ABI 3100)

Stereomikroskop (Stemi 2000)

Sterilbank (Euroflow Klasse IIA)

Stromquellen für Elektrophorese
Sanyo Electric Co., Ltd., Japan

Beckman Coulter $\mathrm{GmbH}$, Krefeld

peqlab Biotechnologie $\mathrm{GmbH}$, Erlangen

W. Krannich GmbH \& Co. K.G., Göttingen

Roche Diagnostics $\mathrm{GmbH} / \mathrm{Hitachi}$, Mannheim

BD Biosciences, Heidelberg

Whatman Inc., New Jersey, USA

Kendro Laboratory Products $\mathrm{GmbH}$; Hanau

Herolab GmbH, Wiesloch

Canon Inc., Japan

Eppendorf, Hamburg

AGFA Deutschland Vertriebsgesellschaft mbH \& Cie, Köln

Satorius AG, Göttingen

Sigma-Aldrich Chemie $\mathrm{GmbH}$, Steinheim

WLD-TEC GmbH, Göttingen

Berthold detection systems $\mathrm{GmbH}$, Pforzheim

Leica Microsysteme Vertrieb $\mathrm{GmbH}$, Bensheim

Eppendorf, Hamburg

Heidolph Instruments, Schwabach

ART-moderne Labortechnik e. K., Müllheim

UVP, Inc., Upland, USA

Carl Zeiss Jena GmbH, Jena

Schott Glas, Mainz

Leica Microsysteme Vertrieb $\mathrm{GmbH}$, Bensheim

Berthold detection systems $\mathrm{GmbH}$, Pforzheim

MembraPure $\mathrm{GmbH}$, Bodenheim

Eppendorf, Hamburg

peqlab Biotechnologie $\mathrm{GmbH}$, Erlangen

peqlab Biotechnologie $\mathrm{GmbH}$, Erlangen

Medite Medizintechnik GmbH, Burgdorf

MWG AG Biotech, Ebersberg

Stratagene, Amsterdam Zuidoost, Niederlande

WTW GmbH, Wien, Österreich

Eppendorf, Hamburg

Brand GmbH \& Co. KG, Wertheim

OSRAM, München

Leica Microsysteme Vertrieb $\mathrm{GmbH}$, Bensheim

New Brunswick Scientific GmbH, Nürtingen

GFL mbH, Burgwedel

Applied Biosystems, Darmstadt

Carl Zeiss Jena GmbH, Jena

Clean Air Techniek bv, Woerden, Niederlande

peqlab Biotechnologie $\mathrm{GmbH}$, Erlangen 
Tank für Flüssigstickstoff

TaqMan (ABI Prism 7900H)

Ultraschallwasserbad

UV-Dokumentation (digital monochrome printer P91D)

UV-Transilliminator / Software

Vakuumpumpe

Vortexer (Vortex-Genie 2)

Western Blot Kammer (\#VEP-2)

Wipp-Taumel-Tisch (Uinmax 1010)

Zählkammer nach Neubauer (Assistent)

Zentrifuge für Zytospins (Cytospin 2)

Zentrifugen (Biofuge pico, fresco, primo, Multifuge $3 \mathrm{~L}-\mathrm{R}$ )

Zwölfkanal-Pipette

\subsection{Gebrauchswaren}

\author{
1,5 ml Reaktionsgefäße \\ $13 \mathrm{ml}$ Röhrchen \\ 2,0 ml Reaktionsgefäße \\ $50 \mathrm{ml}$ Röhrchen \\ 6-Loch-Platten (Tissue culture plate 6-well) \\ 96-Loch Glyzerolstockplatte \\ Aufreinigungsplatte 96-Loch (MAHVN45) \\ Autoradiographie-Filme (Hyperfilm MP) \\ Blotting-Papier (GB 33 B003) \\ Deckgläser \\ Dispensionspipetten (Combitips plus) \\ ECL-Filme (Hyperfilm ECL) \\ EDTA-Röhrchen \\ Einwegspritzen (BD Plastipak) \\ Faltenfilter

\section{Glaswaren}

Kanülen (Sterican Ø 0,45 x 12 mm; Ø 0,8 x 120 mm)

Kryokonservierungsröhrchen (Cryo.s)

Küvetten (UVette)

Luminometer Messplatten (96 well assay plate)

Mikro-Hämatokrit-Kapillaren (Na-Heparin)

Nitrozellulosemembran (Hybond-XL)

Nitrozellulosemembran (Western Blot)

Objektträger (SuperFrost Plus)

Objektträger-Kulturschalen (Culture slides)

Pasteurpipetten

PCR-Reaktionsgefäße und Deckel (ThermoFast 96, nonskirted, natural domed cap strips, natural)

Petrischalen

Pipettenspitzen, gestopft (10 $\mu \mathrm{l}, 100 \mu \mathrm{l}, 200 \mu \mathrm{l}, 1000 \mu \mathrm{l})$
L'air liquide S.A., Paris Cedax, Frankreich

Applied Biosystems, Darmstadt

Carl Roth $\mathrm{GmbH}$, Karlsruhe

Mitsubishi, Ratingen

Intas, Göttingen

Schütt Labortechnik, Göttingen

Scientific Industries, Inc., Bohemia, USA

Owl scientific, Inc., Wobum, USA

Heidolph Instruments, Schwabach

Omnilab-Krannich, Göttingen

Shandon Thermo Electron Corporation, Waltham,USA

Kendro Laboratory Products $\mathrm{GmbH}$, Hanau

Eppendorf, Hamburg

Ochs GmbH, Bovenden / Lenglern

Nunc $\mathrm{GmbH} \&$ Co.KG, Wiesbaden

Sarstedt AG \& Co., Nürnberg

Sarstedt AG \& Co., Nürnberg

Sarstedt AG \& Co., Nürnberg

Nunc GmbH \& Co.KG, Wiesbaden

Millipore $\mathrm{GmbH}$, Schwalbach

Amersham Biosciences Europe $\mathrm{GmbH}$, Freiburg

Heinemann Labortechnik GmbH, Duderstadt

Menzel GmbH \& Co.KG, Braunschweig

Eppendorf, Hamburg

Amersham Biosciences Europe $\mathrm{GmbH}$, Freiburg

Sarstedt AG \& Co., Nürnberg

BD $\mathrm{GmbH}$, Heidelberg

Schleicher \& Schüll, Dassel

Schott AG, Mainz

B. Braun Medical AG, Emmenbrücke

Greiner Bio-One $\mathrm{GmbH}$, Frickenhausen

Eppendorf, Hamburg

Costar, Corning Incorporated, Corning, USA

Brand $\mathrm{GmbH} \&$ Co.KG, Wertheim

Amersham Biosciences Europe $\mathrm{GmbH}$, Freiburg

Bio-rad Laboratories $\mathrm{GmbH}$, München

Menzel GmbH \& Co.KG, Braunschweig

BD Falcon, Heidelberg

Brand $\mathrm{GmbH} \&$ Co.KG, Wertheim

Sarstedt AG \& Co., Nürnberg

Ochs GmbH, Bovenden / Lenglern

G. Kisker GbR, Steinfurt 
Pipettenspitzen, ungestopft ( $10 \mu \mathrm{l}, 200 \mu \mathrm{l})$

Pipettenspitzen, ungestopft (1000 $\mu \mathrm{l})$

Serologische Pipetten ( $5 \mathrm{ml}, 10 \mathrm{ml}, 25 \mathrm{ml}$ )

Skalpelle

Sterilfilter

TaqMan Platten und Folien (96-well optical reaction plate, Optical adhesive covers)

Zellkulturschalen; 100 mm, 35 mm (Nunclon Surface)
Ochs $\mathrm{GmbH}$, Bovenden / Lenglern

Sarstedt AG \& Co., Nürnberg

Sarstedt AG \& Co., Nürnberg

Aesulap AG \& Co.KG, Tuttlingen

Omnilab-Krannich, Göttingen

Applied Biosystems, Darmstadt

Nunc GmbH \& Co.KG, Wiesbaden

\subsection{Chemikalien und Reagenzien}

\section{Die folgenden nicht aufgelisteten Chemikalien wurden von der Firma Carl Roth} $\mathrm{GmbH}$, Karlsruhe, und von der Firma Sigma-Aldrich Chemie $\mathrm{GmbH}$, Steinheim, bezogen.

\author{
$1 \mathrm{~kb}$ DNA und 100 bp DNA Ladder \\ ${ }^{32} \mathrm{P}-\mathrm{dATP}$ \\ 4-Hydroxy-Tamoxifen (4-OHT) \\ Agarose \\ Borsäure \\ Cryoblock Einbettmedium \\ Deoxyribonukleotidtriphosphate (dNTP) \\ Ethylendiamintetraacetat (EDTA) \\ Hemacolor \\ Immuno Mount \\ Ketanest S (25 mg/ml) \\ Lachsspermien-DNA (10 mg/ml;) \\ Montagemedium (Immuno Mount) \\ Montagemedium (Vectrashield mounting medium with \\ DAPI) \\ oligo(dT)-Nukleotide (50 $\mathrm{ng} / \mathrm{\mu l}$ ) \\ PAGE Molekulargewichtsstandard (See blue plus2) \\ Paraformaldehyd \\ Pertex Montagemedium \\ Polyacrylamidgelelektrophorese (PAGE)-Laufpuffer \\ (NuPAGE MES 20x SDS-Running buffer) \\ Rapid-hyb buffer \\ Ringer-Lactat (nach Hartmann) \\ Rnase-freies destilliertes Wasser \\ Rompun (2 \%) \\ Sephadex G-50 fine \\ TRIZOL Reagent \\ Tween20 \\ Wasser für Injektionszwecke (Ampuwa)
}

Invitrogen $\mathrm{GmbH}$, Karlsruhe

Amersham Biosciences Europe $\mathrm{GmbH}$, Freiburg

Sigma-Aldrich, Chemie GmbH, Steinheim

Invitrogen $\mathrm{GmbH}$, Karlsruhe

ICN Biochemicals Inc., Aurora, USA

Medite Medizintechnik GmbH, Burgdorf

Roche Diagnostics $\mathrm{GmbH}$, Mannheim

ICN Biochemicals Inc., Aurora, USA

Merck KgaA, Darmstadt

Shandon Thermo Electron Corporation, Waltham, USA

Pfizer Pharma GmbH, Karlsruhe

Stratagene, Amsterdam Zuidoost, Niederlande

Shandon Thermo Electron Corporation, Waltham

Vector Laboratories, Inc., Burlingame, USA

Roche Diagnostics $\mathrm{GmbH}$, Mannheim

Invitrogen $\mathrm{GmbH}$, Karlsruhe

Fluka Chemie $\mathrm{GmbH}$, Buchs

Medite Medizintechnik GmbH, Burgdorf

Invitrogen $\mathrm{GmbH}$, Karlsruhe

Amersham Biosciences Europe $\mathrm{GmbH}$, Freiburg

B. Braun Melsungen AG, Melsungen

Invitrogen $\mathrm{GmbH}$, Karlsruhe

Bayer AG, Leverkusen

Amersham Biosciences Europe $\mathrm{GmbH}$, Freiburg

Invitrogen $\mathrm{GmbH}$, Karlsruhe

Scharlau Chemie S.A., Barcelona, Spain

Fresenius Kabi Deutschland $\mathrm{GmbH}$, Bad Homburg 


\subsection{Gebrauchsfertige Reaktionssysteme}

Soweit im Text nicht anders erwähnt, wurde bei der Verwendung von gebrauchsfertigen Reaktionssystemen nach den Angaben des Herstellers gearbeitet.

Annexin V-PE apoptosis detection kit
DNAeasy Kit
Dual-Luciferase reporter assay system
EasySep mouse hematopoietic progenitor cell enrichment
kit
Enhanced chemoluminescence (ECL) Kit
MicroSpin G-50 Columns
Oligotex
pGEM-Teasy vector System I
Prime-It RmT Random Primer Labeling Kit
Protein assay Kit
QIAEX II / QIAquick gel extraction kit
QIAGEN plasmid purification
QIAprep miniprep
qPCR core kit
QuantiTect SYBR green PCR
RotiFect
SAWADY Mid Range PCR-System
Smart race cDNA amplification kit
TA cloning kit (pCR II)
TaqMan ribosomal RNA control reagent, VIC probe
TransMessenger transfection reagent
BigDye Terminator v1.1 cycle sequencing kit
Eukaryotic TA expression kit (pCR3.1 unidirectional)
(a)

\author{
BD Biosciences Pharmingen, San Diego, USA \\ Qiagen $\mathrm{GmbH}$, Hilden \\ Promega $\mathrm{GmbH}$, Mannheim \\ CellSystems, St. Katharinen \\ Amersham Biosciences Europe $\mathrm{GmbH}$, Freiburg \\ Amersham Biosciences Europe $\mathrm{GmbH}$, Freiburg \\ Qiagen $\mathrm{GmbH}$, Hilden \\ Promega $\mathrm{GmbH}$, Mannheim \\ Stratagene, Amsterdam Zuidoost, Niederlande \\ Bio-rad Laboratories $\mathrm{GmbH}$, München \\ Qiagen $\mathrm{GmbH}$, Hilden \\ Qiagen $\mathrm{GmbH}$, Hilden \\ Qiagen $\mathrm{GmbH}$, Hilden \\ Eurogentec Deutschland $\mathrm{GmbH}$, Köln \\ Qiagen $\mathrm{GmbH}$, Hilden \\ Carl Roth $\mathrm{GmbH}$, Karlsruhe \\ Peqlab Biotechnologie $\mathrm{GmbH}$, Erlangen \\ BD Bioscience Clontech, Heidelberg \\ Firma Invitrogen $\mathrm{GmbH}$, Karlsruhe \\ Applied Biosystems, Darmstadt \\ Qiagen $\mathrm{GmbH}$, Hilden \\ Applied Biosystems, Darmstadt \\ Invitrogen $\mathrm{GmbH}$, Karlsruhe
}

\subsection{Stammlösungen}

Soweit im Text nicht ausdrücklich erwähnt, wurde für alle Stammlösungen in der MilliQ-Anlage (MembraPure $\mathrm{GmbH}$, Bodenheim) aufbereitetes doppelt-destilliertes Wasser verwendet.

Brilliantkresylblau-Lösung (siehe Kapitel 2.18.2.2)

Citratpuffer (siehe Kapitel siehe Kapitel 2.16.5)

Collagenase H-Lösung (siehe Kapitel 2.17.2)

Cresol (siehe Kapitel 2.15.4)

\begin{tabular}{|c|c|}
\hline \multirow[t]{2}{*}{$1 \%(w / v)$} & \multirow{2}{*}{$\begin{array}{l}\text { Brilliantkresylblau } \\
\text { 1x Phosphat gepufferte } \\
\text { Natriumchlorid Lösung (PBS) }\end{array}$} \\
\hline & \\
\hline $10 \mathrm{mM}$ & Natriumcitrat \\
\hline \multirow[t]{2}{*}{$2 \mathrm{mg} / \mathrm{ml}$} & $\begin{array}{l}\text { Clostridiopepdidase A (Roche } \\
\text { Diagnostics GmbH, Mannheim) }\end{array}$ \\
\hline & DMEM, sterilfiltriert \\
\hline $0,1 \%(w / v)$ & $\begin{array}{l}\text { Cresol } \\
\text { gesättigte Sukrose-Lösung }\end{array}$ \\
\hline
\end{tabular}


Denaturierungspuffer (siehe Kapitel 2.15.6)

$\begin{array}{ll}1,5 \mathrm{M} & \mathrm{NaCl} \\ 0,5 \mathrm{M} & \mathrm{NaOH} \\ 10 \mathrm{mM} & \mathrm{dATP} \\ 10 \mathrm{mM} & \mathrm{dTTP} \\ 10 \mathrm{mM} & \mathrm{dGTP} \\ 10 \mathrm{mM} & \text { dCTP } \\ 1 \%(\mathrm{w} / \mathrm{v}) & \text { Eosin Y (wasserlöslich) } \\ 80 \%(\mathrm{v} / \mathrm{v}) & \text { Ethanol } \\ 0,2 \%(\mathrm{v} / \mathrm{v}) & \text { Glutaralaldeyd } \\ & \text { 1x PBS }\end{array}$

Glyzerolreihe (siehe Kapitel 2.16.1.5.1, 2.19.2)

$15 \%, 30 \%, 50 \%$ bzw. $80 \%$ (v/v)

Deoxyribonukleotidtriphosphate (siehe Kapitel 2.15.4, dNTP-Mix)

Eosin, $1 \%$ (siehe Kapitel 2.16.3.3)

\begin{tabular}{|c|c|}
\hline \multicolumn{2}{|c|}{ Glyzerol } \\
\hline & $1 \times$ PBS \\
\hline \multirow[t]{2}{*}{$100 \mathrm{mM}$} & Glycin \\
\hline & 1x PBS \\
\hline $0,1 \%(w / v)$ & Hämatoxylin \\
\hline $5 \%(w / v)$ & Aluminiumammoniumsulfat \\
\hline $0,02 \%(w / v)$ & Natriumjodat \\
\hline $5 \%(w / v)$ & Chloralhydrat \\
\hline $0,1 \%(w / v)$ & Zitronensäure \\
\hline $0,1 \%(w / v)$ & Natriumdodecylsulfat (SDS) \\
\hline
\end{tabular}

0,2x Standard Natriumcitrat Lösung (SSC)

\begin{tabular}{|c|c|}
\hline $5 \mathrm{mM}$ & $\mathrm{K}_{3} \mathrm{Fe}(\mathrm{CN})_{6}$ \\
\hline $5 \mathrm{mM}$ & $\mathrm{K}_{4} \mathrm{Fe}(\mathrm{CN})_{6}$ \\
\hline $2 \mathrm{mM}$ & $\mathrm{MgCl}_{2}$ \\
\hline $0,02 \%(v / v)$ & NP-40 \\
\hline $0,01 \%(w / v)$ & Natrium Deoxycholat \\
\hline \multirow[t]{2}{*}{$500 \mu \mathrm{g} / \mathrm{ml}$} & X-Gal \\
\hline & 1x PBS \\
\hline $2 \mathrm{mM}$ & $\mathrm{MgCl}_{2}$ \\
\hline $0,02 \%(v / v)$ & NP-40 \\
\hline \multirow[t]{2}{*}{$0,01 \%(w / v)$} & Natrium Deoxycholat \\
\hline & 1x PBS \\
\hline $50 \%(v / v)$ & Glyzerol \\
\hline $0,02 \%(w / v)$ & Xylencyanol \\
\hline $0,02 \%(w / v)$ & Bromphenolblau \\
\hline $0,02 \%(w / v)$ & SDS \\
\hline $100 \mathrm{mM}$ & EDTA \\
\hline $200 \mathrm{mM}$ & $\mathrm{NaOH}$ \\
\hline $1 \%(w / v)$ & SDS \\
\hline $100 \mathrm{mM}$ & Tris/HCl \\
\hline $200 \mathrm{mM}$ & $\mathrm{NaCl}$ \\
\hline $5 \mathrm{mM}$ & EDTA \\
\hline $0,2 \%(w / v)$ & SDS \\
\hline $100 \mu \mathrm{g} / \mathrm{ml}$ & $\begin{array}{l}\text { Proteinase K (Carl Roth GmbH, } \\
\text { Karlsruhe) }\end{array}$ \\
\hline
\end{tabular}

Hoch-stringenter Puffer (siehe Kapitel 2.15.6)

LacZ-Färbepuffer (siehe Kapitel 2.16.1.5)

LacZ-Puffer (siehe Kapitel 2.16.1.5)

Ladepuffer (siehe Kapitel 2.15.5)

Lysepuffer für Plasmid-DNA Isolierungen (siehe Kapitel 2.15.1.1.1)

Lysepuffer für Proteinextrakte (siehe Kapitel 2.15.1.4.1)

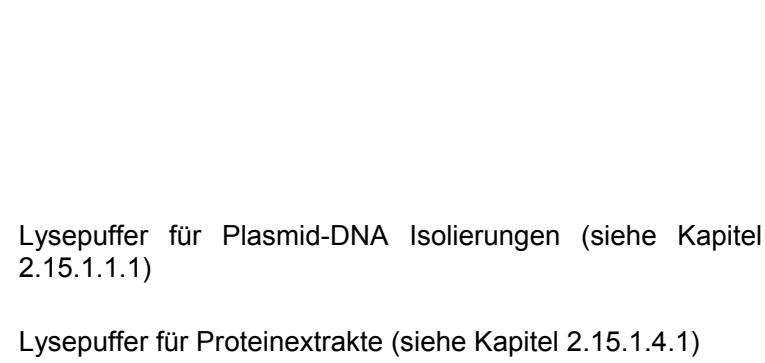

Saures Hämatlaun nach Mayer (siehe Kapitel 2.16.3.3)
Hoch-stringenter Puffer (siehe Kapitel 2.15.6)

Ladepuffer (siehe Kapitel 2.15.5)
Lysepuffer für Plasmid-DNA Isolierungen (siehe Kapitel
2.15.1.1.1)
Lysepuffer für Proteinextrakte (siehe Kapitel 2.15.1.4.1)


M-PBT Puffer (siehe Kapitel 2.16.1.4)

Neutralisierungspuffer (siehe Kapitel 2.15.1.1.1)

Niedrig-stringenter Puffer (siehe Kapitel 2.15.6)

PAGE-Sammelgel (siehe Kapitel 2.16.1.4)

Paraformaldehyd

Phosphat gepufferte Natriumchlorid Lösung, 10x, pH 7,4 (PBS)

Polyacrylamidgelelektrophorese (PAGE)-Laufgel (siehe Kapitel 2.16.1.4,)

Ponceau S Lösung (siehe Kapitel 2.16.1.4)

Protein-Ladepuffer (siehe Kapitel 2.16.1.4)

Resuspensionspuffer (siehe Kapitel 2.15.1.1.1)

SDS-Lysepuffer (siehe Kapitel 2.16.1.1)

Standard Natriumcitrat Lösung, $20 \times \mathrm{pH} 7,0$ (siehe Kapitel 2.15.6; SSC)

\begin{tabular}{|c|c|c|}
\hline $5 \%(w / v)$ & \multicolumn{2}{|l|}{ Magermilchpulver } \\
\hline $0,1 \%(v / v)$ & \multicolumn{2}{|l|}{ Tween20 } \\
\hline $1 x$ & \multicolumn{2}{|l|}{ PBS } \\
\hline $3 \mathrm{M}$ & \multicolumn{2}{|l|}{ Natriumacetat } \\
\hline & \multicolumn{2}{|l|}{ Essigsäure } \\
\hline $0,6 \%(v / v)$ & \multicolumn{2}{|l|}{ N,N-Dimethylformamid } \\
\hline $0,05 \%(w / v)$ & \multicolumn{2}{|l|}{ Levamisol } \\
\hline $0,03 \%(w / v)$ & \multicolumn{2}{|l|}{ Naphtol As-Bi Phosphat } \\
\hline $0,02 \%(w / v)$ & \multicolumn{2}{|l|}{$\mathrm{NaN}_{3}$} \\
\hline $0,01 \%(w / v)$ & \multicolumn{2}{|l|}{ Neu-Fuchsin } \\
\hline & $\begin{array}{l}\text { 1x TBS } \\
\text { (Tris-gepufferte Natriumchlori }\end{array}$ & $\begin{array}{l}\mathrm{pH} 8,8 \\
\text { id Lösung) }\end{array}$ \\
\hline $2,55 \mathrm{M}$ & Kaliumacetat & $\mathrm{pH} 5,5$ \\
\hline \multirow[t]{2}{*}{$0,1 \%$} & SDS & \\
\hline & $2 x$ SSC & $\mathrm{pH} 7,0$ \\
\hline $4 \%(v / v)$ & \multicolumn{2}{|l|}{ Acryl-/Bisacrylamid (1:29) } \\
\hline $180 \mathrm{mM}$ & Tris/HCl & $\mathrm{pH} 6,8$ \\
\hline $0,1 \%(w / v)$ & \multicolumn{2}{|l|}{ SDS } \\
\hline $0,1 \%(w / v)$ & \multicolumn{2}{|l|}{ APS } \\
\hline $0,1 \%(v / v)$ & \multicolumn{2}{|l|}{ TEMED } \\
\hline $4 \%(w / v)$ & \multicolumn{2}{|l|}{ Paraformaldehyd } \\
\hline & \multicolumn{2}{|l|}{ 1x PBS } \\
\hline $1,4 \mathrm{M}$ & \multicolumn{2}{|l|}{$\mathrm{NaCl}$} \\
\hline $27 \mathrm{mM}$ & \multicolumn{2}{|l|}{$\mathrm{KCl}$} \\
\hline $15 \mathrm{mM}$ & \multicolumn{2}{|l|}{$\mathrm{KH}_{2} \mathrm{PO}_{4}$} \\
\hline $65 \mathrm{mM}$ & \multicolumn{2}{|l|}{$\mathrm{Na}_{2} \mathrm{HPO}_{4}$} \\
\hline 7,5 bis $10 \%$ & \multicolumn{2}{|l|}{ Acryl-/Bisacrylamid (1:29) } \\
\hline $375 \mathrm{mM}$ & Tris/HCl & $\mathrm{pH} 8,8$ \\
\hline $0,1 \%(w / v)$ & \multicolumn{2}{|l|}{ SDS } \\
\hline $0,1 \%(w / v)$ & \multicolumn{2}{|l|}{ Ammoniumpersulfat (APS) } \\
\hline $0,1 \%(v / v)$ & $\begin{array}{l}\text { N,N,N',N'Tetramethylethylen- } \\
\text { diamin (TEMED) }\end{array}$ & \\
\hline $0,2 \%(w / v)$ & Ponceau S & \\
\hline $3 \%(v / v)$ & Trichloressigsäure & \\
\hline $100 \mathrm{mM}$ & Tris $/ \mathrm{HCl}$ & $\mathrm{pH} 6,8$ \\
\hline $20 \%(v / v)$ & Glyzerol & \\
\hline $10 \%(v / v)$ & ß-Mercaptoethanol & \\
\hline $4 \%(w / v)$ & SDS & \\
\hline $0,2 \%(w / v)$ & Bromphenolblau & \\
\hline $50 \mathrm{mM}$ & Tris/HCl & $\mathrm{pH} 8,0$ \\
\hline $10 \mathrm{mM}$ & EDTA & \\
\hline $100 \mu \mathrm{g} / \mu \mathrm{l}$ & $\begin{array}{l}\text { RNase A (Ribonuclease A; } \\
\text { Qiagen GmbH, Hildesheim) }\end{array}$ & \\
\hline $10 \mathrm{mM}$ & Tris/HCl & $\mathrm{pH} 7,4$ \\
\hline $1 \mathrm{mM}$ & Natriumorthovanadat & \\
\hline $1 \%(w / v)$ & SDS & \\
\hline $0,3 \mathrm{M}$ & Natriumcitrat & \\
\hline $3,0 \mathrm{M}$ & $\mathrm{NaCl}$ & \\
\hline
\end{tabular}




\begin{tabular}{|c|c|c|c|}
\hline \multirow[t]{4}{*}{ STE-Puffer (siehe Kapitel 2.15.1.4.2) } & $50 \mathrm{mM}$ & Tris/HCl & \multirow[t]{4}{*}{$\mathrm{pH} 8,0$} \\
\hline & $100 \mathrm{mM}$ & $\mathrm{NaCl}$ & \\
\hline & $1 \mathrm{mM}$ & EDTA & \\
\hline & $1 \%(w / v)$ & SDS & \\
\hline \multirow[t]{2}{*}{ Sukrose/1x PBS (siehe Kapitel 2.16.3.1) } & \multirow[t]{2}{*}{$25 \%(w / v)$} & Sukrose & \\
\hline & & 1x PBS & \\
\hline \multirow[t]{3}{*}{ Transferpuffer (siehe Kapitel 2.16.1.4) } & $25 \mathrm{mM}$ & Tris & \\
\hline & $200 \mathrm{mM}$ & Glycin & \\
\hline & $20 \%(v / v)$ & Methanol & \\
\hline \multirow{3}{*}{$\begin{array}{l}\text { Tris-Borsäure-EDTA Lösung, 10x (siehe Kapitel 2.15.5; } \\
\text { TBE) }\end{array}$} & $890 \mathrm{mM}$ & Tris/HCl & \multirow[t]{3}{*}{$\mathrm{pH} 8,0$} \\
\hline & $730 \mathrm{mM}$ & Borsäure & \\
\hline & $12,5 \mathrm{mM}$ & EDTA & \\
\hline \multirow[t]{2}{*}{ Tris-EDTA-Puffer (siehe Kapitel 2.15.3.5;TE) } & $5 \mathrm{mM}$ & Tris/HCl & \multirow[t]{2}{*}{$\mathrm{pH} 7,4$} \\
\hline & $0,1 \mathrm{mM}$ & EDTA & \\
\hline \multirow{2}{*}{$\begin{array}{l}\text { Tris-gepufferte Natriumchlorid Lösung, 10x (siehe Kapitel } \\
2.16 .5, \text { TBS) }\end{array}$} & $0,5 \mathrm{M}$ & Tris/HCl & \multirow[t]{4}{*}{$\mathrm{pH} 7,4$} \\
\hline & $1,5 \mathrm{M}$ & $\mathrm{NaCl}$ & \\
\hline \multirow[t]{2}{*}{ TritonX-100/1x PBS (siehe Kapitel 2.16.6.2) } & \multirow[t]{2}{*}{$0,1 \%(v / v)$} & TritonX-100 & \\
\hline & & 1x PBS & \\
\hline \multirow[t]{2}{*}{ TritonX-100/1x TBS (siehe Kapitel 2.16.5) } & \multirow[t]{2}{*}{$0,1 \%(v / v)$} & TritonX-100 & \\
\hline & & $1 \times$ TBS & \\
\hline \multirow[t]{2}{*}{ X-Gal Stocklösung (siehe Kapitel 2.16.1.5) } & $40 \mathrm{mg} / \mathrm{ml}$ & X-Gal & \\
\hline & $100 \%$ & N.N.-Dimeth & \\
\hline
\end{tabular}

\subsection{Medien}

\subsubsection{Medien für die Bakterienkultur}

Zur Kultivierung von Bakterienkulturen (E. coli; siehe Kapitel 2.15.1.1; 2.15.3.8) wurde mit Luria-Bertani-Medium (LB-Medium) (1 \% (w/v) Bacto-Trypton, 0,5 \% (w/v) Hefeextrakt, $1 \%(w / v), \mathrm{NaCl} ; \mathrm{pH} 7,0)$ gearbeitet.

Das LB-Medium wurde mit doppelt-destilliertem Wasser angesetzt, autoklaviert und bei $4^{\circ} \mathrm{C}$ gelagert. Die Selektion auf jeweilige Resistenz-vermittelnde Gene erfolgte durch Zugabe von $50 \mu \mathrm{g} / \mathrm{ml}$ Ampicillin (Stammkonzentration: $50 \mathrm{mg} / \mathrm{ml}$; Carl Roth $\mathrm{GmbH}$, Karlsruhe) bzw. $25 \mu \mathrm{g} / \mathrm{ml}$ Kanamycin (Stammkonzentration: $50 \mathrm{mg} / \mathrm{ml}$; Carl Roth $\mathrm{GmbH}$, Karlsruhe) direkt vor der Verwendung des Mediums.

\subsubsection{Agarplatten}

Zur Herstellung von LB-Agarplatten wurde dem LB-Medium 1,5\% (w/v) Agar zugegeben, der Ansatz wurde autoklaviert und auf $55^{\circ} \mathrm{C}$ abgekühlt. Nach Zugabe entsprechender Antibiotika (siehe Kapitel 2.9.1) wurde der noch warme LB-Agar in 
$10 \mathrm{~cm}$ Petrischalen gegossen. Nach dem Erstarren des Agars wurden die Platten in sterilen Plastiktüten bei $4^{\circ} \mathrm{C}$ gelagert.

\subsubsection{Medien für die Kultur eukaryotischer Zellen}

Eukaryotische Zellen wurden in Dulbecco's Modified Eagle Medium mit 10 \% fötalem Kälberserum (FCS, fetal calf serum) und Antibiotika kultiviert. Die für die jeweilige Zelllinie verwendeten Antibiotika und die eingesetzten Konzentrationen sind unter 2.10.2 aufgelistet. Bei einigen Experimenten wurde mit abweichenden Serumkonzentrationen gearbeitet, welche bei der Beschreibung der jeweiligen Experimente angegeben sind.

$\begin{array}{ll}\begin{array}{l}\text { Dulbecco's Modified Eagle Medium (DMEM) } \\ \text { fötales Kälberserum (fetal calf serum; FCS) }\end{array} & \text { PAN Biotech GmbH, Aidenbach } \\ \text { Geneticinsulfat (G418, } 100 \mathrm{mg} / \mathrm{ml}) & \text { Gibco, Invitrogen GmbH, Karlsruhe } \\ \text { MethoCult } 3434 \text { (Stem Cell Factor (SCF), Interleukin-3 (IL- } & \text { Carl Roth GmbH, Karlsruhe } \\ \text { 3), Interleukin-6 (IL-6), Erythropoietin (EPO)) } & \\ \text { Penicillin (10000U/ml)/Streptomycin (10 mg/ml) } & \text { PAN Biotech GmbH, Aidenbach } \\ \text { Pferdeserum (horse serum; HS) } & \text { Gibco, Invitrogen GmbH, Karlsruhe } \\ \text { Trypsin/EDTA } & \text { PAN Biotech GmbH, Aidenbach } \\ \text { Zeocin (100 mg/ml) } & \text { Stratagene, Amsterdam Zuidoost, Niederlande }\end{array}$

\subsection{Biologisches Material}

\subsubsection{Bakterienstämme}

Zur Transformation und Amplifikation von Plasmid-DNA wurde der chemischkompetente Wirtsstamm E.coli DH5a (Invitrogen $\mathrm{GmbH}$, Karlsruhe) verwendet.

\subsubsection{Eukaryotische Zelllinien}

Die Kultivierung von eukaryotischen Zelllinien erfolgte mit dem unter 2.9.3 beschriebenen Medium in speziellen Zellkulturschalen bei $37^{\circ} \mathrm{C}$ in einer konstanten $\mathrm{CO}_{2}$-haltigen Atmosphäre $\left(5 \% \mathrm{CO}_{2}\right)$ mit $95 \%$ Luftfeuchtigkeit. 
Tabelle 1: $\quad$ Auflistung der verwendeten eukaryotischen Zelllinien. Spalte 1: Bezeichnung der Zelllinie; 2: Ursprungsspezies und Zelltyp/Morphologie; Spalte 3: Verwendete Antibiotika und eingesetzte Konzentrationen; Spalte 4: Hersteller und Klonnummer/Literaturreferenz; Abkürzungen: PS Penicillin/Streptomycin; G418, Geneticinsulfat; $p G L$ 9xGli-BS, Plasmid zur Gli-responsiver Expression der Firefly Luziferase; $p R L-C M V$, Plasmid zur konstitutiven Expression der Renilla Luziferase unter Kontrolle des CMV (Cytomegalie Virus) Promotor.

\begin{tabular}{|c|c|c|c|}
\hline 1 & 2 & 3 & 4 \\
\hline $\mathrm{C} 2 \mathrm{C} 12$ & Adulte Maus (Muskel/Myoblast) & $1 \%$ PS & $\begin{array}{c}\text { ATCC LGC Promochem, Wesel; CRL-1772; } \\
\text { (Yaffe D und Saxel O, 1977) }\end{array}$ \\
\hline $\mathrm{NIH} / 3 \mathrm{T3}$ & Embryonale Maus (Fibroblast) & $1 \% \mathrm{PS}$ & $\begin{array}{l}\text { ATCC LGC Promochem, Wesel; CRL-1658; } \\
\text { (Jainchill JL et al., 1969) }\end{array}$ \\
\hline $\begin{array}{l}\text { Shh light } 2 \text { (JHU- } \\
68)\end{array}$ & $\begin{array}{l}\text { NIH/3T3 stabil transfiziert mit } p G L 9 x \text { Gli- } \\
\qquad B S \text { und } p R L-C M V\end{array}$ & $\begin{array}{c}0,15 \mathrm{mg} / \mathrm{ml} \text { Zeocin } \\
0,4 \mathrm{mg} / \mathrm{ml} \mathrm{G} 418\end{array}$ & $\begin{array}{c}\text { ATCC LGC Promochem, Wesel; CRL-2795; } \\
\text { (Taipale J et al., 2000a) }\end{array}$ \\
\hline
\end{tabular}

\subsubsection{Mauslinien}

Es wurden die Inzuchtlinien C57BL/6N (Charles River Laboratories, Inc., Wilmington, USA), Balb/c (Charles River Laboratories, Inc., Wilmington, USA), 129Sv (Zucht des Tierstalls des Institutes für Humangenetik, Universität Göttingen) und FVB/N (Zucht des Tierstalls des Institutes für Humangenetik, Universität Göttingen) verwendet. In Tabelle 2 sind die verwendeten genetisch manipulierten Mauslinien aufgelistet. Die Zucht und Haltung der Tiere als auch tierexperimentelle Methoden sind unter 2.19 beschrieben. 
Tabelle 2: Auflistung der verwendeten Mauslinien. Spalte 1: Bezeichnung der Mauslinie; Spalte 2: Genetischer Hintergrund; Spalte 3: Art der genetischen Veränderung; Spalte 4: Literaturreferenz.

\begin{tabular}{|c|c|c|c|}
\hline 1 & 2 & 3 & 4 \\
\hline Pax7 G4 & C57BL/6N & $\begin{array}{l}\text { Gendeletion durch Integration des } \beta \text { - } \\
\text { Galaktosidase-Gens (knock-out) }\end{array}$ & (Mansouri A et al., 1996) \\
\hline $\operatorname{Ptch}^{d 67}$ & C57BL/6N / Balb/c & Gendeletion (knock-out) & (Hahn H et al., 1998) \\
\hline $\operatorname{Ptch}^{N X}$ & $129 \mathrm{~Sv} / \mathrm{C} 57 \mathrm{BL} / 6 \mathrm{~N}$ & konditionelle induzierbare Gendeletion & (diese Arbeit) \\
\hline ROSA26CreERT2 & $129 S v$ & $\begin{array}{c}\text { CreERT2-Gen Integration in den ROSA26 } \\
\text { Lokus }\end{array}$ & $\begin{array}{l}\text { (zur Verfügung gestellt von A } \\
\text { Berns, Niederlanden) }\end{array}$ \\
\hline$R O S A 26-R$ & C57BL/6N & $\begin{array}{l}\text { Integration des } B \text {-Galaktosidase-Gens in den } \\
\text { ROSA26 Lokus }\end{array}$ & (Soriano P, 1999) \\
\hline $\operatorname{Tg}($ Ella-Cre $)$ & C57BL/6N & $\begin{array}{l}\text { Transgen zur Expression einer konstitutiv } \\
\text { aktiven Cre-Rekombinase unter Kontrolle } \\
\text { des Ella-Promotors }\end{array}$ & (Lakso M et al., 1996) \\
\hline $\operatorname{Tg}($ Pax7CreTM) & C57BL/6N & $\begin{array}{c}\text { Transgen zur Expression einer Tamoxifen- } \\
\text { induzierbaren Cre-Rekombinase unter } \\
\text { Kontrolle des Pax7-Promotors }\end{array}$ & (diese Arbeit) \\
\hline
\end{tabular}

\subsection{Plasmide}

\subsubsection{Klonierungsvektoren}

Folgende Vektoren wurden für Klonierungen (siehe Kapitel 2.15.3) verwendet: pGEM-Teasy (Invitrogen $\mathrm{GmbH}$, Karlsruhe), pBSSK ${ }^{+}$(Stratagene, Amsterdam Zuidoost, Niederlande), pCRII (Invitrogen $\mathrm{GmbH}$, Karlsruhe), pCR3.1 (Invitrogen $\mathrm{GmbH}$, Karlsruhe), pGL3-basic (Promega $\mathrm{GmbH}$, Mannheim), pUC19 (Invitrogen $\mathrm{GmbH}$, Karlsruhe).

\subsubsection{Eukaryotische Expressionsplasmide zur Analyse des Shh/Ptch-Signalweges}

Zur Analyse des Shh/Ptch Signalweges wurden die in Tabelle 3 aufgeführten eukaryotischen Expressionsplasmide verwendet. 
Tabelle 3: Auflistung der verwendeten eukaryotischen Expressionsplasmide zur Analyse des Shh/Ptch-Signalweges. Spalte 1: Bezeichnung der Expressionsplasmide; Spalte 2: Bezeichnung der inserierten cDNA/Gen-Sequenz; Spalte 3: Bezeichnung der inserierten Promotorsequenz; Spalte 4: Bezeichnung des Leervektors; Spalte 5: Literaturreferenz. Die Leervektoren $p C R 3.1$ und pcDNA/mycHis wurden von der Firma Invitrogen $\mathrm{GmbH}$, Karlsruhe, $p G L-T K$ von der Firma Promega $\mathrm{GmbH}$, Mannheim bezogen. Abkürzungen: CMV, Cytomegalie Virus; TK, Thymidin Kinase; wt, Wildtyp.

\begin{tabular}{|c|c|c|c|c|}
\hline 1 & 2 & 3 & 4 & 5 \\
\hline pcDNA mGli1 myc-His & Gli1 & CMV Promotor & pcDNA/ myc-His & (Sasaki H et al., 1999) \\
\hline pCMV mShh-N & $\begin{array}{c}\text { Shh-N } \\
(600 \mathrm{bp} ; 1197 \mathrm{AA})\end{array}$ & CMV Promotor & pCMV5 & (Kogerman P et al., 2002) \\
\hline pCR3.1 mPtch $(K) d 67$ & $P_{t c h}^{d 67}$ & $\begin{array}{c}\text { CMV Promotor; Kozak- } \\
\text { Konsensussequenz }\end{array}$ & pCR3.1 & $\begin{array}{c}\text { (Uhmann A et al., 2005) } \\
\text { (diese Arbeit) }\end{array}$ \\
\hline pCR3.1 mPtch $(K) w t$ & wt Ptch & $\begin{array}{c}\text { CMV Promotor; Kozak- } \\
\text { Konsensussequenz }\end{array}$ & pCR3.1 & $\begin{array}{c}\text { (Uhmann A et al., 2005) } \\
\text { (diese Arbeit) }\end{array}$ \\
\hline pGL3 9xGli BS & Firefly Luziferase & $\begin{array}{c}9 \text { Gli Bindestellen (Sasaki } \\
\text { H et al., 1999) proximal } \\
\text { vom TK Promotor }\end{array}$ & $p G L-T K$ & (Beer C et al., 2003) \\
\hline
\end{tabular}

\subsubsection{Pax7 Promotorplasmide}

Zur Analyse der Expression des murinen Pax7 Promotors wurden die in Tabelle Tabelle 4 aufgelisteten Plasmide verwendet. Die Klonierung der Plasmide ist unter 2.15.7.2 beschrieben.

Tabelle 4: $\quad$ Auflistung der verwendeten Pax7 Promotorplasmide. Spalte 1: Bezeichnung des Plasmids; Spalte 2: Bezeichnung der inserierten cDNA/Gen; Spalte 3: Größe des proximalen Teils des Pax7 Promotors; Spalte 4: Bezeichnung/Referenz des Leervektors/Ursprungsvektors. Der Leervektor pGL3-basic wurde von der Firma Promega GmbH, Mannheim, bezogen.

\begin{tabular}{cccc}
\hline $\mathbf{1}$ & $\mathbf{2}$ & $\mathbf{3}$ & $\mathbf{4}$ \\
\hline$p G L 3$ Pax7prom 3,2 & Firefly Luziferase & $3,2 \mathrm{~kb}$ & $p G$ 3-basic \\
$p G L 3$ Pax7prom 2,5 & Firefly Luziferase & $2,5 \mathrm{~kb}$ & $p G L 3$-basic \\
$p G L 3$ Pax7prom 1,5 & Firefly Luziferase & $1,5 \mathrm{~kb}$ & $p$ GL3-basic \\
$p$ Pax7CreTM & MerCreMer & $3,5 \mathrm{~kb}$ & pAN-MerCreMer \\
& & & (Verrou C et al., 1999) \\
\hline
\end{tabular}




\subsubsection{Kontrollexpressionsplasmide}

Die Verwendung der in Tabelle 5 aufgeführten Kontrollexpressionsplasmide ist bei den jeweiligen Experimenten beschrieben.

Tabelle 5: Auflistung der verwendeten Kontrollexpressionsplasmide. Spalte 1: Bezeichnung des Plasmids; Spalte 2: Bezeichnung der inserierten cDNA/Gen-Sequenz; Spalte 3: Bezeichnung des inserierten Promotorsequenz; Spalte 4: Literaturreferenz/Hersteller; Abkürzungen: CMV, Cytomegalie Virus; TK, Thymidin Kinase.

\begin{tabular}{|c|c|c|c|}
\hline 1 & 2 & 3 & 4 \\
\hline pAN MerCerMer & MerCreMer-Rekombinase & B Aktin Promotor & (Verrou C et al., 1999); \\
\hline$p E G F P-N I$ & EGFP & CMV Promotor & BD Bioscience Clontech, Heidelberg \\
\hline pGL3 MG-185 & Firefly Luziferase & $\begin{array}{l}182 \text { bp des proximalen } \\
\text { mMyogenin Promotor }\end{array}$ & $\begin{array}{c}\text { (Ohto H et al., 1999) } \\
\text { Promega GmbH, Mannheim (pGL3-basic) }\end{array}$ \\
\hline pGL3-basic & Firefly Luziferase & - & Promega $\mathrm{GmbH}$, Mannheim \\
\hline ploxNeoloxßGal & $\begin{array}{l}\text { IoxP-flankierte Neomycin- } \\
\text { Resistenzkassette } \\
\text { B-Galaktosidase }\end{array}$ & SV40 Promotor & (Schnutgen F et al., 2003) \\
\hline pMC-Cre & Cre-Rekombinase & TK Promotor & $\begin{array}{c}\text { (Gu H et al., 1993) } \\
\text { Stratagene, Amsterdam Zuidoost, } \\
\text { Niederlande (pMC-neo-polyA) }\end{array}$ \\
\hline$p R L-C M V$ & Renilla-Luziferase & CMV Promotor & Promega $\mathrm{GmbH}$, Mannheim \\
\hline
\end{tabular}




\subsubsection{Plasmidstandards für quantitative real time PCR}

Die verwendeten Plasmidstandards für die quantitative real time PCR (siehe Kapitel 2.15.4.4) sind in Tabelle 6 aufgelistet.

Tabelle 6: Auflistung der verwendeten Plasmidstandards für quantitative real time PCR. Spalte 1: Bezeichnung des Plasmids; Spalte 2: Bezeichnung der inserierten cDNA/Gen-Sequenz; Spalte 3: Bezeichnung des Leervektors; Spalte 4: Plasmidkopienzahl der eingesetzten ersten Verdünnung S1; Spalte 5: Literaturreferenz. Der Leervektor $p B S K S^{+}$wurde von der Firma Stratagene, Amsterdam Zuidoost, Niederlande, der Vektor pEGFP-N1 von der Firma BD Bioscience Clontech, Heidelberg und die Vektoren $p C R$ I/ und $p c D N A 3.1$ von der Firma Invitrogen $\mathrm{GmbH}$, Karlsruhe bezogen.

\begin{tabular}{ccccc}
\hline $\mathbf{1}$ & $\mathbf{2}$ & $\mathbf{3}$ & $\mathbf{4}$ \\
\hline pBSKS ${ }^{+}$mPtch wt & wt Ptch & $p B S K S^{+}$ & 1400000 & (Uhmann A et al., 2005) \\
pcDNA mGli1 myc-His & Gli1 & $p c D N A 3.1$ & 1400000 & (Sasaki H et al., 1999) \\
pCRII 18S rRNA & 18S rRNA & pCR II & 7000000 & (Uhmann A et al., 2005) \\
\hline
\end{tabular}

\subsection{Synthetische Oligonukleotide}

\subsubsection{Synthetische DNA-Oligonukleotide}

Synthetische DNA-Oligonukleotide wurden von der Firma Qiagen GmbH, Hilden, bezogen. Die Stammkonzentration von $100 \mu \mathrm{M}$ wurde mit Ampuwa eingestellt. Die für PCR (siehe Kapitel 2.15.4) eingesetzte Arbeitslösung wurde auf eine Konzentration von $10 \mu \mathrm{M}$ eingestellt.

\subsubsection{DNA-Oligonukleotide zur Genotypisierung von Mäusen}

Die Genotypisierung von Mäusen ist unter 2.15.4.1 und unter 2.19.1.2 beschrieben. Hierzu wurde mit den in Tabelle 7 aufgelisteten DNA-Oligonukleotiden gearbeitet. 
Tabelle 7: Auflistung der verwendeten DNA-Oligonukleotide für Genotypisierung von

Mauslinien. Spalte 1: Bezeichnung der getesteten Mauslinie; Spalte 2: Verwendete Anlagerungstemperatur bei der PCR; Spalte 3: Amplifizierte Fragmentgröße; Spalte 4: Bezeichnung des DNA-Oligonukleotids; Spalte 5: DNA-Oligonukleotidsequenz $\left(5^{\prime} \rightarrow 3^{\prime}\right)$ Spalte 6: Literaturreferenz; Abkürzungen: ${ }^{w t}$ Amplifikatlänge des Wildtyp Allels; ${ }^{m u t}$ Amplifikatlänge des mutanten Allels; ${ }^{\top}$ Amplifikatlänge des transgenen Allels; ${ }^{\text {del }}$ Amplifikatlänge des Allels bei erfolgter Deletion durch CreRekombinase vermittelte Rekombination.

\begin{tabular}{|c|c|c|c|c|c|}
\hline 1 & 2 & 3 & 4 & 5 & 6 \\
\hline Pax7 G4 & $60^{\circ} \mathrm{C}$ & $\begin{array}{l}200 \mathrm{bp}^{\mathrm{mut}} \\
600 \mathrm{bp}^{\mathrm{wt}}\end{array}$ & $\begin{array}{l}\text { Pax7 Exon2-F } \\
\text { Pax7 Exon2-R } \\
\text { Pax7-LacZ }\end{array}$ & $\begin{array}{c}\text { GGGCTTGCTGCCTCCGATAGC } \\
\text { GTGGGGTCTTCATCAACGGTC } \\
\text { TCGTGCTTTACGGTATCGCCGCTCCCG }\end{array}$ & $\begin{array}{c}\text { (Mansouri A et } \\
\text { al., 1996) }\end{array}$ \\
\hline ROSA26-R & $56^{\circ} \mathrm{C}$ & $\begin{array}{l}250 \mathrm{bp}^{\mathrm{mut}} \\
500 \mathrm{bp}^{\mathrm{wt}}\end{array}$ & $\begin{array}{l}\text { Rosa1 } \\
\text { Rosa2 } \\
\text { Rosa3 }\end{array}$ & $\begin{array}{l}\text { AAAGTCGCTCTGAGTTGTTAT } \\
\text { GCGAAGAGTTTGTCCTCAACC } \\
\text { GGAGCGGGAGAAATGGATATG }\end{array}$ & $\begin{array}{c}\text { (Soriano P, } \\
\text { 1999) }\end{array}$ \\
\hline $\operatorname{Tg}($ Ella-Cre $)$ & $67^{\circ} \mathrm{C}$ & $600 \mathrm{bp}^{\top}$ & $\begin{array}{l}\text { Ella-Cre } F \\
\text { Ella-Cre } R\end{array}$ & $\begin{array}{l}\text { CCAGGCTAAGTGCCTTCTCTACA } \\
\text { АATGCTTCTGTCCGTTTGCCGGT }\end{array}$ & $\begin{array}{l}\text { (Lakso M et } \\
\text { al., 1996) }\end{array}$ \\
\hline $\operatorname{Tg}($ Pax7CreTM) & $55^{\circ} \mathrm{C}$ & $460 \mathrm{bp}^{\top}$ & $\begin{array}{c}\text { mPax7seqF4 } \\
\text { MerSeqR1 }\end{array}$ & $\begin{array}{l}\text { AGGAAGAGACGCCAAGAGGTTTATC } \\
\text { CATATGAACCAGCTCССTATCTGC }\end{array}$ & (diese Arbeit) \\
\hline wt Gen Pelota & $59^{\circ} \mathrm{C}$ & $211 b p^{w t}$ & $\begin{array}{l}\text { Pelo-F } \\
\text { Pelo-R }\end{array}$ & $\begin{array}{l}\text { TGAGCCCAGACTGTACGTGAC } \\
\text { TCTGCACCTTAGCGTGAAGCC }\end{array}$ & (diese Arbeit) \\
\hline $\operatorname{Ptch}^{\text {neo67 }}$ & $60^{\circ} \mathrm{C}$ & $\begin{array}{c}b p^{\text {mut }} \\
635 b p^{w t}\end{array}$ & $\begin{array}{c}\text { neo-L } \\
\text { mPTC11R3 } \\
\text { Pst4KF }\end{array}$ & $\begin{array}{c}\text { AGTGCCAGCGGGGCTGCTAAA } \\
\text { CTGCCTGTTATGTGGTTCAAACCG } \\
\text { GGGAGGGGATTTCAGCAGAATGTT }\end{array}$ & $\begin{array}{c}\text { (Hahn H et al., } \\
\text { 1998) }\end{array}$ \\
\hline $\operatorname{Ptch}^{N X}$ & $60^{\circ} \mathrm{C}$ & $843 b p^{\text {mut }}$ & $\begin{array}{l}\text { p910F.4 } \\
\text { Neo-R }\end{array}$ & $\begin{array}{l}\text { AGCACCCTGGACGACATCCTAAA } \\
\text { GCATCAGAGCAGCCGATTGTCTG }\end{array}$ & (diese Arbeit) \\
\hline $\operatorname{Ptch}^{N X}$ & $62^{\circ} \mathrm{C}$ & $1735 \mathrm{bp}^{\mathrm{mut}}$ & $\begin{array}{l}\text { Neo-F } \\
\text { p1011R.2 }\end{array}$ & $\begin{array}{l}\text { CGTGATATTGCTGAAGAGCTTGG } \\
\text { TCTGTCCTGTTTCACTGAATGCATGG }\end{array}$ & (diese Arbeit) \\
\hline wt Ptch & $60^{\circ} \mathrm{C}$ & $1401 \mathrm{bp}^{\mathrm{wt}}$ & $\begin{array}{l}\text { p910F.4 } \\
\text { p1011R.2 }\end{array}$ & $\begin{array}{l}\text { AGCACCCTGGACGACATCCTAAA } \\
\text { TCTGTCCTGTTTCACTGAATGCATGG }\end{array}$ & (diese Arbeit) \\
\hline $\operatorname{Ptch}^{\text {delNX}}$ & $60^{\circ} \mathrm{C}$ & $950 b^{\text {del }}$ & $\begin{array}{l}\text { Exon7-F } \\
\text { Neo-R }\end{array}$ & $\begin{array}{l}\text { AGGAAGTATATGCATTGGCAGGAG } \\
\text { GCATCAGAGCAGCCGATTGTCTG }\end{array}$ & (diese Arbeit) \\
\hline ROSA2CreERT2 & $56^{\circ} \mathrm{C}$ & $269 \mathrm{bp}^{\top}$ & $\begin{array}{l}\text { RosCre ER-F } \\
\text { RosCre ER-R }\end{array}$ & $\begin{array}{c}\text { ACCAGCCAGCTATCAACTC } \\
\text { TATACGCGTGCTAGCGAAGATCTCCAC } \\
\text { TTCCAGCAG }\end{array}$ & $\begin{array}{l}\text { (Berns A.; } \\
\text { persönliche } \\
\text { Mitteilung) }\end{array}$ \\
\hline
\end{tabular}




\subsubsection{DNA-Oligonukleotide für Klonierungen}

Für Klonierungen (siehe Kapitel 2.11.3) wurden die in Tabelle 8 aufgelisteten DNAOligonukleotide verwendet.

Tabelle 8: $\quad$ Auflistung der verwendeten DNA-Oligonukleotide für Klonierungen. Spalte 1: Bezeichnung des zu klonierenden Gens; Spalte 2: Verwendete Anlagerungstemperatur bei der PCR; Spalte 3: Bezeichnung des DNA-Oligonukleotids; Spalte 4: DNA-Oligonukleotidsequenz $\left(5^{\prime} \rightarrow 3^{\prime}\right)$; fettgeschriebene Buchstaben markieren eingeführte/vorhandene RestriktionsendonukleaseSchnittstellen; Spalte 5: Bezeichnung der erkennenden Restriktionsendonuklease.

\begin{tabular}{|c|c|c|c|c|}
\hline 1 & 2 & 3 & 4 & 5 \\
\hline \multirow[t]{2}{*}{ pCR3.1 mPtchwt } & $60^{\circ} \mathrm{C}$ & F-H3-ATG & CCCAAGCTTCCACCATGGCCTCGGCTGGTAA & HindlII \\
\hline & & R-Xbal-Stop & GCTCTAGATCAGTTGGAGCTGCTCCCCCA & Xbal \\
\hline \multirow{2}{*}{$\begin{array}{c}\text { pGEM-Teasy } \\
\text { mPax7prom }\end{array}$} & $60^{\circ} \mathrm{C}$ & mPax7promF1 & AAGCACTGGCTGGAGCTCACAGCTGGAACTGGA & Sstl \\
\hline & & mPaxNcol cn & TTCATGCCATGGCCATTCCTGCGCACGCTGGAGACGAAT & Ncol \\
\hline \multirow{2}{*}{$\begin{array}{l}\text { pGEM-Teasy } \\
\text { MerCreMer } 5\end{array}$} & $60^{\circ} \mathrm{C}$ & MCMfrag1BamHI-F & CGCGGATCCACGAAATGAAATGGGTGCTTC & BamHI \\
\hline & & MCMfrag1Sall-R & CATGGTCTGCAGGTCGACGATCGTGTTGG & Sall \\
\hline \multirow{2}{*}{$\begin{array}{l}\text { pGEM-Teasy } \\
\text { mPax7prom 3' }\end{array}$} & $60^{\circ} \mathrm{C}$ & Paxfrag2 BamHI-F & CTAGGCTCCAGGGATCCCCAGCAGCTATG & $\mathrm{BamHI}$ \\
\hline & & Paxfrag2SnaBI-R & CGCTACGTATCCTGCGCACGCTGGAGACGAATCCAG & SnaBI \\
\hline \multirow[t]{3}{*}{ pGEM-Teasy Cl } & $58^{\circ} \mathrm{C}$ & IntronSnaBI-F & CGCTACGTAAGTATCAAGGTTACAAGACAGGTT & SnaBI \\
\hline & & IntronBamHI-R & CGCGGATCCCCCATCTGTGGAGAGAAAGGCAAAGTGGAT & BamHI \\
\hline & & & GTCAG & \\
\hline
\end{tabular}

\subsubsection{DNA-Oligonukleotide für DNA-Sequenzanalysen}

Die für DNA-Sequenzanalysen (siehe Kapitel 2.15.4.5) verwendeten DNAOligonukleotide sind in Tabelle 9 aufgelistet. 
Tabelle 9: Auflistung der verwendeten DNA-Oligonukleotide für DNA-Sequenzanalysen. Spalte 1: Bezeichnung des sequenzierten Plasmids; Spalte 2: Bezeichnung des sequenzierten DNABereichs; Spalte 3: Bezeichnung des DNA-Oligonukleotids; Spalte 4: DNA-Oligonukleotidsequenz $\left(5^{\prime} \rightarrow 3^{\prime}\right)$.

\begin{tabular}{|c|c|c|c|}
\hline 1 & 2 & 3 & 4 \\
\hline \multirow[t]{2}{*}{ pGEM-Teasy } & variabel & $p G E M-F$ & TTTCCCAGTCACGACGTTGTA \\
\hline & & $p G E M-R$ & TGAGCGGATAACAATTTCACACA \\
\hline \multirow{22}{*}{$\begin{array}{l}\text { pCR3.1 mPtch }(K) w t \\
\text { pCR3.1 mPtch }(K) d 67\end{array}$} & wt Ptch, Ptch ${ }^{d 67}$ & $m P T C 2 R$ & CTGCACCAAGTGGACACTCTCTTCGT \\
\hline & & mPTC5R.2 & TTTGGGGCGACACTTTGATG \\
\hline & & mPTC7 & GCATTCAGTGAAACAGGACA \\
\hline & & mPTC8 & CAGAAGATAGGAGAAGAGCC \\
\hline & & mPTC8R & GGCTCTTC CCTATCTTCTG \\
\hline & & mPTC9 & ATCACGGAGACAGGTTACATGG \\
\hline & & mPTC9R & CCATGTAACCTGTCTCTCCGTGAT \\
\hline & & mPTC10R & GGTTAGCTGTCCCGGACTGTA \\
\hline & & mPTC12 & GCTGTGGTGGTGGTATTCAAT \\
\hline & & mPTC12R & ATTGAATACCACCACCACAGC \\
\hline & & mPTC13R & TGTAGTACACGTGCGTGTGA \\
\hline & & mPTC14R & TCTCCTCCAGCATGACATAC \\
\hline & & mPTC15R & ATGATGCCATCTGCGTCTACCA \\
\hline & & mPTC16R & ACAGTCCCAGGCTCGTATAGT \\
\hline & & mPTC20 & TTCTACTGAAGGGCATTCTGGC \\
\hline & & mPTC21 & GCTATGAGAGCTACCCTGAGACTG \\
\hline & & mPTC23R & AACACTTCAGGG \\
\hline & & mPTCgen1R & GAGGAAGACTGCGCACACTAGAAA \\
\hline & & mPTCgen3R.2 & TACACCCAGCAGAGTGGACACA \\
\hline & & mPTCgen5F & TGTCTCCAGCCAATGGCCTAAA \\
\hline & & mPTCgen5R & ACCCATTGTTCGTGTGACCAGGA \\
\hline & & mPTCgen6F & ACTCCAGACATCAGCCTCCСTT \\
\hline
\end{tabular}




\begin{tabular}{|c|c|c|c|}
\hline 1 & 2 & 3 & 4 \\
\hline \multirow[t]{14}{*}{ pPax7CreTM } & Chimeres Intron & Clseq-R1 & AGGCAAAGTGGATGTCAGTAAGA \\
\hline & mPax7 Promotor & mPax7prseq-F1 & GTTGGAGTGTTTGTTTGTTTGAA \\
\hline & & $m P a x 7 p r s e q-R 1$ & GACCACAGCATCCTTGAGATGA \\
\hline & MerCreMer & MerSeqF1 & CСTTCAGTGAAGCCTCAATGATGG \\
\hline & & MerSeqR1 & CATATGAACCAGCTCCСTATCTGC \\
\hline & & MerSeqF2 & GTACACGTTTCTGTCCAGCACCTT \\
\hline & & MerSeqF3 & TATGACCTGCTCCTGGAGATGTTG \\
\hline & & MerSeqR3 & GTAAGGAATGTGCTGAAGTGGAGC \\
\hline & & MerSeqR4 & GGATCAAAGTGTCTGTGATCTTGT \\
\hline & & CreSeqF1 & AAATGCTTCTGTCCGTTTGCCGGT \\
\hline & & CreSeqF2 & TTCGACCAGGTTCGTTCACTCATG \\
\hline & & CreSeqF3 & ATCTGCCACCAGCCAGCTATCAAC \\
\hline & & CreSeqF4 & AACACGATCGTCGACCTGCAGA \\
\hline & & CreSeqR4 & TTTCGTGGATCTCCAGAACCTCCA \\
\hline
\end{tabular}

\subsubsection{DNA-Oligonukleotide für RT-PCR}

Der spezifische Nachweis von Transkripten erfolgte mittels PCR an cDNA (siehe Kapitel 2.15.4.1) und der in Tabelle 10 aufgelisteten DNA-Oligonukleotiden. 
Tabelle 10: Auflistung der verwendeten DNA-Oligonukleotide für RT-PCR. Spalte 1: Bezeichnung der Gentranskripte; Spalte 2: Verwendete Anlagerungstemperatur bei der PCR; Spalte 3: Amplifizierte Fragmentgröße; Spalte 4: Bezeichnung des DNA-Oligonukleotids; Spalte 5: DNAOligonukleotidsequenz $\left(5^{\prime} \rightarrow 3^{\prime}\right)$ Spalte 6: Literaturreferenz; Abkürzungen: ${ }^{\text {wt }}$ Amplifikatlänge des Wildtyp Transkriptes; del Amplifikatlänge des Transkriptes bei erfolgter Deletion durch CreRekombinase vermittelte Rekombination.

\begin{tabular}{|c|c|c|c|c|c|}
\hline 1 & 2 & 3 & 4 & 5 & 6 \\
\hline Gapd & $58^{\circ} \mathrm{C}$ & $576 \mathrm{bp}$ & $\begin{array}{l}\text { Gapd-F } \\
\text { Gapd-R }\end{array}$ & $\begin{array}{l}\text { ATCTTCTTGTGCAGTGCCAG } \\
\text { ATGACCACAGTCCATGCCAT }\end{array}$ & $\begin{array}{l}\text { (Uhmann A } \\
\text { et al., 2005) }\end{array}$ \\
\hline Gli1 & $60^{\circ} \mathrm{C}$ & $419 \mathrm{bp}$ & $\begin{array}{l}\text { mGliF8 } \\
\text { mGliR9 }\end{array}$ & $\begin{array}{l}\text { TGCACCAAGCGCTACACAGATCCCA } \\
\text { AGCTGATGCAGCTGATCCAGCCTA }\end{array}$ & $\begin{array}{l}\text { Regine } \\
\text { Bauer }\end{array}$ \\
\hline $\operatorname{lgf2}$ & $55^{\circ} \mathrm{C}$ & $454 \mathrm{bp}$ & $\begin{array}{l}\text { Igf2 TaqManF } \\
\text { Igf2 Exon6R }\end{array}$ & $\begin{array}{l}\text { TGTGCTGCATCGCTGCTTAC } \\
\text { TTGCTGGACATCTCCGAAGAG }\end{array}$ & $\begin{array}{l}\text { Regine } \\
\text { Bauer }\end{array}$ \\
\hline Pax7 & $58^{\circ} \mathrm{C}$ & $585 \mathrm{bp}$ & $\begin{array}{l}m P a x 7-F 1 \\
m P a x 7-R 1\end{array}$ & $\begin{array}{l}\text { CCAAGATTCTGTGCCGATATCAGGA } \\
\text { AGCTGGTTAGCTCCTGCCTGCTTA }\end{array}$ & (diese Arbeit) \\
\hline wt Ptch & $55^{\circ} \mathrm{C}$ & $731 \mathrm{bp}{ }^{w t}$ & mPtc11 & AAAGCCGAAGTTGGCCATGGGTAC & (diese Arbeit) \\
\hline $\operatorname{Ptch}^{\text {delN } X}$ & & $451 \mathrm{bp}{ }^{\text {del }}$ & $m P t c 7 R$ & TGTCCTGTTTCACTGAATGC & \\
\hline B Aktin & $58^{\circ} \mathrm{C}$ & $646 \mathrm{bp}$ & $\begin{array}{l}\text { B-actin- } F \\
\text { B-actin- } R\end{array}$ & $\begin{array}{l}\text { CCTAAGGCCAACCGTGAAAAG } \\
\text { TCTTCATGGTGCTAGGAGCCA }\end{array}$ & $\begin{array}{l}\text { (DeKoter RP } \\
\text { et al., 2002) }\end{array}$ \\
\hline$E B F$ & $54^{\circ} \mathrm{C}$ & $649 \mathrm{bp}$ & $\begin{array}{l}E B F-F \\
E B F-R\end{array}$ & $\begin{array}{l}\text { CAAGACAAGAACCCTGAAATG } \\
\text { GTAACCTCTGGAAGCCGTAGT }\end{array}$ & $\begin{array}{l}\text { (DeKoter RP } \\
\text { et al., 2002) }\end{array}$ \\
\hline Flt3 & $54^{\circ} \mathrm{C}$ & $624 \mathrm{bp}$ & $\begin{array}{l}\text { Flt3-F } \\
\text { Flt3-R }\end{array}$ & $\begin{array}{l}\text { TCTTGAGACCGTTACAAACC } \\
\text { АTGTCTGTTCCGAACAACTC }\end{array}$ & $\begin{array}{l}\text { (DeKoter RP } \\
\text { et al., 2002) }\end{array}$ \\
\hline Ikaros & $54^{\circ} \mathrm{C}$ & $464 \mathrm{bp}$ & $\begin{array}{l}\text { Ikaros-F } \\
\text { Ikaros-R }\end{array}$ & $\begin{array}{l}\text { CACTACCTCTGGAGCACAGC } \\
\text { TCTGAGGCATAGAGCTCTTA }\end{array}$ & $\begin{array}{l}\text { (DeKoter RP } \\
\text { et al., 2002) }\end{array}$ \\
\hline IL-7R $\alpha$ & $58^{\circ} \mathrm{C}$ & $315 \mathrm{bp}$ & $\begin{array}{l}I L-7 R \alpha-F \\
I L-7 R \alpha-R\end{array}$ & $\begin{array}{l}\text { TTACTTCAAAGGCTTCTGGAG } \\
\text { CTGGCTTCAACGCCTTTCACCTCA }\end{array}$ & $\begin{array}{l}\text { (DeKoter RP } \\
\text { et al., 2002) }\end{array}$ \\
\hline Pax5 & $54^{\circ} \mathrm{C}$ & $561 \mathrm{bp}$ & $\begin{array}{l}\text { Pax5-F } \\
\text { Pax5-R }\end{array}$ & $\begin{array}{l}\text { CGGGTCAGCCATGGTTGTG } \\
\text { GTGCTGTCTCTCAAACACG }\end{array}$ & $\begin{array}{l}\text { (DeKoter RP } \\
\text { et al., 2002) }\end{array}$ \\
\hline PU.1 & $58^{\circ} \mathrm{C}$ & $391 \mathrm{bp}$ & $\begin{array}{l}\text { PU.1-F } \\
\text { PU.1-R }\end{array}$ & $\begin{array}{l}\text { CGGATGTGCTTCCCTTATCAAAC } \\
\text { TGACTTTCTTCACCTCGCCTGTC }\end{array}$ & $\begin{array}{l}\text { (DeKoter RP } \\
\text { et al., 2002) }\end{array}$ \\
\hline Rag-1 & $58^{\circ} \mathrm{C}$ & $554 \mathrm{bp}$ & $\begin{array}{l}R a g-1-F \\
R a g-1-R\end{array}$ & $\begin{array}{l}\text { TGCAGACATTCTAGCACTCTGGCC } \\
\text { ACATCTGCCTTCACGTCGATCCGG }\end{array}$ & $\begin{array}{l}\text { (DeKoter RP } \\
\text { et al., 2002) }\end{array}$ \\
\hline Rag-2 & $58^{\circ} \mathrm{C}$ & $513 \mathrm{bp}$ & $\begin{array}{l}\text { Rag-2-F } \\
\text { Rag-2-R }\end{array}$ & $\begin{array}{l}\text { CACATCCACAAGCAGGAAGTACAC } \\
\text { TCCCTCGACTATACACCACGTCAA }\end{array}$ & $\begin{array}{l}\text { (DeKoter RP } \\
\text { et al., 2002) }\end{array}$ \\
\hline
\end{tabular}




\subsubsection{DNA-Oligonukleotide für den Transkript-spezifischen PCR-Assay in Ptch ${ }^{\text {neo67/+ }}$ Mäusen}

Zur Unterscheidung zwischen Exon $1 \mathrm{~b}$ enthaltenden mutanten und wt Ptch Transkripten wurde ein Transkript-spezifischer PCR Assay durchgeführt. Als Matritze wurde mit cDNA (siehe Kapitel 2.15.4.2) aus Tumor-RNA (RMS) und SkelettmuskelRNA (siehe Kapitel 2.15.1.5.2) gearbeitet. Die verwendeten DNA-Oligonukleotide sind in Tabelle 11 aufgelistet. Pro PCR-Ansatz wurden die beiden RückwärtsOligonukleotide und das Vorwärtsnukleotid (je 0,43 $\mu \mathrm{M}$ ) eingesetzt und 50 ng cDNA aus Tumor- oder Skelettmuskel zugegeben. Das Vorwärts-Oligonukleotid (mPtch1b-nest) bindet spezifisch an das alternative Exon 1b der Ptch Transkripte. Die Rückwärts-Oligonukleotide vermittelten die Sequenzspezifität für mutante (Ex5/8-R) oder wt (Ex5/6-R) Matrizen-cDNA und wurden so gewählt, dass die Fragmente bei der Amplifikation mit mPtch1b-nest jeweils 631 bp gross sind. Die verwendeten PCR-Bedingungen sind Kapitel 2.15.4 zu entnehmen.

Das so erzeugte Gemisch aus mutanten und wt Ptch Amplifikaten wurden in den Vektor pGEM-Teasy kloniert (siehe Kapitel 2.15.3.6). Dann wurden 90 unabhängige Klone isoliert und die aufgereinigte Plasmid-DNA (siehe Kapitel 2.15.1.1.2) sequenziert (siehe Kapitel 2.15.4.5). Die verwendeten DNA-Oligonukleotide für die Sequenzierung sind unter 2.12.1.3 aufgeführt.

Tabelle 11: Auflistung der verwendeten DNA-Oligonukleotide für den Transkriptspezifischen PCR-Assay zur Analyse des Ursprungsallels des alternativen Ptch Exone $1 \mathrm{~b}$. Spalte 1:Bezeichnung des amplifizierten Transkripts; Spalte 2: Verwendete Anlagerungstemperatur bei der PCR; Spalte 3: Amplifizierte Fragmentgröße; Spalte 4: Bezeichnung des DNA-Oligonukleotids; Spalte 5: DNA-Oligonukleotidsequenz $\left(5^{\prime} \rightarrow 3^{\prime}\right)$ Spalte 6: Literaturreferenz. Die fett gedruckten Nukleotide des Oligonukleotids Ex5/6-R entsprechen der komplementären Sequenz zum Ptch Exon 6. Ebenso ist bei dem Oligonukleotid Ex5/8-R die komplementäre Sequenz zu Ptch Exon 8 markiert. Die normal gedruckten Nukleotide von Ex5/6-R und Ex5/8-R entsprechen komplementären Basen des Ptch Exon 5 (siehe Abbildung 10).

\begin{tabular}{cccccc}
\hline $\mathbf{1}$ & $\mathbf{2}$ & $\mathbf{3}$ & $\mathbf{4}$ & $\mathbf{5}$ & $\mathbf{6}$ \\
\hline $\begin{array}{c}\text { wt Ptch Exon1b } \\
\text { Ptch }{ }^{d 67} \text { Exon1b }\end{array}$ & $58^{\circ} \mathrm{C}$ & $631 \mathrm{bp}$ & mPtch1b-nest & GACCGGGACTATCTGCAC & (Uhmann A et \\
& & & & & al., 2005) \\
& & & Cx5/6-R & CGTAAGGAGGCTTACCTAGGAG & (diese Arbeit) \\
& & & Ex5/8-R & GTTTGCAGGGCGTGAGCAGGAG & (diese Arbeit) \\
\hline
\end{tabular}




\subsubsection{DNA-Oligonukleotide für den RACE-Assay}

Für die Amplifikation von cDNA Enden (RACE, rapid amplification of cDNA ends) wurde mit dem Smart race cDNA amplification kit gearbeitet. Die verwendeten DNAOligonukleotide sind in Tabelle 12 aufgelistet. Das Experiment und die Verwendung der DNA-Oligonukleotide werden in Kapitel 3.1.3.2 beschrieben.

Tabelle 12. Auflistung der verwendeten DNA-Oligonukleotide für den RACE-Assay. Spalte 1: Bezeichnung des amplifizierten Gens; Spalte 2: Verwendete Anlagerungstemperaturen und Zyklenzahlen bei der RACE-PCR (oben) und der nachfolgenden nested RACE-PCR (unten); Spalte 3: Bezeichnung des DNA-Oligonukleotids; Spalte 4: DNA-Oligonukleotidsequenz (5' $\rightarrow$ 3'). Die Verwendung der Oligonukleotide ist in Kapitel 3.1.3.2 beschrieben.

\begin{tabular}{cccc}
\hline 1 & $\mathbf{2}$ & $\mathbf{3}$ & $\mathbf{4}$ \\
\hline Ptch & 5 Zyklen mit $68^{\circ} \mathrm{C}$ und & Exon2Race- $R$ & TCTGAAAACTTCGCTCTCAGCCACAG \\
& 5 Zyklen bei $66^{\circ} \mathrm{C}$ & & \\
20 Zyklen bei $68^{\circ} \mathrm{C}$ und & Exon2Race- $R$ & TCTGAAAACTTCGCTCTCAGCCACAG \\
& 5 Zyklen bei $66^{\circ} \mathrm{C}$ & Exon1nest-F & TCCCGCGGTGTCTCCTAAGGCTG \\
\hline
\end{tabular}

\subsubsection{DNA-Oligonukleotide für die quantitative real time PCR}

DNA-Oligonukleotide für die quantitative real time PCR (siehe Kapitel 2.15.4.4.1) und die quantitative real time PCR mit SYBR green (QuantiTect SYBR green) (siehe Kapitel 2.15.4.4.1.6) sind in Tabelle 13 aufgelistet. 
Tabelle 13: Auflistung der für die quantitative real time PCR verwendeten DNAOligonukleotide. Spalte 1: Bezeichnung der quantifizierten Gentranskripte; Spalte 2: Verwendete Anlagerungstemperatur bei der real time PCR; Spalte 3: Bezeichnung des DNA-Oligonukleotids bzw. der Hybridisierungssonde; Spalte 4: DNA-Oligonukleotidsequenz $\left(5^{\prime} \rightarrow 3^{\prime}\right)$ und evt. ReporterQuenchermarkierung; Spalte 5: Verwendete Endkonzantration der DNA-Oligonukleotide und der Sonden-DNA; Spalte 6: Literaturreferenz; Abkürzungen: 6-FAM, 6-Carboxyfluoreszein; MGB minor groove binder.

\begin{tabular}{|c|c|c|c|c|c|}
\hline 1 & 2 & 3 & 4 & 5 & 6 \\
\hline \multirow[t]{3}{*}{ wt Ptch } & $60^{\circ} \mathrm{C}$ & mPtchwtF & TACCGTCAAGAATGCCACTGG & $300 \mathrm{nM}$ & (Uhmann A et \\
\hline & & mPtchwtR & GTGTTCATACATTTGCTTGGGAGTC & $300 \mathrm{nM}$ & al., 2005) \\
\hline & & mPtchwt Sonde & 6-FAM-AAACTTGTCAGCGCTCA-MGB & $200 \mathrm{nM}$ & (diese Arbeit) \\
\hline \multirow[t]{2}{*}{ Gli1 } & $67^{\circ} \mathrm{C}$ & $m$ Gli1-tq-f & TACATGCTGGTGGTGCACATG & $300 \mathrm{nM}$ & (diese Arbeit) \\
\hline & & $m G l i-t q-r$ & ACCGAAGGTGCGTCTTGAGG & $300 \mathrm{nM}$ & \\
\hline
\end{tabular}

\subsubsection{Synthetische RNA-Oligonukleotide}

Synthetische RNA-Oligonukleotide (doppelsträngige siRNA, short interference RNA) wurden von der Firma Qiagen-Xeragon, Germantown, USA, bezogen und sind in Tabelle 14 aufgelistet. Die Auswahl der RNA-Sequenz erfolgte wie bei Elbashir et al. beschrieben (Elbashir SM et al., 2002). Die Transfektion der siRNA in eukaryotische Zellinien ist in Kapitel 2.17.1.1.2 beschrieben.

Tabelle 14: Auflistung der verwendeten RNA-Oligonukleotide. Spalte 1: Bezeichnung des Zieltranskriptes; Spalte 2: Bezeichnung der RNA-Oligonukleotide; Spalte 3: Art der Fluoreszenzmarkierung; Spalte 4: DNA-Zielsequenz $\left(5^{\prime} \rightarrow 3^{\prime}\right)$; Spalte 5: RNA-Oligonukleotidsequenz $\left(5^{\prime} \rightarrow 3^{\prime}\right)$, die obere Sequenz stellt den kodierenden Strang, die untere Sequenz den kodogenen Strang dar; RNA wurde in Kleinbuchstaben und DNA in Großbuchstaben hervorgehoben.

\begin{tabular}{ccccc}
\hline $\mathbf{1}$ & $\mathbf{2}$ & $\mathbf{3}$ & $\mathbf{4}$ & $\mathbf{5}$ \\
\hline Ptch & mptch_Exon2 si & 3'-Rhodamin & GGCAGCTAATCTCGAGACC & (ggcagcuaaucucgagacc)d(TT) \\
& & & & (ggucucgagauuagcugcc)d(TT) \\
Ptch & mptch_Exon22 si & 3'-Rhodamin & AACCCTGTCTTTGCCCGGT & (aacccugucuuugcccggu)d(TT) \\
& & & & (accgggcaaagacaggguu)d(TT) \\
- Scramble si & 5'-Fluorescin & TTCTCCGAACGTGTCACGT & (uucuccgaacgugucacgu)d(TT) \\
& (unspezifische siRNA) & & (acgugacacguucggagaa)d(TT) \\
\hline
\end{tabular}




\subsection{Enzyme}

\subsubsection{Restriktionsendonukleasen}

Restriktionsendonukleasen wurden von den Firmen Invitrogen $\mathrm{GmbH}$, Karlsruhe, und New England Biolabs $\mathrm{GmbH}$, Frankfurt am Main, bezogen. Es wurden die vom Hersteller mitgelieferten Puffer verwendet und unter Herstellerangaben gearbeitet.

\subsubsection{DNA-Polymerasen}

In Tabelle 15 sind die für PCR (siehe Kapitel 2.15.4) verwendeten DNA-Polymerasen aufgelistet.

Tabelle 15: Auflistung der verwendeten DNA-Polymerasen. Spalte 1: Bezeichnung der DNAPolymerase und deren Ursprungsspezies; Spalte 2: Konzentration in Unit/pl; Spalte 3: optimale Amplifikationstemperatur; Spalte 4: Angabe der Fehlerfrequenz, wobei obere Zahlen die Frequenz einer fehlerhaften Basenpaarung und untere Zahlen die Frequenz einer Leserahmenverschiebung bezeichnen.; Spalte 5: Verwendung; Spalte 6: Hersteller. Die Amplifikationsgeschwindigkeit aller aufgezeigten DNA-Polymerasen beträgt $1 \mathrm{~kb} / \mathrm{min}$.

\begin{tabular}{|c|c|c|c|c|c|}
\hline 1 & 2 & 3 & 4 & 5 & 6 \\
\hline Taq-DNA-Polymerase & $5 U / \mu l$ & $72^{\circ} \mathrm{C}$ & $1 \times 10^{-4}$ & RT-PCR & Amersham Biosciences Europe \\
\hline (Thermus aquaticus) & & & $1 \times 10^{-5}$ & & GmbH, Freiburg \\
\hline Taq-DNA-Polymerase & $5 \mathrm{U} / \mu \mathrm{l}$ & $72^{\circ} \mathrm{C}$ & $1 \times 10^{-4}$ & RT-PCR & Molzym GmbH \& Co.KG, \\
\hline (Thermus aquaticus) & & & $1 \times 10^{-5}$ & & Bremen \\
\hline $\begin{array}{c}\text { SAWADY Mid Range PCR- } \\
\text { System }\end{array}$ & $5 \mathrm{U} / \mu \mathrm{l}$ & $68^{\circ} \mathrm{C}$ & - & Klonierungen & $\begin{array}{c}\text { Peqlab Biotechnologie } \mathrm{GmbH} \text {, } \\
\text { Erlangen }\end{array}$ \\
\hline T4-DNA-Polymerase & $5 \mathrm{U} / \mu \mathrm{l}$ & $37^{\circ} \mathrm{C}$ & - & Auffüllen von 5’- & Invitrogen $\mathrm{GmbH}$, Karlsruhe \\
\hline (T4 N82-infizierte E. coli) & & & & $\begin{array}{c}\text { Enden; Hydrolyse } \\
\text { von 3'-Enden }\end{array}$ & \\
\hline
\end{tabular}

\subsubsection{Weitere Enzyme}

Die Proteinasen Collagenase $\mathrm{H}$ (Clostridiopepdidase $\mathrm{A}$ ) und Proteinase $\mathrm{K}$ wurden von den Firmen Roche Diagnostics $\mathrm{GmbH}$, Mannheim, und Carl Roth $\mathrm{GmbH}$, Karlsruhe, bezogen. Von der Firma Roche Diagnostics $\mathrm{GmbH}$, Mannheim, wurde die RNase $\mathrm{H}$ (Ribonuclease $\mathrm{H} ; 1 \mathrm{U} / \mu \mathrm{l}$ ) bezogen. Des Weiteren wurde mit der T4-Ligase 


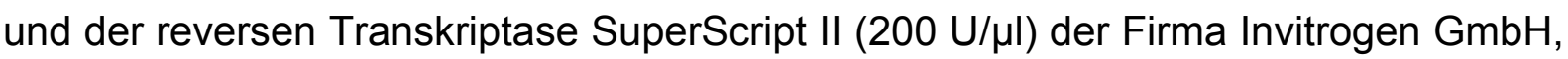
Karlsruhe, gearbeitet.

\subsection{Antikörper}

\subsubsection{Primäre Antikörper}

Die für proteinchemische Methoden (siehe Kapitel 2.16.1.4, 2.16.5, 2.16.6) verwendeten primären Antikörper sind in Tabelle 16 aufgelistet. Die jeweiligen Verdünnungsmedien der Antikörper sind bei der Darstellung der jeweiligen Methode beschrieben.

Tabelle 16: Auflistung der verwendeten primären Antikörper. Spalte 1: Bezeichnung des primären Antikörpers; Spalte 2: Bezeichnung des Antigens und dessen Ursprungsspezies; Spalte 3: Ursprungsspezies des Antikörpers; Spalte 4: Verwendung des Antiköpers und eingesetzte Antikörperverdünnung; Spalte 5: Hersteller. Abkürzungen: IF, Immunfluoreszenz; WB, Western Blot; IHC, Immunhistochemie; FACS, fluorescence-activated cell sorting; FITC, Fluoresceinisothiocyanat; PE, Phycoerythrin; Cy7, Cy5, Indodikarbocyanin-Derivate; RPE, R-Phycoerythrin.

\begin{tabular}{|c|c|c|c|c|}
\hline 1 & 2 & 3 & 4 & 5 \\
\hline anti-Cre-Rekombinase & $\begin{array}{l}\text { Cre Rekombinase } \\
\text { (P1 Bakteriophage) }\end{array}$ & Kaninchen; polyklonal & IF $1: 1000$ & $\begin{array}{c}\text { Covance Inc., HISS Diagnostics } \\
\text { GmbH, Freiburg i. Br. }\end{array}$ \\
\hline anti-ß-Galaktosidase & $\begin{array}{l}\text { ß-Galaktosidase } \\
\text { (E. coli })\end{array}$ & Kaninchen; polyklonal & IF 1:100 & $\begin{array}{l}\text { Molecular Probes; Invitrogen } \\
\text { GmbH, Karlsruhe }\end{array}$ \\
\hline anti-Pax7 & Pax7 (Huhn) & Maus; monoklonal & IF 1:200 & $\begin{array}{c}\text { Developmental Studies } \\
\text { Hybridoma Bank; lowa, USA }\end{array}$ \\
\hline anti-Ptch C-20 & Ptch (Mensch) & Ziege; polyklonal & $\begin{array}{l}\text { IF 1:100 } \\
\text { WB 1:100 }\end{array}$ & $\begin{array}{c}\text { Santa Cruz Biotechnology, Inc., } \\
\text { Heidelberg }\end{array}$ \\
\hline anti-Ptch G-19 & Ptch (Maus) & Ziege; polyklonal & $\begin{array}{l}\text { IF 1:100 } \\
\text { WB 1:100 }\end{array}$ & $\begin{array}{c}\text { Santa Cruz Biotechnology, Inc., } \\
\text { Heidelberg }\end{array}$ \\
\hline anti-CD3 & CD3 (Mensch) & Ratte; monoklonal & $\mathrm{ICH} 1: 200$ & Serotec GmbH, Düsseldorf \\
\hline anti-CD45R/B220 & $\begin{array}{l}\text { CD45R/B220 } \\
\text { (Mensch) }\end{array}$ & Ratte; monoklonal & ICH 1:200 & $\begin{array}{l}\text { BD Biosciences Pharmingen, } \\
\text { San Diego }\end{array}$ \\
\hline anti-CD3 FITC & CD3 (Maus) & Ratte; monoklonal & FACS 1:50 & $\begin{array}{c}\text { BD Biosciences Pharmingen, } \\
\text { San Diego, USA }\end{array}$ \\
\hline anti-CD4 Biotin & CD4 (Maus) & Ratte; monoklonal & FACS 1:50 & $\begin{array}{c}\text { BD Biosciences Pharmingen, } \\
\text { San Diego, USA }\end{array}$ \\
\hline
\end{tabular}




\begin{tabular}{|c|c|c|c|c|}
\hline 1 & 2 & 3 & 4 & 5 \\
\hline anti-CD8 $\alpha$ PE & CD8 $\alpha$ (Maus) & Ratte; monoklonal & FACS 1:50 & $\begin{array}{c}\text { BD Biosciences Pharmingen, } \\
\text { San Diego, USA }\end{array}$ \\
\hline anti-CD8 $\alpha$ PE-Cy7 & CD8 $\alpha$ (Maus) & Ratte; monoklonal & FACS 1:50 & $\begin{array}{c}\text { BD Biosciences Pharmingen, } \\
\text { San Diego, USA }\end{array}$ \\
\hline anti-CD21 FITC & CD21 (Maus) & Ratte; monoklonal & FACS 1:50 & $\begin{array}{c}\text { BD Biosciences Pharmingen, } \\
\text { San Diego, USA }\end{array}$ \\
\hline anti-CD24 PE & CD24 (Maus) & Ratte; monoklonal & FACS 1:50 & $\begin{array}{c}\text { BD Biosciences Pharmingen, } \\
\text { San Diego, USA }\end{array}$ \\
\hline anti-CD25 FITC & CD25 (Maus) & Ratte; monoklonal & FACS 1:50 & $\begin{array}{c}\text { BD Biosciences Pharmingen, } \\
\text { San Diego, USA }\end{array}$ \\
\hline anti-CD43 Biotin & CD43 (Maus) & Ratte; monoklonal & FACS 1:50 & $\begin{array}{c}\text { BD Biosciences Pharmingen, } \\
\text { San Diego, USA }\end{array}$ \\
\hline anti-CD44 PE-Cy5 & CD44 (Maus) & Ratte; monoklonal & FACS 1:50 & $\begin{array}{c}\text { BD Biosciences Pharmingen, } \\
\text { San Diego, USA }\end{array}$ \\
\hline $\begin{array}{c}\text { anti-CD45R/B220 PE- } \\
\text { Cy7 }\end{array}$ & $\begin{array}{l}\text { CD45R/B220 } \\
\text { (Maus) }\end{array}$ & Ratte; monoklonal & FACS 1:50 & $\begin{array}{c}\text { BD Biosciences Pharmingen, } \\
\text { San Diego, USA }\end{array}$ \\
\hline anti-lgD FITC & $\operatorname{lgD}$ (Maus) & Ratte; monoklonal & FACS 1:50 & $\begin{array}{c}\text { BD Biosciences Pharmingen, } \\
\text { San Diego, USA }\end{array}$ \\
\hline anti-TCR $\beta$ FITC & TCR $\beta$ (Maus) & Ratte; monoklonal & FACS $1: 50$ & $\begin{array}{c}\text { BD Biosciences Pharmingen, } \\
\text { San Diego, USA }\end{array}$ \\
\hline anti-IgM RPE & $\lg M$ (Maus) & Ratte; monoklonal & FACS 1:50 & $\begin{array}{c}\text { BD Biosciences Pharmingen, } \\
\text { San Diego, USA }\end{array}$ \\
\hline anti-CD117 (c-kit) Biotin & CD117 (Maus) & Ratte; monoklonal & FACS 1:50 & $\begin{array}{c}\text { BD Biosciences Pharmingen, } \\
\text { San Diego, USA }\end{array}$ \\
\hline anti-CD127 (IL-7R $\alpha)$ PE & CD127 (Maus) & Ratte; monoklonal & FACS 1:50 & $\begin{array}{c}\text { BD Biosciences Pharmingen, } \\
\text { San Diego, USA }\end{array}$ \\
\hline anti-Sca-1 FITC & Sca-1 (Maus) & Ratte; monoklonal & FACS 1:50 & $\begin{array}{c}\text { BD Biosciences Pharmingen, } \\
\text { San Diego, USA }\end{array}$ \\
\hline
\end{tabular}




\subsubsection{Sekundäre Antikörper und Fluorochrom-gekoppelte Streptavidin Reagenzien}

Die für proteinchemische Methoden (siehe Kapitel 2.16.1.4, 2.16.5, 2.16.6) verwendeten sekundären Antikörper sind in Tabelle 17 aufgelistet. Die in Tabelle 18 aufgelisteten Fluorochrom-gekoppelten Streptavidin Reagenzien wurden für die durchflusszytometrische Detektion von biotinylierten primären Antikörpern (siehe Kapitel 2.14.1) verwendet. Da an ein Biotin-Molekül vier Streptavidin-Moleküle binden, wird durch die Verwendung dieses Systems eine 4-fache Verstärkung des primären Antikörpersignals hervorgerufen.

Tabelle 17: Auflistung der verwendeten sekundären Antikörper. Spalte 1: Bezeichnung des sekundären Antikörpers; Spalte 2: Antigen; Spalte 3: Ursprungsspezies des Antikörpers; Spalte 4: Verwendung des Antikörpers und eingesetzte Antikörperverdünnung; Spalte 5: Hersteller; Abkürzungen: IF, Immunfluoreszenz; WB, Western Blot; IHC, Immunhistochemie; Ig, Immunglobulin; HRP, horseradish peroxidase (Meerrettich Peroxidase); FITC, Fluoresceinisothiocyanat; Су3, Indokarbocyanin-Derivat; APAAP, alkalische Phosphatase anti-alkalische Phosphatase.

\begin{tabular}{|c|c|c|c|c|}
\hline 1 & 2 & 3 & 4 & 5 \\
\hline $\begin{array}{c}\text { anti-Maus IgG }(\mathrm{H}+\mathrm{L}) \\
\text { HRP-konjugiert }\end{array}$ & Maus IgG $(\mathrm{H}+\mathrm{L})$ & Kaninchen & WB 1:10.000 & $\begin{array}{c}\text { Jackson ImmunoResearch Europe Ltd., } \\
\text { Cambridgeshire }\end{array}$ \\
\hline $\begin{array}{c}\text { anti-Kaninchen IgG }(\mathrm{H}+\mathrm{L}) \\
\text { HRP-konjugiert }\end{array}$ & $\begin{array}{l}\text { Kaninchen IgG } \\
\qquad(\mathrm{H}+\mathrm{L})\end{array}$ & Ziege & WB 1:10.000 & $\begin{array}{l}\text { Jackson ImmunoResearch Europe Ltd., } \\
\text { Cambridgeshire }\end{array}$ \\
\hline $\begin{array}{c}\text { anti-Ziege IgG }(\mathrm{H}+\mathrm{L}) \\
\text { HRP-konjugiert }\end{array}$ & Ziege IgG $(\mathrm{H}+\mathrm{L})$ & Esel & WB $1: 10.000$ & $\begin{array}{c}\text { Jackson ImmunoResearch Europe Ltd., } \\
\text { Cambridgeshire }\end{array}$ \\
\hline $\begin{array}{c}\text { anti-Ziege IgG }(\mathrm{H}+\mathrm{L}) \\
\text { FITC-konjugiert }\end{array}$ & Ziege IgG $(\mathrm{H}+\mathrm{L})$ & Esel & IF $1: 200$ & $\begin{array}{l}\text { Jackson ImmunoResearch Europe Ltd., } \\
\text { Cambridgeshire }\end{array}$ \\
\hline $\begin{array}{c}\text { anti-Kaninchen IgG } \\
\text { Cy3-konjugiert }\end{array}$ & Kaninchen IgG & Ziege & IF $1: 400$ & $\begin{array}{l}\text { Jackson ImmunoResearch Europe Ltd., } \\
\text { Cambridgeshire }\end{array}$ \\
\hline anti-Maus IgG & Maus IgG & Ziege & IF $1: 200$ & Sigma-Aldrich, Deisenhofen \\
\hline FITC-konjugiert & & & & \\
\hline anti-Ratte IgG & Ratte IgG & Kaninchen & $\mathrm{IHC} 1: 50$ & Dako GmbH, Hamburg \\
\hline APAAP anti Ratte & Ratte; monoklonal & Ratte & IHC 1:50 & Dako GmbH, Hamburg \\
\hline
\end{tabular}


Tabelle 18: Auflistung der verwendeten Fluorochrom-gekoppelten Streptavidin Reagenzien. Spalte 1: Bezeichnung des Reagenz; Spalte 2: Eingesetzte Reagenzverdünnung; Spalte 3: Hersteller. Abkürzungen: PE, Phycoerythrin; Cy7, Indotricarbocyanin-Derivat. FITC, Fluoresceinisothiocyanat.

\begin{tabular}{ccc}
\hline $\mathbf{1}$ & $\mathbf{2}$ & $\mathbf{3}$ \\
\hline Streptavidin PE & $1: 50$ & BD Biosciences Pharmingen, San Diego, USA \\
Streptavidin PE Cy7 & $1: 50$ & BD Biosciences Pharmingen, San Diego, USA \\
Streptavidin FITC & $1: 50$ & Southern Biotechnology Associates, Inc., Birmingham, England \\
\hline
\end{tabular}

\subsection{Molekularbiologische Methoden}

\subsubsection{Isolierung und Aufreinigung von Nukleinsäuren}

\subsubsection{Isolierung von Plasmid-DNA}

\subsection{Plasmidpräparation geringer DNA-Mengen}

Zur schnellen Isolierung von geringen Mengen Plasmid-DNA wurde eine $4 \mathrm{ml}-$ Übernachtkultur transformierter Bakterien (siehe Kapitel 2.15.3.8; E.coli in LBMedium mit Selektivantibiotikum) bei $5000 \times \mathrm{g}$ für 2 min abzentrifugiert. Das Bakterienpellet wurde in $200 \mu \mathrm{l}$ Resuspensionspuffer (siehe Kapitel 2.8) aufgenommen und die Zellen durch Zugabe von $200 \mu$ Lysepuffer (siehe Kapitel 2.8) lysiert. Zelluläre Proteine und genomische DNA wurden mit $200 \mu \mathrm{l}$ Neutralisierungspuffer (siehe Kapitel 2.8) gefällt und abzentrifugiert $(16000 \times$ g; $10 \mathrm{~min}$ ). Der klare Überstand wurde in $0,7 \mathrm{Vol} 100 \%$ Isopropanol überführt und die Plasmid-DNA durch Zentrifugation (16000 x g; 20 min) pelletiert. Anschließend wurde das DNA-Pellet in $70 \%$ Ethanol gewaschen und nach dem Trocknen in 20-50 $\mu \mathrm{l}$ Ampuwa aufgenommen. Die DNA-Konzentration wurde, wie unter 2.15 .2 beschrieben, mit einem Photometer bestimmt. Anschließend wurden je Präparation 100 bis 200 ng DNA mit Hilfe einer oder mehrerer Restriktionshydrolysen (siehe Kapitel 2.15.3.1) analysiert.

\subsection{Plasmidpräparation geringer hochreiner DNA-Mengen}

Für die DNA-Sequenzanalyse (siehe Kapitel 2.15.4.3) wurde hochreine Plasmid-DNA mit Hilfe des QIAprep miniprep Kits isoliert. Dabei wurde nach den Angaben des Herstellers gearbeitet. Die Messung der DNA-Konzentration sowie die Analyse der Präparationen erfolgten wie unter 2.15.1.1.1 beschrieben. 


\subsection{Plasmidpräparation großer DNA-Mengen}

Große Mengen Plasmid-DNA wurden mit dem QIAGEN plasmid purification Kit nach Angaben des Herstellers isoliert. Die Messung der DNA-Konzentration sowie die Analyse der Präparationen erfolgten wie unter 2.15.1.1.1 beschrieben. Je Präparation wurden 100 bis $200 \mathrm{ng}$ aufgereinigter Plasmid-DNA durch mehrere Restriktionshydrolysen analysiert.

\subsubsection{Ethanolfällung von DNA aus wässrigen Lösungen}

Die DNA-Fällung wurde zur Entfernung von Salzen und Schwebstoffen sowie zur Einengung des Lösungsvolumens eingesetzt. Der DNA-Probe wurden 3 Vol $96 \%$ Ethanol und $1 / 10$ Vol $3 \mathrm{M}$ Natriumacetat-Essigsäure $(\mathrm{pH} \mathrm{5,2)} \mathrm{(siehe} \mathrm{Kapitel} \mathrm{2.8)}$ zugegeben. Die Präzipitation erfolgte $10 \mathrm{~min}$ bis über Nacht bei -20 bis $-80^{\circ} \mathrm{C}$. Durch Zentrifugation wurde die DNA pelletiert, mit $70 \%$ Ethanol gewaschen, getrocknet und in einem entsprechendem Volumen Ampuwa aufgenommen.

\subsubsection{Phenol/Chloroform-Aufreinigung von Nukleinsäuren}

Durch die Phenol/Chloroform-Aufreinigung wurden die hydrophilen Nukleinsäuren von den hydrophoben Protein und Membranbestandteile getrennt und gereinigt. Die zu reinigenden Proben wurden mit gleichem Volumen Phenol/Chloroform (1:1) versetzt und kräftig geschüttelt. Die Phasen wurden durch Zentrifugation für $10 \mathrm{~min}$ bei $16000 \times$ g getrennt und die obere wässrige Phase einer Ethanolfällung (siehe Kapitel 2.15.1.2) unterzogen.

\subsubsection{Isolierung von genomischer DNA}

\subsection{Isolierung von genomischer DNA aus eukaryotischer Zellkultur}

Für die Isolierung von genomischer DNA aus Zellkultur wurde das Medium verworfen und die Zellen mit 1x PBS (siehe Kapitel 2.8) gewaschen. Pro Loch einer 6-LochPlatte wurden $1000 \mu \mathrm{l}$ Lysepuffer (siehe Kapitel 2.8) zugegeben, die abgelösten Zellen in $2,0 \mathrm{ml}$ Gefäße überführt und über Nacht bei $37^{\circ} \mathrm{C}$ inkubiert. Dem Ansatz wurde $1 \mathrm{ml} 100 \%$ Isopropanol zugefügt und die DNA durch Zentrifugation bei $16000 \times \mathrm{g}$ für 10 min präzipitiert. Nach dem Waschen des DNA-Pellets in $70 \%$ 
Ethanol, wurde das Pellet getrocknet und in 80 bis $100 \mu$ Ampuwa aufgenommen. Die DNA-Konzentration wurde, wie unter 2.15 .2 beschrieben, mit einem Photometer bestimmt. Anschließend wurden 50 bis $100 \mathrm{ng}$ DNA als Matrizen-DNA für PCR zur Genotypisierung (siehe Kapitel 2.15.4.1) und weiteren PCR Analysen verwendet.

\subsection{Isolierung von genomischer DNA aus Gewebe (Schwanzbiopsie, Dottersack u. ä.)}

Die auf Trockeneis gelagerten oder frischen Gewebeproben wurden in $500 \mu \mathrm{l}$ 1x STE-Puffer (siehe Kapitel 2.8) aufgenommen, 25-50 $\mu$ l Proteinase $\mathrm{K}(10 \mathrm{mg} / \mathrm{ml})$ zugefügt und über Nacht bei $55^{\circ} \mathrm{C}$ inkubiert. Die genomische DNA wurde durch Ethanolfällung präzipitiert (siehe Kapitel 2.15.1.2). Für die Isolierung hochreiner genomischer DNA wurden die Proteinase-behandelten Proben einer Phenol/Chloroform-Aufreinigung (siehe Kapitel 2.15.1.3) unterzogen. Die wässrige Phase wurde in gleichem Volumen Isoamylalkohol/Chloroform (1:25) aufgenommen, kräftig geschüttelt und die Phasen für 10 min bei $16000 \times$ g getrennt. Die genomische DNA der oberen Phase wurde einer Ethanolfällung unterzogen (siehe Kapitel 2.15.1.2). Die genomische DNA einiger Proben wurden mit dem DNAeasy Kit isoliert. Die DNA-Konzentration wurde, wie unter 2.15 .2 beschrieben, mit einem Photometer bestimmt. Anschließend wurden 50 bis $100 \mathrm{ng}$ DNA als Matrizen-DNA für PCRs zur Genotypisierung (siehe Kapitel 2.15.4.1; 2.19.1.2) bzw. 10 bis $20 \mu \mathrm{g}$ DNA für Southern Blot Analysen (siehe Kapitel 2.15.6) verwendet.

\subsubsection{Isolierung von Gesamt-RNA}

Isolierte RNA wurde für die Analyse von Transkripten mittels cDNA-Synthese (siehe Kapitel 2.15.4.2) und anschließender PCR an CDNA (siehe Kapitel 2.15.4.1) verwendet.

\subsection{Isolierung von Gesamt-RNA aus eukaryotischer Zellkultur}

Für die Isolierung von Gesamt-RNA aus Zellkulturen wurde das alte Medium verworfen und die Zellen mit 1x PBS (siehe Kapitel 2.8) gewaschen. Durch die Zugabe von $1 \mathrm{ml}$ TRIZOL Reagent wurden die Zellen lysiert. Die Lysate wurden in ein steriles $2 \mathrm{ml}$ Reaktionsgefäß überführt, auf Eis gelagert und 10 sek homogenisiert 
(Vortexer). Nach einer Inkubation von 5 min bei Raumtemperatur wurden $200 \mu \mathrm{l}$ Chloroform zugegeben, der Ansatz für 15 sek kräftig gemischt (Vortexer) und nochmals für 3 min bei Raumtemperatur inkubiert. Die Phasentrennung erfolgte bei $4000 \times \mathrm{g}$ für $40 \mathrm{~min}$ bei $4^{\circ} \mathrm{C}$. Die obere wässrige Phase wurde in ein neues Gefäß überführt und mit $1 \mathrm{ml} 100 \%$ Isopropanol gemischt. Die Präzipitation der RNA erfolgte durch eine Inkubation des Ansatzes bei $-20^{\circ} \mathrm{C}$ für $10 \mathrm{~min}$ bis über Nacht und einem Zentrifugationsschritt (16000 x g für $35 \mathrm{~min}$ ). Das RNA-Pellet wurde mit $70 \%$ Ethanol gewaschen, getrocknet und in 20 bis $100 \mu$ RNase-freiem destillierten Wasser aufgenommen. Die RNA-Konzentration wurde, wie unter 2.15 .2 beschrieben, bestimmt und um eine Degradierung der RNA auszuschließen, wurden $500 \mathrm{ng}$ bis $2 \mu \mathrm{g}$ Gesamt-RNA durch Agarosegelelektrophorese (siehe Kapitel 2.15.5) überprüft.

\subsection{Isolierung von Gesamt-RNA aus Geweben}

Die auf Trockeneis gelagerten oder frischen Gewebe (siehe Kapitel 2.19.2; 2.19.4.2) wurden mit einem sterilen Skalpell zerkleinert und in ein steriles $13 \mathrm{ml}$ Röhrchen mit $2 \mathrm{ml}$ TRIZOL Reagent überführt. Das Gewebe wurde für 30 bis 60 sek auf Eis homogenisiert (Homogenisator). Nach einer Inkubation von $5 \mathrm{~min}$ bei Raumtemperatur wurden $400 \mu \mathrm{l}$ Chloroform zugegeben und der Ansatz wie unter 2.15.1.5.1 beschrieben, weiterbehandelt.

\subsection{Isolierung von Gesamt-RNA aus Knochenmark}

Knochenmark wurde wie unter 2.16.6.1 beschrieben isoliert und eine Ein-ZellSuspension hergestellt. Das in 1x PBS gewaschene Zellpellet wurde in $200 \mu \mathrm{l}$ TRIZOL Reagent aufgenommen und 10 sek homogenisiert (Vortexer). Nach einer Inkubation von 5 min bei Raumtemperatur wurden $40 \mu$ Chloroform zugegeben und wie unter 2.15.1.5.1 beschrieben weiterbehandelt.

\subsubsection{Isolierung von poly(A) ${ }^{+}-$RNA aus Gesamt-RNA}

Die Isolierung von poly $(A)^{+}-R N A$ aus Gesamt-RNA erfolgte mit dem Oligotex Kit. Dabei wurden $250 \mu \mathrm{gg}$ Gesamt-RNA eingesetzt und nach den Angaben des Herstellers aufgereinigt. 


\subsubsection{Konzentrationsbestimmung von Nukleinsäuren}

Die Konzentration von Nukleinsäuren wurde durch Messung der Absorbtionsmaxima bei $260 \mathrm{~nm}$ mit Hilfe eines Spektralphotometer und Formel 1 bestimmt. Gleichzeitig wurde die Reinheit der Nukleinsäuren aufgrund der Messung der Absorbtionsmaxima von Proteinen (Absorbtionsmaximum bei $280 \mathrm{~nm}$ ) bzw. Salzen (Absorbtionsmaximum bei $230 \mathrm{~nm}$ ) ermittelt. Bei den in Formel 2 angegebenen Verhältnissen der Absorbtionsmaxima bezeichnet man die Nukleinsäurelösungen als rein.

$$
C=O D_{260} \cdot f \cdot C
$$

Formel 1: Formel zur Berechnung von Nukleinsäure-Konzentrationen. Abkürzungen: $c$ gemessene Konzentration in $\mu \mathrm{g} / \mu \mathrm{l} ; f$, Verdünnungsfaktor; $C$, nukleinsäurespezifischer Koeffizient $(0,05$ $\mu \mathrm{g} / \mu \mathrm{l}$ für DNA; 0,04 $\mu \mathrm{g} / \mu \mathrm{l}$ für RNA).

$$
\begin{aligned}
& \text { DNA : } O D_{230} / O D_{260} / O D_{280}=1,0: 1,8: 1,0 \\
& \text { RNA : } O D_{230} / O D_{260} / O D_{280}=1,0: 2,0: 1,0
\end{aligned}
$$

Formel 2: Verhältnisse der Absorbtionsmaxima zur Bestimmung des Reinheitsgrades von DNA und RNA. Abkürzungen: $O D_{230}$, optische Dichte bei $230 \mathrm{~nm} ; O D_{260}$, optische Dichte bei $260 \mathrm{~nm}$; $O D_{280}$, optische Dichte bei $280 \mathrm{~nm}$.

\subsubsection{Klonierungstechniken}

\subsubsection{Restriktionshydrolyse}

Restriktionshydrolysen von DNA wurden in Volumina von mindestens $10 \mu$ bei einer für das Enzym optimalen Temperatur für 1 bis 2 h oder über Nacht inkubiert. Pro $\mu g$ DNA wurden 2 bis $3 \cup$ (Unit) der jeweiligen Restriktionsendonuklease (siehe Kapitel 2.13.1) eingesetzt. Die simultane Hydrolyse einer DNA-Probe mit zwei unterschiedlichen Enzymen erfolgte in einem für beide Enzyme optimalen Puffer. War dies nicht möglich, so wurde die DNA-Probe sequenziell hydrolysiert. Dazu wurde die DNA-Probe zunächst mit Enzym 1 im optimalen Puffer hydrolysiert und anschließend einer Ethanolfällung (siehe Kapitel 2.15.1.2) unterzogen. Darauf hin wurde die Hydrolyse mit Enzym 2 im entsprechenden Puffer durchgeführt. Restriktionshydrolytische Reaktionen wurden durch Zugabe von je $5 \mu$ L Ladepuffer (siehe Kapitel 2.8) abgestoppt. 


\subsubsection{Partielle Restriktionshydrolyse}

Partielle Restriktionshydrolysen wurden wie unter 2.15.3.1 durchgeführt. Dabei wurde jedoch mit verdünnten Restriktionsendonukleasen $(1 \mathrm{U} / \mu \mathrm{l})$ und Inkubationszeiten von 5 bis 30 min gearbeitet. Die Hydrolyse wurde durch Zugabe von je $5 \mu$ Ladepuffer (siehe Kapitel 2.8) abgestoppt.

\subsubsection{Behandlung von DNA mit T4-DNA-Polymerase}

Zum Auffüllen der 5'-Enden sowie zum Hydrolysieren der 3'-Enden von DNAFragmenten nach erfolgter Restriktionshydrolyse (siehe Kapitel 2.15.3.1) wurde mit der T4-DNA-Polymerase gearbeitet. Dabei wurde nach Herstellerangaben vorgegangen.

\subsubsection{Isolierung von DNA-Fragmenten aus Agarosegelen}

Die Isolierung von DNA-Fragmenten aus Agarosegelen erfolgte mit dem Kit QIAquick gel extraction bzw. QIAEX II gel extraction. Die entsprechenden DNA-Fragmente wurden mit einem sterilen Skalpell unter UV-Bestrahlung aus dem Agarosegel geschnitten und die DNA nach den Angaben des Herstellers isoliert.

\subsubsection{Aufreinigung von DNA-Fragmenten für die Herstellung transgener Mauslinien}

Für die Injektion von DNA-Fragmenten in Maus-Oozyten (siehe Kapitel 2.19.1.3) wurde hochreine DNA isoliert. Dazu wurden $100 \mu \mathrm{g}$ DNA des pPax7CreTM Plasmids (siehe Kapitel 2.11.3, 2.15.7.2.2) mit entsprechenden Restriktionsendonukleasen hydrolysiert (siehe Kapitel 2.15.3.1) und das entsprechende DNA-Fragment mit dem Kit QIAEX II aus einem Ethidiumbromid-freien Agarosegel (siehe Kapitel 2.15.5.1) extrahiert. Die DNA wurde mit einer Ethanolfällung (siehe Kapitel 2.15.1.2) präzipitiert und in mindestens $400 \mu \mathrm{l}$ TE-Puffer (siehe Kapitel 2.8) aufgenommen. Um Schwebstoffe zu entfernen wurde die DNA-Lösung zweimal zentrifugiert (15 min, 16000 x g). Nach jedem Zentifugationsschritt wurden jeweils nur $80 \%$ des Überstandes in ein neues Gefäß überführt. Der Rückstand von $20 \%$ wurde verworfen. Die DNA-Konzentration wurde vermessen, auf eine Konzentration von 
$30 \mu \mathrm{g} / \mathrm{ml}$ eingestellt und durch Agarosegelelektrophorese (siehe Kapitel 2.15.5) auf Reinheit und Konzentration hin überprüft. Das linearisierte Expressionskonstrukt wurde am Max-Planck-Institut für experimentelle Medizin, Göttingen, in Maus Oozyten injiziert.

\subsubsection{Klonierung von PCR-Produkten}

Amplifizierte DNA-Fragmente aus PCR Reaktionen (siehe Kapitel 2.15.4.1) wurden mit Hilfe des pGEM-Teasy TA-cloning Kits bzw. dem Eukaryotic TA expression kit (pCR3.1 unidirectional) direkt kloniert. Es wurde nach den Angaben des Herstellers gearbeitet.

\subsubsection{Ligation}

Die Ligation von Restriktionsendonuklease-behandelter Plasmid-DNA mit einsprechend hydrolysierten DNA-Fragmenten (siehe Kapitel 2.15.3.1) erfolgte mit der T4-Ligase. Es wurde nach der Angaben des Herstellers gearbeitet. Die Inkubationen von Ligationsansätzen variierten zwischen $1 \mathrm{~h}$ bei Raumtemperatur und über Nacht bei $4^{\circ} \mathrm{C}$.

\subsubsection{Transformation von Bakterienzellen}

$50 \mu$ l kompetente Zellen (E. coli $\mathrm{DH} 10 \alpha$, Invitrogen $\mathrm{GmbH}$, Karlsruhe) wurden auf Eis aufgetaut und nach der Zugabe von 100 ng reiner Plasmid-DNA (siehe Kapitel 2.15.1.1.3) bzw. 5 bis $10 \mu$ l eines Ligationsansatzes (siehe Kapitel 2.15.3.7) für 20 min auf Eis inkubiert. Durch einen Hitzeschock des Ansatzes bei $42^{\circ} \mathrm{C}$ für 45 sek erfolgte die Transformation der DNA in die Zellen. Der Ansatz wurde für 2 min auf Eis gelagert und anschließend mit $500 \mu \mathrm{l}$ S.O.C.-Medium aufgefüllt. Nach einer Inkubation von $1 \mathrm{~h}$ bei $37^{\circ} \mathrm{C}$ unter leichtem Schwenken wurde 10 bis $250 \mu \mathrm{l}$ transformierte Zellen auf Agarplatten mit entsprechendem Antibiotika (siehe Kapitel 2.9.2) ausplattiert und die Platten über Nacht im Brutschrank bei $37^{\circ} \mathrm{C}$ inkubiert. 


\subsubsection{Polymerase-Kettenreaktion (PCR)}

\subsubsection{Polymerase-Kettenreaktion an Plasmid-DNA, cDNA und genomischer DNA}

Die Amplifikation von DNA (siehe Plasmid-DNA, 2.15.1.1; cDNA, 2.15.1.5, 2.15.4.2; genomische DNA, 2.15.1.4) wurde in Reaktionsvolumina von $10 \mu \mathrm{l}, 20 \mu \mathrm{l}, 30 \mu \mathrm{l}$ oder $50 \mu \mathrm{l}$ pro Ansatz mit folgenden Reagenzien und Endkonzentrationen durchgeführt:

\begin{tabular}{|c|c|}
\hline $10-100$ ng & Matrizen-DNA \\
\hline $0,43 \mu \mathrm{M}$ & sequenzspezifisches Vorwärts-DNA-Oligonukleotid \\
\hline $0,43 \mu \mathrm{M}$ & sequenzspezifisches Rückwärts-DNA-Oligonukleotic \\
\hline $0,2 \mathrm{mM}$ & dNTP-Mix (siehe Kapitel 2.8) \\
\hline $1 \%(v / v)$ & N.N.-Dimethylsulfoxid (DMSO) \\
\hline $0,01 \%(v / v)$ & Cresol (siehe Kapitel 2.8) \\
\hline $1 x$ & Polymerase-Puffer \\
\hline $0,1 \mathrm{U}$ & Polymerase (siehe Kapitel 2.13.2) \\
\hline
\end{tabular}

Die PCR-Bedingungen wurden den verwendeten Matrizen-DNA, DNAOligonukleotiden (siehe Kapitel 2.12.1) und DNA-Polymerasen (siehe Kapitel 2.13.2) angepasst. Der erste Denaturierungsschritt bei $95^{\circ} \mathrm{C}$ wurde für 5 bis $10 \mathrm{~min}$ durchgeführt, darauf folgten 25 bis 35 Zyklen von je einem Denaturierungsschritt $\left(95^{\circ} \mathrm{C}\right.$ für 30 bis 60 sek), je einem DNA-Oligonukleotid-Anlagerungsschritt bei 50 bis $68^{\circ} \mathrm{C}$ (30 sek bis $2 \mathrm{~min}$ ) und je einem Elongationsschritt bei 68 oder $72^{\circ} \mathrm{C}(1$ bis $10 \mathrm{~min}$ ). Am Ende des Programms wurde ein Elongationsschritt von 10 bis $30 \mathrm{~min}$ Länge (68 oder $72^{\circ} \mathrm{C}$ ) zugefügt.

Je nach Weiterverwendung der PCR-Amplifikate wurde entweder der gesamte Ansatz oder nur ein Aliquot mittels Agarosegelelektrophorese (siehe Kapitel 2.15.5) untersucht.

\subsubsection{Reverse Transkription}

Die reverse Transkription von Gesamt-RNA in cDNA erfolgte mit der reversen Transkriptase SuperScript II und oligo(dT)-Nukleotiden, welche komplementär an den poly $(A)^{+}$-Sequenzen der mRNA binden. 
Die reverse Transkription wurde in einem Volumen von $20 \mu$ durchgeführt. Nach der Zugabe von 1 bis $2 \mu \mathrm{g}$ Gesamt-RNA und $250 \mathrm{ng}$ oligo(dT)-Nukleotiden wurde der Ansatz für $10 \mathrm{~min}$ bei $70^{\circ} \mathrm{C}$ inkubiert. Es erfolgte die Zugabe von $100 \mathrm{mM}$ DTT (Dithiothreiol; Endkonzentration 10 mM; Invitrogen $\mathrm{GmbH}$, Karlsruhe), $10 \mu \mathrm{M}$ dNTPMix (Endkonzentration 0,5 mM; siehe Kapitel 2.8) und 5x first strand buffer (Endkonzentration 1x; Invitrogen $\mathrm{GmbH}$, Karlsruhe). Der Ansatz wurde für 10 min bei $25^{\circ} \mathrm{C}$ gelagert, für 2 min bei $42^{\circ} \mathrm{C}$ angewärmt und $1 \mu \mathrm{l}$ SuperScript II (200 U/ $/$ l) unter vorsichtigem Mischen hinzugefügt. Die reverse Transkription wurde bei $42^{\circ} \mathrm{C}$ für $1 \mathrm{~h}$ durchgeführt und danach durch eine Inkubation bei $70^{\circ} \mathrm{C}$ für $10 \mathrm{~min}$ abgestoppt. Die cDNA-Proben wurden durch die Zugabe von $1 \mu \mathrm{l}$ RNase $\mathrm{H}\left(\begin{array}{l}1 \\ \mathrm{U} / \mu \mathrm{l}\end{array}\right)$ und einer Inkubation bei $37^{\circ} \mathrm{C}$ (20 min) von der Matrizen-RNA befreit. Dieser letzte Schritt ist nur für cDNA-Proben angewandt worden, welche anschließend mit der quantitativen real time PCR (siehe Kapitel 2.15.4.4) vermessen wurden. Die Kalkulation der cDNAKonzentration erfolgte durch die Annahme, dass die Effizienz der cDNA-Synthese bei etwa $50 \%$ liegt. Bei der reversen Transkription von $2 \mu \mathrm{g}$ RNA würde somit $1 \mu \mathrm{g}$ cDNA synthetisiert (bei einem Reaktionsvolumen von $20 \mu$ bedeutet das eine Endkonzentration von $50 \mathrm{ng} / \mu \mathrm{l})$.

\subsubsection{Rapid amplification of cDNA ends (RACE)}

Zur Bestimmung der 3'-Enden von Ptch Transkripten wurde das RACE-Kit Smart race cDNA amplification kit verwendet. Dabei wurde nach den Angaben des Herstellers gearbeitet. Die verwendeten DNA-Oligonukleotide sind unter 2.12.1.6 aufgelistet.

\subsubsection{Quantitative real time PCR}

\subsection{Aufbau und Auswertung der quantitativen real time PCR}

\subsection{Relative Quantifizierung}

Der Vergleich verschiedener Expressionsniveaus eines Genes in unterschiedlichem Probenmaterial erfolgte durch eine relative Quantifizierung. Um das Expressionsniveau in den Proben miteinander vergleichen zu können, wurde eine Standardkurve mit Plasmid-DNA als Matrize (siehe Kapitel 2.11.5) erstellt. Zur 
Normalisierung der Expression des Zielgens wurde die Expression eines endogenen Kontrollgens vermessen (siehe Kapitel 2.15.4.4.1.4).

\subsection{Plasmidstandards}

Die zur Erstellung von Standardkurven verwendeten Plasmide sind unter 2.11.5 aufgeführt. Sie beinhalten die jeweils zu amplifizierende cDNA- oder AmplikonSequenz des Zielgens. Die vorhergehende Kalkulierung der eingesetzten Molekülzahl ist unter 2.15.4.4.1.3 aufgeführt. Es wurden 6 serielle fünffach Verdünnungen (S1-S6) der Plasmid-DNA zur Erstellung einer Standardkurve hergestellt und amplifiziert. In Tabelle 6 ist für jedes verwendete Plasmid die erste Verdünnung S1 angegeben. Durch die Auftragung des Logarithmus der eingesetzten Molekülzahl gegen die Zyklusnummer (Ct-Wert; cycle treshold; Schnittpunkt der Amplifikationskurve mit dem Schwellenwert) wurde die jeweilige Standardkurve erstellt.

\subsection{Kalkulation von Plasmid-Molekülzahlen}

Zur Kalkulierung der eingesetzten Plasmid-Molekülzahlen wurden die Molekulargewichte der Plasmid-DNAs bestimmt. Dazu wurde pro Nukleotid das gemittelte Molekulargewicht der vier Nukleotide verwendet $(326,95 \mathrm{~g} / \mathrm{mol})$ und das Gewicht je Plasmid-Molekül errechnet $\left(1 \mathrm{Mol}=6,023^{*} 10^{23}\right.$ Moleküle).

\subsection{Endogene Kontrolle}

Als endogene Kontrolle wurde das Expressionsniveau des 18s rRNA Gens jeder untersuchten cDNA-Probe bestimmt. Dazu wurden das Kit TaqMan ribosomal RNA control reagent, VIC probe nach Herstellerangaben verwendet. 


\subsection{Durchführung und Aufbau der quantitativen real time PCR mit fluoreszenzmarkierten, sequenzspezifischen Sonden}

Die Amplifikation einzelner Zielsequenzen wurde in unabhängigen PCR-Reaktionen durchgeführt. Das Expressionsniveau des Zielgens wurde für jede cDNA-Probe in 2 bis 3 Replikaten je Lauf bestimmt. Um Ungenauigkeiten beim Pipettieren geringer Volumina zu vermeiden, wurden die Plasmidstandards und die cDNA-Proben verdünnt, so dass immer ein Volumen von $10 \mu \mathrm{l}$ je Ansatz pipettiert werden konnte. Die Kalkulation der eingesetzten cDNA-Mengen ist unter 2.15.4.2 beschrieben. Verwendete DNA-Oligonukleotide und fluoreszenzmarkierte, sequenzspezifische Sonden sind unter 2.12.1.7 aufgeführt. Die verwendeten PCR-96-Loch-Platten (TaqMan-Platten) und die TaqMan Abdeckfolien wurden von der Firma Applied Biosystems, Darmstadt, bezogen. Die Amplifikation wurde mit dem Kit qPCR core kit in einem Reaktionsvolumen von $30 \mu \mathrm{l}$ pro Ansatz durchgeführt. Für die Amplifikation des Zielgens wurde 50 ng der Matrizen-cDNA, für die Amplifikation der 18S rRNA wurde $16 \mathrm{pg}$ der Matrizen-cDNA eingesetzt. Die eingesetzte Molekülzahl der Plasmidstandard-DNA ist Tabelle 6 zu entnehmen. Zu jedem PCR-Ansatz wurden 0,3 $\mu \mathrm{Mol}$ sequenzspezifische Vorwärts- bzw. Rückwärts-DNA-Oligonukleotide, $200 \mathrm{nMol}$ fluoreszenzmarkierte, sequenzspezifische Sonde, 0,2 mMol dNTP-Mix, 4,0 mMol $\mathrm{MgCl}_{2}$, 1x Polymerase-Puffer (ROX passive reference; Eurogentec Deutschland $\mathrm{GmbH}$, Köln) und 0,75 U Hot gold star DNA-Polymerase (Eurogentec Deutschland $\mathrm{GmbH}$, Köln) zugegeben. Die DNA-Polymerase wurde für $10 \mathrm{~min}$ bei $95^{\circ} \mathrm{C}$ aktiviert, gefolgt von 40 Zyklen mit je einem 15 sek langen Denaturierungsschritt bei $95^{\circ} \mathrm{C}$ und je einem 60 sek langen Anlagerungs/Elongationsschritt bei $60^{\circ} \mathrm{C}$. Die Amplifikation und Messung erfolgte mit Hilfe des ABI Prism $7900 \mathrm{H}$ Sequence detection system.

\subsection{Durchführung und Aufbau der quantitativen real time PCR mit SYBR green}

Die Bestimmung der Expression des Gli1 Gens in unterschiedlichem Probenmaterial erfolgte durch die relative Quantifizierung unter Verwendung von sequenzspezifischen DNA-Oligonukleotiden (siehe Kapitel 2.12.1.7) und dem Kit QuantiTect SYBR green PCR. Es wurde nach Herstellerangaben gearbeitet. 
Folgendes PCR-Programm wurde verwendet: Die DNA-Polymerase wurde zunächst für $15 \mathrm{~min}$ bei $95^{\circ} \mathrm{C}$ aktiviert, dann folgten 40 Zyklen bestehend aus je einem 15 sek langen Denaturierungsschritt bei $95^{\circ} \mathrm{C}$, einem 30 sek langen Anlagerungsschritt bei $58^{\circ} \mathrm{C}$ und einem 30 sek langen Elongationsschritt bei $72^{\circ} \mathrm{C}$. Durchführung, Messung und Auswertung erfolgten wie unter 2.15.4.4.1.5 beschrieben.

\subsection{Auswertung (Standardkurvenmethode)}

Die Auswertung der quantitativen real time PCR erfolgte mittels der Software SDS2.1 (Applied Biosystems, Darmstadt) und Microsoft EXEL (Microsoft Co., Redmond, USA). Die statistische Auswertung (siehe Kapitel 2.1) von 3 bis 6 Versuchsreihen wurde mit Hilfe der Software Statistica (StatSoft $\mathrm{GmbH}$, Hamburg) durchgeführt. Die statistischen Graphiken wurden in Box-Whisker-Plots dargestellt. Die Signifikanz von Unterschieden und Gleichheit der einzelnen Gruppen wurde mit Hilfe eines t-Tests für unabhängige Gruppen (Mann-Whitney-U-Test) getestet. $P$ Werte von $P<0,05$ wurden als signifikant, und $P$ Werte $P>0,05$ wurden als nicht-signifikant gewertet (siehe Kapitel 2.1).

\subsubsection{DNA Sequenzanalyse}

Die zu sequenzierenden DNA-Proben wurden mit dem BigDye Terminator v1.1 cycle sequencing kit nach Herstellerangaben amplifiziert und mit Sephadex G50 in einer MAHV N45-Platte aufgereinigt. Die Sequenzanalysen wurden mit dem ABI 3100 genetic analyser und der dafür vorgesehenen Software (ABI 3100 genetic analyser data collection 1.0, Applied Biosystems, Darmstadt) durchgeführt. Die Auswertung erfolgte mit der Software Sequencher (Applied Biosystems, Darmstadt).

\subsubsection{Agarosegelelektrophorese}

Die Auftrennung von DNA-Fragmenten und die Überprüfung der 28S rRNA (5.1kb) und $18 \mathrm{~S}$ rRNA $(1,9 \mathrm{~kb})$ von RNA-Proben erfolgten mit Hilfe der Agarosegelelektrophorese. Den Nukleinsäure-Proben wurde vor dem Beladen des Gels 0,2 Vol Ladepuffer (siehe Kapitel 2.8) zugefügt. Je nach Größe der Nukleinsäuresequenzen wurde mit Gelen von 0,7 bis $2,5 \%(w / v)$ Agaroseanteil in 1x TBE (siehe Kapitel 2.8) gearbeitet. Zur Visualisierung der Nukleinsäuren wurde 
dem noch flüssigen Gel unter Schwenken Ethidiumbromid (Endkonzentration $0,2 \mu \mathrm{g} / \mathrm{ml}$ ) zugegeben. Die Auftrennung erfolgte in einer mit 1x TBE (siehe Kapitel 2.8) gefüllten Gelelektrophoresekammer bei einer konstanten Spannung von 30 bis 120 V. Die Dokumentation erfolgte mit Hilfe des UV-Transilluminators der Firma Intas, Göttingen.

Die Größen der Nukleinsäure-Fragmente bei der Gelelektrophorese wurden durch paralleles Mitführen der DNA-Längenstandards 1 kb DNA Ladder und 100 bp DNA Ladder ermittelt. DNA-Konzentrationen wurden durch vergleichendes Abschätzen mit dem Standard 100 bp DNA Ladder überprüft.

\subsubsection{Ethidiumbromid-freie Agarosegelelektrophorese}

Zur Aufreinigung von hochreinen DNA-Fragmenten für die Herstellung transgener Mäuse (siehe Kapitel 2.15.3.5; 2.19.1.3) wurde mit Ethidiumbromid-freien Agarosegelen $(1,5 \% \mathrm{w} / \mathrm{v})$ gearbeitet. Dabei wurde die restriktionshydrolysierte Plasmid-DNA (siehe Kapitel 2.15.3.1) in eine Geltasche geladen, welche sich fast über die gesamte Breite des Gels erstreckte. Eine äußere linke und äußere rechte Tasche wurde mit einem Längenstandard (siehe Kapitel 2.15.5) versehen. Die Auftrennung der Fragmente wurde bei einer konstanten Spannung von $90 \mathrm{~V}$ für 4 bis $5 \mathrm{~h}$ durchgeführt. Die Visualisierung der DNA erfolgte durch Abtrennen der linken und rechten Taschen und einem Stück der mittleren Gelbahn vom restlichen Gel und deren Färbung in einem Ethidiumbromid-Bad (1 $\mathrm{h}$ in $1 \mathrm{x}$ TBE mit 0,2 $\mu \mathrm{g} / \mathrm{ml}$ Ethidiumbromid). Durch das Anlegen der Gelränder konnte die Laufhöhe des entsprechenden DNA-Fragments in dem Ethidiumbromid-freien Gelteil ermittelt werden. Das zu isolierende Fragment wurden aus dem Ethidiumbromid-freien Gelteil mit einem sterilen Skalpell entfernt und wie unter 2.15.3.5 beschrieben aufgereinigt.

\subsubsection{Southern Blot}

10 bis $15 \mu \mathrm{g}$ der zu analysierenden DNA wurden mit einer entsprechenden Restriktionsendonuklease über Nacht bei $37^{\circ} \mathrm{C}$ inkubiert (siehe Kapitel 2.15.3.1). Den Ansätzen wurde 0,2 Vol Ladepuffer (siehe Kapitel 2.8) hinzugefügt und die DNAFragmente in einen 1 bis 1,5\% Agarosegel (siehe Kapitel 2.15.5) über Nacht bei 60 bis $80 \mathrm{~V}$ aufgetrennt. Danach wurden das Gel und ein fluoreszierendes Lineal mittels 
UV-Licht dokumentiert. Dann wurde der Längenstandard (siehe Kapitel 2.15.5) aus dem Gel geschnitten. Das Gel wurde in eine Plastikwanne überführt und für $30 \mathrm{~min}$ in einer 0,25 N HCl-Lösung unter Schwenken (Wipp-Taumel-Tisch) inkubiert. Nach kurzem Schwenken des Gels in MilliQ Wasser wurde es für $30 \mathrm{~min}$ in Denaturierungspuffer (siehe Kapitel 2.8) unter Schwenken inkubiert und erneut in MilliQ Wasser gespült. Danach wurde das Gel in Transferpuffer (20x SSC; siehe Kapitel 2.8) überführt und für 15 min geschwenkt. Es wurde eine Nitrozellulosemembran (Hybond-XL) auf die genaue Gelgröße zugeschnitten, die Seiten (oben, unten, rechts, links) markiert und in 20x SSC äquilibriert. Die Membran wurde ohne Luftblasen auf das Gel gelegt und in ein Blotsystem (Whatman Inc., New Jersey, USA) nach Herstellerangaben eingebaut. Der Transfer der DNA auf die Membran erfolgte über Nacht bei Raumtemperatur. Am nächsten Tag wurde die Membran von dem Gel gezogen, auf einem Filterpapier (siehe Kapitel 2.5) getrocknet und die DNA bei $100 \mathrm{~mJ} / \mathrm{cm}^{2}$ kovalent auf der Membran gebunden (Crosslinker). Zusätzlich wurde die Membran bei $80^{\circ} \mathrm{C}$ für $2 \mathrm{~h}$ gebacken (Hybridisierungofen). Zur Vorhybridisierung wurde die Membran in 2x SSC angefeuchtet, in eine Hybridisierungsröhre überführt und bei $65^{\circ} \mathrm{C}$ im Hybridisierungofen für $2 \mathrm{~h}$ in $5 \mathrm{ml}$ Rapid-hyb buffer mit $200 \mu \mathrm{g} / \mathrm{ml}$ denaturierter Lachsspermien-DNA (Sonicated salmon sperm DNA, $10 \mathrm{mg} / \mathrm{ml}$; Stratagene, Amsterdam Zuidoost, Niederlande) vorhybridisiert.

Der Hybridisierungslokus der verwendeten Sonde für die Detektion der wt Ptch, Ptch $^{N X}$ und Ptch ${ }^{\text {delNX }}$ Xhol-hydrolysierten DNA-Fragmente ist in Abbildung 17 dargestellt. Die Sonde wurde durch Restriktionshydrolyse des Plasmids pGEM-T KO\#13, welches 1200 bp der genomischen Ptch Sequenz enthält, isoliert. Dazu wurde es über Nacht mit EcoRI restriktionshydrolysiert, das 1200 bp lange DNA-Fragment durch zweifache Agarosegelelution aufgereinigt (siehe Kapitel 2.15.3.4) und durch Agarosegelelektrophorese (siehe Kapitel 2.15.5) quantifiziert. 25 bis $50 \mathrm{ng}$ der Hybridisierungssonde wurde mit dem Prime-lt RmT Random Primer Labeling Kit durch den Einbau von alpha ${ }^{32} \mathrm{P}$-dATP radioaktiv markiert. Dabei wurde nach Herstellerangaben gearbeitet. Danach wurde die radioaktiv-markierte Sonde durch Spindialyse aufgereinigt. Hierzu wurde mit den MicroSpin G-50 Säulchen nach Herstellerangaben gearbeitet. Die aufgereinigte Sonden-DNA wurde 5 min bei $99^{\circ} \mathrm{C}$ denaturiert und bis zur Verwendung auf Eis gelagert.

Nach dem Abgießen der Vorhybridsierungslösung aus der Hybridisierungsröhre 
wurden abermals $5 \mathrm{ml}$ des Rapid-hyb buffer mit $200 \mu \mathrm{g} / \mathrm{ml}$ denaturierter Lachsspermien-DNA zugegeben. Die radioaktiv-markierte, denaturierte Sonden-DNA wurde in die Hybridisierungslösung pipettiert und die Membran über Nacht bei $65^{\circ} \mathrm{C}$ hybridisiert. Am nächsten Tag wurde die Hybridisierungslösung abgenommen und die Membran in der Hybridisierungsröhre mit einem niedrig-stringentem Waschpuffer (siehe Kapitel 2.8) zweimal für je 20 min gewaschen. Danach wurde die Membran in eine Plastikwanne überführt und die Strahlungsintensität der Membran mit dem Geiger-Zähler überprüft. Bei einer Strahlung über $5 \mathrm{~Bq} / \mathrm{cm}^{2}$ wurde die Membran mit hoch-stringentem Waschpuffer (siehe Kapitel 2.8) in der Plastikwanne bei $65^{\circ} \mathrm{C}$ für 20 min im Schüttelwasserbad gewaschen. Dieser Schritt wurde so lange wiederholt bis die Strahlungsintensität der Membran einen Wert unter $5 \mathrm{~Bq} / \mathrm{cm}^{2}$ erreichte. Danach wurde die Membran in MilliQ Wasser geschwenkt, auf Filterpapier getrocknet, in Klarsichtfolie eingeschweißt und in eine Filmkassette überführt. Ein Autoradiographie-Film wurde bei $-80^{\circ} \mathrm{C}$ für 2-3 Tage auf der Membran inkubiert. Nach der Entwicklung des Filmes wurde dieser mit Hilfe der Agarosegel-Fotos analysiert.

\subsubsection{Klonierungen von eukaryotischen Expressionsplasmiden}

\subsubsection{Klonierung von Ptch Expressionsplasmiden}

Zur Expression von mutanten und wt Ptch Proteinen der Ptch ${ }^{\text {neo67/+ }}$ Mäuse in eukaryotischer Zellkultur wurde sowohl die wt Ptch als auch die mutante Ptch cDNA Sequenz, bei der die Ptch Exone 6 und 7 fehlen, unter die Kontrolle des CMV (Cytomegalie Virus) Promotor kloniert. Dabei wurde das Translationsstartcodon des alternativen Exone 1b übernommen und eine zusätzliche Kozak-Konsensussequenz (ccrccATGg; r-variable Base; der Transkriptionsstart ist in Großbuchstaben hervorgehoben) hinzugefügt.

\subsection{Klonierung von $p C R 3.1 \mathrm{mPtch}(K) w t$}

Zur Amplifikation der wt Ptch cDNA wurde mit dem DNA-Oligonukleotidpaar F-H3ATG/R-Xbal-Stop (siehe Kapitel 2.12.1.2) gearbeitet. Dabei diente das Plasmid pBSSK ${ }^{+} m P t c h(K) w t$ (zur Verfügung gestellt von M. P. Scott, Howard Hughes Medical Institute, Chevy Chase, USA) als DNA-Matrize. pBSSK ${ }^{+}$Ptch $(K) w t$ umfasst die 
murine wt Ptch cDNA Sequenz mit dem ersten alternativen Exon 1b. Das 4305 bp lange DNA-Fragment wurde in den Vektor pCR3.1 (Invitrogen $\mathrm{GmbH}$, Karlsruhe; 2.15.3.6) ligiert und das Konstrukt pCR3.1 mPtchwt genannt. Da bei dieser Klonierung die Kozak-Konsensussequenz fehlte, wurde das das erste ATG enthaltene DNA-Fragment wieder ausgetauscht. Hierzu wurde aus dem Plasmid pBSSK ${ }^{+} m P t c h(K) w t$ durch eine Xbal/Bglll Restriktionshydrolyse das die KozakKonsensussequenz und das erste ATG enthaltene DNA-Fragment isoliert. Das Fragment wurde gegen das Nhel/Bg/ll des Plasmids pCR3.1 mPtchwt ausgetauscht. Das entstandene Expressionsplasmid wurde pCR3.1 mPtch(K)wt genannt. Um Punktmutationen auszuschließen, wurde die gesamte inserierte Ptch cDNA-Sequenz sequenziert (siehe Kapitel 2.15.4.5). Die für die Sequenzierung verwendeten DNAOligonukleotide sind unter 2.12.1.3 aufgelistet.

\subsection{Klonierung von $p C R 3.1 \mathrm{mPtch}(K) d 67$}

Aus dem Plasmid pCR3.1 mPtch(K)wt wurde durch Restriktionshydrolyse mit Bgll und partieller Restriktionshydrolyse (siehe Kapitel 2.15.3.2) mit Xhol die wt Ptch Sequenz gegen die mutante $P t c h^{d 67}$ Sequenz ausgetauscht. Als Donor für die 1369 bp lange $P t c h^{d 67}$ Sequenz diente das Xhol/Bg/ll hydrolysierte Plasmid $p B S K S^{+} m P t c h d 67$, welches die gesamte mutante $\operatorname{Ptch}^{d 67}$ Sequenz nicht aber die Kozak-Konsensussequenz enthält. Das klonierte Expressionsplasmid wurde pCR3.1 mPtch(K)d67 genannt.

\subsubsection{Klonierung der Pax7 Promotorplasmide}

Zur gewebespezifischen Expression einer Tamoxifen-induzierbaren CreRekombinase wurde der 3217 bp lange proximale Teil des murinen Pax7 Promotors mit dem DNA-Oligonukleotidpaar mPax7promF1/mPaxNcolcn (siehe Kapitel 2.12.1.2) amplifiziert. Als Matrizen-DNA diente murine genomische wt DNA. Es wurde mit dem SAWADY Mid Range PCR-System gearbeitet. Distal wurde eine Sstl Restriktionsschnittstelle durch das Vorwärts-DNA-Oligonukleotid und proximal eine Ncol Restriktionsschnittstelle durch das Rückwärts-DNA-Oligonukleotid eingeführt. Das Amplifikat wurde sowohl in den pGEM-Teasy Vektor als auch in den pCR II TAcloning Vektor kloniert. Die Plasmide wurden pGEM-Teasy Pax7prom und $p C R I I$ Pax7prom genannt und wurden für weitere Subklonierungen verwendet. 


\subsection{Klonierung der pGL3 Pax7prom Reporterplasmide}

Um die Expression des Pax7 Promotors in eukaryotischen Zelllinien zu analysieren wurde das Gen der Firefly Luziferase unter die Kontrolle des Promotors kloniert.

Der 3,2 kb lange murine Pax7 Promotor wurde über die Restriktionsschnittstellen Sstl/Ncol aus pGEM-Teasy Pax7prom (siehe Kapitel 2.11.3) isoliert und in den Sstl/Ncol geöffneten $p G L 3-b a s i c$ kloniert. Dabei schließt der Pax7 Promotor direkt an das erste ATG der Firefly Luziferase an. Das Plasmid wurde pGL3 Pax7prom 3,2 genannt. Für die Klonierung des Plasmids $p G L 3$ Pax7prom 2,5 wurde der Promotor distal um 0,7 kb verkürzt. Dazu wurde das Plasmid pGL3 Pax7prom 3,2 mit den Restriktionsenzymen Sstl/Stul hydrolysiert und das 7300 bp lange Vektor-Fragment nach T4-DNA-Polymerase Behandlung (siehe Kapitel 2.15.3.3) religiert. pGL3 Pax7prom 1,5 enthält ein distal um 1,7 kb verkürztes Promotor-Fragment. Für diese Klonierung wurde das Plasmid pGL3 Pax7prom 3,2 mit Kpnl hydrolysiert, das 6300 bp lange Vektor-Fragment isoliert und religiert (Abbildung 49).

\subsection{Klonierung des pPax7CreTM Plasmids}

Das pPax7CreTM Plasmid (siehe Abbildung 49) enthält 3217 bp der 5'-Sequenz des Pax7 Promotors und daran anschließend ein chimeres Intron sowie das synthetische Gen der durch Tamoxifen induzierbaren MerCreMer Rekombinase (Verrou C et al., 1999). Dabei entspricht die Position des endogene Pax7 Translationsstartcodon der des MerCreMer Rekombinase Gens. Aus dem Expressionsplasmid pAN MerCreMer (zur Verfügung gestellt von $M$. Reth, Max-Planck-Institut für Immunobiologie, Freiburg) stammt auch die Siamian Virus-Polyadenylierungssequenz (SV 40 Poly A Sequenz).

Der 3'-Bereich des MerCreMer Rekombinase Gens wurde aus dem Expressionsplasmid pAN MerCreMer durch Restriktionshydrolyse mit Sall/HindllI (2047 bp) isoliert und in den Sall/Hindlll geöffneten pUC19 Vektor inseriert (pUC MerCreMer 3'; 4747 bp).

Die Amplifikation der 5'-Sequenz des MerCreMer Rekombinase Gens (971 bp) erfolgte mit dem DNA-Oligonukleotidpaar MCMfrag1BamHI-F/MCMfrag1Sall-R (siehe Kapitel 2.12.1.2). Als Matrizen-DNA diente das Expressionsplasmid pAN MerCreMer. Das Amplifikat wurde in den Vektor pGEM-Teasy inseriert und über 
Sequenzanalyse (siehe Kapitel 2.12.1.3) verifiziert. Das inserierte Fragment wurde über die bei der PCR eingeführten Schnittstellen (BamHI/Sall) isoliert und in den BamHI/Sall geöffneten pUC19 Vektor ligiert (pUC MerCreMer 5; 3671 bp).

Die 5'-Sequenz (352 bp) des Pax7 Promotors wurde über die Schnittstellen Sstl/BamHI aus dem Vektor pCRII Pax7prom (siehe Kapitel 2.11.3) isoliert und in den Sstl/BamHI geöffneten Vektor pUC MerCreMer 5' inseriert (pUC Pax7prom 3' MerCreMer 5'; 4023 bp). Die 3'-Sequenz des Pax7 Promotors (2865 bp) wurde mit dem DNA-Oligonukleotidpaar Paxfrag2BamHI-F/ Paxfrag2SnaBI-R (siehe Kapitel 2.12.1.2) und der Matrizen-DNA pCRII Pax7prom (siehe Kapitel 2.11.3) amplifiziert. Das Amplifikat wurde in den Vektor pGEM-Teasy kloniert und sequenziert ( $p$ GEM-Teasy Pax7prom 3'; 5865 bp). Diese 3'-Sequenz des Pax7 Promotors wurde mit einem chimeren Intron kombiniert. Die Isolierung des chimeren Introns (140 bp) erfolgte durch Amplifikation mit dem DNAOligonukleotidpaar IntronSnaBI-F/IntronBamHI-R (siehe Kapitel 2.12.1.2). Als Matrizen-DNA diente das Plasmid pCl-neo (Promega $\mathrm{GmbH}$; Mannheim). Das Amplifikat wurde in den Vektor pGEM-Teasy kloniert ( $p$ GEM-Teasy Cl; 3140 bp) und durch Sequenzierung verifiziert. Das chimere Intron wurde durch Restriktionshydrolyse mit SnaBI/Ncol isoliert und in den SnaBI/Ncol geöffneten Vektor pGEM-Teasy Pax7prom 3' integriert (pGEM-Teasy Pax7prom 3' Cl; 6005 bp).

Die Sequenz Pax7prom 3' Cl (3005 bp) wurde aus dem Vektor pGEMTeasy Pax7prom 3' $\mathrm{Cl}$ durch Restriktionshydrolyse mit BamHI isoliert und in den BamHI geöffneten Vektor pUC Pax7prom 3' MerCreMer 5' integriert. Die korrekte Orientierung des klonierten Fragments wurde durch analytische Restriktionshydrolyse überprüft. Das Plasmid wurde pUC Pax7prom CI MerCreMer 5' genannt (7419 bp).

Der Vektor pUC MerCreMer 3' wurde partiell mit Sstl (siehe Kapitel 2.15.3.2), anschließend mit Sall hydrolysiert und das Fragment pUC MerCreMer 3' (4747 bp) isoliert. In diesen geöffneten Vektor wurde das Sall/Sstl Fragment (4328 bp) aus dem Vektor pUC Pax7prom Cl MerCreMer 5' kloniert. Das Plasmid wurde pUC Pax7prom Cl MerCreMer (9075 bp) genannt. Aus diesem Plasmid wurde durch Restriktionshydrolyse mit Sstl das Fragment Pax7prom Cl MerCreMer (6375 bp) isoliert. Durch Ligation dieses Fragmentes in die Sstl Restriktionsschnittstellen des 
Expressionsplasmids pAN MerCreMer wurde das Plasmid pPax7CreTM kloniert (13700 bp) (Abbildung 49).

Sowohl die Sequenz des chimeren Introns und der MerCreMer Rekombinase als auch das korrekte Leserraster des Translationsstartcodons des Pax7 Gens wurde durch Sequenzierung überprüft (siehe Kapitel 2.12.1.3). Die Amplifikationen wurden mit dem SAWADY Mid Range PCR-System durchgeführt.

Zur Herstellung transgener Mäuse wurden $100 \mu \mathrm{g}$ des pPax7CreTM Plasmids mit den Restriktionsenzymen Swal/Ec/Hkl (Ahdl) linearisiert und das 9282 bp große Fragment (Pax7prom CI MerCreMer SV 40 Poly $A$ ), wie unter 2.15.3.5 und unter 2.19.1.3 beschrieben aufgereinigt und in Oocyten injiziert.

\subsection{Immunhistochemie und Immunzytochemie}

\subsubsection{Proteinchemische Methoden}

\subsubsection{Isolierung von Gesamtprotein}

\subsection{Isolierung von Gesamtprotein aus eukaryotischen Zellkulturen}

Die Zellen wurden mit kaltem 1x PBS (siehe Kapitel 2.8) gespült und in 0,2 bis $2 \mathrm{ml}$ heißem SDS-Lysepuffer (siehe Kapitel 2.8) von der Kulturschale gelöst und in ein $1,5 \mathrm{ml}$ Reaktionsgefäß überführt. Danach wurden die Proben für 30 sek bei $99^{\circ} \mathrm{C}$ inkubiert und die Proteinkonzentrationen (siehe Kapitel 2.16.1.2) bestimmt.

\subsection{Proteinextrakte aus Geweben}

Die auf Trockeneis gelagerten oder frischen Gewebe (siehe Kapitel 2.19.4.2) wurden auf Trockeneis mit einem Skalpell in kleine Stücke geschnitten und in SDSLysepuffer (siehe Kapitel 2.8) aufgenommen. Durch Homogenisierung (Homogenisator) auf Eis wurden die Zellen aufgeschlossen. Die Proben wurden für 30 sek bei $99^{\circ} \mathrm{C}$ inkubiert und die Proteinkonzentrationen (siehe Kapitel 2.16.1.2) bestimmt. 


\subsubsection{Bestimmung von Proteinkonzentrationen}

Die Konzentration von Proteinextrakten wurde mit dem Protein assay Kit bestimmt. Das Reagenz wurde in einem Verhältnis von 1:5 mit Ampuwa verdünnt und durch einen Faltenfilter filtriert. Diese Verdünnung wurde bei Raumtemperatur für höchstens einem Monat gelagert. Die Protein-Proben wurden in einem Verhältnis von 1:160 in Ampuwa verdünnt. Durch die Zugabe von $200 \mu \mathrm{l}$ des verdünnten Protein assay reagent wurde eine Farbreaktion hervorgerufen. Die optische Dichte der Probe wurde im Spektralphotometer bei einer Wellenlänge von $595 \mathrm{~nm}$ vermessen und die Proteinkonzentration berechnet (Formel 3).

$$
c=O D_{595} \cdot f \cdot C
$$

Formel 3: $\quad$ Formel zur Berechnung der Proteinkonzentration unter Verwendung des Protein Assay Kit (Bio-rad, Laboratories $\mathbf{G m b H}$, München). Abkürzungen: $c$, gemessene Konzentration in $\mu \mathrm{g} / \mu \mathrm{l}$; $O D$, optische Dichte; $f$, Verdünnungsfaktor; $C$, proteinspezifischer Koeffizient $(0,02 \mu \mathrm{g} / \mu \mathrm{l})$.

\subsubsection{Polyacrylamidgelelektrophorese (PAGE)}

Für die gelelektrophoretische Auftrennung von Proteinen wurde mit 7,5 bis $10 \%$ Polyacrylamidgelen (siehe Kapitel 2.8), vertikalen PAGE-Kammern und 1x PAGELaufpuffer gearbeitet. Als Molekulargewichtsstandard wurde Seeblue plus 2 eingesetzt. 10 bis $20 \mu \mathrm{g}$ der Proteinproben wurden in 2x SDS-Ladepuffer (siehe Kapitel 2.8) aufgenommen, 5 min bei $99^{\circ} \mathrm{C}$ inkubiert und bei $16000 \times \mathrm{g}$ für $2 \mathrm{~min}$ abzentrifugiert und in die Taschen geladen. Die Auftrennung erfolgte bei $100 \mathrm{~V}$ für 3 bis $4 \mathrm{~h}$ bei Raumtemperatur und wurde wie unter 2.16.1.4 beschrieben weiter behandelt.

\subsubsection{Western Blot}

Das Polyacrylamidgel (siehe Kapitel 2.16.1.3) und die Nitrozellulosemembran für Western Blots wurden für $10 \mathrm{~min}$ in Transferpuffer (siehe Kapitel 2.8) äquilibriert. Danach wurde die Western Blot Kammer wie vom Hersteller beschrieben unter Transferpuffer blasenfrei zusammengesetzt. Der Proteintransfer erfolgte über Nacht bei $4^{\circ} \mathrm{C}$ und $30 \mathrm{~V}$. Der Proteintransfer wurde mit einer Ponceau S Färbung überprüft. Hierzu wurde die Nitrozellulosemembran für 10 min in Ponceau S Lösung (siehe Kapitel 2.8) inkubiert und mit MilliQ Wasser unter Schwenken (Wipp-Taumel-Tisch) 
langsam entfärbt, bis die Proteinbanden sichtbar wurden. Zum Blockieren unspezifischer Bindungen wurde die Membran in M-PBT Puffer (siehe Kapitel 2.8) unter schwenken für mindestens $1 \mathrm{~h}$ bei Raumtemperatur inkubiert. Die Membransondierung mit primärem Antikörper erfolgte in M-PBT Puffer unter Schwenken über Nacht bei $4^{\circ} \mathrm{C}$. Danach wurde der Blot für 3x 10 min in M-PBT Puffer gewaschen und mit dem sekundären Meerrettich-Peroxidase gekoppeltem Antikörper in M-PBT Puffer für $2 \mathrm{~h}$ bei Raumtemperatur unter Schwenken inkubiert. Nach erneutem Waschen des Blots (3x $10 \mathrm{~min}$ in M-PBT Puffer und 1x $10 \mathrm{~min}$ in 1x PBS) wurde die Sondierung mit Hilfe des ECL-Kits auf ECL-Filmen sichtbar gemacht.

Die eingesetzten Verdünnungen der verwendeten primären und sekundären Antikörper sind in Tabelle 16 und Tabelle 17 aufgelistet.

\subsubsection{Aktivitätsnachweis des E. coli ß-Galaktosidase Proteins}

\subsection{X-Gal-Färbung von Embryonen und Muskelfasern}

Die Embryonen wurden nach der Präparation (siehe Kapitel 2.19.2) in 1x PBS (siehe Kapitel 2.8) auf Eis gewaschen und für mindestens $2 \mathrm{~h}$ in $4 \%$ Paraformaldehyd/ 1x PBS fixiert. Die präparierten Muskelfasern (siehe Kapitel 2.17.2) wurden ebenfalls in 1x PBS gewaschen und für 15 min in Paraformaldehyd (siehe Kapitel 2.8) fixiert. Nach dem Waschen (3x $20 \mathrm{~min}$ in 1x PBS auf Eis) wurden die Embryonen/ Muskelfasern in 0,2 \% Glutaraldehyd/1x PBS (siehe Kapitel 2.8) für 10 min auf Eis inkubiert und 3x 10 min lang in LacZ-Puffer (siehe Kapitel 2.8) äquilibriert. Danach wurden die Embryonen/Muskelfasern über Nacht bis 2 Tage in LacZ-Färbepuffer (siehe Kapitel 2.8) bei $30^{\circ} \mathrm{C}$ im Brutschrank inkubiert. Um die Embryonen/ Muskelfasern lichtmikroskopisch zu untersuchen, wurden sie in einer aufsteigenden Glyzerolreihe (15\%, $30 \%, 50 \%, 80 \%$, in 1x PBS für je $12 \mathrm{~h}$ bei $4^{\circ} \mathrm{C}$; siehe Kapitel 2.8) äquilibriert. Das Material kann so bei $4^{\circ} \mathrm{C}$ jahrelang gelagert werden. Die Embryonen wurden mit Hilfe eines Stereomikroskops, die Muskelfasern am inversen Mikroskop analysiert und mit einer Digitalkamera dokumentiert. 


\subsection{X-Gal-Färbung an Kryostatschnitten}

Die Gewebe (siehe Kapitel 2.19.4.2) oder Embryonen (siehe Kapitel 2.19.2) wurden nach der Präparation wie unter 2.16.3 beschrieben in Cryoblock Einbettmedium eingebettet und Kryostatschnitte am Kryostaten angefertigt. Die Schnitte wurden in $0,2 \%$ Glutaraldehyd/1x PBS (siehe Kapitel 2.8) für 10 min auf Eis inkubiert und 3x 10 min in LacZ-Puffer (siehe Kapitel 2.8) äquilibriert. Danach wurden die Schnitte über Nacht bis 2 Tage in LacZ-Färbepuffer (siehe Kapitel 2.8) bei $30^{\circ} \mathrm{C} \mathrm{im}$ Brutschrank inkubiert. Nachfolgend wurden die gefärbten Schnitte in ein DAPI (4'6-Diamino-2-phenylindiol) -enthaltenden Montagemedium mit Hilfe von Deckgläsern eingedeckt. Die Schnitte wurden mit Hilfe eines inversen Mikroskops mit Fluoreszenzfilter analysiert und mit einer Digitalkamera dokumentiert.

\subsubsection{Quantitativer Aktivitätsnachweis der Luziferase (Dualer-Luziferase- Assay) und statistische Auswertung}

Der quantitative Aktivitätsnachweis der Firefly ( $p G L-$ Vektoren) und der Renilla ( $p R L-$ Vektoren) Luziferase erfolgte mit dem Dual-Luciferase reporter assay system nach Herstellerangaben mit Hilfe des Luminometers MPL-3 und der dafür vorgesehenen Software (siehe Kapitel 2.2). Die statistische Auswertung (siehe Kapitel 2.1) der Versuchsreihen wurden mit Hilfe der Software Statistica durchgeführt. Die Graphiken wurden in Box-Whisker-Plots dargestellt. Die Signifikanz von Unterschieden und Gleichheit der einzelnen Gruppen wurde mit Hilfe eines t-Tests für unabhängige Gruppen (Mann-Whitney-U-Test) getestet. $P$ Werte von $P<0,05$ wurden als signifikant und $P$ Werte $P>0,05$ wurden als nicht-signifikant gewertet (siehe Kapitel 2.1).

\subsubsection{Paraffinschnitte von Geweben}

\subsubsection{Gewebeeinbettung zum Anfertigen von Paraffinschnitten}

$\mathrm{Zu}$ analysierende Organe und Gewebe wurden mindestens 2 Tage bei $4^{\circ} \mathrm{C}$ in Paraformaldehyd (siehe Kapitel 2.8) fixiert und ebenso wie perfundierte Tiere (siehe Kapitel 2.19.4.1) in Paraformaldehyd bei $4^{\circ} \mathrm{C}$ gelagert. Vor der Paraffineinbettung wurden die Gewebe und Organe mit Hilfe eines Gewebeeinbett- und - 
entwässerungsautomaten entwässert und anschließend maschinell in Paraffin eingegossen (Paraffinspender und Ausgießstation Tissue Block Dispenser PAG 12).

\subsubsection{Anfertigung von Paraffinschnitten}

Paraffinschnitte wurden am Schlittenmikrotom angefertigt, auf Superfrost Objektträger aufgezogen und über Nacht bei Raumtemperatur getrocknet. Für immunhistologische Antikörperfärbungen (siehe Kapitel 2.16.5) wurden die Paraffinschnitte entparaffiniert. Hierzu wurden die Schnitte für 20 min mit $100 \%$ Xylol inkubiert. Dann wurden sie 1x in einer 1:1 Alkohol/Xylolmischung, 2x in 99 \% Ethanol und jeweils 1x in 90 \% Ethanol, 70 \% Ethanol und 50 \% Ethanol geschwenkt, bevor sie dann kurz in destilliertem Wasser gespült wurden.

\subsubsection{Kryostatschnitte von Embryonen und Geweben}

\subsubsection{Fixierung und Äquilibrierung des Gewebematerials}

Die Fixierung von präparierten Geweben (siehe Kapitel 2.19.4.2), Embryonen (siehe Kapitel 2.19.2) und Muskelfasern (siehe Kapitel 2.17.2) erfolgte in Paraformaldehyd (siehe Kapitel 2.8) für bis zu 2 h auf Eis. Nach drei gründlichen Waschschritten in 1xPBS wurde das Material wie unter 2.16.3.2 beschrieben weiterbehandelt. Skelettmuskeln und Embryonen wurden vor der Einbettung in $25 \%$ Sukrose in 1x PBS (siehe Kapitel 2.8) auf Eis über Nacht äquilibriert. Embryonen wurden danach wie unter 2.16.3.2 beschrieben eingebettet. Skelettmuskeln wurden vor dem Einbetten in Cryoblock Einbettmedium für 30 sek in mit flüssigem Stickstoff gekühltem Isopentan eingefroren.

\subsubsection{Gewebeeinbettung zum Anfertigen von Kryostatschnitten}

Das vorbehandelte Material (siehe Kapitel 2.16.3.1) wurde in vorgekühltem Cryoblock Einbettmedium auf Trockeneis eingebettet. Die eingebetteten Gewebe/Embryonen können so bei $-80^{\circ} \mathrm{C}$ gelagert werden. 


\subsubsection{Anfertigung von Kryostatschnitten}

Es wurden Kryostatschnitte der eingebetteten Gewebe (siehe Kapitel 2.16.3.2) von 2 bis $20 \mu \mathrm{m}$ Dicke am Kryostat angefertigt, welche dann auf Superfrost Objektträger aufgezogen und für maximal $6 \mathrm{~h}$ bei Raumtemperatur getrocknet wurden. Für Antikörperfärbungen und für X-Gal-Färbungen wurden die Schnitte lediglich $2 \mathrm{~h}$ getrocknet und dann direkt gefärbt.

\subsubsection{Hämatoxylin/Eosin (HE)-Färbung und Eindecken von Kryostat- und Paraffinschnitten}

Die getrockneten Schnitte wurden 3 min in Hämatoxylin-Lösung (siehe Kapitel 2.8) inkubiert und in warmem Leitungswasser gebläut. Danach wurden die Schnitte 20 sek in Eosin-Lösung (siehe Kapitel 2.8) inkubiert und in MilliQ Wasser gewaschen. Die Dehydrierung der Schnitte erfolgte in einer aufsteigenden EthanolReihe $(70 \%, 96 \%, 99$ \% Ethanol). Die Präparate wurden dann kurz in Xylol geschwenkt. Abschließend wurde ein Tropfen Pertex Montagemedium auf den Objektträger pipettiert und ein Deckglas blasenfrei auf die Schnitte gelegt. Durch die Inkubation der Präparate bei $55^{\circ} \mathrm{C}$ für 15 min (Brutschrank) wurde das Montagemedium gehärtet. Die gefärbten Schnitte wurden mit Hilfe eines inversen Mikroskops analysiert und mit einer Digitalkamera dokumentiert.

\subsubsection{Immunhistologische Antikörperfärbungen an Paraffinschnitten}

Paraffinschnitte wurden wie unter 2.16 .2 beschrieben angefertigt und entparaffiniert. Die Demaskierung der Epitope erfolgte bei $700 \mathrm{~W}$ (1x 4 min und 4x 3 min in der Mikrowelle) in Citratpuffer (siehe Kapitel 2.8). Die Objektträger wurden in destilliertem Wasser auf Raumtemperatur abgekühlt, in 1x TBS/0,1 \% Triton X-100 (siehe Kapitel 2.8) gespült und unspezifische Bindungen mit $10 \%$ FCS/1x PBS blockiert ( $1 \mathrm{~h}$ bei Raumtemperatur). Die primäre Antikörperfärbung wurde über Nacht bei $4^{\circ} \mathrm{C}$ in einer feuchten Kammer durchgeführt. Nach dem Spülen der Schnitte in 1x TBS/ $0,1 \%$ Triton X-100, wurde die sekundäre Antikörperfärbung für $1 \mathrm{~h}$ bei Raumtemperatur (feuchte Kammer) durchgeführt. Dann wurden die Schnitte erneut in 1x TBS $/ 0,1 \%$ Triton X-100 gespült. Danach folgte die APAAP (alkalische 
Phosphatase anti-alkalische Phosphatase, siehe Kapitel 2.14.2) Färbung für $1 \mathrm{~h}$ bei Raumtemperatur. Nach erneutem Spülen in 1x TBS/0,1 \% Triton X-100 wurde die spezifische Antikörperfärbung durch Färbung mit Neu-Fuchsin Chromogen (siehe Kapitel 2.8) sichtbar gemacht. Die Reaktion wurde nach 20 min mit Leitungswasser gestoppt. Der APAAP-Komplex besteht aus jeweils zwei Molekülen alkalischer Phosphatase aus Kälberdarmmukosa, welche an monoklonale IgG1-Antikörper gebunden vorliegen. Die IgG1-Antikörper binden an den verwendeten sekundären Antikörper. Durch die Zugabe der Neu-Fuchsin-Chromogenlösung hydrolysiert die alkalische Phosphatase das Naphtholphosphat-Ester der Lösung und das so entstehende Naphthol bildet zusammen mit dem farblosen Diazoniumsalz NeuFuchsin einen unlöslichen roten Azofarbstoff.

Als Gegenfärbung wurden die Zellkerne mit saurem Hämalaun nach Mayer für 17 sek angefärbt (siehe Kapitel 2.8, 2.16.4). Die Schnitte wurden anschließend wie unter 2.16.4 beschrieben mit Immuno Mount eingedeckt. Die gefärbten Schnitte wurden mit Hilfe eines inversen Mikroskops analysiert und mit einer Digitalkamera dokumentiert. Die verwendeten Antikörper und Verdünnungen sind in Tabelle 16 und Tabelle 17 aufgelistet und wurden in $10 \%$ FCS/1x PBS verdünnt.

\subsubsection{Immunfluoreszenzanalysen}

\subsubsection{Durchflusszytometrische Analysen (FACS)}

Thymus und Milz wurden aus durch $\mathrm{CO}_{2}$-Narkose getöteten Mäusen isoliert (siehe Kapitel 2.19.4.2) und durch ein feinmaschiges Sieb gedrückt. Zur Isolierung des Knochenmarks wurden Oberschenkel- und Unterschenkelknochen aus Mäusen präpariert und das Mark mit Kanüle (Sterican $\varnothing 0,8$ x $120 \mathrm{~mm}$ ) und Spritze mit DMEM Medium ausgespült. Von Knochenmarks-, Thymus- und Milzsuspensionen wurden durch mehrmaliges Aufziehen durch die Kanüle Ein-Zellsuspensionenen hergestellt. Diese wurden abzentrifugiert (300 g; $\left.4^{\circ} \mathrm{C} ; 4 \mathrm{~min}\right)$, der Überstand verworfen und das Zellpellet in 1x PBS (siehe Kapitel 2.8) aufgenommen. Die Zellen wurden in der Zählkammer quantifiziert und $1 \times 10^{6}$ Zellen pro durchflusszytometrische Färbung eingesetzt. Die Färbungen erfolgten auf Eis in 1xPBS für jeweils $15 \mathrm{~min}$. Die Zellen wurden in 1x PBS gewaschen und abzentrifugiert (300g; $\left.4^{\circ} \mathrm{C}, 4 \mathrm{~min}\right)$. Gegebenenfalls erfolgte ein zweiter Färbeschritt. 
Die verwendeten primären Antikörper und Fluorochrom-gekoppelten Streptavidin Reagenzien sind in Tabelle 16 und Tabelle 18 aufgelistet.

Abschließend wurden die Zellen in 1x PBS gewaschen, abzentrifugiert ( $300 \mathrm{~g} ; 4^{\circ} \mathrm{C}$, $4 \mathrm{~min}$ ), das Zellpellet in $500 \mu \mathrm{l}$ 1x PBS resuspendiert und bis zur Messung auf Eis gelagert (max. $1 \mathrm{~h}$ ). Die Annexin V-Färbung von Thymozyten wurde mit dem Annexin V-PE apoptosis detection kit nach Herstellerangaben durchgeführt.

Die Isolierung und Anreicherung von Lineage-negativen (Lin') hämatopoetischen Stammzellen und Vorläuferzellen aus $1 \times 10^{7}$ Knochenmarkszellen erfolgte durch Depletion von Lineage-positiven Zellen mit Hilfe des EasySep mouse hematopoietic progenitor cell enrichment kit. Dieser Kit enthält einen Antikörper-Mischung von monoklonalen Antikörpern gegen die Mausantigene CD5, CD45R/B220, Mac-1, Gr-1, Ter119 und 7-4.

Alle durchflusszytometrischen Messungen wurden am BD LSR II flow cytometer durchgeführt. Die Software BD FacsDiva ${ }^{\text {TM }}$ diente zur Aufnahme der Daten, die dann mit der Software FlowJo software analysiert wurden.

\subsubsection{Immunfluoreszenzfärbungen an kultivierten Zellen, Muskelfasern und Kryostatschnitten}

Die Zellen, Muskelfasern (siehe Kapitel 2.17.2) und Kryostatschnitte (siehe Kapitel 2.16.3) wurden in Paraformaldehyd (siehe Kapitel 2.8) für 5 bis 15 min fixiert und $3 x$ $5 \mathrm{~min}$ in $100 \mathrm{mM}$ Glycin/1x PBS (siehe Kapitel 2.8) gewaschen. Die Permeabilisierung der Zellmembranen erfolgte für 4 min mit 0,1\% Triton X-100/ 1x PBS (siehe Kapitel 2.8). Nach drei Waschschritten (je 5 min in 1x PBS) wurden unspezifische Bindungen für $1 \mathrm{~h}$ mit $5 \%$ Pferdeserum (HS)/1\% Rinderserumalbumin (BSA)/1x PBS blockiert. Die Inkubation mit den primären Antikörpern erfolgte in $5 \% \mathrm{HS} / 1 \% \mathrm{BSA} / 1 \times$ PBS für mindestens $2 \mathrm{~h}$. Nach drei Waschschritten (je $10 \mathrm{~min}$ in 1x PBS) folgte die Inkubation mit dem sekundären Antikörper in $5 \% \mathrm{HS} / 1 \% \mathrm{BSA} /$ 1xPBS für $1 \mathrm{~h}$. Die Zellen, Muskelfasern und Kryostatschnitte wurden nach 3 weiteren Waschschritten (je $10 \mathrm{~min}$ in 1x PBS) mit $35 \mu \mathrm{l}$ DAPI-Montagemedium und Deckgläsern eingedeckt. 
Für Immunfluoreszenzfärbungen von eukaryotischen Zellen wurden diese auf Objektträger-Kulturschalen kultiviert und direkt auf den Objektträgern fixiert und gefärbt.

Die Färbungen von Kryostatschnitten erfolgten wie bei den Zellkulturen, jedoch wurden die Schnitte hierfür nicht fixiert.

Muskelfasern wurden direkt nach der Präparation in ein $2 \mathrm{ml}$ Reaktionsgefäß überführt und in diesem fixiert und angefärbt. Vor der DAPI-Färbung wurden die Muskelfasern vorsichtig auf einen gereinigten Objektträger überführt, auf diesem mit $35 \mu$ DAPI-Montagemedium versetzt und ein Deckglas aufgelegt.

Alle Schritte wurden bei Raumtemperatur und unter Schwenken (Wipp-TaumelTisch) durchgeführt. Die gefärbten Objekte wurden mit Hilfe eines inversen Mikroskops mit UV-Lampe und Fluoreszenzfilter analysiert und mit einer Digitalkamera dokumentiert. Die eingesetzten Verdünnungen der verwendeten primären und sekundären Antikörper sind in Tabelle 16 und Tabelle 17 aufgelistet.

\subsection{Zellbiologische Methoden}

\subsubsection{Zellkultur eukaryotischer Zellen}

Die Kultivierung eukaryotischer Zellen erfolgte in Zellkulturschalen im Begasungsbrutschrank in einer wasserdampfgesättigten Atmosphäre mit $16 \% \mathrm{O}_{2}$, $5 \% \mathrm{CO}_{2}$ und $79 \% \mathrm{~N}_{2}$ bei $37^{\circ} \mathrm{C}$. Die verwendeten Medien sind unter 2.9.3 aufgeführt. Für bestimmte Experimente und Zellen wurde mit unterschiedlichen Serumkonzentrationen bzw. unterschiedlichen Antibiotika gearbeitet. Diese Angaben sind unter 2.10.2 und bei der Beschreibung der Experimente angegeben.

Die verwendeten eukaryotischen Zelllinien sind unter 2.10.2 aufgeführt. Alle Zelllinien wurden von der Firma ATCC LGC Promochem, Wesel, bezogen und wie unter 2.17.1 beschrieben kultiviert. Die Zellen wurden maximal 20x passagiert.

Zur Kryokonservierung von Zelllinien wurde das Medium abgenommen, die Zellen mit 1x PBS (siehe Kapitel 2.8) gewaschen und mit $5 \mathrm{ml}$ Trypsin/EDTA von einer $10 \mathrm{~cm}$ Zellkulturschale abgelöst. Nach der Zugabe von $3 \mathrm{ml}$ Medium wurde durch vorsichtiges Auf- und Ab-Pipettieren eine Ein-Zellsuspension hergestellt. Diese wurde bei 300 x g abzentrifugiert und der Überstand vorsichtig abgenommen. Das 
Zellpellet wurde in $10 \mathrm{ml}$ Medium mit $10 \%$ DMSO aufgenommen. Die durch vorsichtiges Auf- und Ab-Pipettieren hergestellte Ein-Zellsuspension wurde zu je $1 \mathrm{ml}$ in Kryokonservierungsröhrchen aliquotiert. Das Einfrieren der Zelllinien erfolgte zunächst für 1 bis $2 \mathrm{~h}$ bei $-20^{\circ} \mathrm{C}$. Danach wurden die Zellen über Nacht bei $-80^{\circ} \mathrm{C}$ gelagert, bevor sie zur Dauerlagerung in flüssigem Stickstoff überführt wurden.

Zur Revitalisierung von Zelllinien wurde ein Zellaliquot aus dem Stickstofftank schnell bei $37^{\circ} \mathrm{C}$ aufgetaut und die Zellen in eine Zellkulturschale mit auf $37^{\circ} \mathrm{C}$ vorgewärmtem Medium überführt.

\subsubsection{Transfektion eukaryotischer Zellen}

\subsection{Transfektion eukaryotischer Zellen mit Expressionsplasmid-DNA}

Die Transfektion von Zelllinien mit Expressionsplasmid-DNA (siehe Kapitel 2.11.2; 2.11.3) erfolgte mit dem Transfektionsmedium RotiFect. Hierbei wurde nach den Angaben des Herstellers gearbeitet. Falls nicht anders angegeben, wurden pro Loch einer 6-Loch-Platte 1 bis $3 \mu$ Expressionsplasmid-DNA mit $3 \mu$ RotiFect transfiziert.

\subsection{Transfektion eukaryotischer Zellen mit siRNA}

Die Transfektion von siRNA wurde mit dem Kit TransMessenger transfection reagent durchgeführt. Dabei wurde nach Herstellerangaben gearbeitet. Pro Loch einer 6Loch-Platte wurden 1,6 $\mathrm{\mu g}$ siRNA eingesetzt. Das Verhältnis von eingesetzter Nukleinsäuremenge zu TransMessenger transfection reagent Volumen (in $\mu \mathrm{g} / \mu \mathrm{l}$ ) betrug dabei 1:5. Die verwendeten RNA-Oligonukleotide sind unter 2.12.2 aufgelistet.

\subsubsection{Stimulation des Shh/Ptch Signalweges durch Shh-N Protein}

Die Stimulation des Shh/Ptch Signalweges erfolgte in einigen Experimenten durch Zugabe von rekombinantem murinen Shh (Shh-N; R\&D Systems, EiesbadenNordenstadt) zum Medium. Das lyophilisierte Protein wurde in 0,1 \% BSA/1x PBS $(100 \mu \mathrm{g} / \mathrm{ml})$ gelöst und bei $-80^{\circ} \mathrm{C}$ bis zur Verwendung gelagert. Die Stimulation der Zellen erfolgte $4 \mathrm{~h}$ nach siRNA-Transfektion (2.17.1.1.2) durch Zugabe von $4 \mathrm{\mu g} / \mathrm{ml}$ Shh-N zum Medium (DMEM/0,5 \% FCS). Die Zellen wurden danach für weitere 24 bis zu 48 h kultiviert. 


\subsubsection{Isolierung und Kultivierung einzelner Muskelfasern}

Die Isolierung und Kultivierung von einzelnen Muskelfasern erfolgte nach einem abgewandelten Protokoll nach Rosenblatt et al. (Rosenblatt JD et al., 1995).

Die Muskelstränge des tibialis anterior, soleus und extensor digitorum longus des Unterschenkels einer Maus wurden präpariert. Um jegliche Spannung zu vermeiden, wurden die Muskeln nur an den Sehnen mit feinen Pinzetten erfasst. Die präparierten Muskelstränge wurden in $37^{\circ} \mathrm{C}$ warmem DMEM für maximal $1 \mathrm{~h}$ gelagert. Zum Vereinzeln der Muskelfasern wurden die Muskelstränge in einer Collagenase $\mathrm{H}$ Lösung (siehe Kapitel 2.8) für 1 bis $1,5 \mathrm{~h}$ bei $35^{\circ} \mathrm{C}$ im Schüttelwasserbad inkubiert. Danach wurde jeder Muskel in eine separate, mit HS gespülte Petrischale mit $37^{\circ} \mathrm{C}$ warmem DMEM überführt. Die Muskelfasern wurden mit Hilfe einer abgewinkelten Glas-Pasteurpipette (mit einer unter Feuer abgerundeten ca. $1 \mathrm{~mm}$ großen Öffnung) durch Auf- und Ab-Pipettieren aus dem Muskel gelöst. Überlebensfähige Fasern erscheinen lang und gerade. Diese Fasern wurden durch seriellen Transfer in 2 bis 3 mit HS gespülte Petrischalen in DMEM von den restlichen Fasern isoliert und konnten nun direkt fixiert oder in Kultur genommen werden. Die direkte Fixierung der Muskelfasern erfolgte in 2,0 ml Reaktionsgefäßen, in die die Fasern überführt und mit 4\% Paraformaldehyd (siehe Kapitel 2.8; Endkonzentration ca. $3 \%$ ) für 5 min bei Raumtemperatur überschichtet wurden. Nach dem Waschen (3x 10 min in 1x PBS) der Fasern (siehe Kapitel 2.8) wurden die Fasern für Antikörperfärbung (siehe Kapitel 2.16.6.1) oder X-Gal-Färbung (siehe Kapitel 2.16.1.5.1) verwendet.

\subsection{Zytologische und chemische Blut- und}

\section{Knochenmarksanalysen}

\subsubsection{Assay zur Bestimmung der kolonieformenden Aktivität von \\ Stamm- und Vorläuferzellen des Knochenmarks (Colony forming-unit Assay, CFU-Assay)}

Die kolonieformende Aktivität von Lin Knochenmarkszellen wurde mit einem auf Methylzellulose-basierenden Medium (MethoCult 3434) analysiert. Die Isolierung von Lin` Zellen aus Knochenmark ist unter 2.16.6.1 beschrieben. Nach Quantifizierung der angereicherten Lin $^{-}$Zellen (Zählkammer) wurden je Tier 2x $10^{3}$ Lin $^{-}$ Knochenmarkszellen in Triplikaten in $35 \mathrm{~mm}$ Zellkulturschalen ausgesät. Dabei 
wurde nach Herstellerangaben gearbeitet. Die Differenzierung und Zählung der Kolonien erfolgte 7 Tage nach dem Aussähen der Lin` Zellen an einem inversen Mikroskop.

\subsubsection{Vollblutanalysen}

\subsubsection{Differentialblutbild und Blutausstriche}

Das zu analysierende Blut wurde direkt in EDTA-Röhrchen überführt und gut gemischt. Die Blutproben wurden bis zur Analyse auf $4^{\circ} \mathrm{C}$ (bis zu $6 \mathrm{~h}$ ) gelagert.

Differentialblutbilder von EDTA-Vollblut aus Herzpunktionen (siehe Kapitel 2.19.3.2) wurden am AcT 5 hematology analyzer erstellt.

Blutausstriche wurden aus EDTA-Vollblut von Herzpunktionen (siehe Kapitel 2.19.3.2) und aus Blutabnahmen aus dem Augenhintergrund (siehe Kapitel 2.19.3.2) angefertigt. Die Zellen wurden mit Hemacolor angefärbt und ausgezählt.

\subsubsection{Retikulozyten-Färbung an Vollblut}

EDTA-Vollblut aus Blutabnahmen aus dem Augenhintergrund (siehe Kapitel 2.19.3.2) wurde zu gleichen Teilen mit 1 \% Brilliantkresylblau (siehe Kapitel 2.8) gemischt und Ausstriche angefertigt. Pro Ausstrich wurde die Anzahl der Retikulozyten je 1000 gezählter Zellen bestimmt.

\subsubsection{Biochemische Analysen von Serumproben}

EDTA-Vollblut aus Herzpunktionen wurde abzentrifugiert (800 g; $4{ }^{\circ} \mathrm{C} ; 10 \mathrm{~min}$ ) und das Serum in ein steriles $1,5 \mathrm{ml}$ Reaktionsgefäß überführt. Die Proben wurden bis zur Analyse bei $-80^{\circ} \mathrm{C}$ gelagert. Die biochemische Analyse der Serumproben (Glukose, Cholesterin, Triglyceride, Glutamat-Pyruvat-Transaminase, GesamtBilirubin, Harnstoff, Gesamtprotein) erfolgte mit enzymatischen in vitro Assays am MODULAR P. 


\subsubsection{Zytospin-Präparation von Knochenmarkszellen}

Knochenmarkszellen wurden wie unter 2.16.6.1 beschrieben isoliert. $2 \times 10^{5}$ Zellen jeder Probe wurden auf Objektträger zentrifugiert (Cytospin 2). Die Zellen wurden mit einer panoptischen Färbung nach Pappenheim angefärbt. 500 Zellen wurde ausgezählt und die Anzahl der erythropoetischen Vorläuferzellen bestimmt.

\subsection{Tierexperimentelle Methoden}

\subsubsection{Zucht und Haltung von Mus musculus}

Die verwendeten Mausstämme (siehe Kapitel 2.10.3) wurden im institutseigenen Tierstall (Gentechnischer Arbeitsbereich S1; Institut für Humangenetik, Universität Göttingen) gezüchtet. Die Tierhaltung erfolgte in Makrolonkäfigen Typ II und III, bei einem zwölfstündigen Hell-Dunkel-Rhythmus (Hell-Periode: 6.00-18.00 Uhr), einer Temperatur von $20 \pm 2^{\circ} \mathrm{C}$ und einer relativer Luftfeuchtigkeit von $50 \pm 10 \%$. Pelletierte Zuchtdiät (Alleinfutter für Mäuse-Zucht, Ssniff Spezialdiäten $\mathrm{GmbH}$, Soest) und Wasser (Leitungswasser) standen den Tieren ständig zur Verfügung.

\subsubsection{Schwanzbiopsie und Ohrlochmarkierung}

Schwanzbiopsien (ca. $0,5 \mathrm{~cm}$ der Schwanzspitze) und gleichzeitige Ohrlochmarkierungen (Nummerierung der Mäuse) von 4 Wochen alten Mäusen wurden vom Tierstallpersonal im institutseigenen Tierstall vorgenommen.

\subsubsection{Genotypisierung von Mäusen}

Die Genotypisierungen von Mäusen erfolgte durch PCR (siehe Kapitel 2.15.4.1) an genomischer DNA aus Schwanzbiopsien (siehe Kapitel 2.15.1.4.2). Die für die unterschiedlichen Mauslinien verwendeten spezifischen DNA-Oligonukleotide und PCR-Konditionen sind unter 2.12.1.1 aufgeführt. Einige Genotypisierungen wurde mit Southern Blot Analyse (siehe Kapitel 2.15.6) verifiziert. 


\subsubsection{Herstellung von transgenen Mauslinien}

Die Injektion von linearisierter Expressionsplasmid-DNA (siehe Kapitel 2.15.3.5) in Oozyten und die Herstellung transgener Mäuse wurde vom Max-Planck-Institut für experimentelle Medizin, Göttingen, durchgeführt. Transgene „Founder“ Tiere wurden in das Institut für Humangenetik, Universität Göttingen, überführt, wo sie zum Zuchtaufbau eingesetzt wurden.

\subsubsection{Bestimmung des Kopulationszeitpunktes und der Trächtigkeit sowie Isolierung von Mausembryonen}

Um Embryonen eines bestimmten Alters zu isolieren, wurden jeden Morgen Weibchen aus Verpaarungen auf eine erfolgte Kopulation untersucht. Das Koagulat des Ejakulats bildet bis $\mathrm{zu} 24 \mathrm{~h}$ nach erfolgter Ejakulation eine sichtbare Vaginalplaque. Der Zeitpunkt der Vaginalplaquesichtung wurde als Tag 0,5 nach erfolgter Kopulation definiert (days post coitum; dpc). Die tatsächliche Trächtigkeit der vaginalplaque-positiven Weibchen wurde visuell erst nach 9,5 bis 10,5 Tagen bestätigt. Für die Isolierung früherer Embryonalstadien wurden vaginalplaquepositive Weibchen präpariert und die Embryonen isoliert. Die Isolierung von Mausembryonen erfolgte zu definierten Stadien der Embryonalentwicklung. Der Zeitpunkt der Isolierung wurde, wie oben beschrieben, bestimmt. Die tragenden Weibchen wurden schmerzfrei getötet $\left(\mathrm{CO}_{2}\right.$-Narkose, zervikale Dislokation) und der Uterus mit den Embryonen isoliert. Die Embryonen wurden in 1x PBS (siehe Kapitel 2.8) auf Eis aus dem Uterusgewebe präpariert. Zur Genotypisierung der Embryonen wurde der jeweilige Dottersack aufbewahrt (siehe Kapitel 2.15.1.4.2). Für die Isolierung von embryonaler Gesamt-RNA wurden die Embryonen direkt in TRIZOL Reagent aufgenommen und wie unter 2.15.1.5.2 beschrieben weiterbehandelt. Zur Fixierung der Embryonen wurden die Hirnhöhlen mit einer sterilen Kanüle (B. Braun Medical AG, Emmenbrücke) geöffnet und somit für das Fixativ zugänglich gemacht. Die Embryonen wurden in 1x PBS gewaschen und für mindestens $2 \mathrm{~h}$ in Paraformaldehyd (siehe Kapitel 2.8) auf Eis fixiert. Um die Embryonen ohne weitere Behandlung lichtmikroskopisch untersuchen zu können, wurden sie in einer aufsteigenden Glyzerolreihe (15\%, $30 \%, 50 \%, 80 \%$, in $1 \mathrm{x}$ PBS je $12 \mathrm{~h}$ bei $4^{\circ} \mathrm{C}$ ) äquilibriert. 


\subsubsection{Injektionen und Blutabnahmen}

\subsubsection{Intraperitoneale und intramuskuläre Injektion von Tamoxifen}

Zur Induktion der Cre-Rekombinase der Mauslinien ROSA26CreERT2 und $\mathrm{Tg}$ (Pax7CreTM) wurde eine $100 \mathrm{mg} / \mathrm{ml}$ Tamoxifen (Sigma-Aldrich, Chemie $\mathrm{GmbH}$, Steinheim) Lösung in $96 \%$ Ethanol hergestellt und diese in sterilem Sonnenblumenöl (Sigma-Aldrich Chemie $\mathrm{GmbH}$, Steinheim) 1:10 verdünnt $(10 \mathrm{mg} / \mathrm{ml})$. Die Emulsion wurde bis zur Verwendung bei $-20^{\circ} \mathrm{C}$ gelagert.

Zur Induktion der MerCreMer-Rekombinase wurde eine $250 \mathrm{mg} / \mathrm{ml}$ 4-HydroxyTamoxifen (4-OHT) Lösung in 96\% Ethanol hergestellt und diese in sterilem Sonnenblumenöl 1:25 verdünnt $(10 \mathrm{mg} / \mathrm{ml})$. Eine Emulgierung der Verdünnung wurde durch 5 min Ultraschallbehandlung erreicht. Die Emulsion wurde bei $-20^{\circ} \mathrm{C}$ gelagert.

Die Mäuse wurden im Genick fixiert und $100 \mu \mathrm{l}$ der Tamoxifenemulsion $(10 \mathrm{mg} / \mathrm{ml})$ intraperitoneal injiziert (tägliche Dosis $1 \mathrm{mg}$ Tamoxifen). Intramuskulär (musculus soleus) wurden die fixierten Tiere einmalig mit $10 \mu \mathrm{l} \mathrm{der} 10 \mathrm{mg} / \mathrm{ml}$ konzentrierten Tamoxifenemulsion injiziert (einmalige Dosis $100 \mu \mathrm{g}$ ). Es wurden sterile Spritzen und Kanülen (Sterican $\varnothing 0,45 \times 12 \mathrm{~mm}$ ) verwendet. Kontrolltieren wurden jeweils $100 \mu \mathrm{l}$ bzw. $10 \mu \mathrm{l}$ der Emulsion ohne Tamoxifen gespritzt.

\subsubsection{Blutabnahme aus dem retroorbitalen Venenplexus und durch Herzpunktion}

Die Blutabnahme aus dem Augenhintergrund (retroorbitaler Venenplexus) erfolgte mit angebrochenen Mikro-Hämatokrit-Kapillaren. Herzpunktionen wurden an narkotisierten Mäusen (siehe Kapitel 2.19.4.1) nach vorheriger Öffnung des Brustraumes durchgeführt. Das zu analysierende Blut wurde direkt in EDTARöhrchen überführt und gut gemischt. Die Blutproben wurden bis zur Analyse auf $4^{\circ} \mathrm{C}$ (bis zu $6 \mathrm{~h}$ ) gelagert.

\subsubsection{Sichtung und Präparation von Tumoren}

Mäuse mit erhöhter Tumorprädisposition wurden engmaschig beobachtet. 2 bis $3 \mathrm{Mal}$ pro Woche wurden sie auf typische Symptome eines Medulloblastoms (MB) hin 
untersucht (Ataxie, Abmagerung, Gangunsicherheit, Zittern). Bauchraum, Abdomen, Rücken sowie Extremitäten wurden abgetastet, um die Entwicklung von Weichteiltumoren zu diagnostizieren.

Tiere mit schwerer Ataxie wurden sofort schmerzfrei getötet $\left(\mathrm{CO}_{2}\right.$-Narkose). Das Kleinhirn wurde zu weiteren Analyse präpariert (siehe Kapitel 2.19.4.2). Bei Auftreten eines Weichteiltumors wurde das Datum vermerkt und die weitere Tumorprogression engmaschig beobachtet. Bei einer geschätzten Tumorgröße von ca. $1 \mathrm{~cm}$ Durchmesser wurde die Maus schmerzfrei getötet $\left(\mathrm{CO}_{2}\right.$-Narkose, zervikale Dislokation) und Tumor sowie Referenzgewebe aus dem Tier isoliert (siehe Kapitel 2.19.4.2).

\subsubsection{Perfusion von Mäusen mit Paraformaldehyd}

Mäuse wurden mit einer letalen Dosis $1 \mathrm{mg}$ Rompun und 1,6 \% Ketanest $\mathrm{S}$ (Ketanest $\mathrm{S}, 25 \mathrm{mg} / \mathrm{ml}$ ) (Rompun $2 \%$ ) betäubt. Der Brustraum der Tiere wurde geöffnet und das Herz freigelegt. Das rechte Atrium wurde zur Eröffnung des Blutkreislaufs punktiert und gegebenenfalls das Blut für weitere Analysen verwendet. Der linke Ventrikel wurde punktiert, die Blutgefäße 10 min mit Ringer-Lactat und nachfolgend 10 min mit Paraformaldehyd (siehe Kapitel 2.8) gespült. Die fixierte Maus wurde bis zur Analyse in Paraformaldehyd bei $4^{\circ} \mathrm{C}$ gelagert.

\subsubsection{Präparation von Tumoren und Geweben}

$\mathrm{Zu}$ präparierende Mäuse wurden schmerzfrei durch $\mathrm{CO}_{2}$-Narkose oder zervikale Dislokation getötet. Das Tier wurde auf dem Präparationstisch fixiert und die Bauchhaut mit $70 \%$ Ethanol desinfiziert und entfernt. Das Abdomen wurde entlang der Mittellinie geöffnet. Dann wurde vorsichtig die Bauchaorta durchtrennt, um die Maus auszubluten. Die jeweiligen Organe wurden dem Bauchraum entnommen und je nach Verwendungszweck weiterbehandelt. Zur Isolierung von RMS wurde zuerst die Haut über und um den Tumor entfernt und der Tumor sauber aus dem umliegenden Gewebe isoliert. Referenzgewebe (Skelettmuskel) wurde aus einem möglichst weit entfernt vom Tumor liegenden Skelettmuskel isoliert. Zur Präparation des Kleinhirns bzw. MB erfolgte die Tötung der Mäuse ausschließlich durch $\mathrm{CO}_{2}$ Narkose. Die Kopfhaut wurde mit 70 \% Ethanol desinfiziert und abpräpariert. Die 
Freilegung des Hirns erfolgte durch die Entfernung der Schädelkalotte ausgehend vom Foramen magnum. Das Kleinhirn wurde mit einem sterilen Spatel isoliert.

RMS, Referenzgewebe und Kleinhirn wurden auf Trockeneis eingefroren und bei $-80^{\circ} \mathrm{C}$ bis zur histologischen Abklärung gelagert (siehe Kapitel 2.16.3). Diese erfolgte durch einen erfahrenen Pathologen (Dr. W. Schulz-Schaeffer) anhand von HEgefärbten Gewebeschnitten (siehe Kapitel 2.16.2, 2.16.3, 2.16.4). Danach wurden die Gewebe weiteren Analysen zugeführt. 


\section{Ergebnisse}

\subsection{Entstehung von RMS in konventionellen Ptch $^{\text {neo67/+ }}$ knock-out Mäusen}

\subsubsection{Verminderte Expression von wt Ptch Transkripten und Überexpression mutanter $P_{t c h}^{d 67}$ Transkripte in RMS von Ptch ${ }^{\text {neo67/+ }}$ Mäusen}

Heterozygote Ptch ${ }^{\text {neo67/+ }}$ Mäuse (siehe Abbildung 2) entwickeln abhängig vom genetischen Hintergrund mit unterschiedlicher Inzidenz RMS (Hahn $\mathrm{H}$ et al., 2004). Über die Entstehung von Ptch-assoziierten RMS ist bisher jedoch nicht viel bekannt.

Wie bereits in der Einleitung beschrieben, konnte gezeigt werden, dass RMS aus $P t c h^{n e 067 / 4}$ Tieren keine zusätzlichen inaktivierenden Mutationen im verbleibenden wt Ptch Allel aufweisen, welche zu einer biallelischen Ptch Inaktivierung führen würden (Calzada-Wack J et al., 2002). Dies lässt vermuten, dass die Entstehung von RMS in diesem Mausmodell durch einen anderen Mechanismus ausgelöst wird.

In unserer Arbeitsgruppe konnte gezeigt werden, dass RMS und MB von Ptch ${ }^{\text {ne067/+ }}$ Mäusen Ptch Transkripte überexprimieren (Hahn H et al., 1998). Die Überexpression von Ptch kommt hierbei nicht durch wt Ptch Transkripte, sondern durch die Überexpression von mutanten Transkripten (im Folgenden als Ptch ${ }^{d 67}$ Transkripte bezeichnet) zustande (Calzada-Wack J et al., 2002; Uhmann A et al., 2005). Dies konnte sowohl durch Northern Blot Experimente (Calzada-Wack J et al., 2002) als auch durch Transkript-spezifische TaqMan-Analysen (Uhmann A et al., 2005) (Vorarbeiten von U. Ferch, Universität Göttingen, Institut für Humangenetik, Diplomandin) demonstriert werden.

Zum besseren Verständnis der nun folgenden Ergebnisse sind die quantitativen real time PCR-Analysen, die von Uta Ferch durchgeführt wurden, in Abbildung 5 dargestellt. 

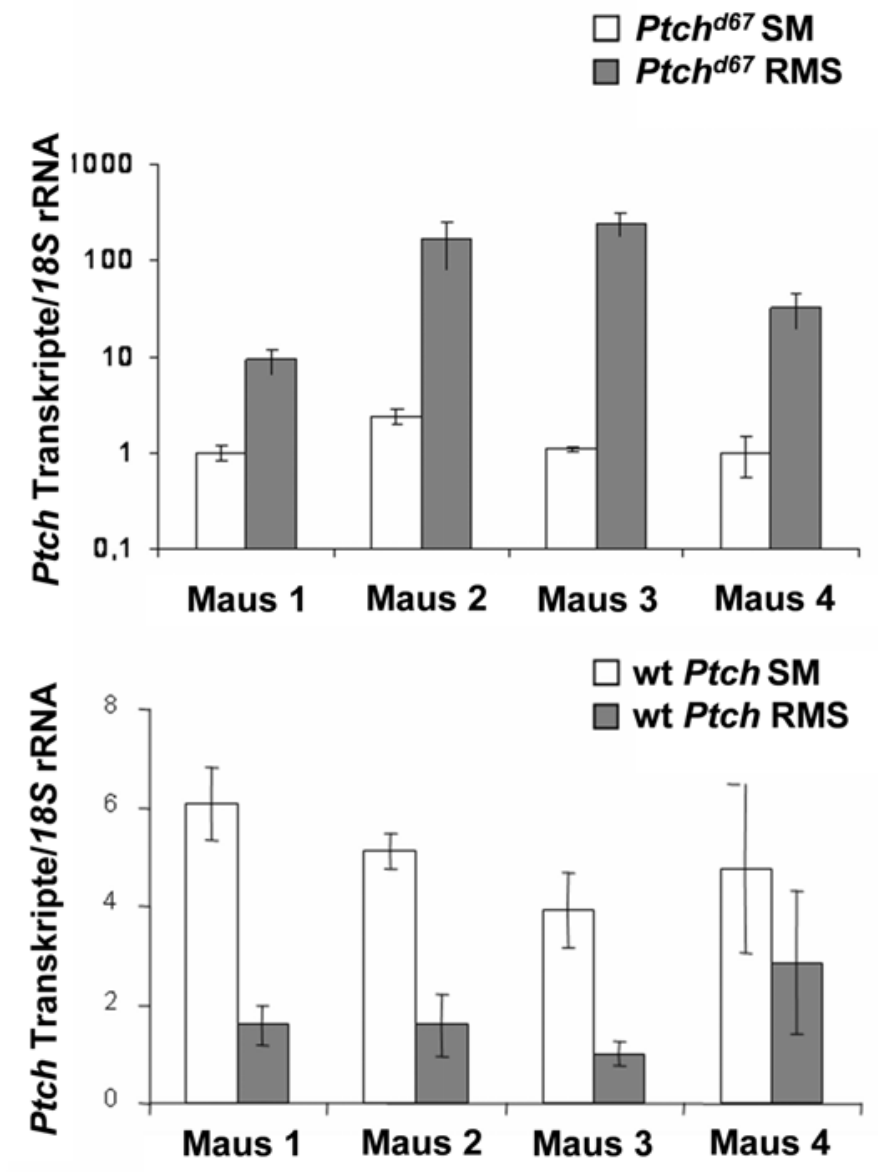

Abbildung 5: Mutante $\operatorname{Ptch}^{\text {d67 }}$ Transkripte werden im RMS von Ptch ${ }^{\text {neo67/+ }}$ Mäusen überexprimiert. Dargestellt sind Auswertungen von quantitativen real time PCR-Analysen von RMSund Skelettmuskel-cDNA aus $4 \mathrm{Ptch}^{\text {neo67/+ }}$ Mäusen. Der Nachweis der unterschiedlichen Ptch Transkripte erfolgte mit Transkript-spezifischen Sonden (siehe Text). Jede Probe wurde in Triplikaten vermessen und die Werte auf die Expression von 18S rRNA normalisiert (Uhmann A et al., 2005).

Bei der Transkription des mutanten Ptch $^{d 67}$ Allels von $P t c h^{\text {neo67/+ }}$ Mäusen wird Exon 5 ohne Leserasterverschiebung in das Exon 8 gespleisst (Abbildung 10) (CalzadaWack J et al., 2002; Uhmann A et al., 2005). Dadurch ist die Unterscheidung der wt und der mutanten Ptch Transkripte möglich. In Transkript-spezifischen quantitativen real time PCR-Analysen wurden zwei unterschiedliche Sonden verwendet. Der Nachweis von wt Transkripten erfolgte mit einer Sonde, welche spezifisch an die Übergangssequenz von Exon 5 und 6 bindet. Die Sonde zum Nachweis der mutanten Ptch $^{d 67}$ Transkripte bindet dagegen an die Übergangsequenz von Exon 5 und 8.

In Organen von heterozygoten Ptch $^{\text {neo67/+ }}$ Mäusen werden beide Allele gleich stark exprimiert. Im RMS ist dagegen ein deutliches Ungleichgewicht der Expression 
beider Transkripte zu beobachten. Während die Transkripte des mutanten Ptch ${ }^{d 67}$ Allels deutlich überrepräsentiert sind, ist die Expression des wt Ptch Allels in RMS verglichen mit den meisten normalen Geweben deutlich verringert (Abbildung 5) (Uhmann A et al., 2005).

\subsubsection{Verminderung der Expression von wt Ptch führt zur Aktivierung der Shh/Ptch Signalkaskade}

Wie bereits ausführlich in der Einleitung beschrieben wurde, führt die Fehlregulation der Shh/Ptch Signalkaskade zur Expression von Zielgenen der Kaskade. Hierzu gehören Gli1, lgf2 und Ptch. In den von uns untersuchten RMS werden diese Gene verstärkt exprimiert (Dahmane $\mathrm{N}$ et al., 1997; Hahn H et al., 2000; Kappler R et al., 2003). Da eine monoallelische Ptch Mutation für eine solche Fehlregulation nicht ausreichend ist (sonst wären alle Individuen mit heterozygoten Ptch Mutationen nicht lebensfähig), wurde zunächst überprüft, ob die Signalkaskade auch durch eine einfache Verminderung von wt Ptch Transkripten/Proteinen aktiviert werden kann.

Um eine durch Ptch Inaktivierung induzierte Signalwegaktivierung zu analysieren, wurden RNA Interferenz (RNAi) Experimente durchgeführt.

In einem Vorversuch wurde die Spezifität der verwendeten siRNA-Oligonukleotide (siRNA, short interference RNA) überprüft (Elbashir SM et al., 2002). Hierzu wurden $\mathrm{NIH} / 3 \mathrm{~T} 3$ Zellen mit dem Expressionsplasmid pCR3.1 mPtch(K)wt und Ptchspezifischer siRNA co-transfiziert (mPtch_Exon22 si oder mPtch_Exon2 si, Tabelle 14). 24,48 und $72 \mathrm{~h}$ nach der Transfektion wurde die Ptch Expression quantifiziert (siehe unten). Als Kontrolle wurde unspezifische siRNA mit dem Expressionsplasmid co-transfiziert.

Im Vergleich zur Transfektion von unspezifischer siRNA wurde $24 \mathrm{~h}$ nach der Transfektion von Ptch-spezifischer siRNA (mPtch_Exon22 si oder mPtch_Exon2 si, Tabelle 14) eine naherzu 80 \%ige Reduktion der Ptch Transkripte induziert. $48 \mathrm{~h}$ nach erfolgter Transfektion verringerte sich die Ptch mRNA Degradation und $72 \mathrm{~h}$ nach der Transfektion konnte kein Unterschied mehr zur Kontrolle (transfiziert mit unspezifischer siRNA) festgestellt werden (Abbildung 6). 


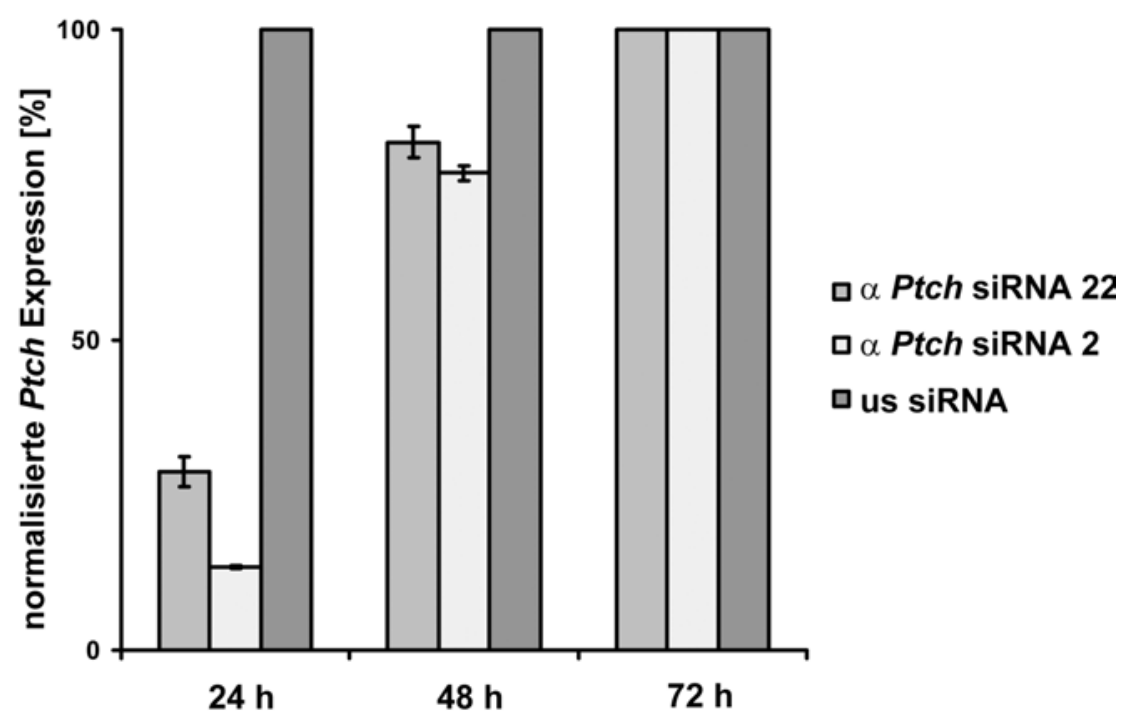

Abbildung 6: siRNA-vermittelte Degradation von Ptch Transkripten. NIH/3T3 Zellen wurden mit dem Expressionsvektor pCR3.1 mPtch(K)wt und siRNA co-transfiziert. Es wurden zwei Ptchspezifische siRNA verwendet. Das RNA-Oligonukleotid mPtch_Exon22 si ( $\alpha$ Ptch siRNA 22) bindet an die Sequenz des Exone 22; mPtch_Exon2 si ( $\alpha$ Ptch siRNA 22) bindet an die Sequenz von Exon 2 des Ptch Transkriptes (Tabelle 14). Als Kontrolle wurde unspezifische siRNA (us siRNA) transfiziert. 24, 48 und 72 h nach der Transfektion wurden die Ptch Transkripte anhand eines Ptch-spezifischen quantitativen real time Assay gemessen und auf die Expression von 18S rRNA normalisiert. Die siRNA-vermittelte verminderte Ptch Expression wurde prozentual im Verhältnis zur Ptch Expression von mit unspezifischer siRNA transfizierten Kontrolle dargestellt. Die Daten entsprechen den Mittelwerten aus 3 unabhängigen in Tripletten vermessenen Experimenten.

Nach diesem Vorexperiment wurde die Aktivität der Signalkaskade mittels der Zelllinie Shh light 2 (Taipale $\mathrm{J}$ et al., 2000b) analysiert. Diese Zellen exprimieren konstitutiv die Renilla Luziferase (zur Normalisierung der Daten) sowie das Expressionsplasmid $p G L 9 x G / i-B S$, welches das Firefly Luziferasegen unter einem mit 9 Gli1 Bindungsstellen versehenen Tymidinkinase Promotor exprimiert. Eine Stimulation der Shh/Ptch Signalkaskade, welche eine Aktivierung von Gli1 umfasst, führt in diesen Zelllinien somit zu einer erhöhten Firefly Luziferase-Aktivität.

Shh light 2 Zellen wurden sowohl mit Ptch-spezifischer siRNA oder unspezifischer siRNA zur Messung der endogenen Gli1 Aktivität transfiziert. Als Positivkontrolle für die Aktivierung des Signalweges wurden die Zellen mit einem ShhExpressionsplasmid ( $p C M V$ mShh- $N$ ) (Kogerman $P$ et al., 2002) zusammen mit unspezifischer siRNA co-transfiziert. In einigen Experimenten wurden die 
Positivkontrollen auch mit rekombinantem murinen Shh-N Protein stimuliert (siehe Kapitel 2.17.1.2).

Dann wurde die zeitabhängige Degradierung der Ptch mRNA (24, 48, 60 und $72 \mathrm{~h}$ nach erfolgter Transfektion) sowie das Expressionsniveau von Gli1 Transkripten mittels quantitativer real time PCR analysiert und auf die Expression der 18S rRNA normalisiert. Um die Aktivierung der Shh/Ptch Signalkaskade auf Proteinebene zu analysieren, wurde die Aktivität des Signalweges über Luziferase-Messung an den Zellysaten mit dem Dualen-Luziferase-Assay bestimmt. Für beide Assays wurden jeweils 3 unabhängige Experimente durchgeführt, wobei jede Probe in Dubletten vermessen wurde.

Obwohl die Degradation von Ptch nach $24 \mathrm{~h}$ am stärksten war (siehe Abbildung 6), wurde anhand von Vorexperimenten festgestellt, dass die Gli1-Expression zu diesem Zeitpunkt nicht stimuliert wurde (Daten nicht gezeigt). Erst 48 bis $60 \mathrm{~h}$ nach Transfektion führte die siRNA-vermittelte Degradation der Ptch mRNA zur Induktion der Gli1 Expression (Abbildung 7). Die Induktion war jedoch wesentlich geringer als diejenige, die durch Shh Expression stimuliert werden konnte. Abbildung 8 zeigt nochmals eine statistische Analyse und eine Darstellung der ermittelten Werte im Box-Whisker-Plot. $48 \mathrm{~h}$ nach der Transfektion mit Ptch-spezifischer siRNA konnte durch Ptch "knock-down“ eine signifikante Stimulierung der Gli1 Transkription $(P<0,05)$ erzielt werden. 60 bis $72 \mathrm{~h}$ nach der siRNA Transfektion nahm diese wieder ab. Das Expressionniveau von Gli1 blieb jedoch im Vergleich zur Transfektion mit unspezifischer siRNA auch noch nach $72 \mathrm{~h}$ erhöht.

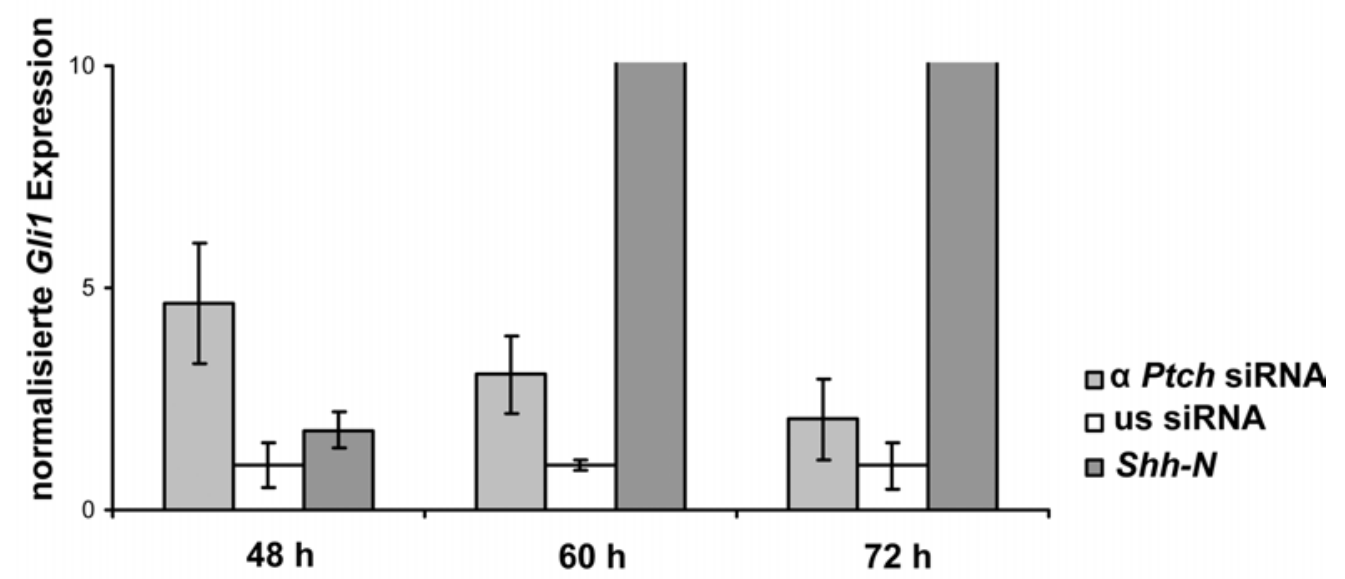

Abbildung 7: siRNA-vermittelte Degradation von Ptch mRNA führt zu einer erhöhten Gli1 Expression. Die Zellinie Shh light 2 wurde mit Ptch-spezifischer siRNA (a Ptch siRNA), unspezifischer siRNA (us siRNA) oder pCMV mShh-N (Shh-N) transfiziert. 48, 60 bzw. $72 \mathrm{~h}$ nach der 
Transfektion wurde cDNA aus Gesamt-RNA hergestellt. Die Gli1 Expression wurde im quantitativen real time PCR-Assay bestimmt, auf die Expression der 18S rRNA normalisiert und die Mittelwerte der Daten aus 3 unabhängigen in Dupletten vermessenen Experimenten berechnet.

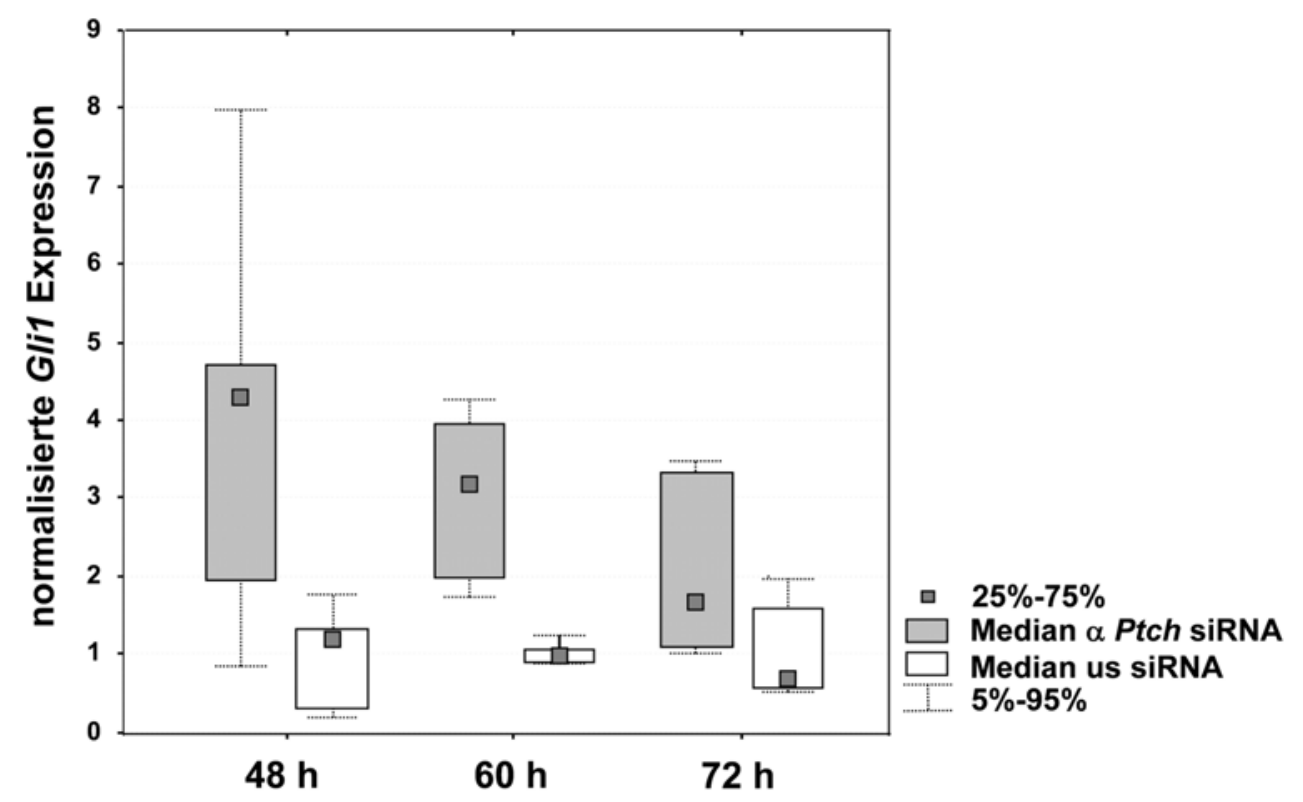

Abbildung 8: Signifikant erhöhte Gli1 Expression durch siRNA-vermittelte Degradation von Ptch Transkripten. Die Daten aus 3 unabhängigen Transfektionen von Shh light 2 mit Ptchspezifischer siRNA ( $\alpha$ Ptch siRNA) oder unspezifischer siRNA (us siRNA) wurden im Box-WhiskerPlot dargestellt. Signifikante Unterschiede wurden über den Mann-Whitney-U-Test berechnet und nach 48 und 60 h detektiert $(P<0,05)$.

Anhand von Dualen-Luziferase-Messungen wurde nun die Aktivität des Signalweges analysiert. Dabei wurde deutlich, dass die siRNA-vermittelte Degradation der Ptch mRNA im Vergleich zur Stimulation mit Shh-N Protein nur zu einer geringen aber signifikaten Aktivierung führte (Abbildung 9). 


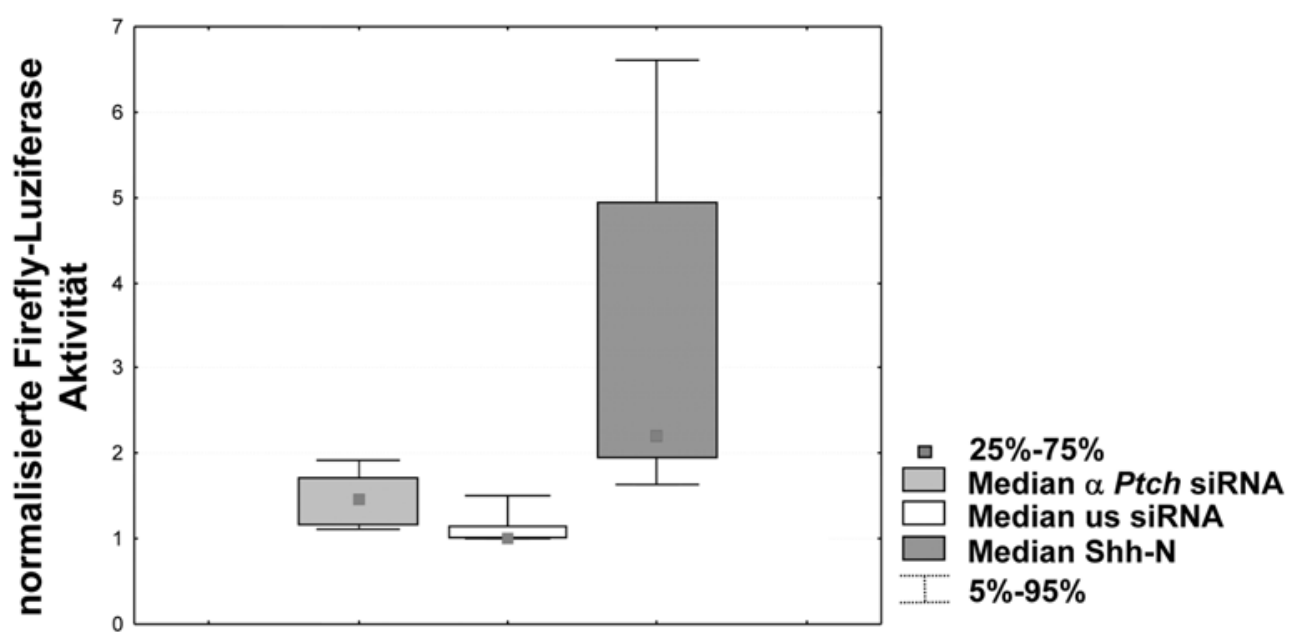

$48 \mathrm{~h}$

Abbildung 9: Signifikant erhöhte Aktivität des Shh/Ptch Signalweges durch siRNA-vermittelte Degradation von Ptch Transkripten. Die Daten aus 3 unabhängigen Transfektionen von Shh light 2 mit Ptch-spezifischer siRNA ( $\alpha$ Ptch siRNA) oder unspezifischer siRNA (us siRNA) wurden im BoxWhisker-Plot dargestellt. Signifikante Unterschiede wurden über den Mann-Whitney-U-Test berechnet und nach $48 \mathrm{~h}$ detektiert $(\mathrm{P}<0,05)$. Als Positivkontrolle wurden die Zellen mit unspezifischer siRNA transfiziert und mit Shh-N Protein (Shh-N) behandelt (Zugabe erfolgte $4 \mathrm{~h}$ nach der Transfektion). Zellen, welche nicht mit Shh-N stimuliert werden sollten, wurden mit Lösungsmittel $(0,1 \%$ BSA $)$ behandelt.

Zusammengefasst zeigen diese Ergebnisse, dass transient transfizierte Ptchspezifische siRNA zu einer Degradation von Ptch Transkripten führt. Daraus resultiert eine Aktivierung der Gli1 Transkription, die frühestens $48 \mathrm{~h}$ nach erfolgter Transfektion deutlich wird. Die vermehrte Gli1 Transkription führt außerdem nach $48 \mathrm{~h}$ zu einer Aktivierung von Gli1 Protein, und damit zur Aktivierung der Signalkaskade.

\subsubsection{Molekulare und funktionelle Analysen zur Expression des mutanten Ptch ${ }^{\text {neo67 }}$ Allels in Ptch-assozierten RMS}

Die bisherigen, oben beschriebenen Daten weisen darauf hin, dass die verminderte Expression des wt Allels der Auslöser für die RMS Entstehung sein könnte. Da jedoch das mutante $\operatorname{Ptch}^{d 67}$ Allel im RMS sehr stark überexprimiert ist und das entsprechende Protein möglicherweise einen dominant-negativen Einfluss auf das wt Ptch Protein ausüben könnte, wurde die Funktion des $\operatorname{Ptch}^{d 67}$ Proteins untersucht. 
Hier ist anzumerken, dass eine für das Gorlin-Goltz-Syndrom verantwortliche PTCH Mutation (G509V) in $D$. melanogaster aufgrund eines dominant-negativem Mechanismus zur Aktivierung von Smo führt (Hime GR et al., 2004).

Daneben gibt es noch eine weitere Möglichkeit, wie man sich die Tumorentstehung erklären könnte. So wurde von Kogerman et al. postuliert, dass die alternativen ersten Exone des wt PTCH Gens (Exon1, Exon 1a, Exon1b) in normalen Geweben unterschiedlich stark exprimiert werden. PTCH Transkripte, welche das alternative Exon 1b exprimieren, sind dabei in humanen nodulären Basaliomen sehr stark überrepräsentiert. Obwohl in vitro alle 3 beschriebenen Transkripte zur Interaktion mit SMO befähigt sind, wurde gezeigt, dass nur Exon 1b zur vollständigen Inaktivierung des Shh/Ptch Signalweges in der Lage ist. Daraus wurde geschlossen, dass in PTCH-assoziierten Tumoren der PTCH 1b Promotor stark aktiviert wird, was zur Überexpression von $\mathrm{PTCH}$ 1b-haltigen Transkripten in den Basaliomen führt. Da diese Transkripte/Proteine jedoch in Basaliomen mutiert sein müssen (biallelischer Ausfall von PTCH in den meisten Basaliomen), können sie den Signalweg nicht mehr hemmen. Hierdurch kommt es dann zu einer „Runaway“ Aktivierung der Kaskade (Kogerman P et al., 2002).

Aufgrund dieser Tatsachen und Hypothesen wurde die Zusammensetzung und die Expression der Ptch Transkripte und Proteine in RMS von Ptch ${ }^{\text {neo67/+ }}$ Mäusen untersucht. Zusätzlich wurde die Funktion der hauptsächlich exprimierten Ptch Proteine bestimmt.

\subsubsection{Exon 1a, 1b und 1c Ptch Spleissvarianten sind in murinen RMS überexprimiert}

Humane PTCH Transkripte können neben den alternativen ersten Exone 1a, 1b, 1c und $1 \mathrm{~d}$ ein weiteres alternatives Exon, das Exon 1e, enthalten (Abbildung 10).

Die genomische Region des murinen Ptch Gens umfasst ebenfalls 5 alternative erste Exone (Kogerman $\mathrm{P}$ et al., 2002; Nagao $\mathrm{K}$ et al., 2005a; Nagao $\mathrm{K}$ et al., 2005b) (siehe Abbildung 10). Wie die Arbeiten von Z. Arziman (Universität Göttingen, Institut für Humangenetik, Praktikantin) gezeigt haben, werden die alternativen Exone 1a, 1b und 1c im RMS von Ptch ${ }^{\text {neo67/+ }}$ Tieren im Vergleich zum Skelettmuskel stark exprimiert. Das Exon 1d weist dagegen ein etwa gleiches Expressionsniveau in Tumor und Skelettmuskel auf (Uhmann A et al., 2005). Dasselbe trifft für das 
Aquivalent des humanen Exon 1e zu. Jedoch wurde bei RT-PCR-Analysen mit in homologen Regionen bindenden DNA-Oligonukleotiden beobachtet, dass die Größe des murinen Exon 1e Amplifikats sich wesentlich vom humanen Homolog unterscheidet.

Diese Daten zeigten zunächst, dass nicht nur das Exon $1 \mathrm{~b}$ im Tumor überexprimiert wird, sondern auch Exon 1a und 1c. Daher lässt sich die Hypothese von Kogermann et al. über eine vermehrte Aktivierung eines Exon 1b Promotors in Tumoren zunächst nicht mehr aufrechterhalten.

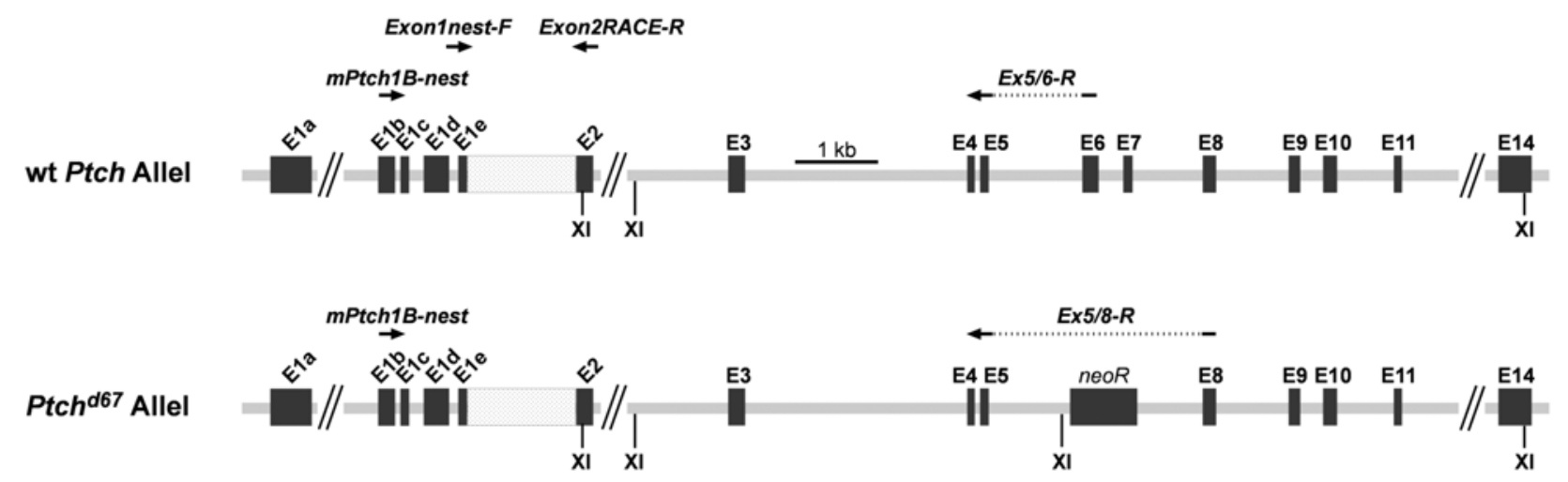

Abbildung 10: Schematische Darstellung des wt Ptch Allels und des mutanten Ptch $^{d 67}$ Allels. Dargestellt sind die Exon- und Introngrenzen vom alternativen Exon 1a bis Exon 14 (E1a bis E14) des wt Ptch Allels (wt Ptch Allel) und des mutanten Ptch ${ }^{d 67}$ Allels. Das Ptch ${ }^{d 67}$ Allel enthält anstelle von Exon 6 und 7 eine Neomycin-Resistenzkassette (neoR). Die Rückwärts-Oligonukleotide Ex6/7-R und Ex5/8-R wurden zusammen mit dem Vorwärts-Oligonukleotid mPtch1B-nest für die PCR-Analyse der Exon 1b-enthaltenden wt Ptch und Ptch ${ }^{d 67}$ Transkripte aus RMS von Ptch ${ }^{\text {neo67/+ }}$ Tieren verwendet (Tabelle 11, siehe Kapitel 3.1.3.3). Das Oligonukleotidpaar Exon1nest-F/Exon2RACE-R wurde für die Analyse des alternativen Ptch Exons 1e verwendet (Tabelle 12).

\subsubsection{Das murine Homolog von Exon 1e ist Teil des murinen Exon 2}

Aufgrund der RT-PCR Analysen von Z. Arziman wurde vermutet, dass das murine Ptch Exon $1 \mathrm{e}$ eine andere Struktur als das humane Äquivalent besitzt (Kogerman $\mathrm{P}$ et al., 2002; Nagao K et al., 2005a; Nagao K et al., 2005b; Uhmann A et al., 2005). Zur Verifizierung dieser Vermutung wurde eine RACE-Analyse (rapid amplification of cDNA ends) an PolyA ${ }^{+}$RNA aus murinem wt Lebergewebe durchgeführt.

Für das RACE-Experiment wurde ein für das Ptch Exon 2 spezifischer RückwärtsDNA-Oligonukleotid eingesetzt (Exon2Race-R; Abbildung 10). Danach wurden $25 \mathrm{ng}$ des Amplifikats als Matrize für eine PCR-Analyse mit dem DNA-Oligonukleotidpaar 
Exon1nest-F/Exon2Race- $R$ verwendet (Abbildung 10). Die beiden amplifizierten Fragmente (1300 bp, 650 bp) wurden in den Vektor pGEM-Teasy kloniert und jeweils 10 Klone sequenziert. Alle analysierten Klone entsprachen der murinen genomischen Region zwischen dem postulieren Exon 1e und Exon 2. Daraus kann geschlossen werden, dass kein gesondert-gespleisstes murines Exon 1e existiert, sondern dass die Sequenz des Exons 1e ein Teil des alternativen Ptch Exon 2 Transkripts ist. Eine Zusammenfassung der murinen Ptch Transkripte wird in Abbildung 11 gezeigt.

Ptch Exon 1a

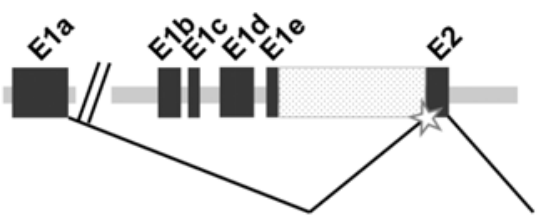

Ptch Exon 1b

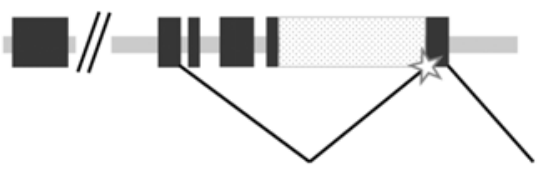

Ptch Exon 1c

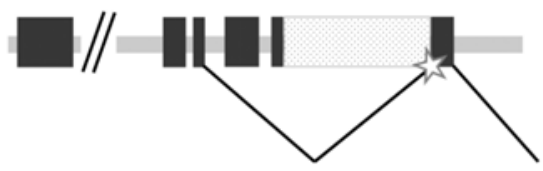

Ptch Exon 1d

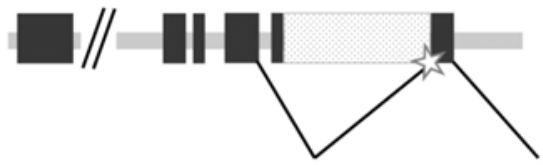

Ptch Exon 2

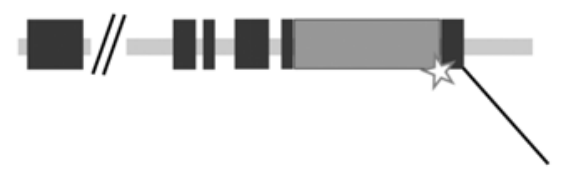

Abbildung 11: Schematische Darstellung der alternativen ersten Exone des Ptch Gens. Dargestellt sind die ersten alternativen Exone 1a, 1b, 1c, 1d und 2 (E1a bis E2). Der Stern markiert die Akzeptorspleissstelle für die Exone 1a bis 1d. Die Analyse der Struktur des humanen Äquivalents von Exon 1e ergab, dass die Sequenz des murinen Exon 1e ein Teil des alternativen Ptch Exon 2 Transkripts ist (graue Box, unten). Im Gegensatz zum humanen Exon 1e wird es nicht in Exon 2 gespleisst.

\subsubsection{3 Überexpression von Exon 1b Ptch ${ }^{d 67}$ Transkripten in RMS}

Im Rahmen dieser Arbeit sollte nun untersucht werden, ob Exon 1b im RMS tatsächlich - wie von Kogermann et al. vermutet - vermehrt in das mutierte Ptch Transkript gespleisst wird. Hierzu wurde eine Transkript-spezifische PCR-Analyse durchgeführt. 
Dabei erfolgte zunächst die Amplifikation der Ptch cDNA mit einem spezifischen Exon 1b Vorwärts-DNA-Oligonukleotid (mPtch1b-nest) und zwei Rückwärts-DNAOligonukleotiden, wovon eines spezifisch für das mutante $\operatorname{Ptch}^{d 67}$ (bindet am Übergang von Exon 5 zu Exon $8, E x 5 / 8-R$ ) und eines spezifisch für das wt Transkript (bindet am Übergang von Exon 5 zu Exon 6, Ex5/8-R) war (Abbildung 10). Die DNAOligonukleotide wurden so ausgewählt, dass sich die zu amplifizierenden Fragmente in ihren Basenpaarlängen exakt entsprachen (631 bp). Eine gleich starke Amplifikationseffizienz der eingesetzten Rückwärts-Oligonukleotide wurde durch eine PCR an cDNA überprüft, wobei die Rückwärts-DNA-Oligonukleotide getrennt verwendet worden sind (Daten nicht gezeigt).

Der PCR-Assay mit den drei Primern wurde sowohl an cDNA von RMS als auch von Skelettmuskel desselben Ptch $^{d 67 /+}$ Tieres in doppeltem Ansatz durchgeführt (Abbildung 12). Das Gemisch aus Transkriptamplifikaten wurde in den Vektor $p G E M$ Teasy kloniert und 90 Klone sequenziert. Die wt Ptch Amplifikate wurden von den Ptch $^{d 67}$ Amplifikaten aufgrund der Sequenzen des Exons 6 (Ptch) und des Exons 8 $\left(P t c h^{d 67}\right)$ unterschieden.

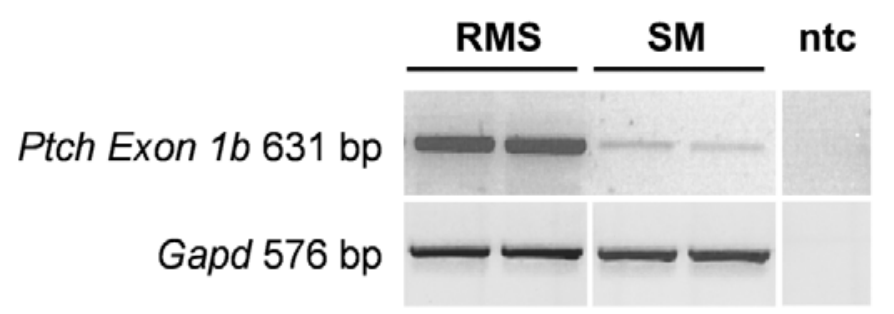

Abbildung 12: PCR-Assay zur gleichzeitigen Amplifikation von Exon 1b wt Ptch und Ptch ${ }^{d 67}$ Transkripten. Als Matrize diente cDNA aus RMS und Skelettmuskel (SM) eines Ptch ${ }^{\text {neo67/+ }}$ Tiers. Die Ptch Exon 1b Transkripte wurden mit dem Vorwärts-DNA-Oligonukleotid mPtch1b-nest und den Rückwärts-DNA-Oligonukleotiden Ex5/6-R und Ex5/8-R amplifiziert (Tabelle 11, siehe Abbildung 12). Als Kontrolle der eingesetzten Matrizen-cDNA wurden murine Gapd (Glycerinaldehyd-3-phosphatasedehydrogenase) Transkripte amplifiziert. Abkürzungen: ntc, no template control.

Abbildung 13 zeigt, dass $82 \%$ der im Tumorgewebe exprimierten Exon 1benthaltenen Ptch Transkripte vom mutierten Ptch ${ }^{d 67}$ Lokus stammen. Im Skelettmuskel sind dagegen $72 \%$ der Exon 1b-exprimierenden Transkripte wt Ptch Transkripte. Dies zeigt, dass die erhöhte Expression von Exon 1b im RMS auf eine im Vergleich zum Skelettmuskel erhöhte Expression des mutanten Ptch $^{d 67}$ Allels zurückzuführen ist. Dies bedeutet, dass als Mechanismus der verstärkten 
Signalwegsaktivierung in Ptch-assoziierten Tumoren die Überexpression eines nichtfunktionellen Ptch $^{d 67}$ Proteins (hier des Exons 1b Transkripts; siehe Kapitel 3.1.2) als auch die verminderte Expression des wt Ptch Allels (siehe Kapitel 3.1.2) diskutiert werden darf.

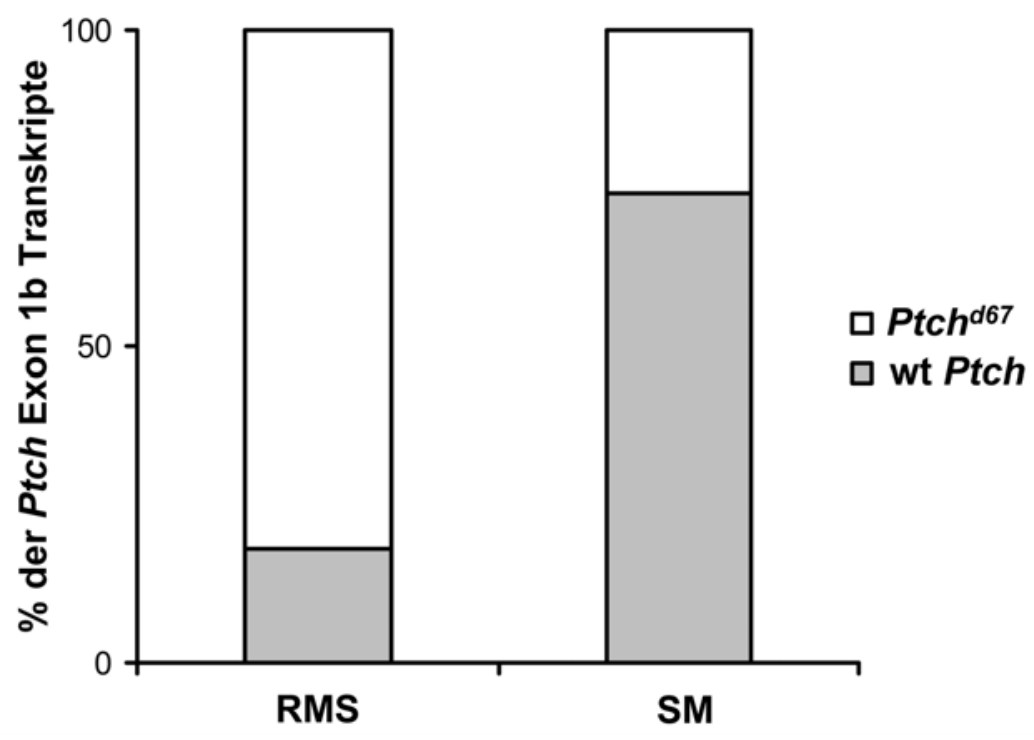

Abbildung 13: In RMS von Ptch ${ }^{\text {neo67/+ }}$ Tieren werden Ptch Exon 1b Transkripte vom Ptch ${ }^{d 67}$ Allel überexprimiert. Das Gemisch aus Ptch Transkriptamplifikaten (mPtch1b-nest/Ex5/6-R/Ex5/8-R) von RMS bzw. Skelettmuskel (SM) wurde in den Vektor pGEM-Teasy kloniert, 90 Klone sequenziert und die jeweiligen prozentualen Anteile der wt Ptch oder $\operatorname{Ptch}^{d 67}$ Amplifikate bestimmt.

\subsubsection{Das Ptch $^{d 67}$ Transkript wird zu einem Ptch $^{d 67}$ Protein translatiert}

Exon 1b $P_{t c h}^{d 67}$ Transkripte sind im RMS stark überrepräsentiert. Da in diesem Transkript Exon 5 ohne Leserasterverschiebung in das Exon 8 gespleisst wird, sollte bei der Translation ein aberantes Ptch ${ }^{\mathrm{d} 67}$ Protein synthetisiert werden. Das errechnete Molekulargewicht des mutanten Ptch ${ }^{\mathrm{d} 67}$ Proteins entspricht $147 \mathrm{kDa}$, da es im Vergleich zum wt Protein (159 kDa) um 147 Aminosäuren verkürzt ist. Die fehlende Proteinregion umfasst Teile der SSD des Ptch Proteins, was zu einem vollständigen Funktionsverlust von $\operatorname{Ptch}^{\mathrm{d} 67}$ führt (siehe Abbildung 3 , Abbildung 10) (Hahn H et al., 1998). 


\subsection{Immunfluoreszenz-Nachweis von $\mathrm{Ptch}^{\mathrm{d} 67}$ in transient transfizierten NIH/3T3 Zellen}

Zum immunchemischen Nachweis des mutanten $\mathrm{Ptch}^{\mathrm{d} 67}$ Proteins wurden Expressionsplasmide zur Expression des mutanten Ptch $^{\mathrm{d} 67}$ Proteins $(p C R 3.1 \mathrm{mPtch}$ (K)d67) und des wt Ptch Proteins (pCR3.1 mPtch(K)wt) in die murine Fibroblastenzellline NIH/3T3 transfiziert. Es wurden 2 anti-Ptch Antikörper verwendet, welche sich durch ihre Antigen-Epitop-Spezifität unterscheiden. Anti-Ptch G-19 bindet an ein Epitop im Exon 1B und anti-Ptch C-20 an eine C-terminale Region des Ptch Proteins, so dass sowohl das wt Ptch Protein als auch der unveränderte N- bzw. C-Terminus des mutanten Ptch $^{\mathrm{d} 67}$ Proteins nachgewiesen werden konnte. In Immunfluoreszenz-Analysen der transfizierten Zellen wurde sowohl das mutante als auch das wt Protein mit beiden Antikörpern detektiert (Abbildung 14). Wie bereits bei Denef et al. für die subzelluläre Lokalisation von wt Ptch beschrieben worden ist (Denef $\mathrm{N}$ et al., 2000; Incardona JP et al., 2000), zeigten beide Proteine eine vergleichbare zytoplasmatische (vesikuläre) bzw. membranständige Lokalisation auf. Eine endogene Ptch Expression in untransfizierten $\mathrm{NIH} / 3 \mathrm{~T} 3$ Zellen wurde nicht nachgewiesen.
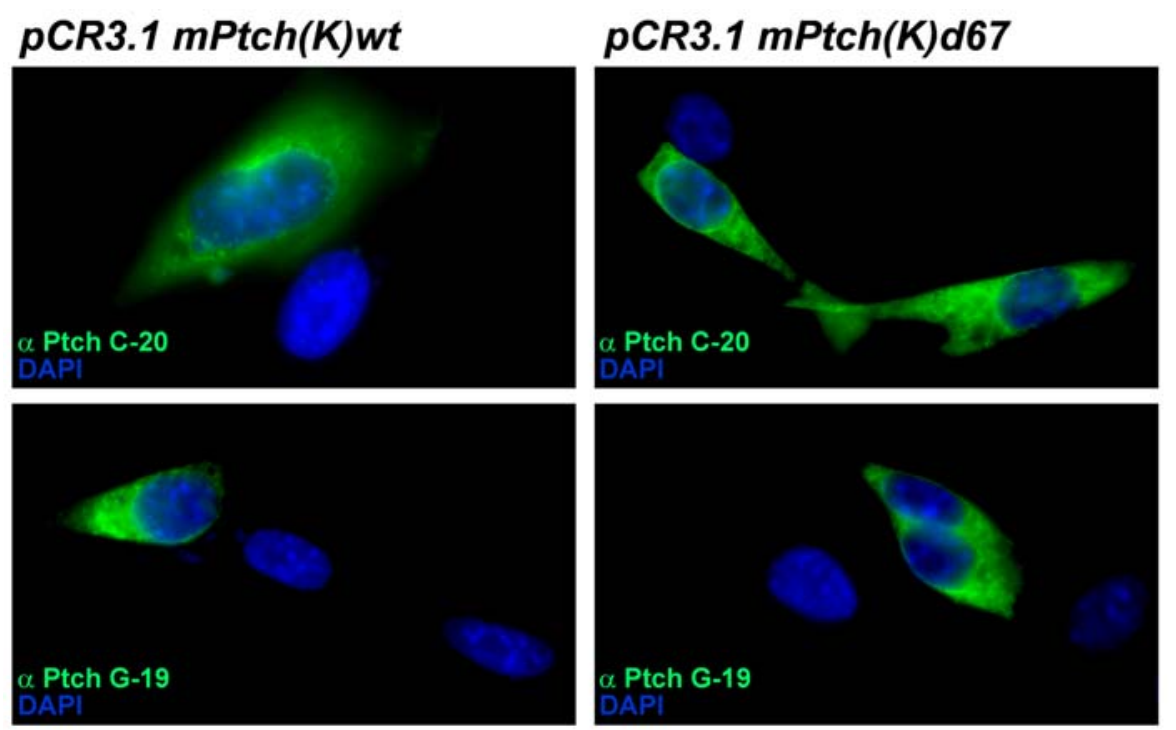

Abbildung 14: Immunfluoreszenz-Nachweis von wt Ptch und $\mathrm{Ptch}^{\mathrm{d} 67}$ Protein. NIH/3T3 Zellen wurden transient mit dem Plasmid pCR3.1 mPtch(K)wt oder $p C R 3.1 \mathrm{mPtch}(K) d 67$ transfiziert, fixiert, mit anti-Ptch Antikörpern gefärbt und mit einem DAPI-enthaltenden Montagemedium eingedeckt. Die beiden verwendeten Antikörper unterscheiden sich durch ihre Antigen-Epitop-Spezifität. Anti-Ptch G19 (unten) bindet an ein Epitop im Exon 1B und anti-Ptch C-20 (oben) an eine C-terminale Region des Ptch Proteins. In Blau ist die DAPI-Kernfärbung und in Grün die Ptch-spezifische Färbung dargestellt. 


\subsection{Nachweis von Ptch ${ }^{\mathrm{d} 67}$ im Western Blot}

Zum Vergleich der molekularen Größe beider Ptch Proteine wurden Proteinextrakte aus transfizierten NIH/3T3 Zellen und aus murinem Testisgewebe (Positivkontrolle) im Western Blot analysiert. Abbildung 15 zeigt, dass mit den verwendeten anti-Ptch Antikörpern (G-19, C-20) Proteinbanden detektiert wurden, welche aufgrund ihrer Laufgeschwindigkeit den errechneten Molekulargewichten der Ptch Proteine (Ptch $159 \mathrm{kDa}, \operatorname{Ptch}^{\mathrm{d} 67} 147 \mathrm{kDa}$ ) entsprechen. Mit beiden Antikörpern wurden sowohl endogenes Ptch Protein im Testisextrakt (Testis) und das wt Ptch Protein in pCR3.1 mPtch $(K) w t$ transfizierten Zellen als auch das mutante Protein in pCR3.1 mPtch(K)d67 transfizierten Zellen nachgewiesen. Der anti-Ptch G-19 Antikörper zeigte dabei eine höhere Spezifität für das endogen von NIH/3T3 Zellen exprimierte Ptch Protein als der anti-Ptch C-20 Antikörper.

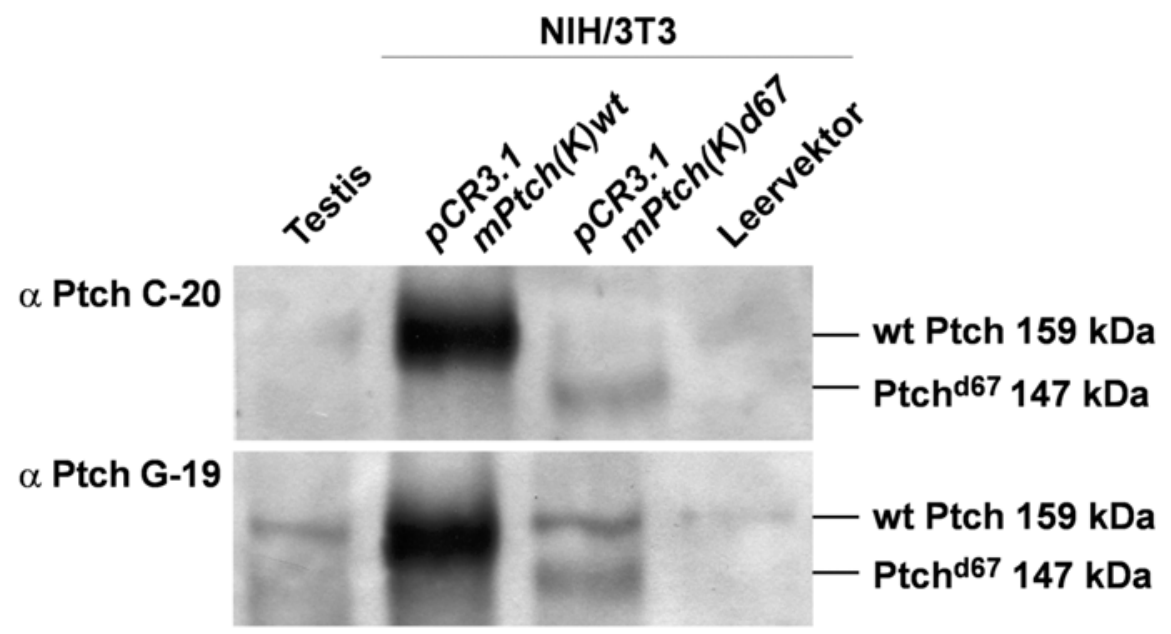

Abbildung 15: Western Blot Nachweis von wt Ptch und Ptch ${ }^{\mathrm{d} 67}$ Protein. NIH/3T3 Zellen wurden transient mit dem Plasmid pCR3.1 mPtch(K)wt, pCR3.1 mPtch(K)d67 oder mit dem pCR3.1 Leervektor (Leervektor) transfiziert. Die Proteinextrakte der Zellen wurde zusammen mit einem Proteinextrakt aus murinem Testisgewebe (Testis) im Western Blot mit den Antikörpern anti-Ptch C-20 (oben) und anti-Ptch G-19 (unten) analysiert. Die Proteinbanden entsprechen den errechneten Molekulargewichten der Ptch Proteine (Ptch 159 kDa, Ptch ${ }^{\mathrm{d} 67} 147 \mathrm{kDa}$ ).

Zusammengefasst zeigen die Ergebnisse der Proteinexpressionsanalysen, dass das mutante Ptch $^{d 67}$ Transkript in vitro translatiert wird. Die Größe des Ptch ${ }^{d 67}$ Proteins entspricht dem errechneten Molekulargewicht. Vergleichbar dem wt Protein ist das mutante Protein zytoplasmatisch (vesikulär) sowie membranständig lokalisiert (Denef $\mathrm{N}$ et al., 2000; Incardona JP et al., 2000). 


\subsubsection{Ptch ${ }^{\mathrm{d} 67}$ Protein hat einen hemmenden Einfluss auf das Ptch wt Protein}

Um den Effekt des mutanten Ptch ${ }^{\mathrm{d} 67}$ Proteins auf den Hh/Ptch Signalweg zu untersuchen, wurden NIH/3T3 Zellen mit einem der beiden Ptch Expressionsplasmide, dem $p G L$ 9xGli-BS Reporterplasmid und $p R L-C M V$ (Normalisierungsplasmid zur konstitutiven Expression der Renilla Luziferase) cotransfiziert. Das verwendete Reporterplasmid $p G L$ 9xGli-BS enthält das Firefly Luziferasegen unter der Kontrolle eines Thymidinkinase Promotors. Durch 9 distal vom Promotor integrierte Gli-Bindestellen wird das Firefly Luziferasegen in Anwesenheit von Gli1 exprimiert (Beer $C$ et al., 2003). Die im Dualen-LuziferaseAssay gemessene Aktivität der Firefly Luziferase wurde auf die Renilla LuziferaseAktivität normalisiert. Als Kontrolle des aktiven Signalweges wurde der $p C R 3.1$ Leervektor zusammen mit $p R L-C M V$ und $p G L$ 9xGli-BS co-transfiziert. Es wurden jeweils 6 unabhängige Experimente durchgeführt, wobei jede Probe in Triplikaten vermessen wurde.

Die Expression des wt Ptch Proteins führte im Vergleich zur Leervektor-transfizierten Kontrolle zu einer Hemmung der Expression des Reportergens (Abbildung 16; $P<0,05)$. Durch eine Expression des mutanten $\mathrm{Ptch}^{\mathrm{d} 67}$ Proteins wurde dagegen kein Aktivitätsverlust des Signalweges nachgewiesen. 


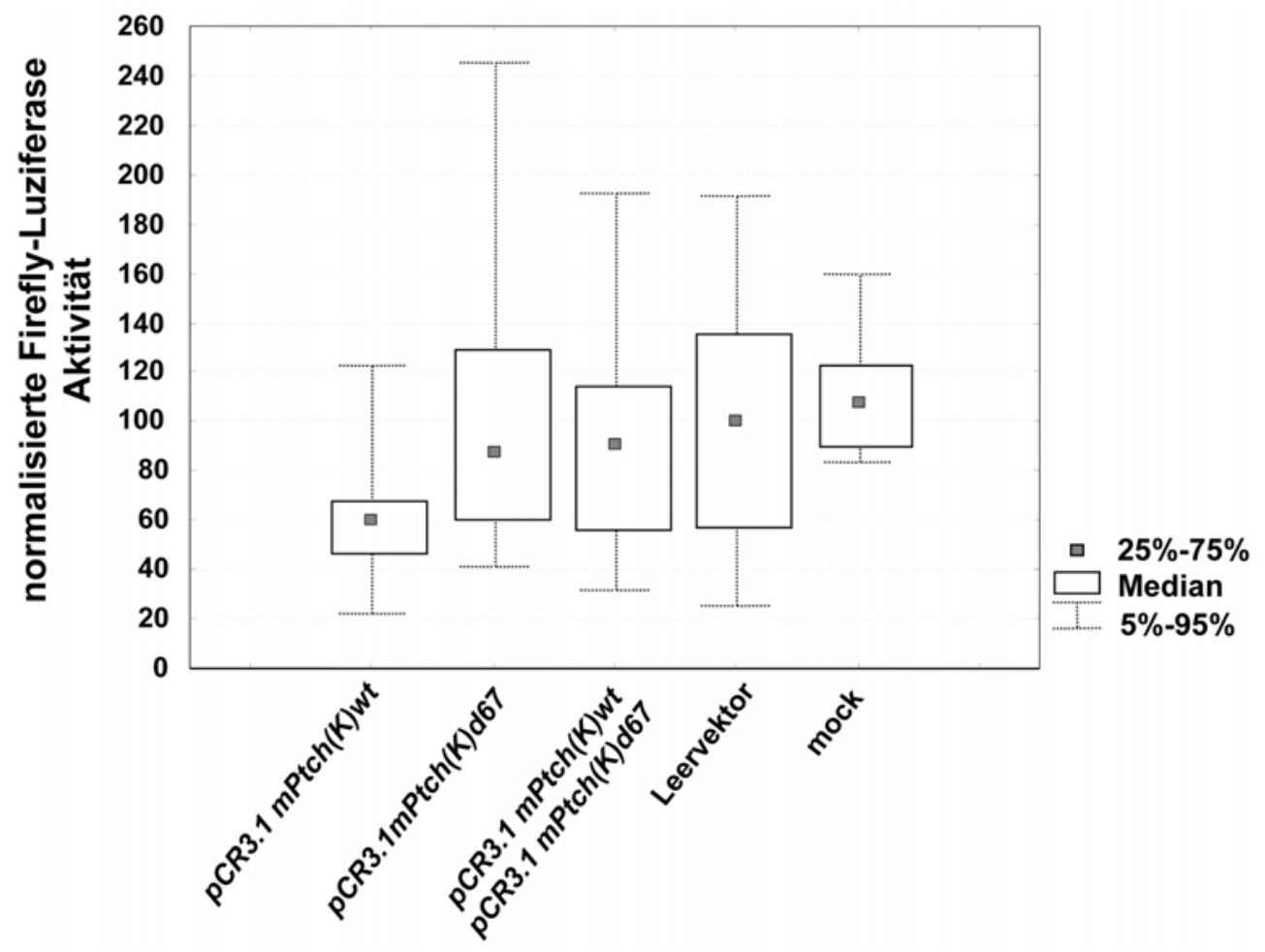

Abbildung 16: Funktionsverlust von $\mathrm{Ptch}^{\mathrm{d} 67}$. NIH/3T3 Zellen wurden transient mit den Ptch Expressionsplasmiden pCR3.1 mPtch(K)wt, pCR3.1 mPtch(K)d67, pCR3.1 Leervektor oder ohne Expressionsplasmid (mock) mit $p R L-C M V$ und $p G L$ 9xGli-BS co-transfiziert Die Proteinextrakte wurden im Dualen-Luziferase-Assay analysiert und die Werte der Firefly Luziferase-Aktivität auf die Werte der Renilla Luziferase-Aktivität normalisiert. Die Daten repräsentieren 6 unabhängige in Triplikaten vermessene Experimente. Die Ergebnisse sind als Box-Whisker-Plot dargestellt. Die Signifikanz $(P<0,05)$ wurde mit dem Mann-Whitney-U-Test getestet.

Die Ergebnisse zeigen, dass die Deletion der Exone 6 und $7 \mathrm{zu}$ einem Funktionsverlust des Ptch ${ }^{\mathrm{d} 67}$ Proteins führt. So ist Ptch ${ }^{\mathrm{d} 67}$ im Gegensatz zu wt Ptch Protein nicht in der Lage den Shh/Ptch Signalweg zu inaktivieren. Weiterhin führte die simultane Expression von wt und mutantem Protein zu keinem Aktivitätsverlust des Signalweges. Dies weist darauf hin, dass das wt Protein in seiner Aktivität als Signalwegsrepressor effizient durch das mutante Protein inhibiert wird, möglicherweise über einen dominant-negativen Mechanismus. 


\subsection{Analyse der konditionellen Ptch knock-out Mäuse}

Spontane Ptch-inaktivierende Mutationen führen zu einer abnormalen Aktivierung des Shh/Ptch Signalweges. Heterozygot vererbte Ptch Mutationen resultieren in Entwicklungsdefekten und Tumoren (Goodrich LV et al., 1997; Hahn $\mathrm{H}$ et al., 1998). Da der homozygote Verlust von Ptch embryonal letal ist, beschränkten sich Analysen des Shh/Ptch Signalweges in adultem Gewebe mit einer homozygoten Ptch Mutation bisher auf in vitro Studien. Um untersuchen zu können, wie sich der biallelische Verlust von Ptch in adulten Mäusen auswirkt, ob ein biallelischer Verlust von Ptch zur schnelleren Tumorigenese beiträgt und um die Funktion von Ptch Gewebe-spezifisch und altersabhängig untersuchen zu können, wurde eine konditionelle Ptch Nullmutation unter Verwendung des Cre-loxP Systems in der Maus etabliert (Uhmann A et al., 2006 eingereicht).

Abbildung 17 zeigt das wt Ptch Allel, den Zielvektor ( $p P t c h^{N X}$ ) sowie das $P t c h^{N X}$ Allel, welches durch homologe Rekombination des Zielvektors in den genomischen Ptch Lokus generiert wurde. Im Ptch ${ }^{N X}$ Lokus befinden sich in Intron 7 und in Intron 9 IoxP-Sequenzen. Durch eine Cre-Rekombinase-vermittelte Rekombination können so die Exone 8 und $9 \mathrm{im}$ Ptch $^{N X}$ Allel deletiert werden. Die Deletion der Exone induziert eine Leserasterverschiebung des Transkripts, welche zu einem vorzeitigen Abbruch der Translation führt. Das postulierte Ptch ${ }^{\text {delNX }}$ Protein ist 341 Aminosäuren lang und gegenüber dem wt Ptch Protein um 1093 Aminosäuren verkürzt. Der CTerminus des Ptch $^{\text {delNX }}$ Proteins umfasst dabei 5 zusätzliche im wt Protein nicht vorhandene Aminosäuren.

Der Ptch ${ }^{N X}$ Lokus enthält weiterhin eine von frt-Sequenzen flankierte NeomycinResistenzkassette in Intron 9. Diese Kassette kann durch die Expression einer FLPase deletiert werden (Rodriguez $\mathrm{Cl}$ et al., 2000), falls sie die korrekte Transkription des Ptch $^{N X}$ Allels stören sollte. Der Zielvektor $p P t c h^{N X}$ wurde in unserem Labor von Dr. M. Koleva generiert. 


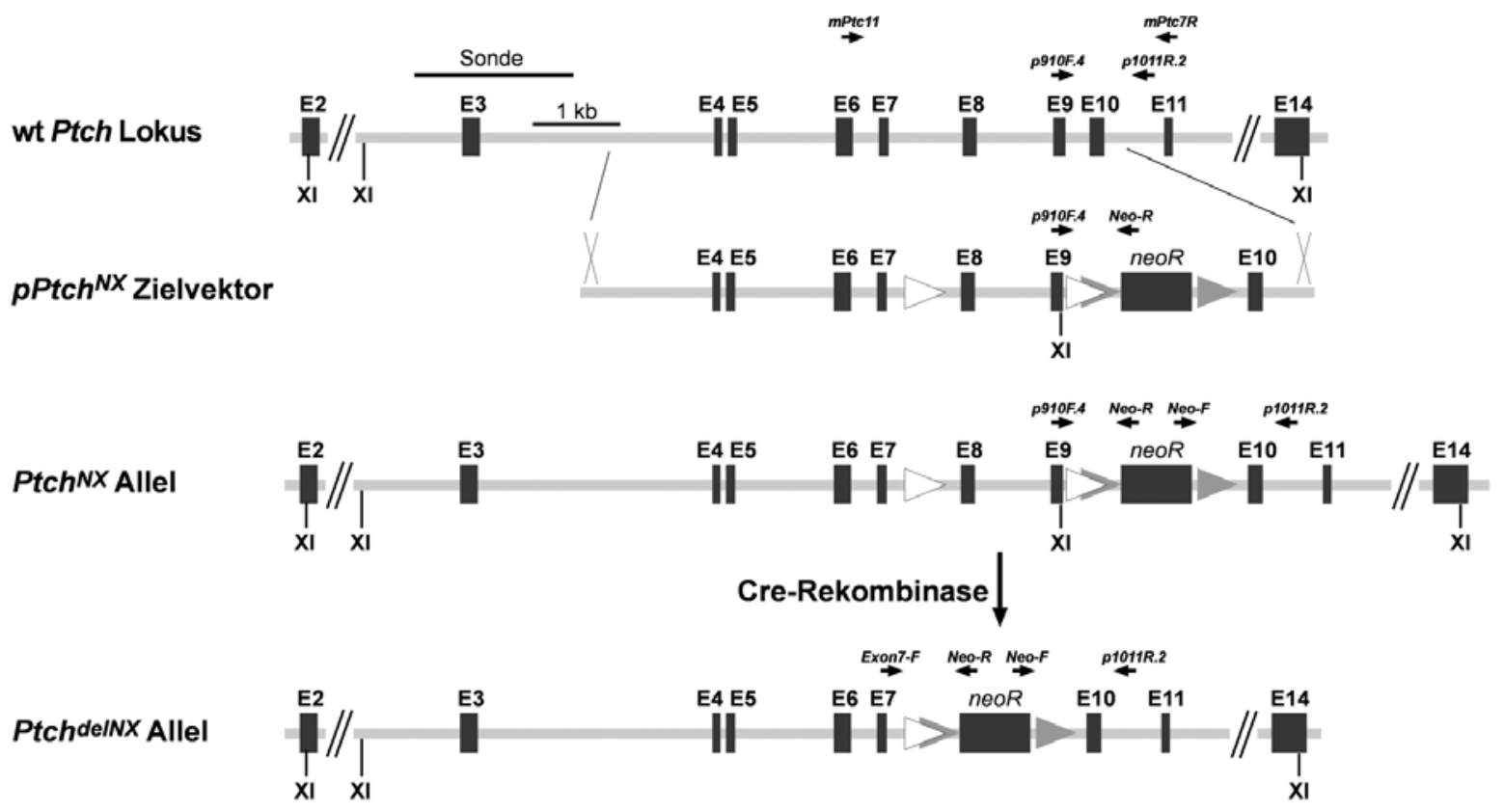

Abbildung 17: Schematische Darstellung der Strategie zur Herstellung einer konditionellen Ptch Deletion. Dargestellt sind die Exon- und Introngrenzen von Exon 2 bis Exon 14 (E2 bis E14) des wt Ptch Allels, des Ptch ${ }^{N X}$ Allels und des Ptch ${ }^{\text {delNX }}$ Allels. Durch homologe Rekombination wurde die Sequenz des Zielvektors $p$ Ptch $^{N X}$ gegen die entsprechende wt Ptch Sequenz ausgetauscht, so dass in den Introns 7 und 9 jeweils eine loxP-Sequenz und im Intron 9 eine frt-Sequenz-flankierte NeomycinResistenzkassette (neoR) eingefügt wurde (Ptch ${ }^{N X}$ Allel). Durch Cre-vermittelte Rekombination der loxP-Sequenzen wird eine Deletion der Exone 8 und 9 induziert ( $P t c h^{\text {delNX }}$ Allel). Zur Genotypisierung des Ptch $^{N X}$ Allels wurden sowohl das DNA-Oligonukleotidpaar p910F.4/Neo-R als auch das DNAOligonukleotidpaar Neo-F/p1011R.2 verwendet, wobei das DNA-Oligonukleotid p1011R.2 außerhalb des integrierten Zielvektors bindet. Das wt Ptch Allel wurde mit dem DNA-Oligonukleotidpaar p910F.4/p1011R.2 und das Ptch ${ }^{\text {delNX }}$ Allel mit dem DNA-Oligonukleotidpaar Exon7-F/Neo-R detektiert. Das DNA-Oligonukleotidpaar mPtc11/mPtc7R wurde für RT-PCR-Analysen der Ptch Transkripte eingesetzt. Die Lokalisation der für Southern Blot Analysen verwendeten Sonde ist ebenfalls dargestellt. Sie bindet außerhalb des integrierten Zielvektors. Abkürzungen: XI, Xhol.

\subsubsection{Cre-vermittelte Rekombination des $p P t c h^{N X}$ Zielvektors in vitro}

Vor der Elektroporation des pPtch ${ }^{N X}$ Zielvektors in embryonale Stammzellen (ESZellen, siehe Kapitel 3.2.2) wurde der Vektor zusammen mit einem Plasmid zur Expression einer konstitutiv aktiven Cre-Rekombinase ( $p M C$-Cre) in die Zelllinie C2C12 wie unter 3.3.1.1.3 beschrieben transfiziert. Zur Kontrolle wurden Zellen lediglich mit dem $p P t c h^{N X}$ Zielvektor transfiziert. $48 \mathrm{~h}$ nach erfolgter Transfektion wurde die Gesamt-DNA der Zellen isoliert und die Rekombination von $p P t c h^{N X}$ mittels PCR analysiert. Hierzu wurde das DNA-Oligonukleotidpaar Exon7-F/Neo-R (Abbildung 17) verwendet. Abbildung 18 zeigt, dass durch die Co-Transfektion mit 
pMC-Cre die Exone 8 und 9 des $p P t c h^{N X}$ Vektors deletiert wurden $\left(p P t c h^{\text {delNX }}\right.$ $950 \mathrm{bp})$. Bei der Kontrolltransfektion ohne $p M C$-Cre wurde kein $p P t c h^{\text {delNX}}$ -

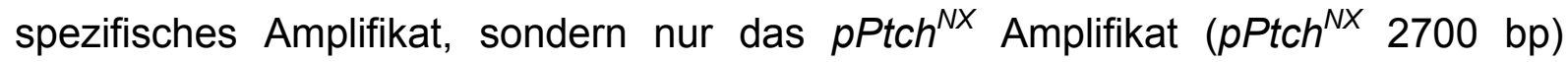
detektiert.

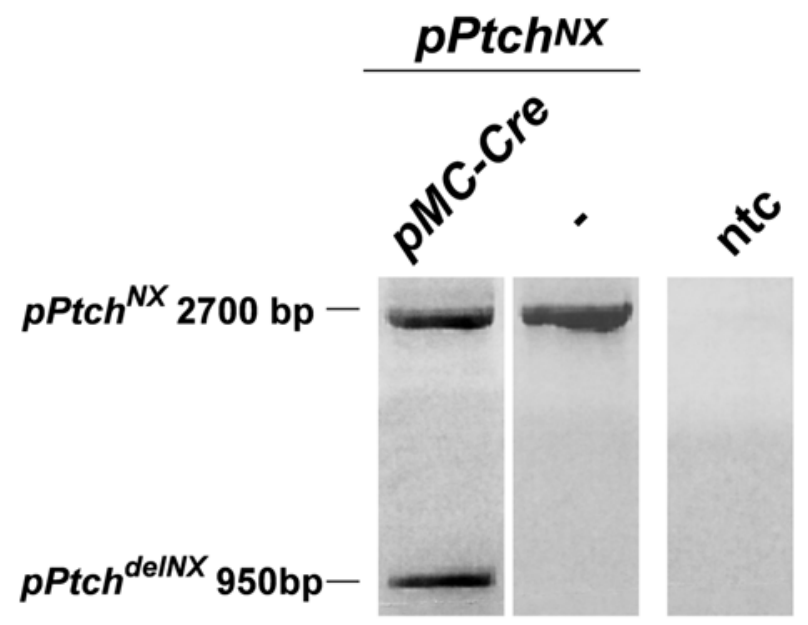

Abbildung 18: Rekombination des $p P t c h^{N X}$ Zielvektors durch Expression des pMC-Cre Plasmid. Der $p P t c h^{N X}$ Zielvektor wurde mit den Plasmid pMC-Cre in C2C12 Zellen transfiziert. Als Kontrolle wurde der $p P t c h^{N X}$ Zielvektor ohne Cre-exprimierenden Vektor transfiziert. Die Gesamt-DNA der Zellen wurde isoliert und eine PCR-Analyse mit dem Oligonukleotidpaar Exon7-F/Neo-R (Tabelle 7, Abbildung 17) durchgeführt. Abkürzungen: ntc, no template control.

\subsubsection{Etablierung von homozygoten $\operatorname{Ptch}^{N X / N X}$ Mäusen}

Die Elektroporation des $p P t c h^{N X}$ Zielvektors in RI ES-Zellen wurde von Dr. I. Adham (Universität Göttingen, Institut für Humangenetik) durchgeführt. Es wurden 3 Klone mittels PCR und Southern Blot Analyse identifiziert, bei denen die homologe Rekombination am Ptch Lokus stattgefunden hatte. Zellen dieser positiven Klone wurden in Blastozysten von C57BL/6N Mäusen injiziert und in 129Sv Ziehmütter transferiert. Die chimären Nachkommen (gemischer genetischer Hintergrund, C57BL/6N x 129Sv) wurden mit C57BL/6N Weibchen verpaart. Heterozygote Nachkommen $\left(P t c h^{N X /+}\right)$ der F1 Generation der chimären Mäuse besaßen nach erfolgter Keimbahntransmission des Ptch $^{N X}$ Allels die Fellfarbe „agouti“. Zur Überprüfung des Genotyps wurden die Tiere mittels Southern Blot (Abbildung 19) und PCR-Analysen (Abbildung 20) genotypisiert. Die Anlagerungsposition der Southern Blot Sonde und die DNA-Oligonukleotidpaare zur Genotypisierung sind der Abbildung $17 \mathrm{zu}$ entnehmen. Die Homozygote Mauslinie Ptch $^{N X / N X}$ wurde durch Geschwisterverpaarung von Ptch ${ }^{N X /+}$ Tieren etabliert. 
wt Ptch Allel 15948 bp

$\operatorname{Ptch}^{N X}$ Allel 8640 bp

Abbildung 19: Southern Blot Analyse von $\mathrm{Ptch}^{+/+}$und $\mathrm{Ptch}^{\mathrm{NX} /+}$ Tieren. Genomische DNA aus Schwanzbiopsien wurde mit Xhol restriktionshydrolysiert und im Southern Blot mit der in Abbildung 17 angegebenen Sonde hybridisiert. In der linken Spalte wurde genomische DNA aus einem Ptch $^{+/+}$und in der rechten Spalte aus einem $P_{t c h}{ }^{N X /+}$ Tier aufgetragen.

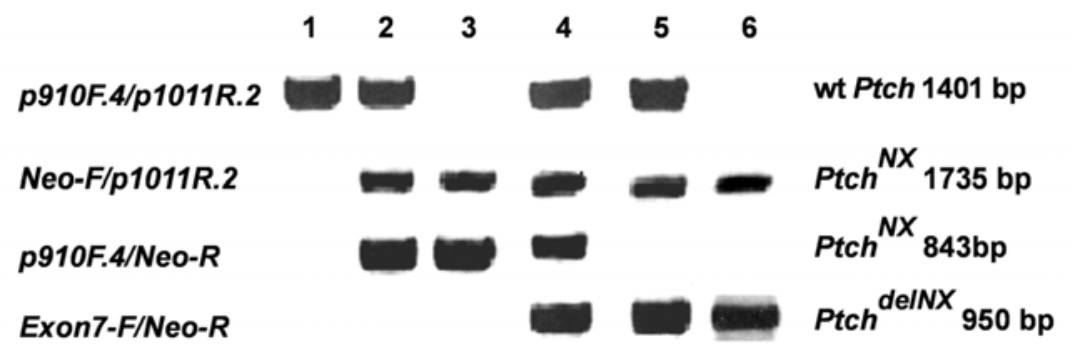

Abbildung 20: PCR-Analysen zur Genotypisierung der unterschiedlichen Ptch Allele. Zur Genotypisierung von genomischer DNA aus Schwanzbiopsien wurden das wt Ptch Allel mit dem Oligonukleotidpaar p910F.4/p1011R.2, das Ptch ${ }^{N X}$ Allel mit den DNA-Oligonukleotidpaaren Neo-F/p1011R.2 und p910F.4/Neo-R sowie das Ptch ${ }^{\text {delNX }}$ Allel mit den DNA-Oligonukleotidpaar Exon7-F/Neo-R nachgewiesen (Tabelle 7). Die Anlagerungsstellen der DNA-Oligonukleotide sind Abbildung 17 zu entnehmen. Spur 1: Ptch $^{+/+}$DNA; Spur 2: Ptch ${ }^{N X /+}$ DNA; Spur 3: Ptch ${ }^{N X / N X}$ DNA; Spur

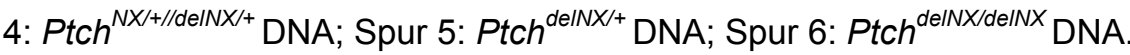

\subsubsection{Homozygote Ptch $^{N X / N X}$ Mäuse sind phänotypisch unauffällig}

Um auszuschließen, dass die loxP-Sequenzen in den Introns 7 und 9 sowie das Neomycin-Resistenzgen in Intron 9 die Funktionalität des Ptch $^{N X}$ Allels beeinträchtigen, wurden Ptch Transkripte aus diversen Organen von $P t c h^{N X / N X}$ und wt Tieren des gleichen genetischen Hintergrunds untersucht. Hierzu wurden RT-PCRAnalysen mit dem DNA-Oligonukleotidpaar mPtc11/mPtc7R (Tabelle 10, Abbildung 17) durchgeführt. Das DNA-Oligonukleotidpaar wurde so gewählt, dass sowohl das wt Ptch Transkript (731 bp) als auch das mutante Ptch ${ }^{\text {delNX }}$ Transkript (451 bp) in einem PCR-Assay detektiert werden können. Als interne Matrizenkontrolle wurde die Amplifikation von Gapd Transkripten mitgeführt. Abbildung 21 zeigt die amplifizierten Ptch Transkripte von homozygoten Ptch $^{N X / N X}$ Tieren im Vergleich zu wt Tieren. In keinem der untersuchten Ptch $^{N X / N X}$ Organe wurden abnormale Ptch Spleissprodukte 
festgestellt. In allen untersuchten Organen wurde das wt Ptch Transkript (731 bp) exprimiert. Im Skelettmuskel von Ptch ${ }^{N X / N X}$ Tieren wurde zusätzlich eine weitere Ptch Spleissvariante detektiert (siehe Abbildung 21). Durch Sequenzanalysen wurde gezeigt, dass diese einer normalen in wt Tieren exprimierten Ptch Spleissvariante entspricht (574 bp) (Nagao K et al., 2005a; Nagao K et al., 2005b). Hierbei handelt es sich um eine Ptch Isoform, welche durch das Spleissen von Exon 9 in Exon 11 zustande kommt.

Keines der heterozygoten $\operatorname{Ptch}^{N X /+}$ (71 Tiere) oder homozygoten $\operatorname{Ptch}^{N X / N X}$ (75 Tiere) Tiere entwickelte über einen Zeitraum von 15 Monaten Tumore. Das Ptch ${ }^{N X}$ Allel wurde im korrekten Mendel'schen Verhältnis vererbt. Alle die Tiere waren gesund, phänotypisch unauffällig und fertil.

Zusammenfassend kann festgehalten werden, dass der genetisch veränderte $\operatorname{Ptch}^{N X}$ Lokus die Transkription und das Spleissen von Ptch Transkripten nicht beeinflusst und keinen nachteiligen Effekt auf die Entwicklung der Tiere hat. Aus diesem Grund wurde auf die Deletion des Neomycin-Resistenzgenes durch Kreuzung der Ptch ${ }^{N X}$ Tiere mit FLPase-exprimierenden Mäusen verzichtet.

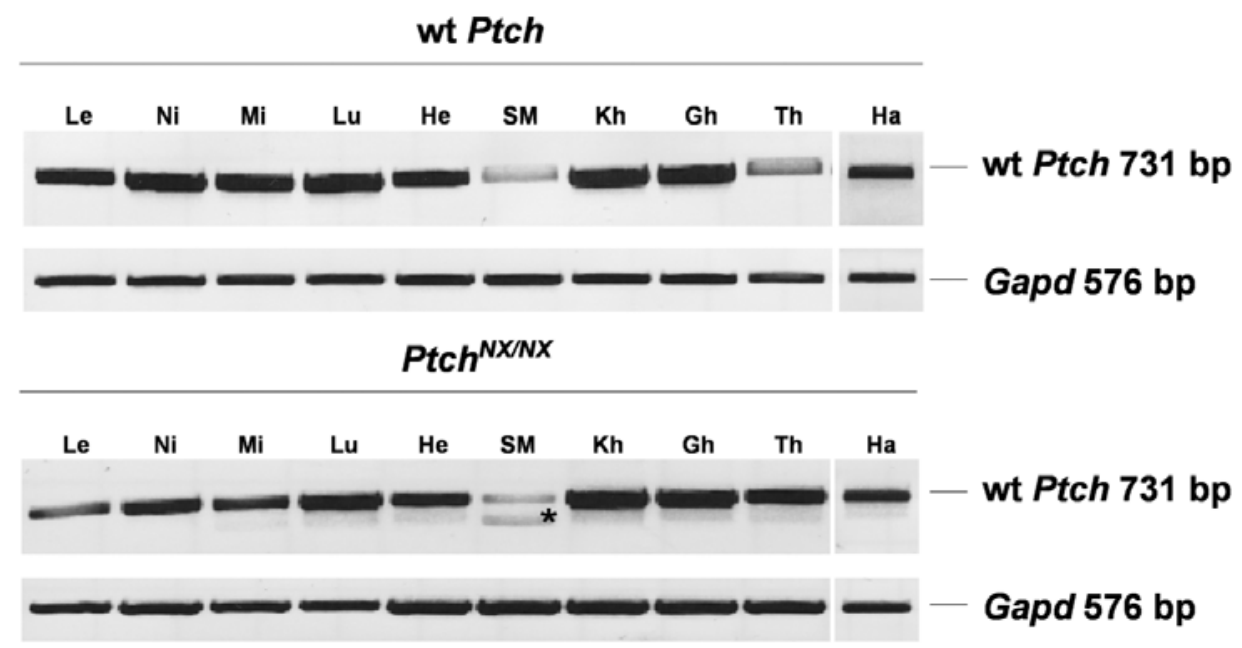

\begin{abstract}
Abbildung 21: $\boldsymbol{P t c h}^{N X / N X}$ Tiere exprimieren wt Ptch Transkripte. Es wurden RT-PCR-Analysen an cDNA von Gesamt-RNA aus Organen von Ptch $^{+/+}$(wt Ptch) und Ptch $^{N X / N X}$ Tieren mit dem DNAOligonukleotidpaar mPtc11/mPtc7R zur Analyse der Ptch Transkripte durchgeführt (Tabelle 10). Die Anlagerungsstellen der DNA-Oligonukleotide am Ptch Lokus sind Abbildung 17 zu entnehmen. Zur Kontrolle der cDNA wurden Gapd Transkripte amplifiziert. Die mit einem Stern markierte Ptch SpleissVariante im Skelettmuskel (SM) entspricht einem bei Nagao K et al. beschriebenen wt Ptch Transkript (Nagao K et al., 2005a; Nagao K et al., 2005b). Abkürzungen: Le, Leber; Ni, Niere; Mi, Milz; Lu, Lunge; He, Herz; SM, Skelettmuskel; Kh, Kleinhirn; Gh, Großhirn; Th, Thymus; Ha, Haut.
\end{abstract}




\subsubsection{Cre-Rekombinase-vermittelte Deletion von Ptch in der Keimbahn}

Konventionelle $\operatorname{Ptch}^{\text {neo67/+ }}$ Mäuse entwickeln abhängig vom genetischen Hintergrund RMS und MB (Hahn $\mathrm{H}$ et al., 2004). Homozygote mutante Ptch ${ }^{\text {neo67/neo67 Embryonen }}$ sterben aufgrund von Neuralrohr- und Herzdefekten am Tag 9,0 dpc bis 10,5 dpc in utero (Goodrich LV et al., 1997; Hahn $\mathrm{H}$ et al., 1998). Um den Phänotyp von

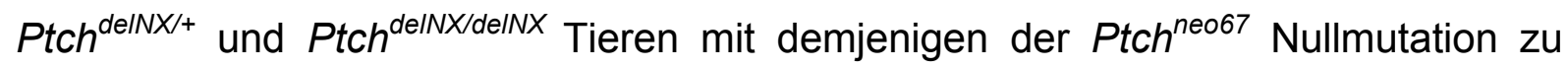
vergleichen, wurden männliche $\mathrm{Ptch}^{N X /+}$ Mäuse mit weiblichen $\mathrm{Tg}$ (Ella-Cre) Mäusen (Lakso M et al., 1996) verpaart. Tg(Ella-Cre) Mäuse exprimieren die CreRekombinase unter dem Ella Promotor, dessen höchste Aktivität sich auf die erste meiotische Teilung der Keimbahnzellen beschränkt (Lakso M et al., 1996). Daher wurde in den direkten Nachkommen der oben genannten Kreuzung durch die CreRekombinase eine unvollständige Rekombination am $\mathrm{Ptch}^{N X}$ Locus erzeugt. Die

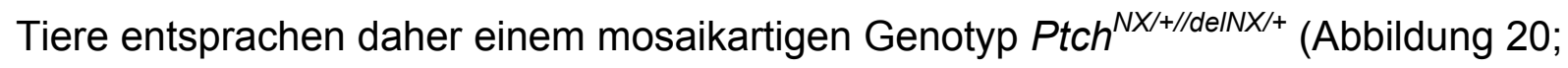
Spur 4).

Weibliche Mäuse des Genotyps Ptch ${ }^{N X /+/ / d / N X /+} T g$ (Ella-Cre) wurden mit männlichen wt Mäusen, welche aus der Zucht von C57BL/6N x Balb/c Mäusen stammten, verpaart. Da bekannt ist, dass rezessive Allele des C57BL/6N und dominante Allele des Balb/c Hintergrundes zu einer Prädisposition für die Entwicklung von RMS und MB führen (Hahn $\mathrm{H}$ et al., 2004), konnte durch diese Kreuzung die Wahrscheinlichkeit der Tumorentwicklung in den Nachkommen erhöht werden. Heterozygote Ptch ${ }^{\text {delNX/+ }}$ Nachkommen mit diesem gemischten 129Sv/C57BL/6N/Balb/c genetischen Hintergrund wurden sowohl über Southern Blot Analyse (Abbildung 19) als auch durch PCR-Analysen an genomischer DNA aus Schwanzbiopsien identifiziert (Abbildung 20; Spur 5). Die Tiere wurden engmaschig auf die Entwicklung von Tumoren untersucht.

\subsubsection{Heterozygote $P t c h^{\text {delNX/+ }}$ Mäuse entwickeln RMS und MB}

Unter den Nachkommen der unter 3.2.4 beschriebenen Verpaarungen entwickelten sowohl Ptch ${ }^{N X /+/ / d e l N X /+}$ Mosaiktiere als auch heterozygote Ptch $^{\text {delNX/+ }}$ Tiere RMS und MB. Beide Tumortypen wurden durch Kryostatschnitte und HE-Färbungen von einem erfahrenen Pathologen (Dr. W. Schulz-Schaeffer; Universitätsklinikum Göttingen, Abt. Neuropathologie) bestätigt. Die Abbildung 22 zeigt die Tumorhäufigkeit der untersuchten Tiere. 39 \% der Mosaiktiere entwickelten RMS und $15 \%$ MB (33 Tiere). 
Heterozygote Ptch ${ }^{\text {delNX/+ }}$ Mäuse entwickelten mit einer Inzidenz von $33 \%$ RMS und 27 \% MB (30 Tiere). Die Häufigkeit der Tumorentwicklung der letzteren Kohorte ist damit vergleichbar zu der beschriebenen Tumorinzidenz von heterozygoten $P_{t c h}{ }^{\text {neo67/+ }}$ Mäusen des konventionellen knock-outs eines ähnlichen gemischten genetischen Hintergrundes (29 \% für RMS und $25 \%$ für MB) (Hahn $\mathrm{H}$ et al., 2004). $\mathrm{Ptch}^{N X /+}$ Kontrolltiere (22 Tiere) entwickelten über einen Zeitraum von 200 Tagen keine Tumore.

In RT-PCR-Analysen, die an cDNA von Tumor- und Referenzgeweben durchgeführt wurden, konnte in RMS im Vergleich zum untersuchten normalen Skelettmuskel eine abnormal hohe Expression von Zielgenen des Shh/Ptch Signalweges festgestellt werden (Abbildung 23). Weiterhin zeigte die RT-PCR-Analyse, dass in den untersuchten RMS das mutante Ptch ${ }^{\text {delNX }}$ Transkript verglichen mit der Expression des wt Transkriptes in normalem Muskelgewebe deutlich überrepräsentiert war (Abbildung 23). Als interne Matrizenkontrolle wurde die Amplifikation von Gapd Transkripten mitgeführt.

Diese Daten zeigen, dass heterozygote $P t c h^{\text {delNX/+ }}$ Mäuse wie auch $P t c h^{\text {neo67/+ }}$ und Ptch $^{\text {neo12/+ }}$ Mäuse zur Entwicklung von RMS und MB prädisponiert sind (Goodrich LV et al., 1997; Hahn $\mathrm{H}$ et al., 1998).

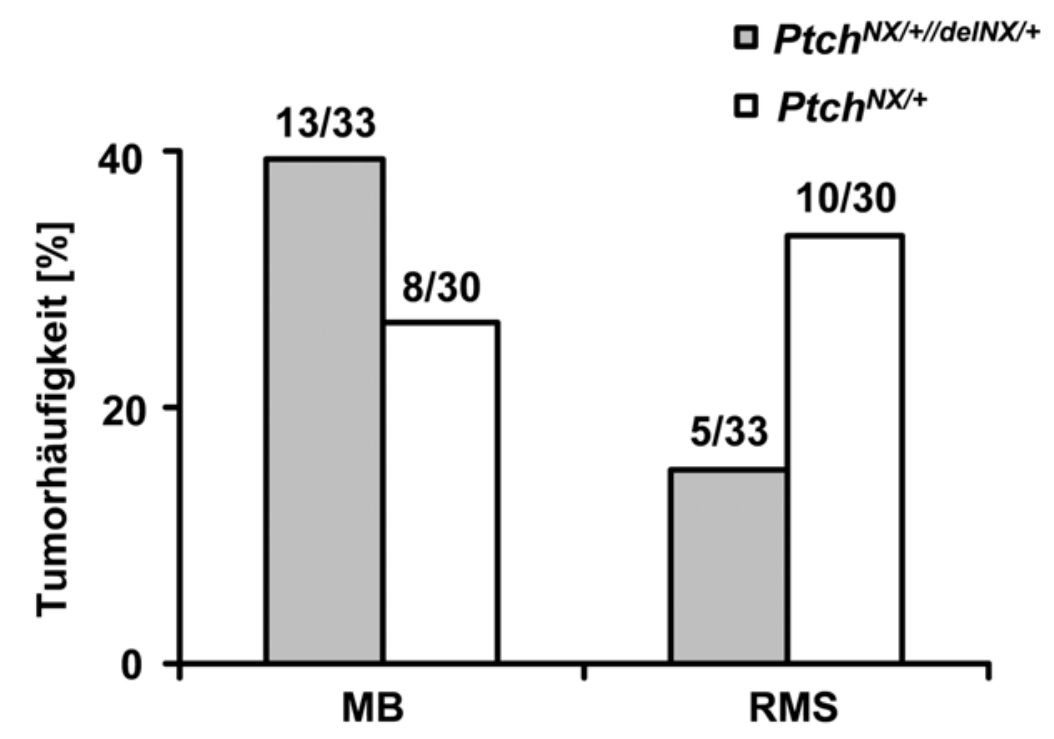

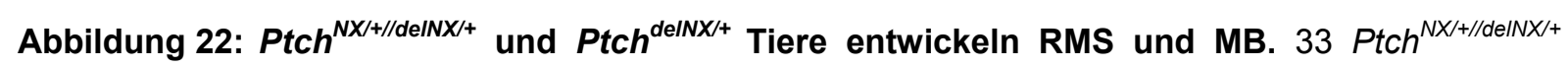
Tiere und 30 Ptch $^{\text {delNX/+ }}$ Tiere aus einer Rückkreuzung von weiblichen Ptch $^{\text {NX/+//delNX/+ }}$ Tieren mit männlichen Tieren eines gemischten C57BL/6N x Balb/c genetischen Hintergrundes wurden über 200 Tage engmaschig auf die Entwicklung von RMS und MB untersucht. 13 der 33 Ptch $^{\mathrm{NX/+//de/NX/+}}$ Tiere entwickelten MB und 5 entwickelten RMS. 8 der 30 Ptch $^{\text {delNX/+ }}$ Tiere entwickelten MB und 10 
entwickelten RMS. Keines der $22 \mathrm{Ptch}^{\mathrm{NX/+}}$ Kontrolltiere des jeweiligen genetischer Hintergrunds entwickelte Tumore.

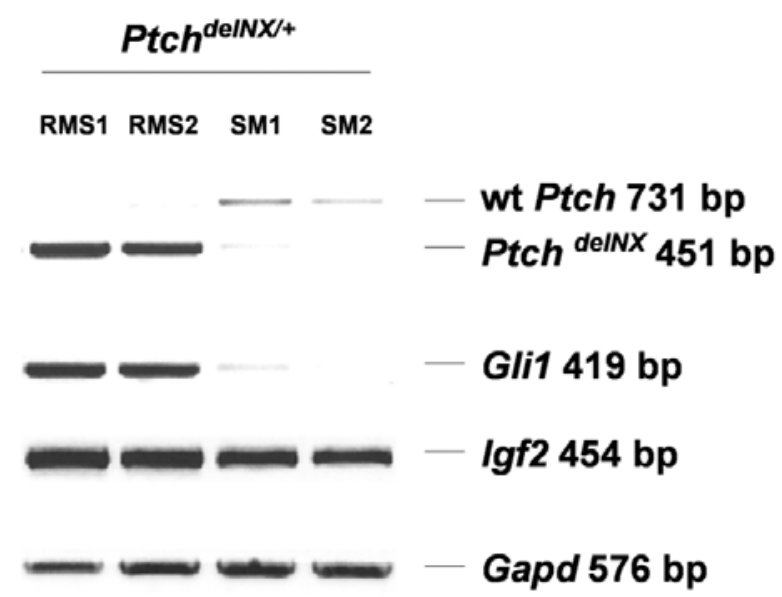

Abbildung 23: In RMS von von Ptch $^{\text {delNX/+ }}$ Tieren ist der Shh/Ptch Signalweg pathologisch aktiv. Es wurden RT-PCR-Untersuchungen von RMS und normalem Muskelgewebe (SM) von Ptch ${ }^{\text {delNX/+ }}$ Tieren mit dem DNA-Oligonukleotidpaar mPtc11/mPtc7R (Tabelle 10) durchgeführt. Die Anlagerungsstellen der DNA-Oligonukleotide am Ptch Lokus sind Abbildung 17 zu entnehmen. Mit den DNA-Oligonukleotidpaar mGliF8/ mGliR9 (Tabelle 10) wurde die Expression von Gli1 und mit Igf2 TaqManF/lgf2 Exon6R (Tabelle 10) die Expression von Igf2 nachgewiesen. Zur Kontrolle der cDNA wurden Gapd Transkripte amplifiziert.

\subsubsection{Die homozygote $P$ tch $^{\text {delNX/delNX }}$ Mutation ist embryonal letal}

Zur Analyse des Phänotyps von homozygoten Ptch delNX/deINX Embryonen wurden heterozygote Ptch ${ }^{\text {delNX/+ }}$ Tiere verpaart.

Die Genotypen der geborenen Nachkommen aus 6 Würfen, die aus dieser Verpaarung hervorgingen, wurden mit PCR-Analysen an genomischer DNA aus Schwanzbiopsien bestimmt.

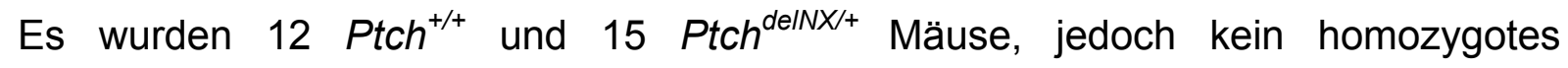
$P t c h^{\text {deINX/deINX }}$ Tier geboren (Tabelle 19). Um den Zeitpunkt des Todes der homozygoten Ptch ${ }^{\text {delNX/delNX }}$ Embryonen festzustellen, wurden die Weibchen aus den Geschwisterverpaarungen täglich auf erfolgte Kopulation untersucht. Vaginalplaquepositive Weibchen wurden von den Männchen getrennt, die Embryonen am Tag 9,5 $d p c$ bis 10,5 dpc isoliert und von den umgebenden Dottersäcken getrennt. Die Embryonen wurden in 4 \% Paraformaldehyd fixiert oder direkt zur Isolierung von Gesamt-RNA verwendet. Die Genotypen der isolierten Embryonen wurden über 
PCR-Analysen an genomischer DNA aus den entsprechenden Dottersäcken bestimmt.

Am Tag 9,5 $d p c$ bis 10,5 $d p c$ konnten nur noch wenige der homozygot mutanten Embryonen isoliert werden (Tabelle 20). Die Zahl entsprach lediglich $50 \%$ der nach Mendel erwarteten Anzahl. 7 resorbierte Embryonen wurden detektiert. Daraus kann geschlossen werden, dass homozygoten Ptch $^{\text {delNX/deINX }}$ Embryonen in utero absterben.

Tabelle 19: Genotypen geborener Nachkommen aus der Geschwisterverpaarung von Ptch $^{\text {del/+ }}$ Tieren. Nachkommen aus Geschwisterverpaarungen von heterozygoten Ptch $^{\text {delNX/+ }}$ Tieren wurden anhand von PCR-Analysen an genomischer-DNA aus Schwanzbiopsien genotypisiert. In jeder Zeile sind die Gesamtanzahl der Nachkommen und die Anzahl der jeweiligen Genotypen pro Wurf dargestellt.

\begin{tabular}{|c|c|c|c|}
\hline & \multirow{2}{*}{$\begin{array}{l}\text { Gesamtzahl } \\
\text { geborener } \\
\text { Nachkommen }\end{array}$} & \multicolumn{2}{|c|}{$\begin{array}{c}\text { Anzahl der genotypisierten } \\
\text { Nachkommen }\end{array}$} \\
\hline & & $\operatorname{Ptch}^{+/+}$ & $P t c h^{d e l l} X /++$ \\
\hline & 5 & 4 & 1 \\
\hline & 5 & 2 & 3 \\
\hline & 5 & 2 & 3 \\
\hline & 4 & 2 & 2 \\
\hline & 4 & 2 & 2 \\
\hline & 4 & 0 & 4 \\
\hline $\begin{array}{l}\text { Summe der } \\
\text { analysierten } \\
\text { Nachkommen }\end{array}$ & 27 & 12 & 15 \\
\hline
\end{tabular}

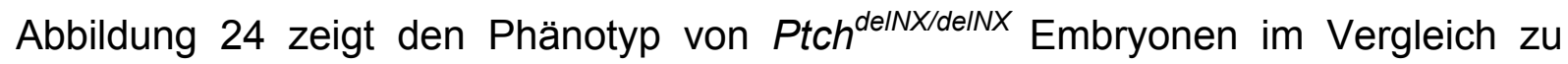
$\mathrm{Ptch}^{+/+}$Geschwisterembryonen. Der Ptch delNX/deINX Phänotyp gleicht dem beschriebenen embryonalen Phänotyp der Ptch ${ }^{\text {neo67/neo67 }}$ bzw. Ptch $h^{\text {neo12/neo12 }}$ Nullmutation und ist $u$. a. durch schwere kraniofaziale Defekte, fehlende Großhirnstrukturen, starkes Wachstum und Verschlussdefekte des Neuralrohrs charakterisiert (Goodrich LV et al., 1997; Hahn H et al., 1998). 
Tabelle 20: Genotypen isolierter Embryonen aus der Geschwisterverpaarung von Ptch ${ }^{\text {delNX/+ }}$

Tieren. Embryonen aus Geschwisterverpaarungen von heterozygoten $\operatorname{Ptch}^{\text {deINX/+}}$ Tieren wurden am Tag 9,5 dpc bis 10,5 $d p c$ isoliert und anhand von PCR-Analysen an genomischer DNA aus den entsprechenden Dottersäcken genotypisiert. Der Genotyp der abgestorbenen und resorbierten Embryonen konnte nicht bestimmt werden. In jeder Zeile sind die Gesamtanzahl der Embryonen, die Anzahl der entsprechenden Genotypen und die Anzahl der abgestorbenen, resorbierten Embryonen pro Wurf dargestellt.

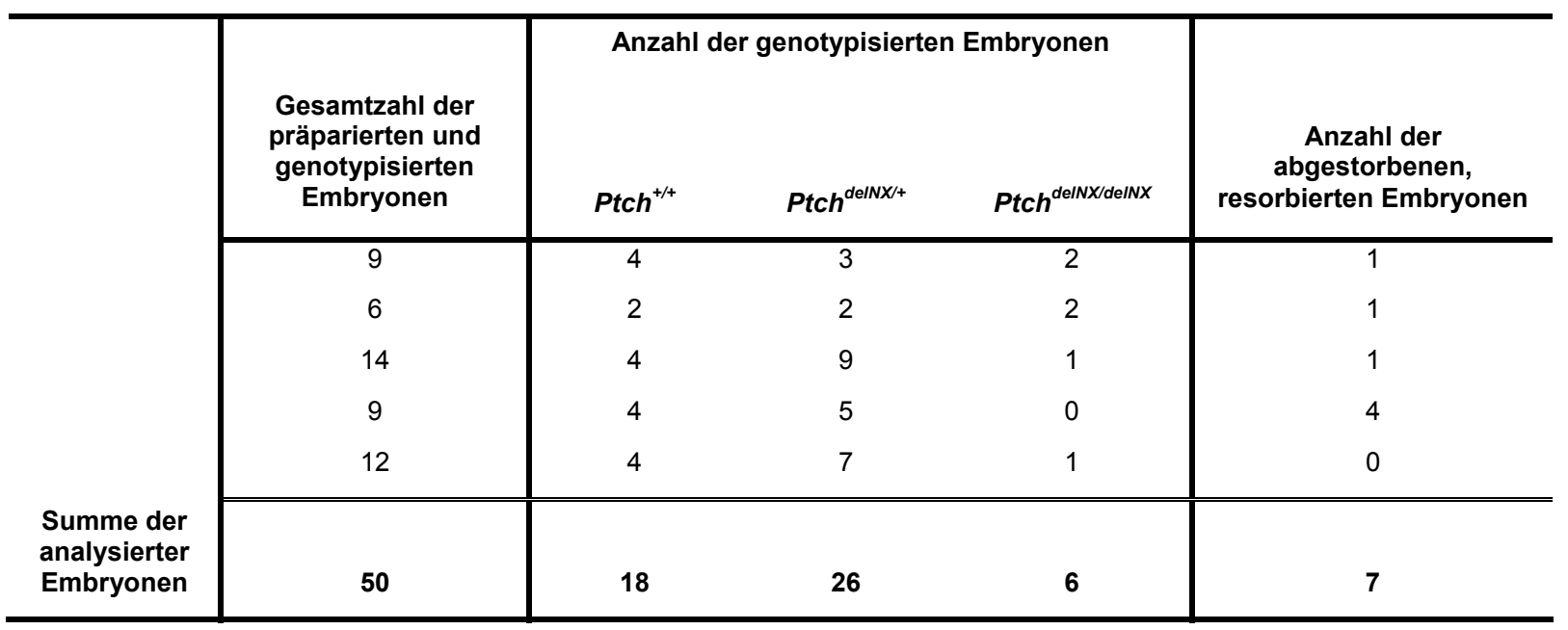
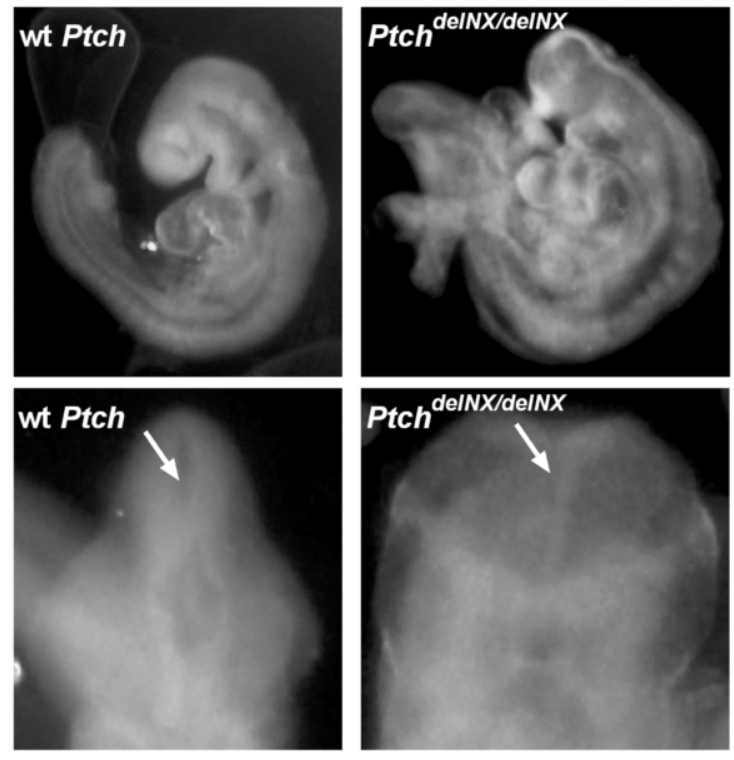

Abbildung 24: Ptch ${ }^{\text {delNX/delNX }}$ Embryonen sterben in utero und zeigen Entwicklungsdefekte. Embryonen aus Geschwisterverpaarungen von Ptch $^{\text {delNX/+ }}$ Tieren wurden im Alter von 9,5 dpc bis $10,5 d p c$ präpariert, fixiert und phänotypisiert. Die Genotypen der Embryonen wurden über PCRAnalysen an genomischer DNA aus den entsprechenden Dottersäcken bestimmt. Die Pfeile weisen auf das Neuralrohr. 
Abbildung 25 zeigt RT-PCR-Analysen an cDNA aus embryonaler Ptch $^{\text {delNX/delNX }}$ RNA im Vergleich zu Analysen von heterozygoten und wt Geschwisterembryonen. Es konnte gezeigt werden, dass homozygot mutante Embryonen nur das mutante $P t c h^{\text {deINX }}$ Transkript exprimieren. In den heterozygoten Ptch $^{\text {deINX/+ }}$ Embryonen wurden sowohl das wt Ptch als auch das Ptch ${ }^{\text {delNX }}$ Transkript detektiert. Sequenzanalysen des amplifizierten Ptch $^{\text {delNX }}$ Transkriptes belegten, dass in diesem Transkript die Exone 8 und 9 deletiert waren. Des Weiteren wurde eine leichte Überexpression von

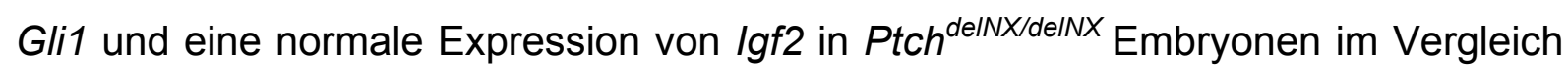
zu $\mathrm{Ptch}^{+/+}$und Ptch $^{\text {delNX/+ }}$ Embryonen detektiert.

Zusammengefasst zeigen die Daten, dass die $\operatorname{Ptch}^{\text {delNX }}$ Mutation nach Mendel vererbt wird, eine leichte abnormale Induktion des Shh/Ptch Signalweges bewirkt, zu dem in konventionellen Ptch knock-out Mäusen bereits beschriebenen homozygot letalen Phänotyp führt und im heterozygoten Zustand zu Tumoren prädisponiert.

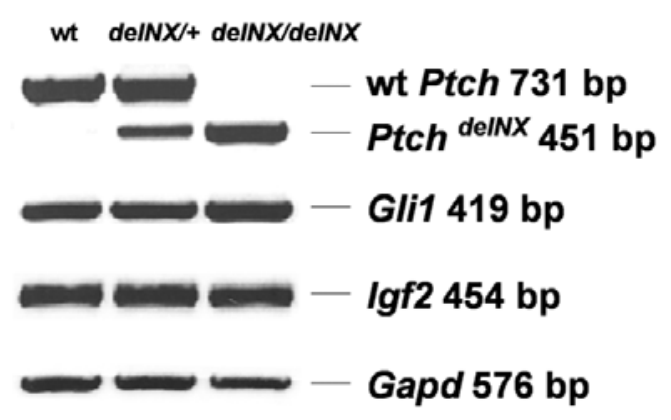

Abbildung 25: Ptch delNX/delNX Embryonen exprimieren das mutante Ptch ${ }^{\text {delNX}}$ Transkript. Embryonen aus Geschwisterverpaarungen von Ptch $^{\text {delNX/+ }}$ Tieren wurden im Alter von 9,5 dpc bis $10,5 d p c$ präpariert. Die Genotypen der Embryonen wurden über PCR-Analysen an genomischer DNA aus den entsprechenden Dottersäcken bestimmt. Nach Isolation der Gesamt-RNA der Embryonen wurden cDNA synthetisiert und RT-PCR-Analysen durchgeführt. Mit dem DNA-Oligonukleotidpaar mPtc11/mPtc7R (Tabelle 10) wurden die Ptch Transkripte nachgewiesen. Die Anlagerungsstellen der DNA-Oligonukleotide am Ptch Lokus sind Abbildung $17 \mathrm{zu}$ entnehmen. Mit dem DNAOligonukleotidpaar mGliF8/mGliR9 (Tabelle 10) wurde die Expression von Gli1 und mit Igf2 TaqManF/lgf2 Exon6R (Tabelle 10) die Expression von lgf2 nachgewiesen. Zur Kontrolle der cDNA wurden Gapd Transkripte amplifiziert. 


\subsubsection{Deletion von Ptch in adulten Mäusen mittels einer Tamoxifen- induzierbaren Cre-Rekombinase}

Um die Ptch Nullmutation in adulten Tieren induzieren zu können, wurden ROSA26CreERT2 Mäuse (ERT2; genetischer Hintergrund, 129Sv; A. Berns, Netherland Cancer Institute, Amsterdam; persönliche Mitteilung) mit Ptch $^{N X / N X}$ Tieren verpaart. ERT2 Mäuse exprimieren ein CreERT2-Rekombinaseprotein unter der Kontrolle des endogenen ROSA26 Promotor (Friedrich G und Soriano P, 1991), welches erst durch die Bindung des Medikamentes Tamoxifen aktiviert wird.

Von den Nachkommen wurden $P \operatorname{tch}{ }^{N X /+} E R T 2^{+/-}$mit $P \operatorname{tch}{ }^{N X / N X}$ Tieren weiterverpaart,

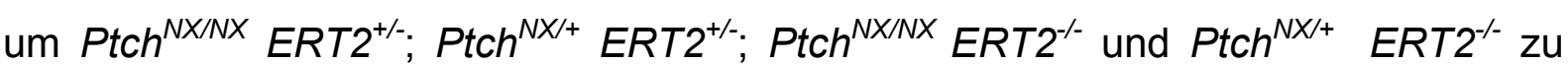
generieren. Diese Tiere wurden im Alter von 8 Wochen mit einer Gesamtdosis $5 \mathrm{mg}$ Tamoxifen (gespritzt wurde jeweils $1 \mathrm{mg}$ pro Tag über 5 Tage) oder Lösungsmittel (Emulsion aus Ethanol und Sonnenblumenöl) behandelt (Imai T et al., 2001). Die Tiere wurden engmaschig während und nach den Injektionen beobachtet und jeden zweiten Tag gewogen.

Die mit Tamoxifen-behandelten Ptch $^{N X / N X} E_{R T 2^{+/}}$Tiere werden im Weiteren als tPtch ${ }^{-/}$Mäuse bezeichnet.

\subsubsection{Phänotyp adulter Ptch $^{-/-}$Mäuse nach induzierter Inaktivierung von Ptch}

\subsection{In vivo Rekombinationseffizienz des Ptch $^{N X}$ Lokus}

Die Tamoxifen-induzierte Rekombinationsrate des $\operatorname{Ptch}^{N X}$ Lokus wurde mittels quantitativer real time PCR an genomischer DNA aus Organen von 6 Tieren des Genotyps $P t c h^{N X / N X} E R T 2^{+/}$von Dr. A. Zibat (Universität Göttingen, Institut für Humangenetik, wissenschaftlicher Assistent) ermittelt. Es wurden 3 Tiere mit Tamoxifen und 3 Tiere mit Lösungsmittel behandelt. Die Organe der Tiere wurden 10 Tage nach der ersten Injektion präpariert und die genomische DNA der Organe isoliert. Standardkurven wurden durch die Amplifikation des Ptch $^{N X}$ Lokus aus Organen von Ptch $^{N X N X} E R T 2^{-/}$Tieren erstellt. Für die Normalisierung der Rekombinationsdaten des Ptch ${ }^{N X}$ Lokus wurde ein pelota Gen-spezifischer PCRAssay verwendet. Die Daten wurden mit der Standardkuven-Methode für relative Quantifizierung ausgewertet und die Deletionseffizienz als Verhältnis des detektierten $P t c h^{\text {delNX }}$ Allels zur Summe der totalen Amplifikation von $\operatorname{Ptch}^{N X / N X}$ ERT2 ${ }^{-/}$DNA und 
dem detektierten Ptch $^{\text {deINX }}$ Allel kalkuliert. In Abbildung 26 ist die Effizienz der Rekombination in Prozent am Ptch ${ }^{N X}$ Lokus verschiedener Organe dargestellt.

Anhand dieser Analysen konnte eine Rekombination am Ptch ${ }^{N X}$ Lokus auch in Lösungsmittel-behandelten Ptch $^{N X / N X} E R T 2^{+/-}$Mäusen festgestellt werden (Abbildung 26). Es wurde allerdings keine Rekombinationsrate in einem der Gewebe dieser Tiere von über $50 \%$ beobachtet. Dies zeigt, dass die CreERT2-Rekombinase eine gewisse Grundaktivität ohne Gabe von Tamoxifen aufweist und somit "leaky“ ist. Aufgrund weiterer Analysen der Tiere konnte aber ein nachteiliger Effekt auf die Gesundheit der Mäuse durch diese "leakyness" ausgeschlossen werden (siehe Kapitel 3.2.5.1.2 bis 3.2.5.1.7).

Weiterhin wurde gezeigt, dass in $\operatorname{Ptch}^{N X / N X} E R T 2^{+/-}$Mäusen durch die Gabe von Tamoxifen $\left(\right.$ Ptch $\left.^{--}\right)$eine hohe Rekombinationsrate am Ptch $^{N X}$ Lokus hervorgerufen wird (Abbildung 26). In Leber, Milz, Thymus und Haut wurden Rekombinationsraten von über $80 \%$ festgestellt. Die erfolgte Rekombination des Ptch $^{N X}{\text { Lokus in } t P t c h^{-1}}^{-}$ Mäusen wurde auch über RT-PCR-Analysen mit den DNA-Oligonukleotiden mPtc11/mPtc7R (Tabelle 10) an cDNA von unterschiedlichen Organen von Ptch $^{-1}$ Tieren 19 Tage nach der Tamoxifengabe analysiert (Abbildung 27). Die Analyse zeigte, dass 19 Tage nach Induktion der CreERT2-Rekombinaseaktivität in Leber, Milz, Thymus und Haut fast ausschließlich mutante Ptch ${ }^{\text {delNX}}$ Transkripte exprimiert werden (Abbildung 27). Auch in Niere, Lunge, Herz und Skelettmuskel wurden Ptch $^{\text {delNX }}$ Transkripte detektiert. Jedoch werden in diesen Organen auch wt Transkripte exprimiert. Im Kleinhirn und Großhirn von $t$ Ptch $^{-/}$Tieren wurde nur die Expression von wt Ptch Transkripten beobachtet, was durch die geringe Aktivität des ROSA26 Promotors in diesen Geweben zu begründen ist (A. Berns, Netherland Cancer Institute, Amsterdam; persönliche Mitteilung).

Die Daten aus der Analyse der genomischen DNA stimmen daher mit den Expressionsanalysen überein. In Organen mit einer Rekombinationseffizienz von über 80 \% (Abbildung 26; Leber, Milz, Thymus, Haut) werden vorwiegend $P t c h^{d e I N X}$ Transkripte exprimiert (Abbildung 27). In Niere, Lunge, Herz und Skelettmuskel mit einer Rekombinationseffizienz am Ptch ${ }^{N X}$ Lokus von 60 bis $75 \%$ (Abbildung 26), werden sowohl Ptch ${ }^{\text {delNX}}$ als auch wt Transkripte exprimiert (Abbildung 27). 


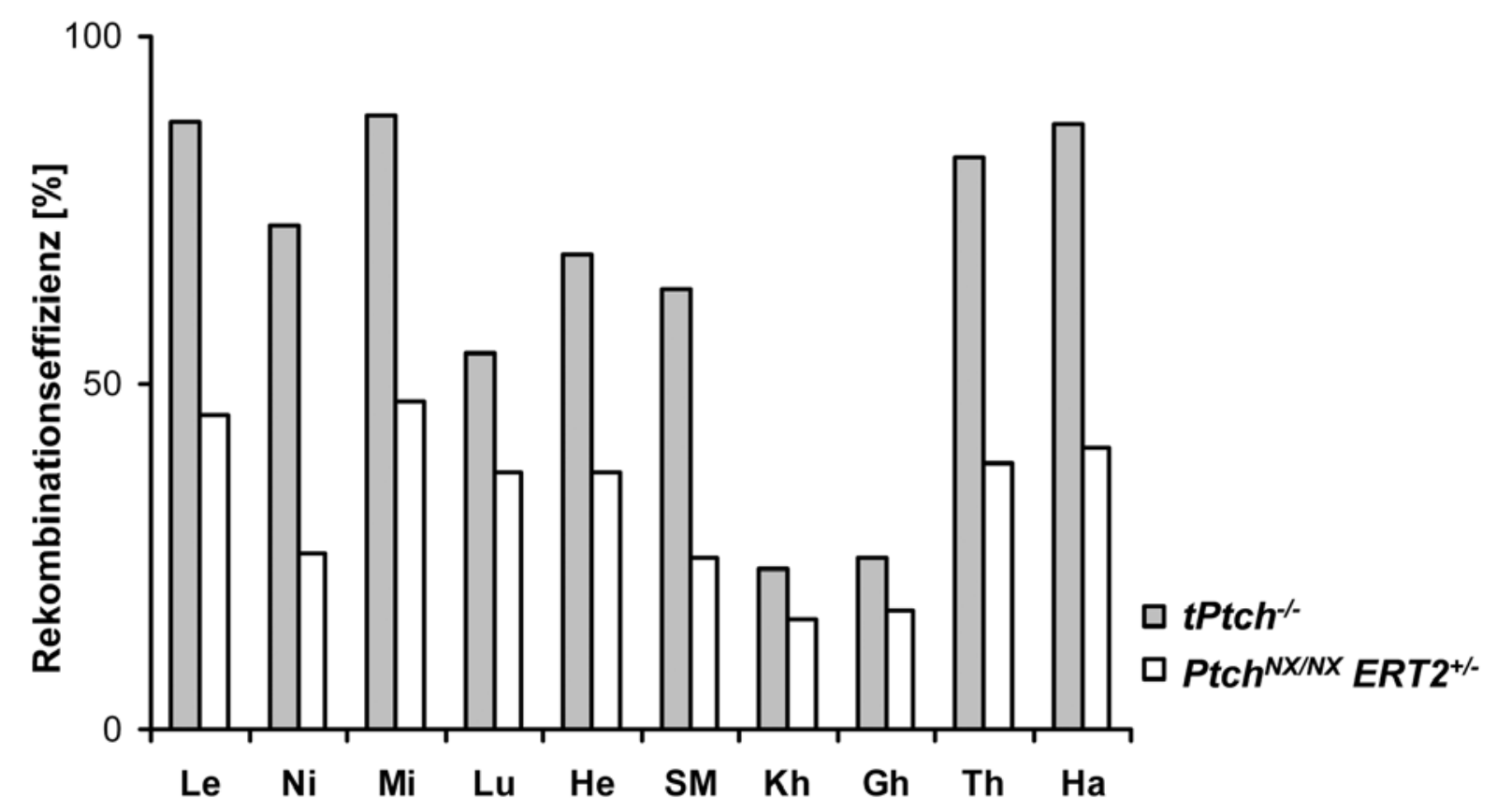

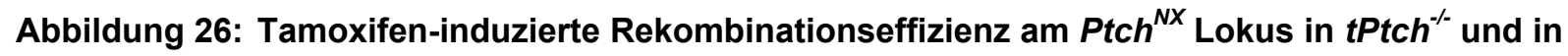
Lösungsmittel-behandelten Ptch $^{N \times / N X} E R T 2^{+/-}$Mäusen. Dargestellt ist die durch quantitative real time PCR an genomischer DNA ermittelten Rekombinationseffizienzen am Ptch ${ }^{N X}$ Lokus in Organen von Ptch $^{N X / N X}$ ERT2 ${ }^{+-}$Tieren 10 Tage nach der ersten Tamoxifen- $\left(t P t c h^{-/}\right)$bzw. Lösungsmittelgabe $\left(\right.$ Ptch $\left.^{N X / N X} E^{+} T_{2}^{+-}\right)$. Die gezeigten Daten entsprechen den Mittelwerten von jeweils 3 Organen aus 3 unterschiedlichen Tieren. Abkürzungen: Le, Leber; Ni, Niere; Mi, Milz; Lu, Lunge; He, Herz; SM, Skelettmuskel; Kh, Kleinhirn; Gh, Großhirn; Th, Thymus; Ha, Haut.

\section{tPtch $^{-/-}$}

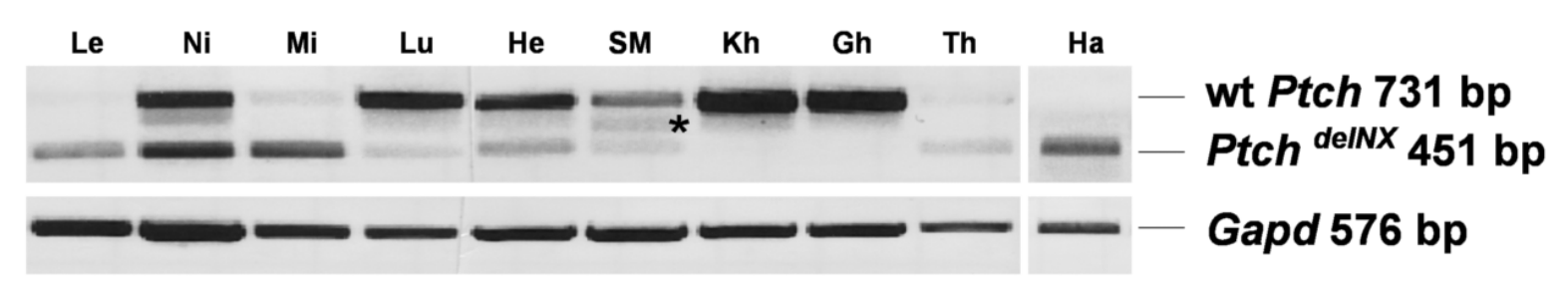

Abbildung 27: Expression des Ptch ${ }^{\text {delNx }}$ Allels in Organen von $\boldsymbol{t P t c h}^{-/}$Tieren. Es wurden Ptch Transkript-spezifische RT-PCR-Analysen an cDNA verschiedener Organe von tPtch $^{-/}$Tieren 19 Tage nach der ersten Tamoxifengabe durchgeführt. Hierzu wurde das DNA-Oligonukleotidpaar mPtc11/mPtc7R (Tabelle 10) verwendet. Zur Kontrolle der cDNA wurden Gapd Transkripte amplifiziert. Das mit einem Stern markierte Transkript im Skelettmuskel (SM) entspricht einer Ptch Spleiss-Variante (Nagao K et al., 2005a; Nagao K et al., 2005b). Abkürzungen: Le, Leber; Ni, Niere; Mi, Milz; Lu, Lunge; He, Herz; SM, Skelettmuskel; Kh, Kleinhirn; Gh, Großhirn; Th, Thymus; Ha, Haut. 


\subsection{Hyperproliferative Organveränderungen in $\mathrm{tPtch}^{-/}$Mäusen}

Erste phänotypische Veränderungen der $\mathrm{PPtch}^{-/}$Tiere wurden 10 Tage nach der ersten Tamoxifengabe beobachtet. Die Tiere verloren stark an Gewicht (bis zu $20 \%$ nach 20 Tagen) und putzen sich intensiv, was nach 12 Tagen zu kahlen Hautstellen führte (Abbildung 28). Da sich die körperliche Verfassung zunehmend verschlechterte, wurden die Tiere spätestens 23 Tage nach der ersten Tamoxifengabe getötet.

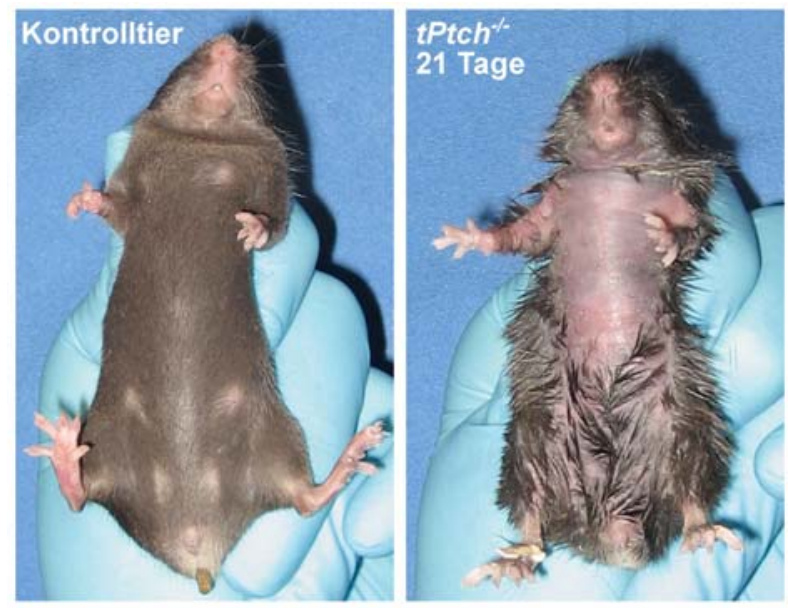

Abbildung 28: Fellveränderungen von $\boldsymbol{t P t c h}^{-/-}$Tieren. Dargestellt ist ein $\mathrm{tPtch}^{-/}$Tier 21 Tage nach der ersten Tamoxifengabe (rechts) im Vergleich zu einem mit Lösungsmittel-behandelten Ptch $^{N X / N X}$ $E_{R T 2}{ }^{+/}$Geschwistertier (links). tPtch $^{-/}$Tiere nehmen stark an Gewicht ab, zeigen einen stark ausgeprägten Putztrieb und die Fellhaare fallen ventral aus.

Histologische Untersuchungen von perfundierten PPtch $^{-/}$Tieren zeigten schon 19 Tage nach der ersten Tamoxifengabe schwere Abnormitäten der Haut. Es wurde eine starke Proliferation der interfollikulären und follikulären Epidermis festgestellt (Abbildung 29). Außerdem entwickelten die Tiere hyperproliferative Bereiche in der Magenwand (Abbildung 30) und im Mesenterium (Abbildung 31). Herz, Lunge, Leber, Niere, Pankreas und Skelettmuskeln von $\mathrm{tPtch}^{-/}$Mäusen zeigten nach 19 Tagen keine histologischen Veränderungen (Daten nicht gezeigt).

Die Blutwerte von $\mathrm{PPtch}^{-/}$Tieren waren weitgehend unauffällig (Tabelle 21). Jedoch wiesen erhöhte Harnstoffwerte in Ptch $^{-/}$Tieren 15 Tage nach der ersten Tamoxifengabe auf eine abnormale Nierenfunktion hin, obwohl keine auffällige Morphologie von $\mathrm{tPtch}^{-/}$Nierengewebe festgestellt werden konnte. Des Weiteren wiesen $\mathrm{tPtch}^{-/}$Tiere erniedrigte Glukosewerte auf, was auf endokrinologische Defekte oder erhöhte Glukoneogenese im Magen-Darmtrakt zurückzuführen sein 
könnte. In keiner der Kontrollkohorten wurden entsprechende Abnormitäten beobachtet. Die biochemische Analyse der Blutserumparameter wurde von Dr. T. Heller (Universitätsklinikum Göttingen, Abt. Klinische Chemie) durchgeführt.
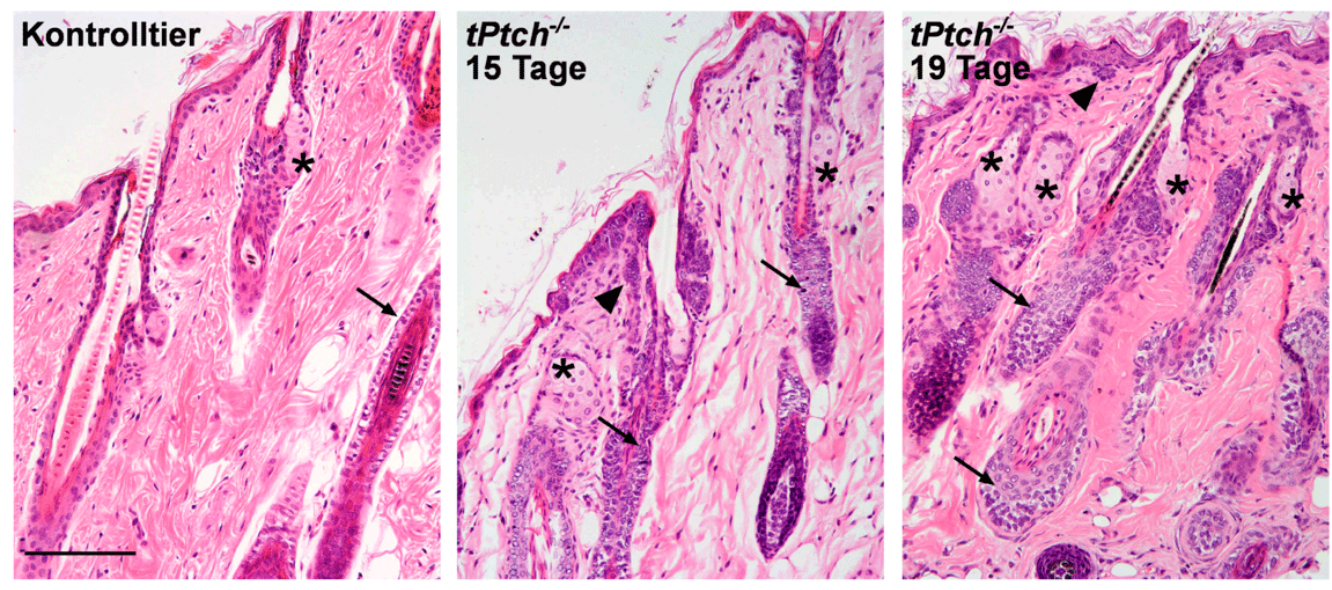

Abbildung 29: Hyperproliferative Areale der Epidermis von Ptch $^{-/}$Mäusen. Dargestellt sind HE gefärbte Paraffinschnitte von Ptch $^{-/}$Tieren 15 Tage (Mitte) und 19 Tage (rechts) nach der ersten Tamoxifengabe im Vergleich zu einem mit Lösungsmittel-behandelten $\operatorname{Ptch}^{N X / N X} E R T 2^{+/}$Tier (links). Die Pfeilköpfe zeigen auf Areale mit irregulärer interfollikulärer Proliferation der Epidermis. Pfeile kennzeichnen die äußere Wurzelscheide und Sterne die Talgdrüsen. Der Balken entspricht $2 \mathrm{~mm}$ im Präparat.
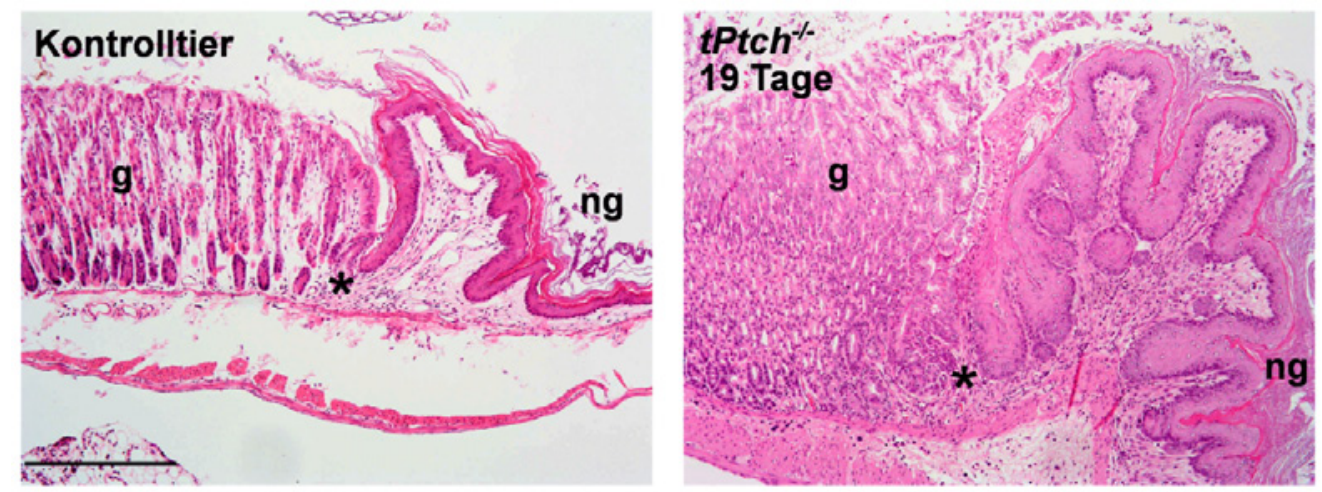

Abbildung 30: Hyperproliferative Areale des Magens von Ptch $^{-/}$Mäusen. Dargestellt sind HE gefärbte Paraffinschnitte eines $\mathrm{tPtch}^{-/}$Tiers 19 Tage (rechts) nach der ersten Tamoxifengabe im Vergleich zu einem mit Lösungsmittel-behandelten $P t c h^{N X / N X} E R T 2^{+/}$Tier (links). Sterne markieren den Übergang vom nicht-glandulären, kutanen (ng) zum glandulären, mukösen Magen (g). Der Balken entspricht $5 \mathrm{~mm}$ im Präparat. 

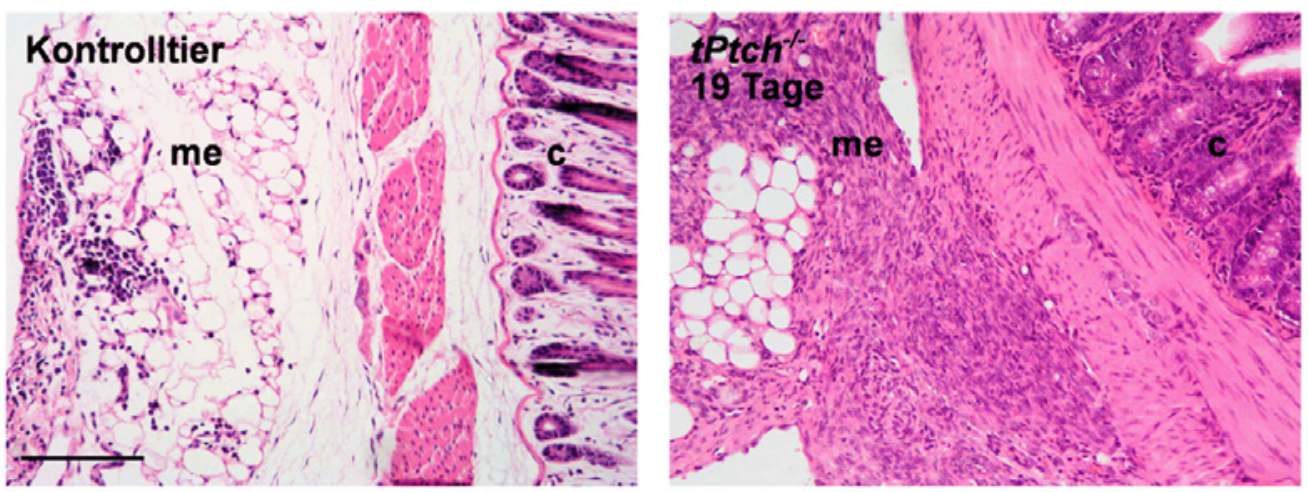

Abbildung 31: Hyperproliferative Areale des Mesenteriums von $\boldsymbol{t P t c h}^{-/-}$Mäusen. Dargestellt sind HE gefärbte Paraffinschnitte eines Ptch $^{-/}$Tiers 19 Tage (rechts) nach der ersten Tamoxifengabe im Vergleich zu einem mit Lösungsmittel-behandelten $\operatorname{Ptch}^{N X / N X} E R T 2^{+/-}$Tier (links). Der Balken entspricht 2 mm im Präparat. Abkürzungen: me, Mesenterium; c, Magenkorpus.

Tabelle 21: Biochemische Analyse von Blutserumparametern von Ptch $^{-/}$Mäusen. Aus durch Herzpunktion entnommenem Vollblut wurde 15 Tage nach der ersten Tamoxifengabe das Serum von tPtch $^{-/}$, von Tamoxifen-behandelten Ptch ${ }^{N X / N X} E R T 2^{-/}$und Lösungsmittel-behandelten Ptch ${ }^{N X / N X}$ $E R T 2^{+/}$Mäusen gewonnen und Blutserumparameter bestimmt. Abkürzungen: Glu, Glukose; Chol, Cholesterin; TG, Triglyceride; SGPT, Serum-Glutamat-Pyruvat-Transaminase; Bil-T, Gesamt-Bilirubin; BUN, Blutharnstoff; Tprot, Gesamt-Protein. Die Anzahl der jeweils analysierten Tiere ist in der Spalte $\mathrm{n}$ angegeben. P Werte wurden mit dem Mann-Whitney-U-Test berechnet. Parameter mit signifikanten Unterschieden $(P$ Wert $<0,05)$ zwischen $t P t c h{ }^{-/}$und Kontrolltieren sind grau unterlegt.

\begin{tabular}{|c|c|c|c|c|c|c|c|c|c|c|}
\hline & Tamox & $\begin{array}{l}\text { n-behandelte } \\
\text { ntrollen }\end{array}$ & & Lösung & $\begin{array}{l}\text { ittel-behandelt } \\
\text { ntrollen }\end{array}$ & & & $\operatorname{Ptch}^{-/}$ & & \\
\hline & Mittelwert & $\begin{array}{l}\text { Mittelwert- } \\
\text { abweichung }\end{array}$ & $\mathrm{n}$ & Mittelwert & $\begin{array}{l}\text { Mittelwert- } \\
\text { abweichung }\end{array}$ & $\mathrm{n}$ & Mittelwert & $\begin{array}{l}\text { Mittelwert- } \\
\text { abweichung }\end{array}$ & $\mathbf{n}$ & P Wert \\
\hline $\begin{array}{c}\text { Glu } \\
{[\mathrm{mg} / \mathrm{dl}]}\end{array}$ & 262,1 & 50,1 & 17 & 302,8 & 52,9 & 17 & 170,7 & 42,1 & 9 & 0,00006 \\
\hline $\begin{array}{c}\begin{array}{c}\text { Chol } \\
\text { [mg/dl] }\end{array} \\
\text { TG }\end{array}$ & 98,4 & 14,5 & 13 & 122,3 & 31,8 & 15 & 114,4 & 25,5 & 8 & 0,83382 \\
\hline [g/dl] & 149,0 & 38,6 & 13 & 165,5 & 43,4 & 13 & 179,9 & 44,7 & 7 & 0,36815 \\
\hline $\begin{array}{l}\text { SGPT } \\
{[I U / I]}\end{array}$ & 59,7 & 11,5 & 10 & 67,1 & 27,5 & 8 & 57,5 & 10,5 & 6 & 0,68420 \\
\hline $\begin{array}{c}\text { Bil-T } \\
{[\mathrm{mg} / \mathrm{dl}]}\end{array}$ & 0,3 & 0,1 & 13 & 0,2 & 0,1 & 15 & 0,2 & 0,2 & 10 & 0,51867 \\
\hline $\begin{array}{c}\text { BUN } \\
{[\mathrm{mg} / \mathrm{dl}]}\end{array}$ & 25,8 & 4,5 & 15 & 20,4 & 2,9 & 16 & 31,1 & 5,1 & 11 & 0,00646 \\
\hline $\begin{array}{l}\text { Tprot } \\
\text { [g/dl] }\end{array}$ & 5,3 & 0,3 & 11 & 5,3 & 0,8 & 15 & 5,7 & 0,4 & 6 & 0,26770 \\
\hline
\end{tabular}




\subsection{T Zelldefekte in Thymi von tPtch $^{-/-}$Mäusen}

\subsection{Histologische Analysen von $\boldsymbol{t P t c h}^{-/}$Thymi}

Ab dem 15. Tag nach der ersten Tamoxifengabe zeigten tPtch $^{-/}$Tiere eine zunehmende Verkleinerung des Thymus (Abbildung 32). Die histologische Analyse der Thymi zeigte eine deutliche Reduktion der Thymusrinde (Kortex) (Abbildung 33). Nach 19 Tagen war diese in HE-Färbungen nicht mehr vom Mark des Thymus (Medulla) abgrenzbar. Immunhistologische Färbungen der T Zellpopulationen mit einem anti-CD3 Antikörper zeigten, dass die markständige $\mathrm{T}$ Zellfraktion in den tPtch $^{-/}$Thymi erhalten blieb. Im Thymuskortex war jedoch ein dramatischer Verlust von $\mathrm{CD}^{+} \mathrm{T}$ Zellen zu beobachten (Abbildung 34, oben). Dagegen wurde keine Veränderung der B220 ${ }^{+} \mathrm{B}$ Zellpopulation in den $t P t c h^{--}$Thymi detektiert (Abbildung 34, unten). Aufgrund der Lokalisation von T und B Zellen konnte Kortex und Medulla der tPtch $^{-/}$Thymi selbst am Tag 19 nach der ersten Tamoxifeninjektion noch unterschieden werden (vergleiche Abbildung 33 und Abbildung 34), was an HE gefärbten Paraffinschnitten zu diesem Zeitpunkt nicht mehr möglich war.

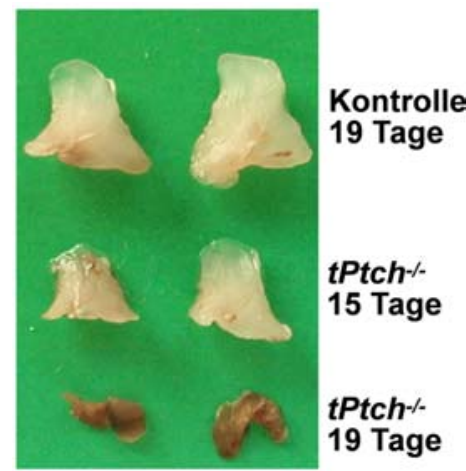

Abbildung 32: Reduktion der Thymusgröße in $\mathbf{t P t c h}^{-/}$Mäusen. Dargestellt sind die präparierten Thymi von $\mathrm{tPtch}^{-/}$Tieren 15 Tage (Mitte) und 19 Tage (unten) nach der ersten Tamoxifengabe im Vergleich zu einem mit Lösungsmittel-behandelten $\operatorname{Ptch}^{N X / N X} E R T 2^{+/-}$Tier (oben).
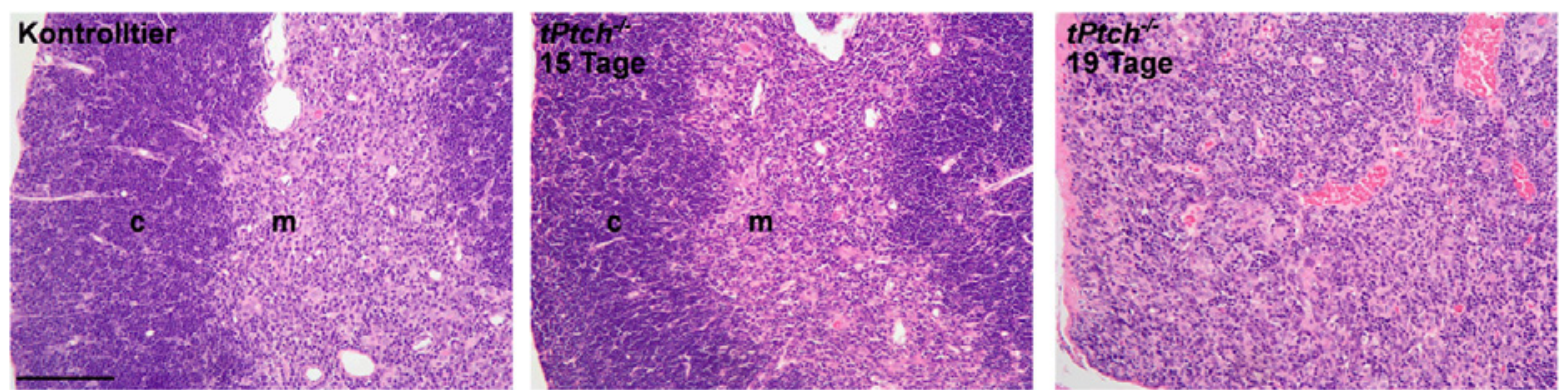

Abbildung 33: Reduktion des Thymuskortex in $\mathbf{t P t c h}^{-/}$Mäusen. Dargestellt sind HE gefärbte Paraffinschnitte von Thymi aus Ptch $^{-/}$Tieren 15 Tage (Mitte) und 19 Tage (rechts) nach der ersten 
Tamoxifengabe im Vergleich zu einem mit Lösungsmittel-behandelten $\operatorname{Ptch}^{N X / N X} E R T 2^{+/-}$Tier (links). Der Balken entspricht 2 mm im Präparat. Abkürzungen: c, Kortex; m, Medulla.
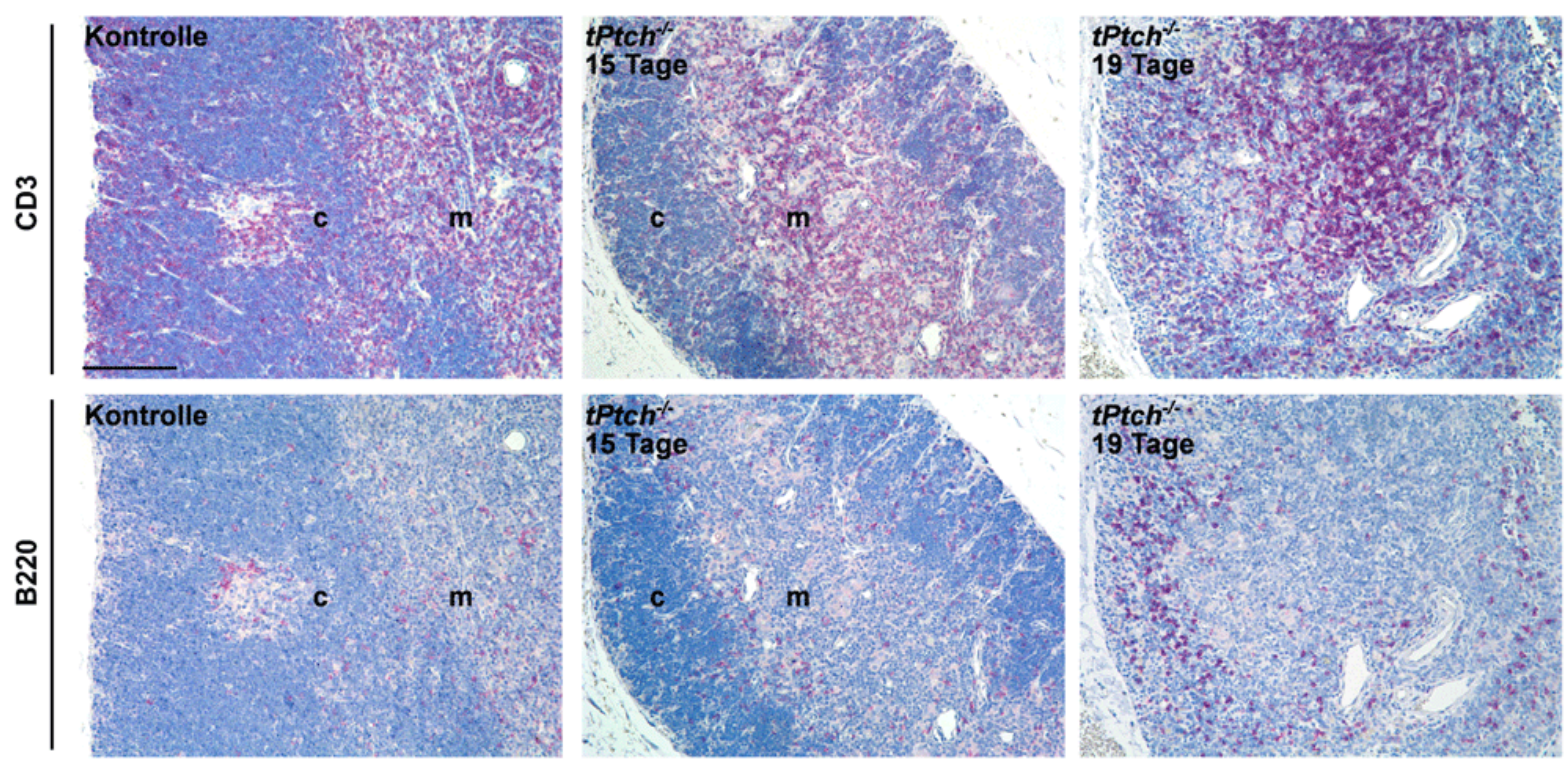

Abbildung 34: Reduktion der T Zellpopulationen im Thymuskortex in $\mathbf{t P t c h}^{-/}$Mäusen. Dargestellt sind anti-CD3 (oben) und anti-B220 (unten) gefärbte Paraffinschnitte von Thymi aus Ptch $^{-/}$Tieren 15 Tage (Mitte) und 19 Tage (rechts) nach der ersten Tamoxifengabe im Vergleich zu einem mit Lösungsmittel-behandelten Ptch $^{N X N X} E R T 2^{+/}$Tier (links). Der Balken entspricht $2 \mathrm{~mm}$ im Präparat. Abkürzungen: c, Kortex; m, Medulla.

\subsection{Durchflusszytometrische Analysen von $\operatorname{tPtch}^{-/}$Thymozyten}

Aufgrund der histologischen Abnormitäten von Ptch $^{-/}$Thymi wurden die Oberflächenproteine von Thymozyten durchflusszytometrisch untersucht. Mittels dieser Methode können Größe, Granularität und Fluoreszenz von Zellen untersucht werden. Zur Messung werden die Zellen in einem Flüssigkeitsstrom einzeln von einem Laserstrahl vermessen. Dabei dient die Lichtstreuung des Laserstrahls nach dem Auftreffen auf die Zelle zur Messung der Größe und der Granularität der Zelle. Die Lichtstreuung nach vorn (forward scatter, FSC) ist ein Maß für die Größe der Zelle. Mit der seitwärts gerichteter Lichtstreuung (side scatter, SSC) wird die intrazelluläre Granularität gemessen. Zum Nachweis von Oberflächenproteinen der Zellen werden mit Fluoreszenzfarbstoffen gekoppelte Antikörper verwendet, die das jeweilig nachzuweisende Antigen binden.

Anhand der spezifischen Expression von Oberflächenproteinen lassen sich die einzelnen Stadien der Thymozytendifferenzierung verfolgen. Die in den Thymus eingewanderten frühen $\mathrm{T}$ Zellvorläufer (early $\mathrm{T}$ cell progenitor; ETP) sind 
charakterisiert durch die hohe Expression von c-kit (kit Onkogen). Im Verlauf ihrer Differenzierung zu Thymozyten durchlaufen sie die so genannten doppelt negativen Stadien, da in diesen Stadien weder CD4 noch CD8 exprimiert werden (DN CD4 CD8-). Die DN Stadien können über die unterschiedliche Expression der Proteine CD44 und CD25 unterschieden werden (DN1 bis DN4). Ab dem DN3 Stadium $\left(C D 44^{-} \mathrm{CD}^{+} 5^{+}\right.$) exprimieren Thymozyten zusätzlich CD3 und den T Zellrezeptor $B$ ( $T$ cell receptor; TCRß), durch deren Nachweis auch frühe DN Stadien von späteren Thymozytenstadien unterschieden werden können. Während der weiteren Entwicklung der Thymozyten erhöht sich die Expression von CD4 und CD8. So exprimieren späte Thymozyten CD4 und CD8 (CD4 ${ }^{+} \mathrm{CD} 8^{+}$doppelt positiv; DP). Die Stadien der einfach positiven $\mathrm{CD}^{+}$oder $\mathrm{CD}^{+}$Thymozyten (SP, single positive) stellen die Endstufe der Differenzierung der T Zellen dar, wobei CD4 ${ }^{+}$SP T Zellen die Population der T Helferzellen und CD8 ${ }^{+}$SP T Zellen die Population der zytotoxischen T Lymphozyten bilden (Rothenberg EV und Taghon T, 2005).

Um die Thymozytenentwicklung von $\mathrm{tPtch}^{-/}$Tieren zu untersuchen, wurden daher durchflusszytometrische Untersuchungen von simultanen Antikörperfärbungen mit anti-CD25/CD44/CD4/CD8 Antikörpern sowie Antikörperfärbungen mit anti-CD3 Antikörpern und mit anti-TCRß Antikörpern durchgeführt. Als Kontrollen wurden bei jeder Färbung und Messung Thymozyten von Lösungsmittel-behandelten Ptch $^{N X / N X}$ $E R T 2^{+/}$, und Tamoxifen-behandelten bzw. Lösungsmittel-behandelten Ptch ${ }^{N X / N X}$ $E R T 2^{-/}$Mäusen mitgeführt. Die Analyse der Thymozyten wurden sowohl 15 als auch 19 Tage nach der Tamoxifen-bzw. Lösungsmittelgabe durchgeführt.

Besonders auffällig war zunächst die starke Reduktion der GesamtThymozytenanzahl in den Ptch $^{-/}$Thymi (Abbildung 35, Abbildung 36; links). Die Werte in Abbildung 35 wurden anhand aller durchgeführten durchflusszytometrischen Analysen von Thymozyten ermittelt. Die Granularität wurde gegen die Größe (SSC/FSC) aller Zellen aufgetragen (Abbildung 36, links). Aufgrund der definierten Granularität und Größe der Lymphozyten konnte so die Anzahl der Thymozyten in den vermessenen Proben ermittelt werden (Abbildung 36). Abbildung 35 zeigt, dass die relative Anzahl der Thymozytenfraktion aus Ptch $^{-1}$ Thymi 13- bis 20-fach gegenüber der Kontrollthymi reduziert war.

Im Vergleich zu den Kontrolltieren wurde in den einzelnen T Zellpopulationen von tPtch $^{--}$Tieren eine stark reduzierte Zahl von $\mathrm{CD} 4^{+} \mathrm{CD} 8^{+}$DP T Zellen beobachtet. 
Dagegen nahm die Zahl der unreifen CD4 ${ }^{-C D 8} 8^{-}$DN und reifen CD4 SP bzw. CD8 SP T Zellen zu (Abbildung 36; Mitte). Der Defekt war 19 Tage nach der ersten Tamoxifengabe noch deutlicher ausgeprägt als nach 15 Tagen.

Zusätzlich wurde eine Analyse der CD3 und TCRß Expression der Ptch $^{-\alpha}$ Thymozyten durchgeführt. Diese erlaubte die Unterscheidung von späten T Zellen, welche $\mathrm{CD} 3$ und TCRß stark exprimieren und frühen $\mathrm{T}$ Zellen, die beide Oberflächenproteine nur gering exprimieren. Die Ergebnisse in Abbildung 37 zeigen, dass die Thymozyten aus $\mathrm{tPtch}^{-/}$Thymi eine reduzierte CD3 und TCRß schwach exprimierende Fraktion aufwiesen, während die Populationen von $\mathrm{CD}^{+}$und $\mathrm{TCR}^{+}$ T Zellen relativ erhalten blieb (links und Mitte).

Diese Daten bestätigen die Ergebnisse der anti-CD4/CD8 Antikörperfärbungen (Abbildung 36; Mitte) und zeigen, dass die Abnahme von unreifen T Zellen mit einer relativen Zunahme von reifen T Zellen in den $t P t c h{ }^{-/}$Thymi gekoppelt ist. Ob die Ptch Deletion die Funktionalität des T Zellrezeptors beeinflusst, ist mit dieser Analyse nicht eindeutig zu klären.

Zusammengefasst wiesen diese Ergebnisse auf einen Entwicklungsdefekt der T Zellen in $\mathrm{tPtch}^{-/}$Mäusen zwischen dem DN und dem DP Stadium hin. Der Verlust der T Zellen wurde hierbei nicht durch Apoptose induziert, was durch Analyse der Annexin $\vee$ Expression der Thymozyten gezeigt werden konnte (Abbildung 37; rechts). So wurde im Vergleich zu den Kontrollkohorten keine signifikante Erhöhung von Annexin V-positiven Ptch $^{-/}$Thymozyten in den untersuchten T Zell Populationen (DN; CD4 SP oder CD8 SP) beobachtet.

Um den Differenzierungsdefekt von tPtch $^{-/}$Thymozyten näher zu definieren, wurden nun DN Thymozyten anhand der Expression von CD44 und CD25 untersucht. Die DN1 Population ist durch die Expression von CD44 (CD44 $\left.{ }^{+} \mathrm{CD} 25^{\circ}\right)$ charakterisiert und besitzt noch multiples Differenzierungspotential. Während der weiteren Entwicklung zum DN2 Stadium wird zusätzlich zu CD44 auch CD25 exprimiert $\left(C D 44^{+} \mathrm{CD} 25^{+}\right)$. Die Expression von CD44 und CD25 wird nachfolgend nacheinander reduziert, so dass im DN3 Stadium kein CD44 mehr exprimiert wird (CD44-CD25 $\left.{ }^{+}\right)$und im DN4 Stadium beide Oberflächenproteine nicht mehr nachweisbar sind (CD44-CD25) (Huesmann M et al., 1991; Ardavin C et al., 1993; Godfrey Dl et al., 1993; Wu L et al., 1996; Bhandoola A und Sambandam A, 2006b). 
Bereits 15 Tage nach der ersten Tamoxifengabe zeigten die DN Populationen der tPtch $^{-/}$Mäuse deutliche Unterschiede zu den untersuchten Kontrollkohorten (Abbildung 36; rechts). Es wurde eine relative Erhöhung der Anzahl von DN1 Thymozyten beobachtet, während die DN2 und DN3 Populationen deutlich reduziert waren. 19 Tage nach der ersten Tamoxifengabe war die DN1 Population stark überrepräsentiert, und DN2 und DN3 Thymozyten konnten nicht mehr detektiert werden. Veränderungen der relativen Zahlen von DN4 T Zellen wurden aber nicht festgestellt.

Die relative Erhöhung der DN1 Population in $\operatorname{tPtch}^{-/}$Thymi ließ auf einen Entwicklungsdefekt der Thymozyten im oder nach dem DN1 Stadium schließen. Durch einen solchen Defekt lässt sich der komplette Verlust der DN2 und DN3 Populationen erklären. Die gleich bleibende Anzahl der DN4 Population könnte bedeuten, dass Ptch eventuell eine zusätzliche Rolle im oder nach dem DN4 Stadium spielen könnte.

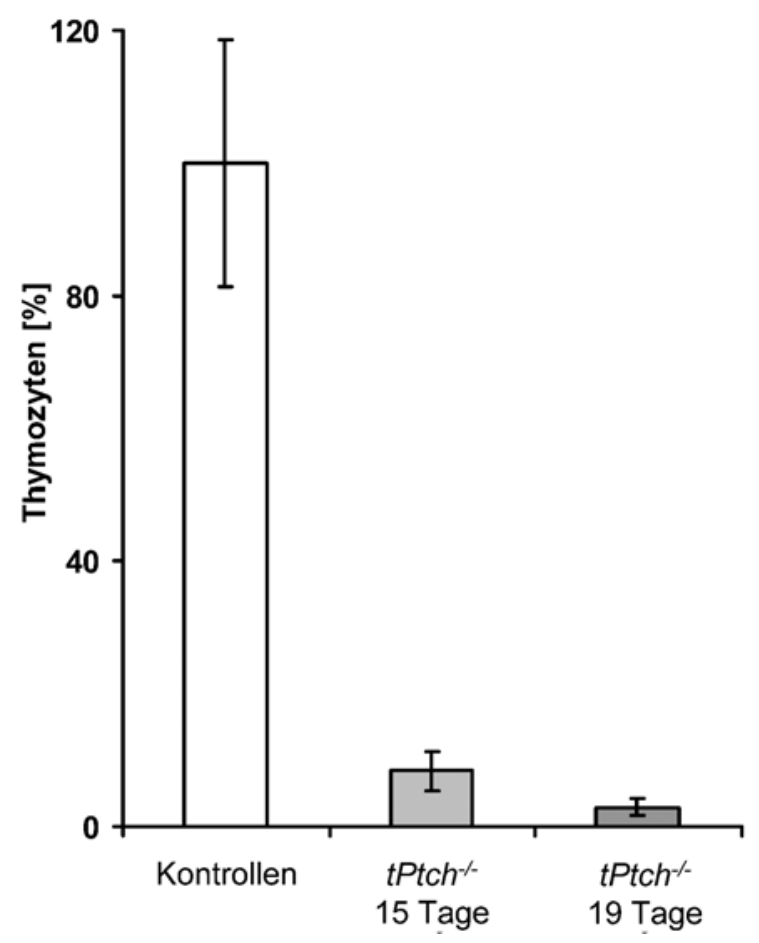

Abbildung 35: Reduktion der Thymozyten in $\mathbf{t P t c h}^{-/}$Thymi. Dargestellt ist die relative Thymozytenzahl aus Thymi von Ptch $^{-/}$Tieren 15 Tage (Mitte; 4 Tiere) sowie 19 Tage (rechts; 3 Tiere) nach der ersten Tamoxifengabe und von Kontrolltieren (links; die Werte von 9 Tamoxifen- und 7 Lösungsmittel-behandelten Tieren wurden hierbei zusammengefasst). Die relative Anzahl der Thymozyten wurde in durchflusszytometrischen Messungen im SSC/FSC Plot (siehe Abbildung 36) bestimmt. 

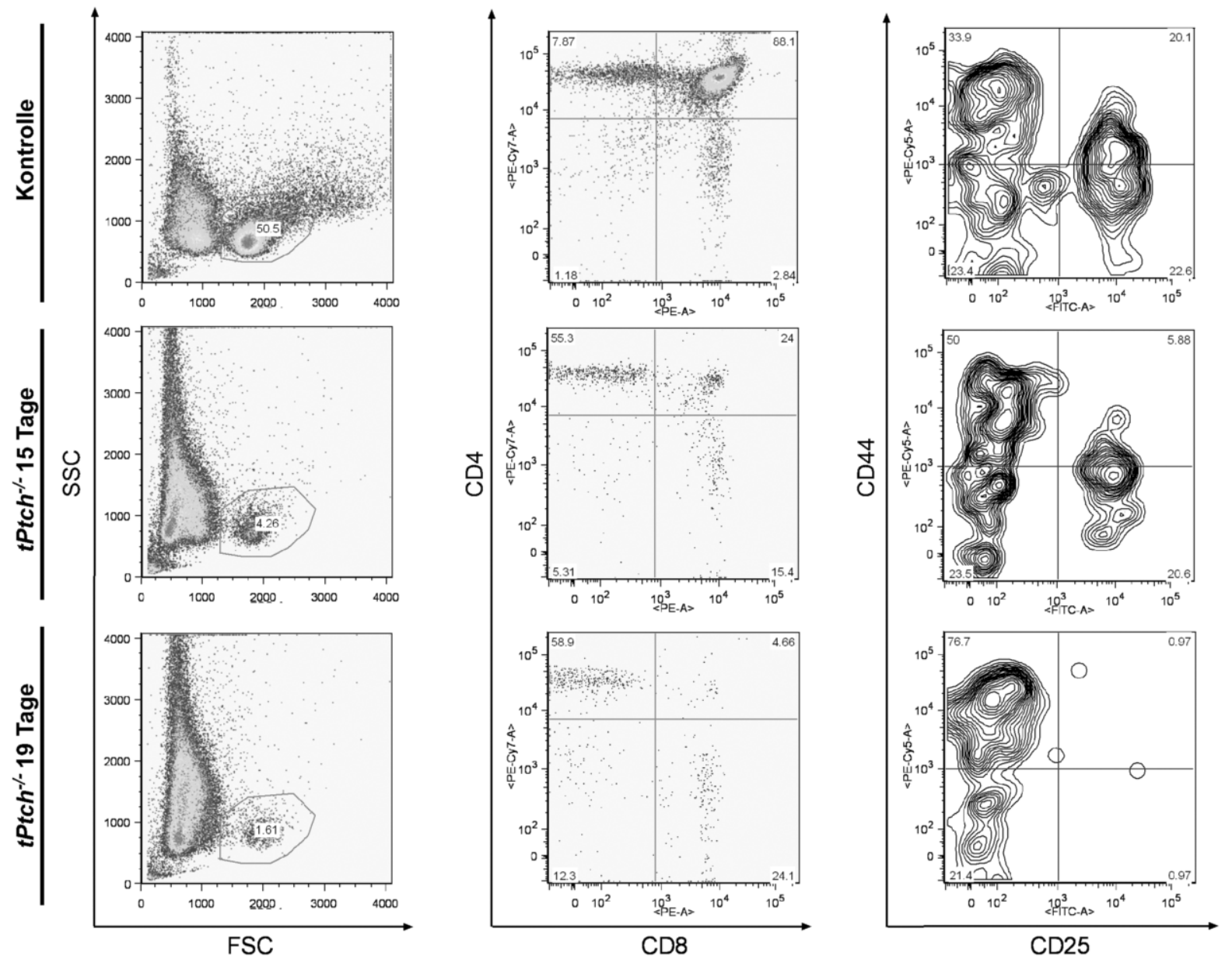

Abbildung 36: Reifungsdefekt von $\mathrm{T}$ Zellen in Thymi von Ptch $^{-/}$Mäusen. Dargestellt sind durchflusszytometrische Analysen von Thymozyten, welche aus Thymi von Lösungsmittelbehandelten Ptch $^{N X / N X} E R T 2^{+/}$(oben) und P $t c h^{-/}$Tieren 15 Tage (Mitte) oder 19 Tage (unten) nach der ersten Tamoxifengabe isoliert wurden. Tamoxifen-behandelte $\operatorname{Ptch}^{N X / N X} E R T 2^{-/}$Kontrolltiere zeigten ebenfalls eine normale T Zellentwicklung (Daten nicht gezeigt). Rechts ist der SSC/FCS Plot von Gesamtthymuszellen aus der Färbung mit anti-CD44/CD25/CD4/CD8 Antikörpern dargestellt. Der Kreis markiert das verwendete Lymphozytenfenster. Die Zellen des Lymphozytenfesters wurden anhand ihrer anti-CD4/CD8 Färbung aufgetragen (Mitte). Rechts ist die anti-CD44/CD25 Färbung von CD4 CD8 DN Thymozyten (Mitte) dargestellt. Die relativen prozentualen Anteile der Populationen sind in den Quadranten bzw. Fenstern angegeben. Die gezeigten Daten sind repräsentativ für Ergebnisse aus 4 unabhängigen Experimenten. 

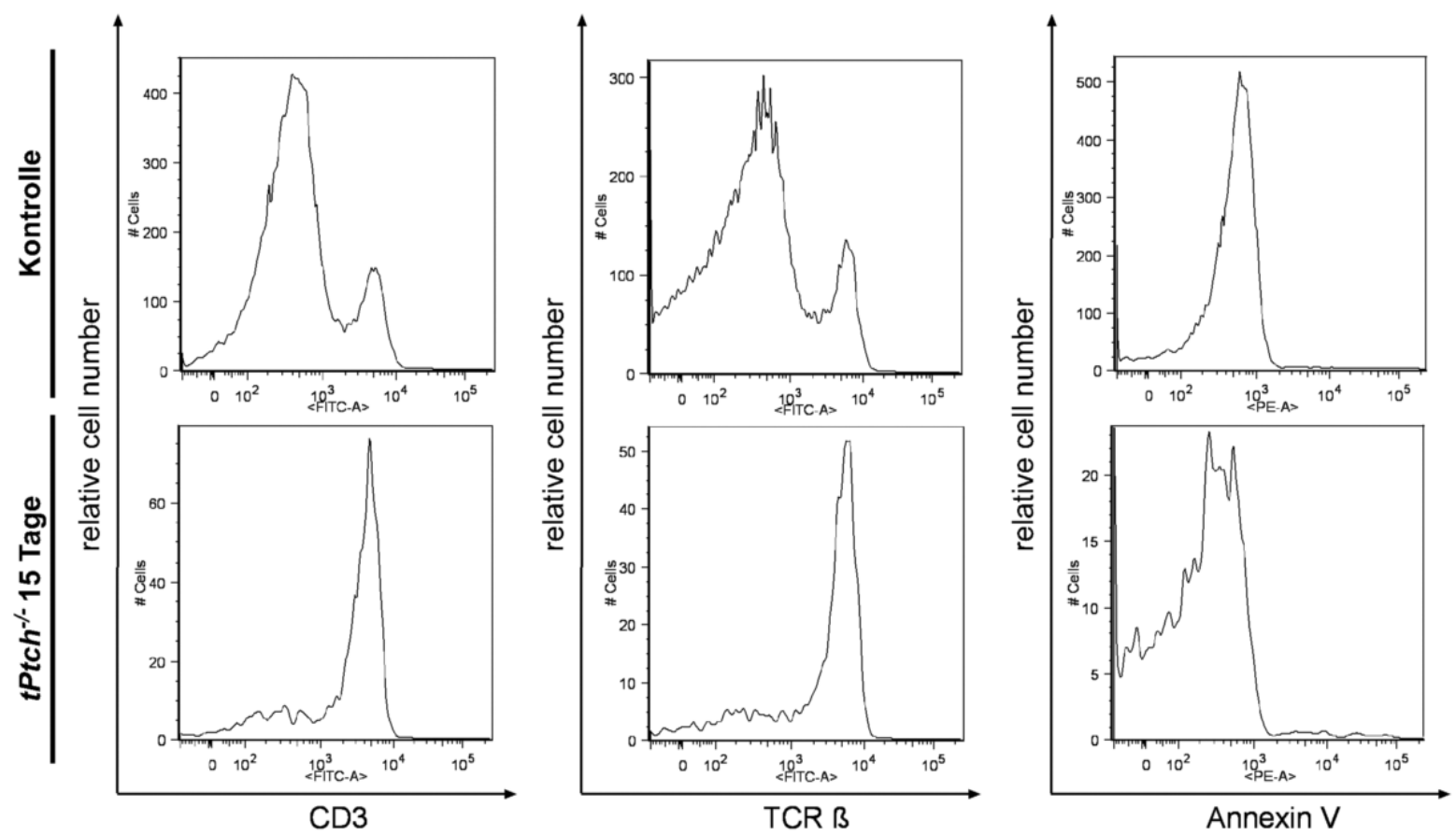

Abbildung 37: Analyse der CD3, TCRß und Annexin V Expression von tPtch ${ }^{-/}$Thymozyten. Dargestellt sind durchflusszytometrische Analysen von Thymozyten, welche aus Thymi von Lösungsmittel-behandelten Ptch $^{N X / N X}$ ERT2 $^{+-}$(oben) und tPtch $^{-/}$Tieren 15 Tage nach der ersten Tamoxifengabe (unten) isoliert wurden. Gezeigt sind die Auswertungen von anti-CD3 (links), antiTCRß (Mitte) und anti-Annexin V (rechts) Färbungen der Thymozyten des in Abbildung 36 (links) dargestellten Lymphozytenfensters. Die gezeigten Daten sind repräsentativ für Ergebnisse aus 4 unabhängigen Experimenten.

\subsection{B Zelldefekte in Milzen von $t P t c h^{-/}$Mäusen}

Um zu untersuchen, ob es sich bei dem oben beschriebenen T Zelldefekt in $t_{P t c h}{ }^{-1-}$ Mäusen um einen zellspezifischen oder aber um einen umfassenderen Immundefekt handelte, wurden weitere Analysen angeschlossen.

Trotz der normalen Histologie wurde zunächst die Milz als peripheres lymphatisches Organ der B Zell Reifung in Ptch $^{-/}$Mäusen untersucht.

Vom Knochenmark wandern unreife B Zellen in die Milz ein, wo sie sich zu reifen B Zellen differenzieren. Die B Zellen der Milz lassen sich aufgrund der Expression von Oberflächenproteinen unterscheiden. So exprimieren unreife Typ 1 B Zellvorläufer (transitional $\mathrm{B}$ cell of type 1; T1;) B220 und CD24 aber kein CD21 $\left(\mathrm{B} 220^{+} \mathrm{CD} 24^{+} \mathrm{CD} 21^{-}\right)$. Typ 2 B Zellvorläufer (transitional B cell of type 2; T2) exprimieren hingegen sowohl B220, CD24 als auch CD21 (B220 $\left.{ }^{+} \mathrm{CD} 24^{+} \mathrm{CD} 21^{+}\right)$. Beide B Zellvorläufertypen entwickeln sich zu reifen B Zellen (mature B cell, M), die 
durch eine niedrige Expression von CD24 und CD21 gekennzeichnet sind

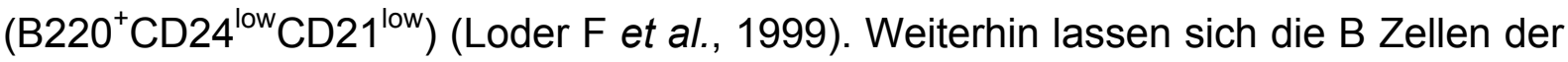
Milz aufgrund inrer Expression von IgM und IgD ebenfalls in diese Populationen einteilen. Die T1 B Zellpopulation exprimiert auf hohem Niveau IgM, aber nur

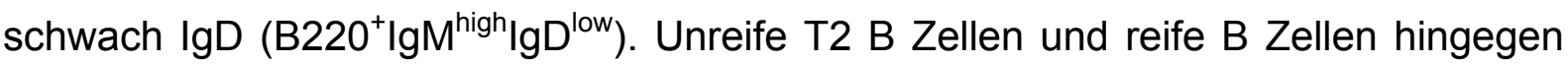
sind durch die starke Expression beider Oberflächenproteine gekennzeichnet $\left(\mathrm{B}^{2} 20^{+} \lg \mathrm{M}^{\text {high }} \lg ^{\text {high }}\right.$ ) (Loder F et al., 1999).

Wie Abbildung 38 (links) zeigt, wurde bei durchflusszytometrischen Untersuchungen der B Lymphozyten aus Ptch $^{-/}$Milzen 19 Tage nach der ersten Tamoxifengabe eine starke Reduktion der T1 B Zellpopulation (T1; B220 $\left.{ }^{+} \mathrm{CD} 24^{+} \mathrm{CD} 21^{-}\right)$beobachtet. Die Fraktion der T2 B Zellen blieb stabil (T2; $\left.\mathrm{B} 220^{+} \mathrm{CD} 24^{+} \mathrm{CD} 21^{+}\right)$, während die reifen $\mathrm{B}$ Zellen überrepräsentiert waren $\left(\mathrm{M} ; \mathrm{B} 220^{+} \mathrm{CD} 24^{\text {low }} \mathrm{CD} 21^{\text {low }}\right)$.

Um diese Ergebnisse weiter zu untermauern, wurde auch die Expression von IgD und IgM von B Zellen der Milz analysiert. Abbildung 38 (rechts) zeigt, dass die T1 Population ( $\mathrm{T} 1$; $\mathrm{B} 22 \mathrm{O}^{+} \mathrm{IgM}^{\text {high }} \mathrm{Ig} \mathrm{D}^{\text {low }}$ ) von $\mathrm{tPtch}^{-/}$Milzen deutlich reduziert war. Die Zahl der reifen B Zellen (T2, B220 ${ }^{+} \operatorname{lgM}^{\text {high }} \lg \mathrm{D}^{\text {high }}$ und $\left.\mathrm{M}, \mathrm{B}^{2} 20^{+} \operatorname{lgM}{ }^{\text {low }} \lg \mathrm{D}^{\text {high }}\right)$ dagegen war relativ erhöht. Diese Daten bestätigen die beobachtete Abnahme der T1 B Zellpopulation (Abbildung 38; links) in $\mathrm{Ptch}^{-/}$Milzen und weisen auf einen frühen Entwicklungsdefekt in der B Zelldifferenzierung hin.

In den Tamoxifen-behandelten Ptch $^{N X / N X}$ Kontrolltieren wurde 15 Tage nach der ersten Tamoxifengabe ein mäßiger Effekt von Tamoxifen auf die T1 B Zellpopulation beobachtet (Abbildung 39; links). Dieser Effekt war jedoch nach 19 Tagen nicht mehr detektierbar (Abbildung 39; rechts).

Die Ergebnisse lassen darauf schließen, dass in $\mathrm{Ptch}^{-/}$Mäusen einen Defekt der B Zellentwicklung vorliegt. 

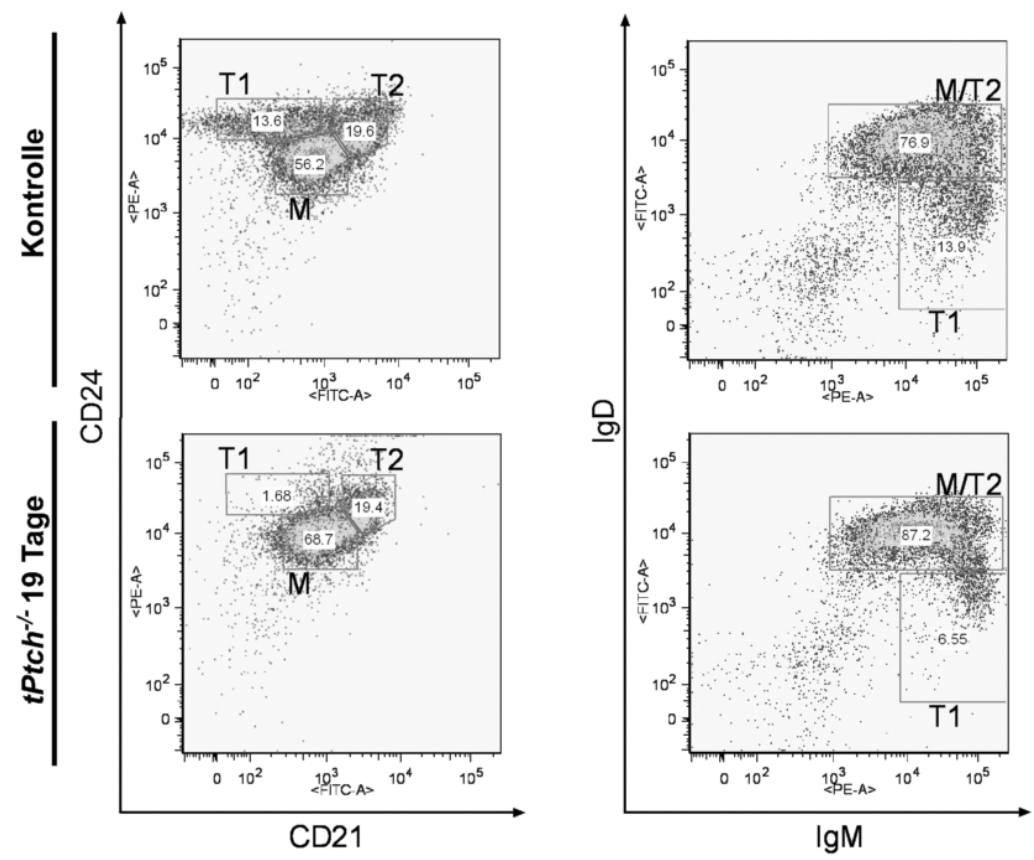

Abbildung 38: Reduktion der T1 B Zellen in Milzen von Ptch $^{-/}$Mäusen. Dargestellt sind durchflusszytometrische Analysen von B Zellen, welche 19 Tage nach der ersten Tamoxifengabe aus der Milz eines tPtch $^{-1}$ Tiers (unten) isoliert wurden. Zum Vergleich sind B Zellen einer mit Lösungsmittel-behandelten Ptch $^{N X / N X} E R T 2^{+/}$Maus (oben) dargestellt. Die Zellen wurden mit antiCD24/CD21/B220 oder anti-lgD/lgM/B220 Antikörpern gefärbt. Gezeigt werden B220 ${ }^{+}$Zellen (B Zellen), die je nach ihrer Expression von CD24 und CD21 (links) oder IgM und IgD (rechts) in verschiedene Populationen eingeteilt werden können. Die gekennzeichneten Subpopulationen in der Auftragung anti-CD24/CD21 entsprechen den T1 (B220 $\left.{ }^{+} \mathrm{CD} 24^{+} \mathrm{CD} 21^{-}\right)$, T2 $\left(\mathrm{B} 220^{+} \mathrm{CD} 24^{+} \mathrm{CD} 21^{+}\right)$und den reifen (M, mature; B220 $\left.{ }^{+} \mathrm{CD} 24^{\text {low }} \mathrm{CD} 21^{\text {low }}\right)$ B Zellen. Bei der Färbung mit anti-B220/lgM/lgD sind die T1 B Zellen durch B220+ $\operatorname{IgM}^{\text {high }} \operatorname{IgD}^{\text {low }}$ (T1) und die Populationen der T2 und reifen B Zellen (T2/M) durch $\mathrm{B}_{220^{+}} \mathrm{IgM}^{\text {low/high }} \operatorname{lgD}^{\text {high }}$ Expression gekennzeichnet. Die relativen prozentualen Anteile der Populationen sind in den Fenstern angegeben. Die gezeigten Daten sind repräsentativ für Ergebnisse aus 4 unabhängigen Experimenten. 

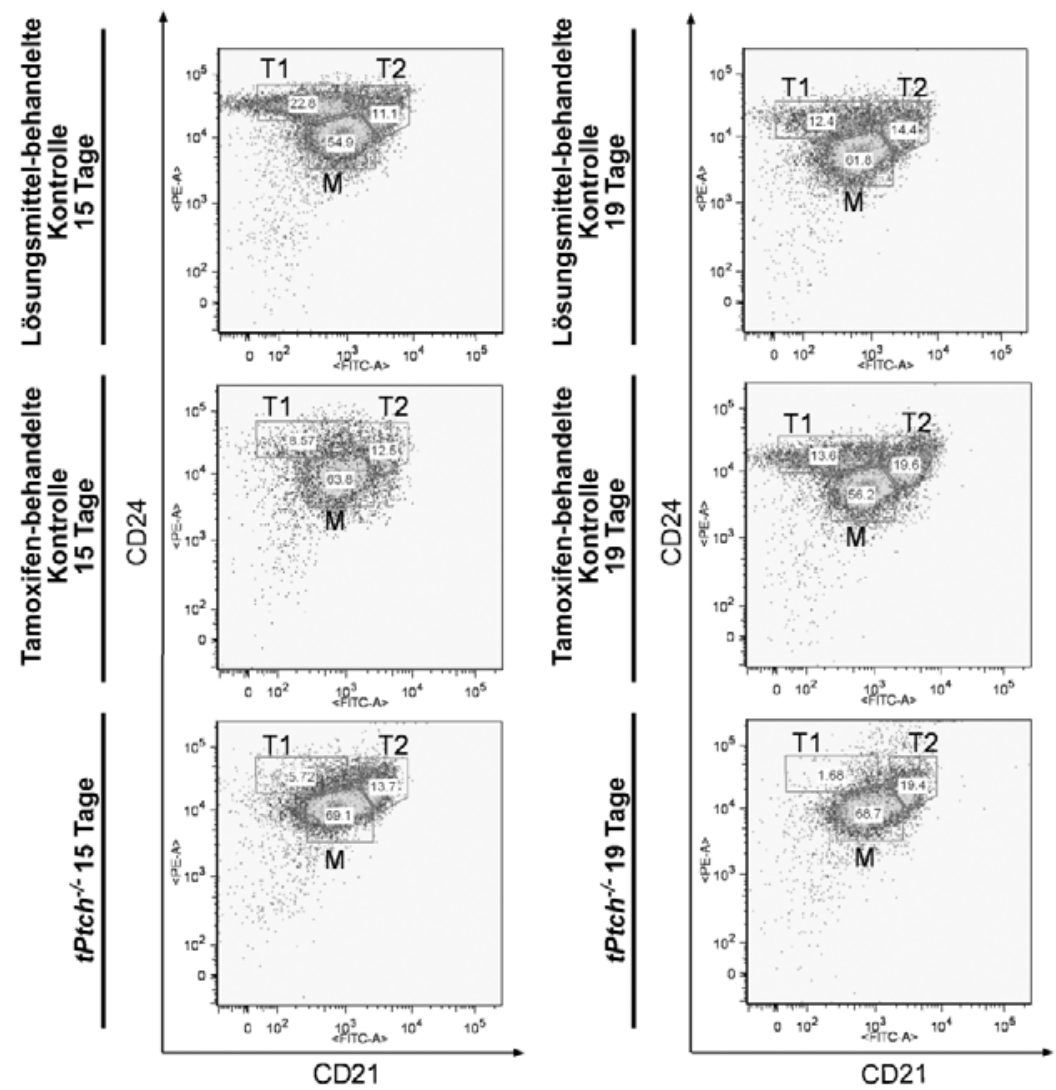

Abbildung 39: Vergleich der B Zellpopulationen von Milzen aus Lösungsmittel-behandelten Ptch $^{N X / N X} E_{R T 2}^{+/}$, Tamoxifen-behandelten Ptch $^{N X / N X} E_{R T 2^{-/}}$und tPtch $^{-/}$Mäusen 15 und 19 Tage nach der ersten Injektion. Dargestellt sind durchflusszytometrische Analysen von B Zellen, welche 15 (links) oder 19 Tage (rechts) nach der ersten Tamoxifengabe aus der Milz von Ptch $^{-/}$Maus (unten) isoliert wurden. Zum Vergleich sind B Zellfärbungen eines mit Lösungsmittel-behandelten Ptch $^{N X N X}$ $E R T 2^{+/-}$Tiers (oben) und eines mit Tamoxifen-behandelten Ptch $^{N X / N X} E R T 2^{-/-}$(Mitte) Tiers dargestellt. Gezeigt werden B220 ${ }^{+}$Zellen (B Zellen) einer anti-B220/CD24/CD21 Färbung, die aufgrund ihrer Expression von CD24 und CD21 in $\mathrm{T} 1\left(\mathrm{~B} 220^{+} \mathrm{CD} 24^{+} \mathrm{CD} 21^{-}\right), \mathrm{T} 2\left(\mathrm{~B} 220^{+} \mathrm{CD} 24^{+} \mathrm{CD} 21^{+}\right)$und reife (M, mature; B220 ${ }^{+} \mathrm{CD} 24^{\text {low }} \mathrm{CD} 21^{\text {low }}$ ) B Zellen unterteilt werden können. Die relativen prozentualen Anteile der Populationen sind in den Fenstern angegeben. Die gezeigten Daten sind repräsentativ für Ergebnisse aus 4 unabhängigen Experimenten.

\subsection{B Zelldefekt im Knochenmark von $\boldsymbol{t P t c h}^{-/}$Mäusen}

Da die beschriebenen Defekte in der T und B Zellentwicklung in Thymus und Milz auch durch Defekte in früheren hämatopoetischen Entwicklungsstadien ausgelöst werden können, wurde das Knochenmark von $t P t c h^{-/}$Mäusen untersucht.

Die verschiedenen B Zellentwicklungsstadien im Knochenmark können durch ein spezifisches Expressionsmuster von B220, CD43 und IgM unterschieden werden. Frühe B Zellvorläufer exprimieren bis zum pro-B Zellstadium B220 und CD43, jedoch 
kaum IgM (B220 $\left.{ }^{\text {high }} \mathrm{CD} 3^{+} \operatorname{lgM}^{\mathrm{low}}\right)$. Bei der weiteren Entwicklung zum pre-B Zellstadium nimmt die Expression von CD43 ab, wohingegen die Expression von B220 stetig bis zum Stadium der unreifen B Zellen zunimmt. Diese unreifen B Zellen exprimieren stark B220, mäßig IgM und kein CD43 (B220 high $\mathrm{CD}^{-1}{ }^{-} \mathrm{Ig}^{\text {low-high }}$ ).

Auf den reifen, immunkompetenten rezirkulierenden B Zellen wird zusätzlich der B Zellrezeptor IgD exprimiert (B220 ${ }^{\text {high }} C D 43^{-} \operatorname{lgM}^{\text {low }} \lg D^{\text {high }}$ ). Reife B Zellen haben daher einen B220 ${ }^{\text {high }} \mathrm{CD}^{-} 3^{-} \operatorname{lgM}^{\text {low }} \lg ^{\text {high }}$ Phänotyp (Busslinger M, 2004; Nagasawa T, 2006).

Im Knochenmark von tPtch $^{-/}$Tieren wurde zunächst eine leichte Reduktion der gesamten Lymphozytenfraktion im Vergleich zu den Kontrollkohorten beobachtet. Dies wird anhand des SSC/FSC Plot in Abbildung 40 (links) gezeigt.

Durch die simultane Färbung mit anti-B220/CD43/lgM Antikörpern konnte eine Differenzierung der B Zellpopulationen vorgenommen werden. Abbildung 40 (Mitte links, Mitte rechts) zeigt die Auswertung dieser Färbung. Es fällt vor allem der fast vollständige Verlust der pre-B Zellen (Mitte links; Fraktion II; $\mathrm{B}_{220^{+}} \mathrm{CD}^{-} 3^{-}$) auf, während die relativen Zahlen der pro-B Zellen kaum Veränderungen zeigten (Mitte links; Fraktion I; $\mathrm{B} 220^{+} \mathrm{CD} 43^{+}$). Die Population der unreifen und rezirkulierenden $\mathrm{B}$ Zellen (Mitte links; Fraktion III; B220 ${ }^{\text {high }} \mathrm{CD} 43^{-}$) hingegen war überrepräsentiert. Durch die Analyse der IgM Expression der einzelnen B Zellpopulationen (Abbildung 40; Mitte rechts) wurde die Vermehrung der unreifen (Fraktion II; B220 ${ }^{\text {low }} \mathrm{IgM}^{\text {low }}$ ) und rezirkulierenden (Fraktion III; B220 high $\mathrm{IgM}^{\text {high }}$ ) B Zellpopulationen bestätigt.

Anhand einer simultanen anti-B220/lgM/lgD Färbung (Abbildung 40, rechts) der Knochenmarkszellen konnte außerdem die relativ erhöhte Anzahl von rezirkulierenden $B$ Zellen gezeigt werden $\left(\mathrm{B}_{2} 20^{+} \lg \mathrm{D}^{\text {high }} \operatorname{lgM}^{\text {high }}\right)$. Die Reduktion von pro- und pre-B Zellen als auch von unreifen $B$ Zellen in $t P t c h^{-/}$Knochenmark und die damit verbundene relative Zunahme von rezirkulierenden B Zellen weist darauf hin, dass der Verlust von Ptch zu einer schweren Blockade der frühen B Zellentwicklung im pro- oder pre-B Zellstadium führt.

Auch im Knochenmark wurde ein Tamoxifen-spezifischer Effekt auf die B Zellentwicklung festgestellt. So wurde am Tag 15 nach der ersten Tamoxifengabe eine Reduktion von pro-, pre- und unreifen B Zellen beobachtet (Abbildung 41; links). Dieser Effekt war aber 19 Tage nach der ersten Tamoxifeninjektion nicht mehr messbar (Abbildung 41; rechts). 

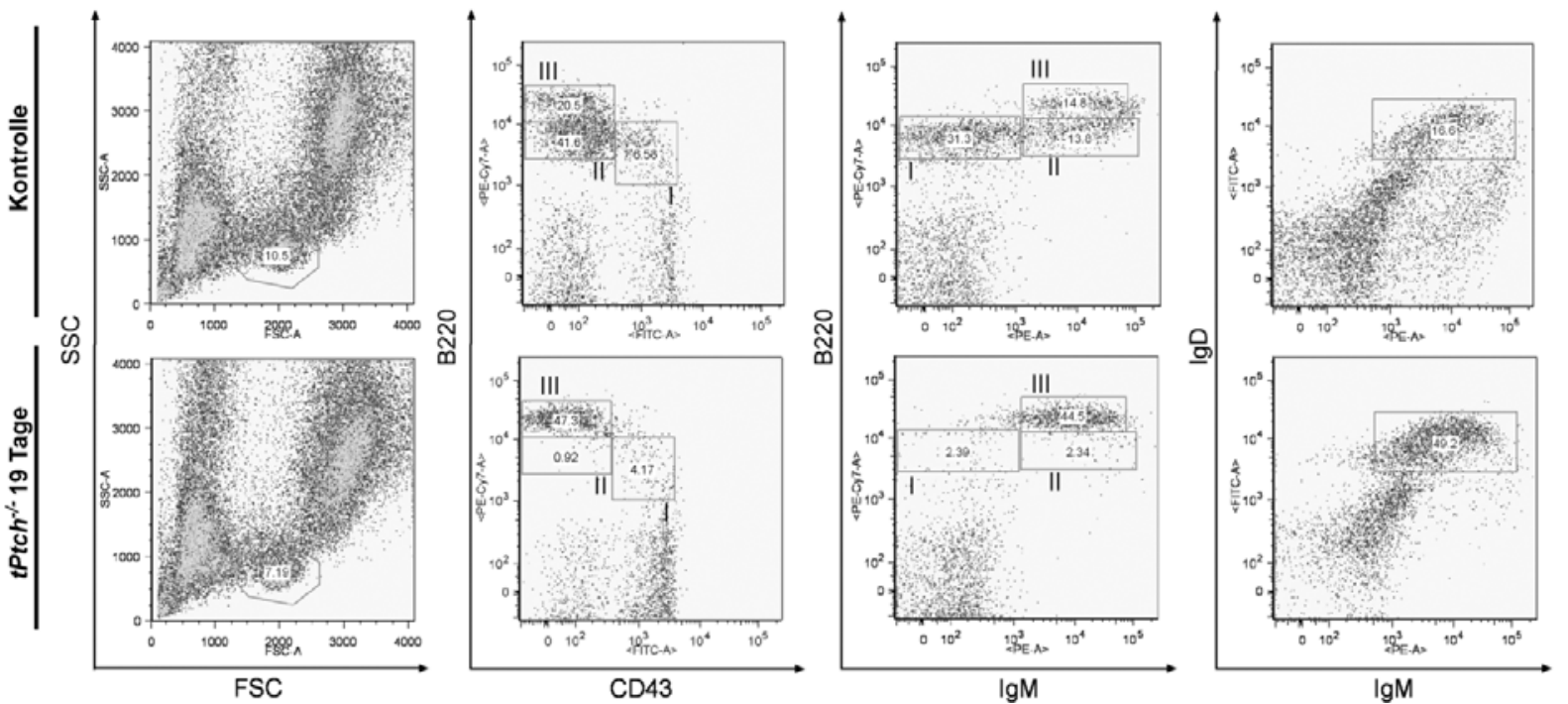

Abbildung 40: Reifungsdefekt von B Zellen im Knochenmark von Ptch $^{-/}$Mäusen. Dargestellt sind durchflusszytometrische Analysen von B Zellen, welche 19 Tage nach der ersten Tamoxifengabe aus dem Knochenmark einer PPtch $^{-/}$Maus (unten) isoliert wurden. Zum Vergleich sind B Zellen eines Lösungsmittel-behandelten Ptch $^{N X / N X}$ ERT2 ${ }^{+/-}$Kontrolltiers (oben) dargestellt. Die Zellen wurden mit anti-B220/CD43/lgM (Mitte links und Mitte rechts) oder anti-B220/lgM/lgD (rechts) Antikörpern gefärbt. Links ist der SSC/FSC Plot des Gesamtknochenmarks mit den im Weiteren verwendeten Lymphozytenfenstern dargestellt. Durch die Auftragung von B220 gegen CD43 können die B Zellen in 3 Fraktionen aufgeteilt werden (Mitte links). Hierbei entspricht Fraktion I den pro-B Zellen (B220 $\mathrm{CD}^{+} 3^{+}$), Fraktion II den pre-B Zellen (B220 $\left.{ }^{+} \mathrm{CD} 43^{-}\right)$und Fraktion III den unreifen, und gleichzeitig auch den reifen, rezirkulierenden $B$ Zellen (B220 $\left.{ }^{\text {high }} \mathrm{CD} 43^{-}\right)$. Mittels der Auftragung von B220 gegen IgM können ebenso 3 B Zellpopulationen unterschieden werden (Mitte rechts). Fraktion I entspricht pro-

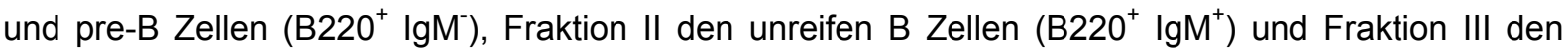
reifen, rezirkulierenden $B$ Zellen $\left(B 220^{\text {high }} \operatorname{lgM}^{+}\right)$. Rechts ist die Auswertung der Färbung mit antiB220/lgD/lgM Antikörpern abgebildet. Die B220 ${ }^{+}$Lymphozyten aus den links dargestellten Lymphozytenfenstern sind rechts im IgD/lgM Plot dargestellt. Der Kasten markiert die $\mathrm{B}_{2} 20^{+} \lg \mathrm{D}^{\text {high }}$ $\operatorname{lgM}^{\text {high }}$ reife rezirkulierende B Zellfraktion. Die relativen prozentualen Anteile der Populationen sind in den Fenstern angegeben. Die gezeigten Daten sind repräsentativ für Ergebnisse aus 4 unabhängigen Experimenten. 

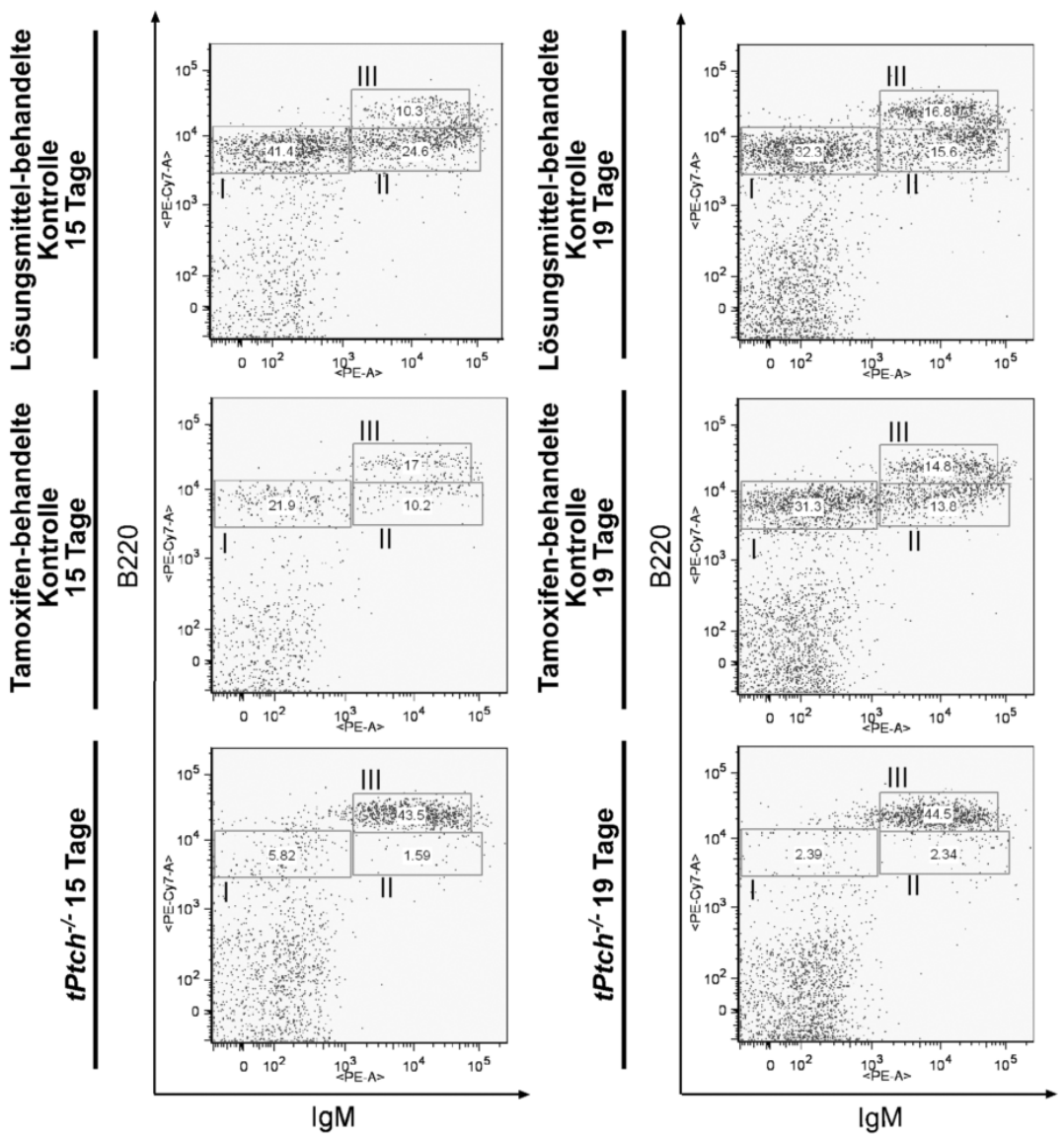

Abbildung 41: Vergleich von B Zellpopulationen des Knochenmarks von Lösungsmittelbehandelten Ptch $^{N X / N X} E_{R T 2}^{+/}$, Tamoxifen-behandelten Ptch $^{N X / N X} E R T 2^{-/}$und Ptch $^{-/-}$Tieren 15 und 19 Tage nach der ersten Injektion. Dargestellt sind durchflusszytometrische Analysen von B Zellen, welche aus Knochenmark einer Lösungsmittel-behandelten $\operatorname{Ptch}^{N X / N X} E R T 2^{+/-}$Maus (oben), einer Tamoxifen-behandelten Ptch $^{N X / N X}$ ERT2 ${ }^{-/}$Maus (Mitte) und einer $t$ Ptch ${ }^{-/}$Maus(unten) 15 (links) oder 19 (rechts) Tage nach der ersten Tamoxifengabe isoliert worden sind. Aufgetragen sind die antiB220/lgM Färbung der Lymphozyten (verwendetes Lymphozytenfenster siehe Abbildung 40) aus der simultanen Färbung mit anti-B220/CD43/lgM. Fraktion I entspricht pro- und pre-B Zellen (B220 $\left.{ }^{+} \operatorname{lgM}^{-}\right)$, Fraktion II den unreifen B Zellen $\left(\mathrm{B}^{220^{+}} \mathrm{IgM}^{+}\right)$und Fraktion III den reifen, rezirkulierenden B Zellen $\left(\mathrm{B}^{2} 2 \mathrm{~h}^{\text {high }} \operatorname{lgM}^{+}\right)$. Die relativen prozentualen Anteile der Populationen sind in den Fenstern angegeben. Die gezeigten Daten sind repräsentativ für Ergebnisse aus 4 unabhängigen Experimenten.

\subsection{Entwicklungsdefekt früher B Zellvorläufer im Knochenmark von Ptch $^{-/}$ Mäusen}

Die Differenzierung von frühen B Zellvorläufern aus Stammzellen des Knochenmarks kann über die Expression verschiedener Transkriptionsfaktoren und Rezeptorproteine verfolgt werden. Für die Differenzierung der allgemeinen lymphoiden Vorläuferzellen (common lymphoid progenitor, CLP) aus multipotenten Vorläuferzellen (multipotent progenitor, MPP) wird die Expression der 
Transkriptionsfaktoren PU.1 (Sfpi1, SFFV proviral integration 1) und Ikaros (Zfpn1a1, zinc finger protein, subfamily $1 \mathrm{~A}, 1$ ) sowie die Expression des Rezeptors FIt3 (FMSlike tyrosine kinase 3 ) und die $\alpha$-Kette des Interleukin-7 Rezeptors (IL-7R $\alpha$ ) benötigt (Laiosa CV et al., 2006). Die aktivierte IL-7R (Interleukin-7 receptor) Signalkaskade bewirkt die Entwicklung vom CLP zu B Zellvorläufern. Weiterhin führt die Expression des frühen B Zelltranskriptionsfaktors EBF (early B cell factor 1) zur Expression von Rag1/2 (recombination activating gene 1 bzw. 2) und damit zur VDJ Rekombination. Die Expression von EBF reguliert auch die Expression des B Zell-spezifischen Transkriptionsfaktors Pax5, welcher für die weitere Differenzierung der B Zelllinie unerlässlich ist (Busslinger M, 2004).

Um den Defekt in der B Zellentwicklung von $\mathrm{Ptch}^{-/}$Mäusen genauer zu definieren, wurde die Expression der frühen Transkriptionsfaktoren PU.1 und Ikaros sowie des Rezeptors Flt3 untersucht. Die Expression dieser Transkripte zeigte im Gesamtknochenmark keinen Unterschied zwischen Ptch $^{-/}$Knochenmark und Kontrolltieren (Abbildung 42).

Jedoch wurde im Knochenmark von Ptch $^{-/}$Tieren im Vergleich zu den Kontrolltieren eine stark verminderte Expression von IL-7R $\alpha, E B F, R a g 1 / 2$ und Pax5 detektiert (Abbildung 42). Da diese Faktoren essentiell für die korrekte Entwicklung früher B Zellen sind, lässt sich aus den Ergebnissen schließen, dass in $t P t c h^{-/}$Mäusen ein schwerer Defekt in der frühen B Zellentwicklung vorliegt. Anhand dieser Daten kann außerdem vermutet werden, dass ein Entwicklungsdefekt bei der Transition vom CLP-Stadium zu frühen B Zellvorläufern vorliegen könnte. 


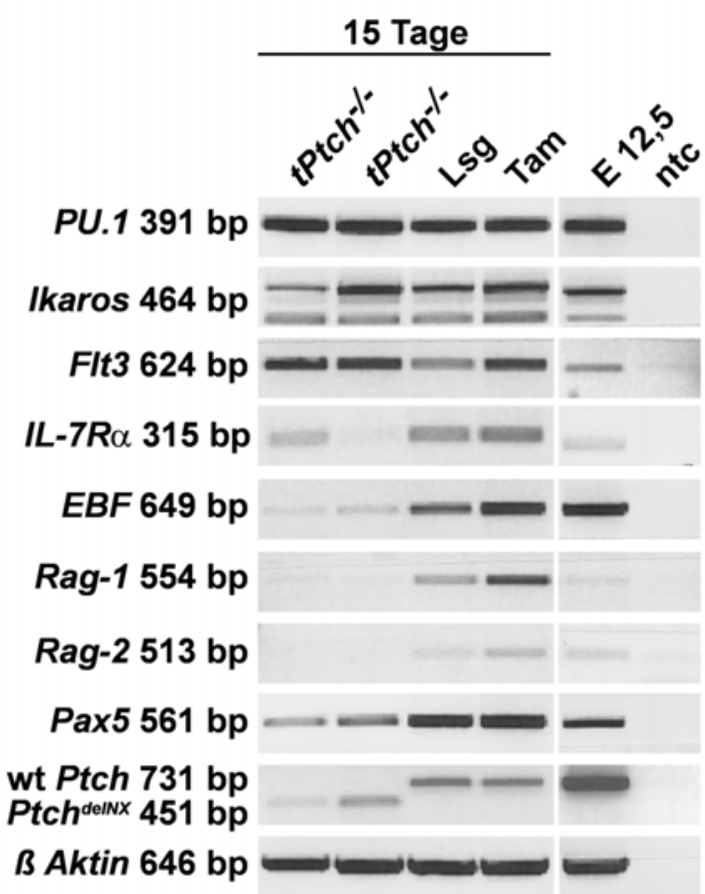

Abbildung 42: Expressionsanalyse früher Transkriptionsfaktoren und Rezeptoren im Knochenmark von Ptch $^{-/}$Mäusen. 15 Tage nach der ersten Tamoxifengabe wurde das Knochenmark von 2 tPtch $^{-/-}$Tieren und einer Ptch ${ }^{N X / N X}$ ERT2 ${ }^{-/-}$Maus (Tam) sowie von einem Lösungsmittel-behandelten $\mathrm{Ptch}^{\mathrm{NX} / N X} E R T 2^{+/}$Tier (Lsg) isoliert und RT-PCR-Analysen durchgeführt. Die Expression von Ptch ${ }^{\text {deINX}}$ Transkripten zeigt die effiziente Rekombination am Ptch ${ }^{N X}$ Lokus im Knochenmark (Tabelle 10; Abbildung 17). Die weiteren verwendeten Oligonukleotidpaare sind in Tabelle 10 aufgeführt und die amplifizierten Gentranskripte im Text beschrieben. Zur Kontrolle der cDNA wurden B Aktin Transkripte amplifiziert. Als Positivkontrolle für die PCR-Assays wurde cDNA aus embryonaler RNA (12,5 dpc) als Matrize verwendet. Abkürzungen: ntc, no template control.

\subsection{Differenzierungsdefekt der lymphoiden Linie im CLP-Stadium in tPtch $^{-/}$Mäusen}

Zur detaillierten Analyse des frühen $\mathrm{T}$ und $\mathrm{B}$ Zelldefektes von $\mathrm{tPtch}^{-/}$Mäusen wurden Stamm- und Vorläuferzellen des Knochenmarks dieser Tiere durchflusszytometrisch analysiert.

Stamm- und Vorläuferzellen des Knochenmarks exprimieren keine Oberflächenproteine differenzierter Zellen und werden als Lineage-negativ (Lin') bezeichnet. So kann anhand von Markerproteinen der hämatopoetischen Linien eine Negativselektion der Stamm- und Vorläuferzellen vorgenommen werden (AntikörperMix aus monoklonalen Antikörpern gegen folgende Mausantigene: CD5, CD45R/B220, Mac-1, Gr-1, Ter119 und 7-4). Die verbleibende Fraktion der kleinen, 


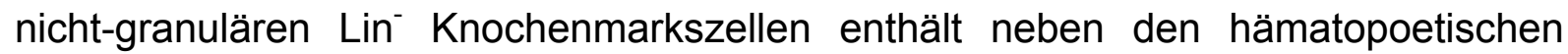
Stammzellen (hematopoetic stem cell, HSC) auch Vorläuferzellen der myeloischen und lymphoiden Linie (Porse BT et al., 2005). Während der hämatopoetischen Differenzierung wird ausgehend von den HSC zuerst die Population der MPP gebildet, die sich in die Megakaryozyt/Erythrozyt Vorläuferzellen (megakaryocyte/erythrocyte progenitor, MEP) und die lymphoid-spezifische multipotente Vorläuferlinie (lymphoid-primed multipotential progenitor, LMPP) verzweigt. Aus der LMPP Population entsteht dann die Population der Granulozyt/Makrophage Vorläuferzellen (granulocyte/macrophage progenitor, GMP) und die CLPs. Aus den MEP entwickeln sich sowohl Megakaryozyten als auch Erythrozyten, während die GMP sich zu Granulozyten oder Makrophagen differenzieren (siehe Abbildung 58) (Kondo $\mathrm{M}$ et al., 1997; Akashi $\mathrm{K}$ et al., 2000; Laiosa CV et al., 2006).

Die Unterscheidung der Lin ${ }^{-}$Stamm- und Vorläuferzellen des Knochenmarks erfolgt durch eine Expressionsanalyse der Oberflächenproteine Sca-1 (Ly6a; lymphocyte antigen 6 complex, locus A) und c-kit. Die Populationen der HSC und MPP sind durch die hohe Expression von c-kit und Sca-1 ( Lin $^{-}$Sca- $~^{\text {high }}{ }^{\text {c-kit }}{ }^{\text {high }}$ ) charakterisiert. Während ihrer Differenzierung zu myeloischen oder lymphoiden Vorläuferzellen wird die Expression von Sca-1 vermindert. Jedoch sind die Vorläuferzellen der myeloischen Linie, zu der die MEP und GMP gehören, durch die hohe Expression

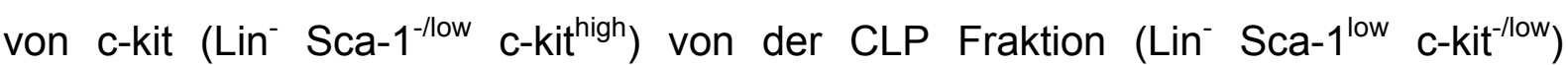
unterscheidbar (Metcalf D, 1999). Weiterhin ist die Fraktion der CLP durch die Expression von IL-7R $\alpha$ identifizierbar (Bhandoola A und Sambandam A, 2006b).

Zur Analyse des frühen T und B Zelldefektes wurden daher Lin' Knochenmarkszellen aus PPtch $^{-/}$Mäusen anhand von simultanen anti-Sca-1/c-kit/L-7R $\alpha$ Antikörperfärbungen durchflusszytometrisch analysiert.

Im Vergleich zu Kontrolltieren wurde in Ptch $^{-/}$Tieren eine relativ erhöhte Anzahl von Lin ${ }^{-}$Sca- $1^{\text {high }}$ c-kit ${ }^{\text {high }}$ Stammzellen und eine reduzierte Anzahl von Lin ${ }^{-}$Sca- $1^{\text {low }}$ c-kit ${ }^{\text {low }}$ Vorläuferzellen detektiert (Abbildung 43, Fraktion II). Die Lin ${ }^{-}$Sca-1 ${ }^{\text {low }}$ c-kit $^{\text {low }}$ Population, welche größtenteils die lymphoiden Vorläuferzellen enthält, benötigt zur weiteren Differenzierung zu CLP die Expression von IL-7R $\alpha$ (Bhandoola A und Sambandam A, 2006b). Im Vergleich zu Kontrolltieren waren in PPtch $^{-/}$Tieren die IL-7Ra ${ }^{+}$Zellen innerhalb der Lin ${ }^{-}$Sca- $1^{\text {low }}$ c-kit ${ }^{\text {low }}$ Population deutlich reduziert 
(Abbildung 43, blau hervorgehobene Punkte). Der relative Anteil der Lin ${ }^{-}$c-kithigh Sca-1-1/low Population, welcher den Großteil der myeloischen Vorläuferzellen enthält, veränderte sich dagegen nicht (Abbildung 43, Fraktionl) (Okada $S$ et al., 1992; Katayama N et al., 1993; Porse BT et al., 2005).

Diese Daten zeigen, dass die Inaktivierung von Ptch zu einem Differenzierungsdefekt der frühen lymphoiden Vorläuferzellen führt. Dieser Defekt muss vor oder während des CLP Stadiums stattfinden, da die Lin- Sca- ${ }^{\text {low }}$ C-kit ${ }^{\text {low }}$ IL-7R $\alpha^{+}$Population deutlich reduziert ist. Ein Einfluss der Ptch Deletion auf die Entwicklung der myeloischen Linie konnte in dieser Analyse nicht festgestellt werden.

Tamoxifen-behandelte Ptch ${ }^{N X / N X} E R T 2^{-/}$Kontrolltiere zeigten keine Abnormitäten der Lin Zellen (Daten nicht gezeigt). Daher kann davon ausgegangen werden, dass der beschriebene Tamoxifen-spezifische Effekt auf die B Zellentwicklung (siehe Kapitel 3.2.5.1.4; 3.2.5.1.5) nicht durch die Lin $^{-}$Knochmarksfraktion vermittelt wurde.
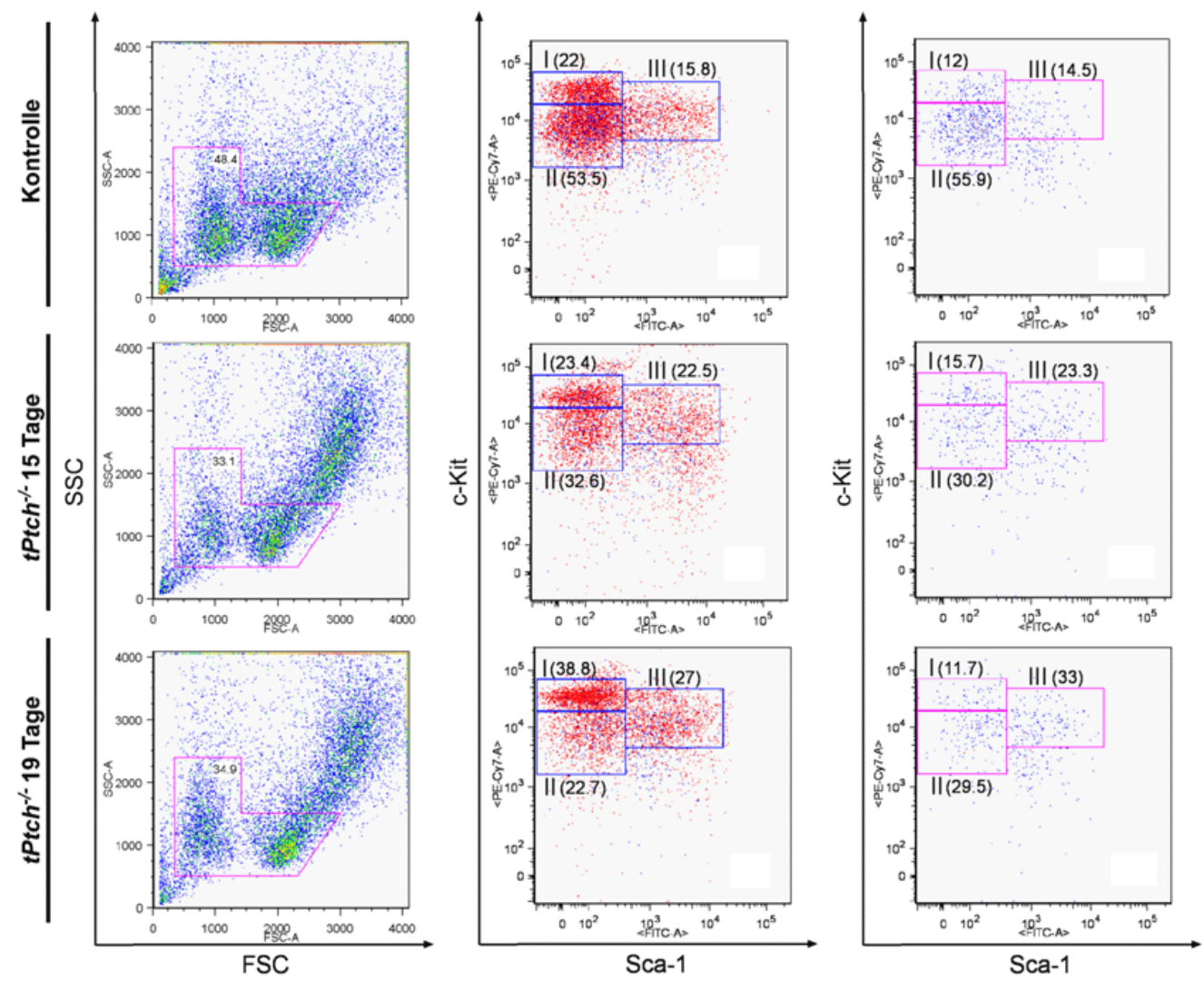

Abbildung 43: Abnormale Differenzierung früher B Zellvorläufer im Knochenmark von tPtch $^{-/-}$ Mäusen. Dargestellt sind durchflusszytometrische Analysen von anti-Sca-1/c-kit/L-7R $\alpha$ gefärbten Lin Knochenmarkszellen von einer mit Lösungsmittel-behandelten $\operatorname{Ptch}^{N X N X} E R T 2^{+/}$Maus (oben) und jeweils einer Ptch $^{-/}$Maus 15 Tage (Mitte) oder 19 Tage (unten) nach der ersten Tamoxifengabe. Lin Zellen wurden zunächst im SSC/FSC Plot dargestellt (links). Für die weitere Auswertung wurden kleine, nicht-granuläre Zellen gewählt (Porse BT et al., 2005). Die gefärbten Zellen wurden in einer 
anti-c-Kit/Sca-1 Auftragung dargestellt (Mitte und rechts). Alle Lin Zellen sind in rot dargestellt und die IL-7R $\alpha^{+}$Lin $^{-}$Zellen sind in blau hervorgehoben. Im rechten Teil der Abbildung sind nur Lin IL-7R ${ }^{+}$ Zellen dargestellt. Die markierten Populationen entsprechen den Vorläufern der myeloischen Linie (Fraktion I; Lin ${ }^{-}$C-kit ${ }^{\text {high }}$ Sca-1 ${ }^{- \text {llow }}$ ), der CLP-enthaltenden Fraktion (Fraktion II; Lin ${ }^{-}$c-kit ${ }^{\text {low }}$ Sca-1 ${ }^{- \text {llow }}$ ) und der Population, welche HSC und MPP (Fraktion III, Lin ${ }^{-}$c-kit ${ }^{\text {high }}$ Sca- ${ }^{\text {high }}$ ) enthält. Die relativen prozentualen Anteile der Populationen sind in den Fenstern angegeben. Die gezeigten Daten repräsentieren die Ergebnisse aus 3 unabhängigen Experimenten.

\subsection{Ungestörte Granulozyten- und Makrophagendifferenzierung und partieller Defekt der Megakaryozyten- und Erythrozytenentwicklung in tPtch $^{-/}$Mäusen}

Zur detaillierten Analyse des Entwicklungspotentials von myeloischen Vorläuferzellen von $t t_{t c h}{ }^{-/}$Mäusen wurde die koloniebildende Aktivität von Lin ${ }^{-}$Knochenmarkszellen ermittelt. 15 und 19 Tage nach der ersten Tamoxifengabe wurden $2000 \mathrm{Lin}^{-}$ Knochenmarkszellen in einem Methylzellulosemedium über 7 Tage kultiviert und die Anzahl der koloniebildenden Einheiten (colony-forming unit, CFU) ermittelt (2.18.1). Im Vergleich zu Tamoxifen- und Lösungsmittel-behandelten Kontrolltieren wurde kein signifikanter Einfluss der Ptch Mutation auf die Differenzierung von Lin Zellen zu Granulozyten/ Erythrozyten/ Makrophagen/ Megakaryozyten (CFU-GEMM), Granulozyten (CFU-G), Makrophagen (CFU-M), Granulozyten/ Makrophagen (CFUGM) und erythroiden Vorläufern (burst-forming unit-erythroid, BFU-E) festgestellt (Tabelle 22).

An den gleichen Tierkohorten wurde eine Analyse von Zytospin-Präparationen von Gesamtknochenmark von Prof. Dr. C. Binder (Universitätsklinikum Göttingen, Abt. Onkologie) durchgeführt. Hierbei wurde in den $\mathrm{Ptch}^{-/}$Tieren eine starke Reduktion von pro-Erythroblasten beobachtet (Tabelle 23). Die Morphologie und die Anzahl aller anderen Knochenmarkszellen aus Ptch $^{-/}$Tieren zeigten jedoch keinerlei Auffälligkeiten im Vergleich zu den Kontrollkohorten.

Des Weiteren wurde die Morphologie und Anzahl von Blutzellen aus Vollblutausstrichen und durch automatisierte Zellzählungen analysiert (Dr. T. Heller; Universitätsklinikum Göttingen, Abt. Klinische Chemie und G. Hindermann; Universität Göttingen, Institut für Humangenetik). Diese Analyse zeigte, dass die peripheren Lymphozyten in Ptch $^{-/}$Tieren stark reduziert waren (Tabelle 24). 
Dagegen war die Zahl der neutrophilen Granulozyten in den PPtch $^{-/}$Tieren erhöht. Alle anderen Blutzellwerte sowie die Morphologie der Zellen waren unauffällig.

Die normalen Erythrozytenzahlen im Vollblut (Tabelle 24) stehen im Gegensatz zu der beobachteten Reduktion der pro-Erythroblasten im Knochenmark (Tabelle 23). $\mathrm{Da}$ jedoch die CFU-GEMM und BFU-E kolonieformende Aktivität von Lin Knochenmarkszellen aus Ptch $^{-/-}$Tieren normal war (Tabelle 22) und die Anzahl der kurzlebigen Thrombozyten im Vollblut ebenfalls im Normalbereich lag (Tabelle 24), ruft die Inaktivierung von Ptch keinen generellen Entwicklungsdefekt der myeloischen Linie hervor, sondern bewirkt einen spezifischen Entwicklungsdefekt von Erythrozyten-Vorläuferzellen nach dem BFU-E-Stadium.

Tabelle 22: Auszählung der koloniebildenden Einheiten von Lin Knochenmarkszellen aus tPtch $^{-/}$Mäusen (colony forming-unit assay, CFU-Assay). Lin ${ }^{-}$Knochenmarkszellen wurden von tPtch $^{-/}$Tieren 19 Tage nach der ersten Tamoxifengabe sowie von Tamoxifen- oder Lösungsmittelbehandelten Kontrolltieren isoliert und in einem Methylzellulosemedium kultiviert. Pro Tier wurden $2 x$

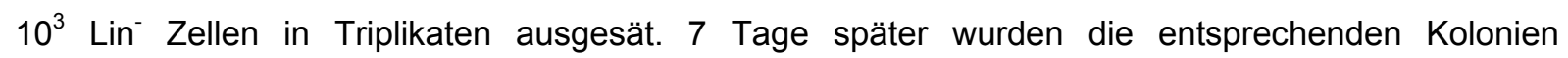
ausgezählt. Es wurde der prozentuale Anteil der verschiedenen Subpopulationen und der Gesamtkoloniezahl ermittelt. Die Anzahl der so analysierten Tiere ist in Spalte $\mathrm{n}$ angegeben. $\mathrm{P}$ Werte wurden mit dem Mann-Whitney-U-Test berechnet. Abkürzungen: CFU, colony-forming unit (koloniebildende Einheit); CFU-GEMM, Granulozyten/ Erythrozyten/Makrophagen/Megakaryozyten; CFU-GM, Granulozyten/ Makrophagen; CFU-G, Granulozyten; CFU-M, Makrophagen; BFU-E, burstforming unit-erythroid, erythroide Vorläufer.

\begin{tabular}{|c|c|c|c|c|c|c|c|}
\hline & \multicolumn{3}{|c|}{ Kontrollen } & \multicolumn{4}{|c|}{ tPtch $^{-/-}$} \\
\hline & Mittelwert & $\begin{array}{l}\text { Mittelwert- } \\
\text { abweichung }\end{array}$ & $\mathbf{n}$ & Mittelwert & $\begin{array}{c}\text { Mittelwert- } \\
\text { abweichung }\end{array}$ & $\mathbf{n}$ & P Wert \\
\hline CFU-GEMM & 0,6 & 0,8 & 5 & 0,5 & 0,5 & 4 & 0,810985 \\
\hline CFU-GM & 16,9 & 6,4 & 5 & 13,9 & 6,8 & 4 & 0,312278 \\
\hline CFU-G & 45,8 & 6,0 & 5 & 48,5 & 12,2 & 4 & 0,394041 \\
\hline CFU-M & 62,8 & 5,7 & 5 & 61,7 & 15,7 & 4 & 0,635421 \\
\hline BFU-E & 2,8 & 1,8 & 5 & 2,3 & 1,4 & 4 & 0,533895 \\
\hline
\end{tabular}




\section{Tabelle 23: Auszählung von pro-Erythroblasten im Knochenmark von tPtch $^{-/}$Mäusen:} Zytospin-Präparationen von Gesamt-Knochenmark wurden sowohl aus $t$ Ptch $^{-/}$Tieren (15 und 19 Tage nach der ersten Tamoxifengabe) als auch von Tamoxifen- bzw. Lösungsmittel-behandelten Kontrolltieren angefertigt. Nach einer panoptischen Färbung nach Pappenheim wurden die proErythroblasten/500 Zellen ausgezählt. Da sich die Anzahl der pro-Erythroblasten von tPtch $^{-/}$Tieren 15 und 19 Tage nach der ersten Tamoxifengabe nicht unterschieden, wurden die Werte der Auszählung in der Tabelle zusammengefasst. Die Anzahl der jeweils analysierten Tiere ist in Spalte $\mathrm{n}$ angegeben. $P$ Werte wurden mit dem Mann-Whitney-U-Test berechnet. Es wurde ein signifikanter Unterschied (P Wert $<0,05)$ zwischen der pro-Erythroblastenanzahl von $\mathrm{Ptch}^{-/}$und Kontrolltieren festgestellt.

\begin{tabular}{c|ccc|cccc}
\hline & \multicolumn{2}{|c|}{ Kontrollen } & \multicolumn{3}{|c}{ tPtch $^{\text {T- }}$} \\
\hline & Mittelwert & $\begin{array}{c}\text { Mittelwert- } \\
\text { abweichung }\end{array}$ & $\mathbf{n}$ & Mittelwert & $\begin{array}{c}\text { Mittelwert- } \\
\text { abweichung }\end{array}$ & $\mathbf{n}$ & P Wert \\
\hline $\begin{array}{c}\text { pro-Erythroblasten [Anzahl/500 } \\
\text { Zellen] }\end{array}$ & 99.3 & 9.3 & 4 & 38.5 & 6.7 & 4 & 0.000008 \\
\hline
\end{tabular}

Tabelle 24: Differentialblutbild von $\boldsymbol{t P t c h}^{-/}$Mäusen: In Vollblut (gewonnen aus Herzpunktionen oder aus dem Augenhintergrund) von $t \mathrm{Ptch}^{-/}$Tieren (19 Tage nach der ersten Tamoxifengabe) und Tamoxifen-behandelten Kontrolltieren wurden der Hämatokrit- und der Hämoglobingehalt automatisch bestimmt. Das Differentialblutbild wurde entweder von Blutausstrichen ausgezählt oder aber automatisch bestimmt. Die Quantifizierung der Retikulozyten erfolgte wie unter 2.18.2.2 beschrieben. Die Anzahl der analysierten Tiere ist in Spalte $n$ angegeben. $P$ Werte wurden mit dem Mann-Whitney-

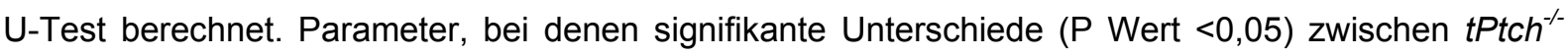
und Kontrolltieren festgestellt wurden, sind grau unterlegt. Abkürzungen: Hkt, Hämatokrit; Hgb, Hämoglobin; Ery, Erythrozyten; Re, Retikulozyten; Leu, Leukozyten; Thr, Thrombozyten; Ne, neutrophile Granulozyten; Ly, Lymphozyten; Mo, Monozyten; Eo, eosinophile Granulozyten; Ba, basophile Granulozyten.

\begin{tabular}{|c|c|c|c|c|c|c|c|}
\hline & Mittelwert & $\begin{array}{l}\text { ntrollen } \\
\text { Mittelwert- } \\
\text { abweichung }\end{array}$ & $\mathrm{n}$ & Mittelwert & $\begin{array}{c}\text { tPtch }^{-/-} \\
\text {Mittelwert- } \\
\text { abweichung }\end{array}$ & $\mathbf{n}$ & P Wert \\
\hline Hkt [\%] & 42,5 & 2,8 & 7 & 40,9 & 6,2 & 5 & 0,663133 \\
\hline $\mathrm{Hgb}[\mathrm{g} / \mathrm{dl}]$ & 13,4 & 0,6 & 6 & 13,1 & 1,8 & 5 & 0,810412 \\
\hline Ery $\left[\times 10^{6} / \mathrm{mm}^{3}\right]$ & 9,4 & 1,6 & 7 & 8,0 & 1,2 & 5 & 0,306530 \\
\hline $\operatorname{Re}[\% 0]$ & 40,5 & 19,6 & 10 & 33,8 & 5,6 & 4 & 0,266562 \\
\hline Leu $\left[\times 10^{3} / \mathrm{mm}^{3}\right]$ & 6,1 & 1,9 & 7 & 7,7 & 3,8 & 5 & 0,517902 \\
\hline $\operatorname{Thr}\left[10^{5} / \mathrm{mm}^{3}\right]$ & 287,0 & 187,7 & 6 & 319,6 & 147,5 & 5 & 0,806576 \\
\hline $\mathrm{Ne}[\%]$ & 25,7 & 9,1 & 11 & 47,4 & 17,1 & 7 & 0,010858 \\
\hline Ly [\%] & 65,5 & 8,3 & 11 & 39,0 & 9,1 & 8 & 0,000164 \\
\hline Mo [\%] & 4,1 & 3,2 & 11 & 3,0 & 1,9 & 8 & 0,521337 \\
\hline Eo [\%] & 2,0 & 1,9 & 11 & 4,0 & 4,1 & 7 & 0,341399 \\
\hline $\mathrm{Ba}[\%]$ & 2,8 & 2,4 & 11 & 5,9 & 4,5 & 7 & 0,142791 \\
\hline
\end{tabular}




\subsubsection{Versuch der Induktion von RMS in $\operatorname{Ptch}^{N X / N X} E R T^{+/ /}$Mäusen}

Bei der Bestimmung der Rekombinationseffizienz des Ptch $^{N X}$ Lokus in $t P t c h^{-/}$Tieren wurde gezeigt, dass durch die systemische Tamoxifengabe eine effiziente Rekombination des Ptch $^{N X}$ Lokus in vielen Geweben, einschließlich der Haut und der Skelettmuskulatur induziert wird (Abbildung 26; Abbildung 27). Das Zeitfenster von der Induktion der Rekombinase bis zum Tod der Tiere (maximal 23 Tage) war jedoch für eine eindeutige Tumorentwicklung in $\operatorname{tPtch}^{-/}$Mäusen zu klein. Die Tumorigenese konnte daher in $\mathrm{Ptch}^{-/}$Tieren nicht untersucht werden.

Wie in der Einleitung beschrieben, wird vermutet, dass sich RMS aus Satellitenzellen entwickeln. Falls diese Hypothese stimmen sollte, müsste es möglich sein, durch das gezielte Ausschalten von Ptch in diesen Zellen RMS zu induzieren.

Um zu überprüfen, ob die hier verwendeten ERT2-Mäuse für eine solches Experiment geeignet sind und auch tatsächlich Cre-Rekombinase in Satellitenzellen exprimieren, wurden Immunfluoreszenzfärbungen an Muskelfasern aus 6 Wochen alten $E R T 2^{+/}$Mäusen durchgeführt. Durch die simultane Färbung mit Antikörpern gegen Cre-Rekombinase und dem Satellitenzellmarker Pax7 (Seale P et al., 2000; Relaix $\mathrm{F}$ et al., 2005; Kuang $\mathrm{S}$ et al., 2006) wurde die Expression der ERT2 Rekombinase in Satellitenzellen nachgewiesen (Abbildung 44).

Um auch die induzierbare Aktivität der CreERT2-Rekombinase nach Tamoxifengabe in Satellitenzellen in ERT2 Mäusen zu dokumentieren, wurden Kryostatschnitte von Skelettmuskeln (musculus soleus) aus doppelt heterozygoten ROSA26- $R^{+/-} E R T 2^{+/-}$ (ROSA26-R Reportermauslinie, siehe Kapitel 3.3.1.2.1) Tieren nach intramuskulärer Tamoxifeninjektion (einmalige Dosis: $100 \mu \mathrm{g}$ Tamoxifen in $10 \mu \mathrm{l}$ Lösungsmittel) mit Antikörpern gegen Pax7 und B-Galaktosidase analysiert. Wie Abbildung 45 zeigt, wurde durch die Aktivierung der CreERT2-Rekombinase mit Tamoxifen eine Expression der ß-Galaktosidase in Satellitenzellen (Pax7-positive Zellen), aber auch in anderen Zellen des Skelettmuskels, detektiert.

Aufgrund dieser Daten wurde in einem Pilotexperiment untersucht, ob sich a) in diesen Tieren durch eine solche Behandlung Muskeltumoren induzieren lassen und b) ob die lokale Injektion von $100 \mu \mathrm{g}$ Tamoxifen in $\mathrm{Ptch}^{\mathrm{NX} / \mathrm{NX}} E R T 2^{+/}$Mäuse einen systemischen Effekt hat und den unter 3.2.5.1 beschriebenen Phänotyp hervorruft .

Dazu wurden Tiere des Genotyps Ptch $^{N X /+}$ ERT2 $2^{+-}$und Ptch $^{N X / N X} E R T 2^{+/-}$im Alter von 6 Wochen einmalig $100 \mu \mathrm{g}$ Tamoxifen intramuskulär (in den musculus soleus) 
injiziert. Als Kontrolle wurden Tiere des gleichen Genotyps mit $10 \mu \mathrm{l}$ des Lösungsmittels behandelt. Um Sekundäreffekte durch Tamoxifen ausschließen zu können, wurden auch Mäuse der Genotypen $\operatorname{Ptch}^{N X /+} E R T 2^{-/}$und $\operatorname{Ptch}^{N X / N X} E R T 2^{-/-}$ mit Tamoxifen behandelt. Alle Tiere wurden nach der Behandlung engmaschig beobachtet. Bis zum Abschluss dieser Arbeit hatte keines der analysierten Tiere Weichteiltumoren entwickelt.
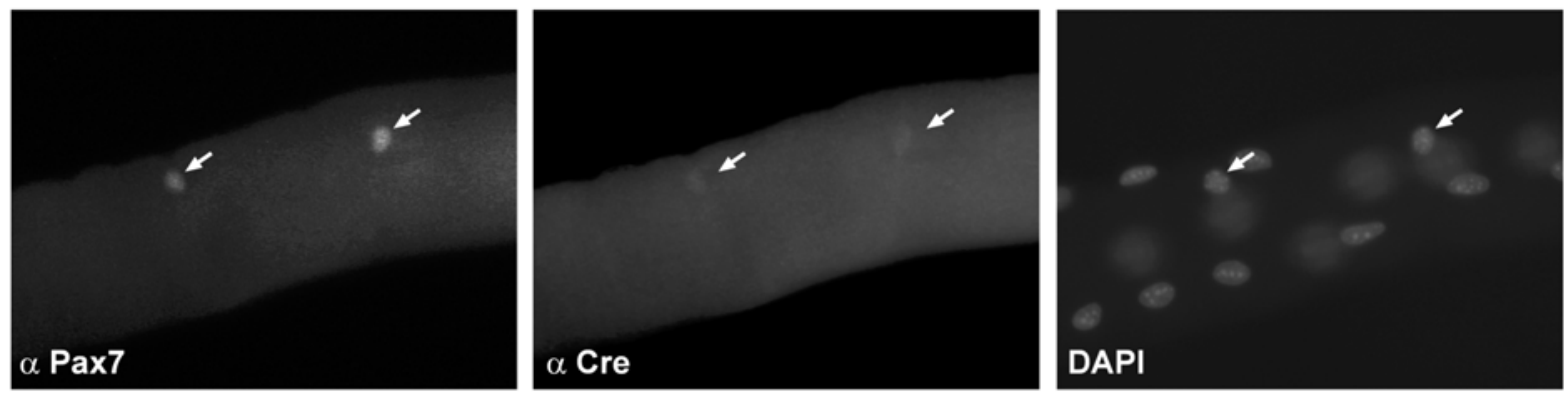

Abbildung 44: Expression der CreERT2-Rekombinase in Satellitenzellen von ERT2 ${ }^{\text {+/ }}$ Mäusen. Dargestellt ist die simultane Immunfluoreszenzfärbung mit anti-Pax7 (links) und anti-Cre-Rekombinase (Mitte) Antikörpern von fixierten einzelnen Muskelfasern einer $E R T 2^{+/}$Maus. Die gefärbten Muskelfasern wurden in einem DAPI-enthaltenden Montagemedium (rechts) eingedeckt. Die Pfeile markieren Pax7 positive Satellitenzellen, die gleichzeitig CreERT2-Rekombinase exprimieren.
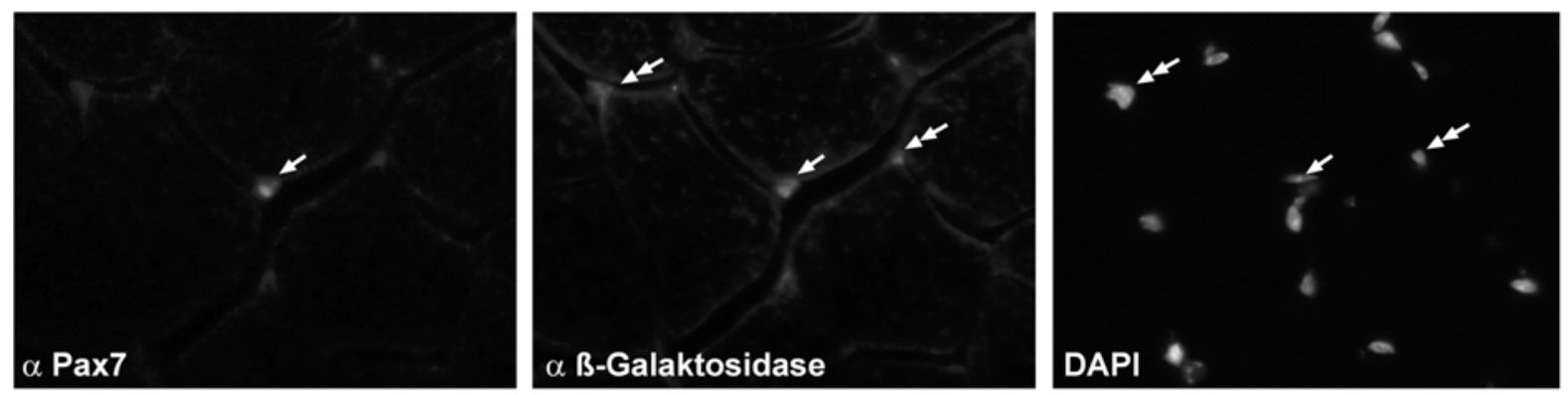

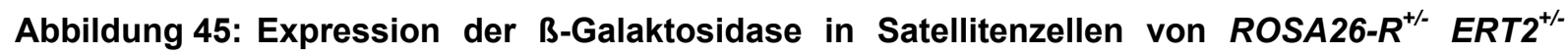
Mäusen nach intramuskulärer Tamoxifengabe $(100 \mu \mathrm{g})$. Dargestellt ist die simultane Immunfluoreszenzfärbung mit anti-Pax7 (links) und anti-ß-Galaktosidase (Mitte) Antikörpern an Kryostatschnitten des Muskels einer ROSA26- $R^{+/-} E R T^{+/-}$Maus 10 Tage nach intramuskulärer Tamoxifengabe. Die gefärbten Schnitte wurden in einem DAPI-enthaltenden Montagemedium (rechts) eingedeckt. Die einfachen Pfeile markieren eine ß-Galaktosidase exprimierende, Pax7 positive Satellitenzelle, während die Doppelpfeile auf ß-Galaktosidase exprimierende, Pax7 negative Muskelzellkerne weisen.

\subsubsection{Induktion von Basaliomen in $\operatorname{tPtch}^{-/}$Mäusen}

Interessanterweise wurden 1,5 bis 2 Monate nach der intramuskulären Tamoxifengabe bei den Ptch $^{N X / N X} E_{R T 2}^{+/-}$Tieren ( 9 von 10 Tieren) hyperproliferative 
Hautveränderungen an Ohren, Schwanz und auch an der Haut der Plantarseite der Pfoten beobachtet (Abbildung 46). Keines der Tamoxifen-behandelten $\mathrm{Ptch}^{N X /+}$ ERT2 $^{+/-}$oder Lösungsmittel-behandelten Ptch $^{N X / N X} E^{2} T_{2}^{+/-}$Tiere zeigten diese Hautveränderungen.

Histologische Untersuchungen der Hautveränderungen zeigten, dass durch die einmalige intramuskuläre Gabe von $100 \mu \mathrm{g}$ Tamoxifen in $\operatorname{Ptch}^{N X / N X} E R T 2^{+/}$Mäuse in gering behaarten Hautbereichen Basaliome entstehen (Abbildung 47, links und Mitte). Erst 6 Monate nach der Tamoxifengabe wurden auch erste hyperproliferative Veränderungen an der behaarten Haut der Tiere beobachtet (Abbildung 47, rechts). Im Gegensatz zu tPtch ${ }^{-/}$Mäusen entwickelten die intramuskulär behandelten Tiere keinen starken Putztrieb. Die Tiere zeigten auch keine auffälligen Gewichts- oder Fellverluste (siehe Abbildung 28). Ebenso wurden keine Auffälligkeiten bei durchflusszytometrischen Analysen von Knochenmark, Milz und Thymus detektiert (Daten nicht gezeigt).
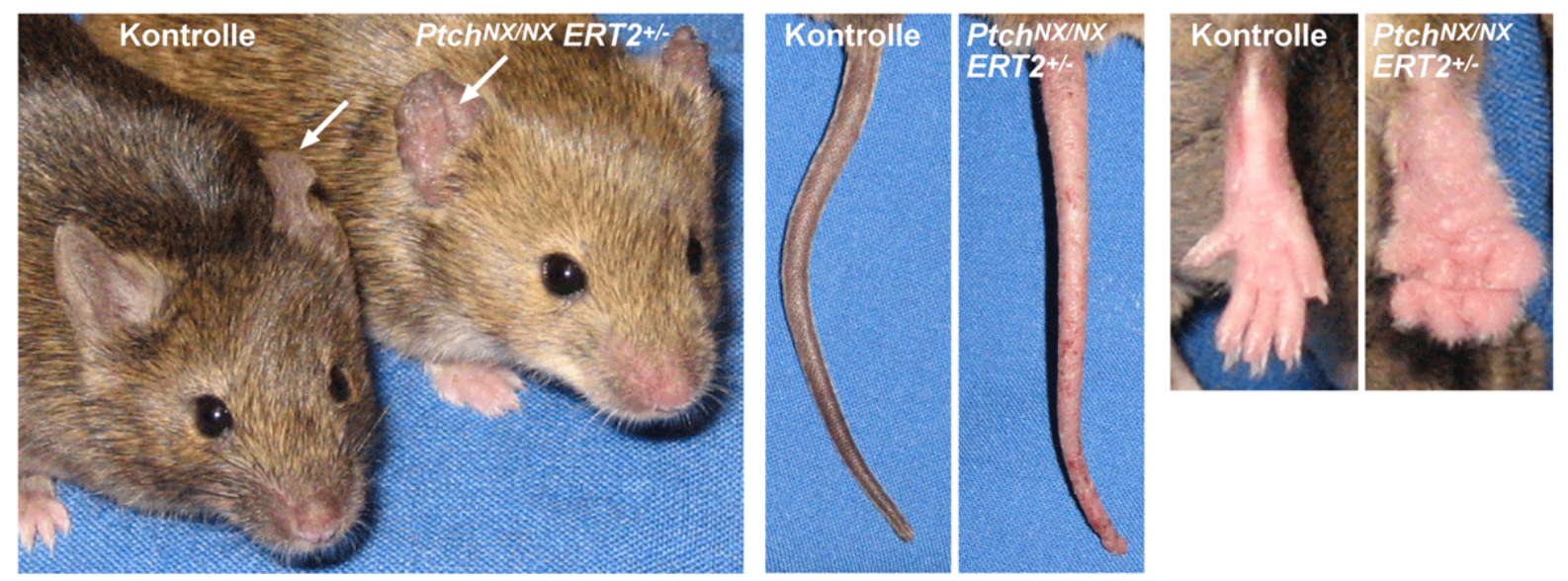

Abbildung 46: Die intramuskuläre Injektion von $100 \mu \mathrm{g}$ Tamoxifen in $\operatorname{Ptch}^{N X / N X} E^{2}{ }^{+/-}$Mäuse induziert die Tumorigenese von Basaliomen an unbehaarten Hautarealen. Dargestellt sind ein Ptch $^{N X / N X}$ ERT2 $^{+/-}$Tier 2 Monate nach der intramuskulären Tamoxifeninjektion und ein Lösungsmittelbehandeltes Ptch $^{N X / N X}$ ERT2 ${ }^{+-}$Tier (Kontrolle). Die weißen Pfeile markieren die Ohren der beiden Tiere. Weiterhin sind die Schwänze und die Plantarflächen der Pfoten beider Tiere gezeigt. Die hyperproliferativen Veränderungen des Tamoxifen-behandelten Tieres sind sowohl an Ohren, Schwanz und Fuß makroskopisch sichtbar. 


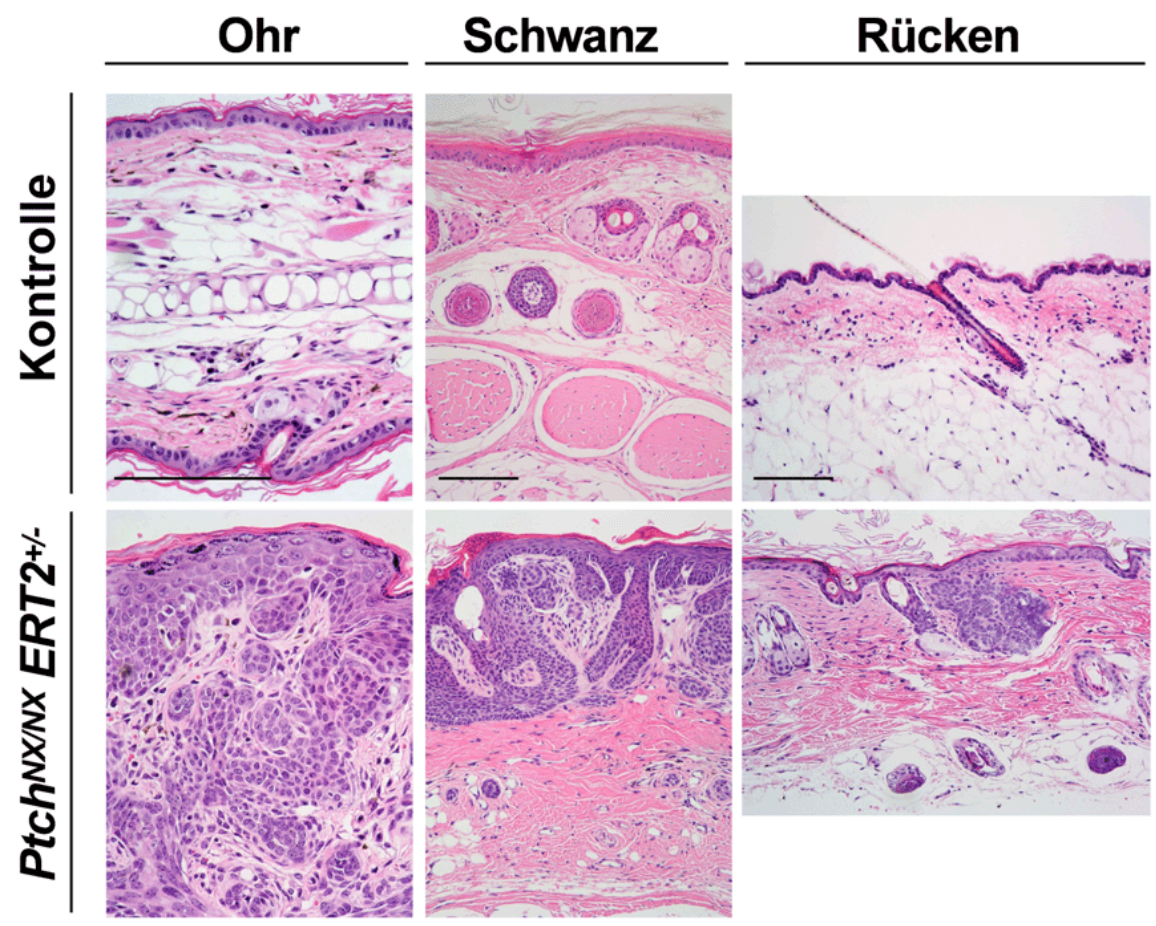

Abbildung 47: Die intramuskuläre Injektion von $100 \mu \mathrm{g}$ Tamoxifen in Ptch $^{N X / N X} E_{R T 2}{ }^{+/}$Mäuse induziert die Tumorigenese von Basaliomen. Dargestellt sind HE-Färbungen von Ohr- (links), Schwanz- (Mitte) und Rückenhaut (rechts) eines Ptch $^{N X / N X} E R T 2^{+/}$Tiers 6 Monate nach der intramuskulären Tamoxifeninjektion und eines Lösungsmittel-behandeltes Ptch $^{N X / N X} E R T 2^{+/}$Tiers (Kontrolle). Die Entstehung von Basaliomen ist sowohl an Ohr-, Schwanz- und Rückenhaut erkennbar. Die Balken entsprechen $2 \mathrm{~mm}$ im Präparat. 


\subsection{Herstellung der $\operatorname{Tg}(\operatorname{Pax} 7 \mathrm{CreTM})$ Mauslinien}

\subsubsection{Pax7 spezifische Expression einer Tamoxifen-induzierbaren Cre-}

\section{Rekombinase}

Mit Hilfe des konditionellen Ptch knock-outs sollte es möglich sein, die Ursprungszelle des RMS zu definieren. Da angenommen wird, dass RMS aus den adulten Stammzellen des Muskels, den Satellitenzellen, entstehen, sollte hierzu eine Maus generiert werden, die in diesen Zellen eine induzierbare Cre-Rekombinase exprimiert. Diese Maus sollte dann mit $\operatorname{Ptch}^{N X / N X}$ Mäusen gekreuzt werden. Die Induktion der Cre-Rekombinase (z. B. durch Tamoxifen) sollte es erlauben, Ptch spezifisch in Satellitenzellen zu deletieren.

Wie bereits in der Einleitung beschrieben, wurde der Pax7 Promotor zur Expression einer induzierbaren Cre-Rekombinase gewählt. Dies resultiert aus der Tatsache, dass Pax7 nicht nur in Satellitenzellen exprimiert wird, sondern für die Entwicklung dieser Zellen auch essentiell ist. Wie in Abbildung 48 gezeigt, wird Pax7 auch in Ptch-assoziierten RMS aus Ptch ${ }^{\text {neo67// }}$ Mäusen exprimiert.

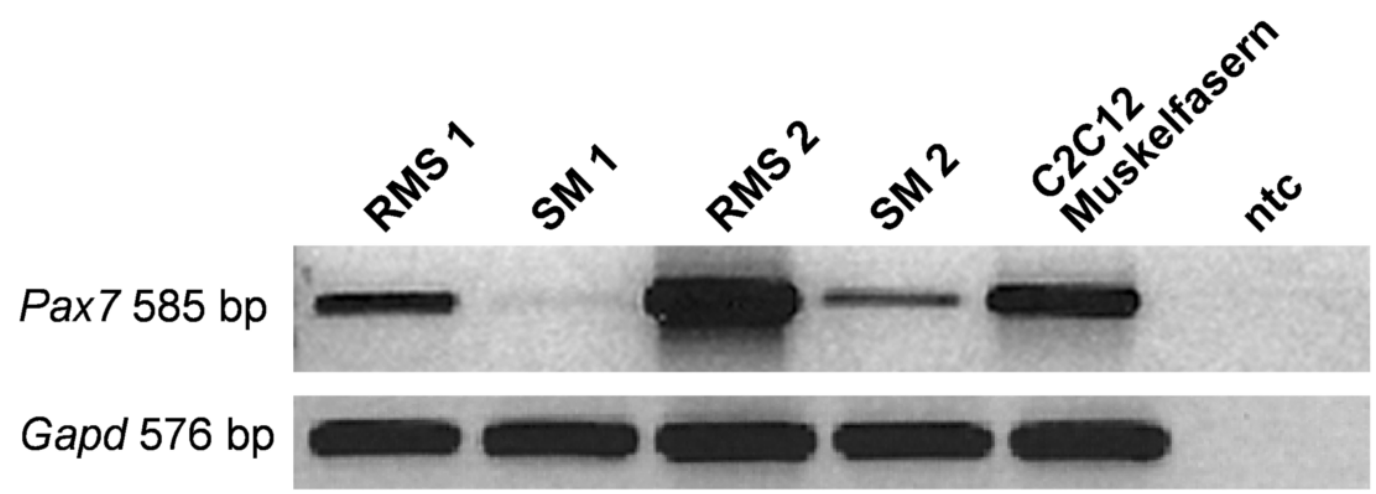

Abbildung 48: Pax7 Expression in Ptch-assoziierten RMS. RT-PCR-Analyse von cDNA aus Gesamt-RNA von RMS und entsprechendem Skelettmuskel (SM) von Ptch ${ }^{\text {neo67/+ }}$ Tieren. Als Positivkontrolle wurde cDNA aus differenzierten Muskelfasern der myogenen Zelllinie C2C12 verwendet. Für die Amplifikation der murinen Pax7 Transkripte wurde mit dem Oligonukleotidpaar mPax7-F1/mPax7-R1 gearbeitet (Tabelle 10). Als Kontrolle der cDNA-Matrizen diente die Amplifikation von Gapd Transkripten. Abkürzungen: ntc, no template control.

Zur Herstellung einer transgenen Mauslinie, welche unter Kontrolle des Pax7 Promotors eine induzierbare Cre-Rekombinase exprimiert, wurde zunächst ein 3217 bp langes Fragment aus genomischer Maus DNA isoliert. Dieses Fragment beinhaltet laut National Center for Biotechnology Information (NCBI; 
http://www.ncbi.nlm.nih.gov/) den Pax7 Promotor (Abbildung 49) und wurde, wie auch mehrere am 5'-Ende deletierte Fragmente, für in vitro Analysen in den pGL3basic Vektor kloniert (siehe Kapitel 2.15.7.2.1). Die Promotor-Luziferase Konstrukte sind in Abbildung 49 dargestellt. Nach der funktionellen Analyse der Konstrukte (siehe Kapitel 3.3.1.1) wurde das Plasmid pPax7CreTM hergestellt (siehe Kapitel 2.15.7.2.2), welches ebenfalls in Abbildung 49 gezeigt ist.

Pax7 Promoter (3217 bp)

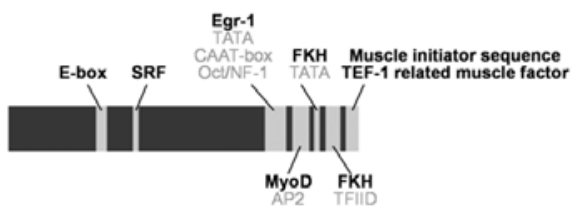

pGL3 Pax7prom 3,2

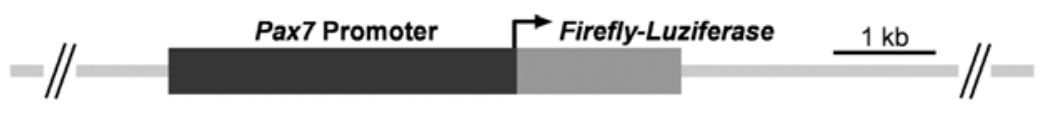

pGL3 Pax7prom 2,5

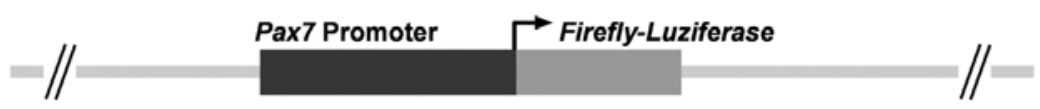

pGL3 Pax7prom 1,5

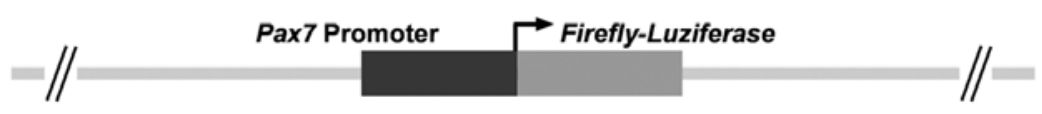

pPax7CreTM Zielvektor

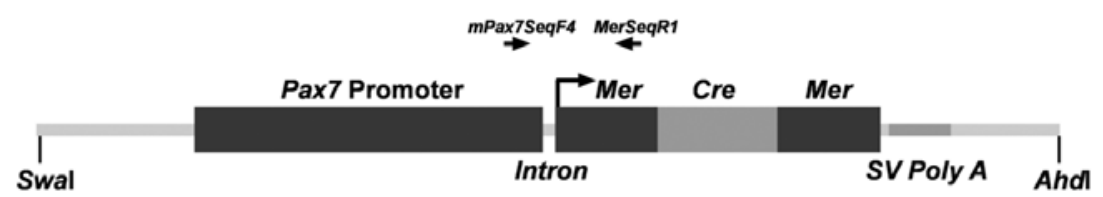

Abbildung 49: Schematische Darstellung des murinen Pax7 Promotors, der Luziferase Reporterkonstrukte sowie des Plasmids pPax7CreTM. Das analysierte Promotor Fragment umfasst 3217 bp des proximalen murinen Pax7 Promotors (obere Zeile). Bindestellen (graue Boxen) für allgemeine (grau Lettern) und gewebespezifische (fette, schwarze Lettern) Transkriptionsfaktoren wurden durch Datenbankanalysen der Promotorsequenz bestimmt (MatInspektor).

Die analysierten Pax7 Luziferase Reporterplasmide ( $p G L$ Pax7prom 3,2; $p G L$ Pax7prom 2,5; pGL3 Pax7prom 1,5) enthalten 3217 bp; 2489 bp bzw. 1499 bp des proximalen murinen Pax7 Promotors. Hierbei wurde der endogene Pax7 Transkriptionsstart (schwarzer Pfeil) direkt mit dem des Firefly Luziferasegens verbunden.

Der pPax7CreTM Zielvektor enthält 3217 bp des proximalen murinen Pax7 Promotors. Anschließend enthält das Plasmid ein chimeres Intron, das Gen der induzierbaren MerCreMer-Rekombinase (Verrou C et al., 1999) und eine Siamian Virus 40-Polyadenylierungssequenz (SV Poly A). Es wurde so kloniert, dass die Position des endogenen Pax7 Translationsstartcodons dem der MerCreMer Rekombinase entspricht. Zur Herstellung $T g(P a x 7 C r e T M)$ transgener Mäuse wurde der Zielvektor mit den Restriktionsendonukleasen Swal/Ec/Hkl (Ahdl) liniearisiert. Mit dem Oligonukleotidpaar 
mPax7SeqF4/MerSeqR1 wurde die Mauslinie Tg(Pax7CreTM) genotypisiert. Die exakten Klonierungsstrategien der Plasmide sind unter 2.11 .3 beschrieben.

Abkürzungen: E-box, typische Proteinbindungsdomäne für myogene Helix-Loop-Helix Transkriptionsfaktoren; SRF, Proteinbindungsdomäne für das Protein serum response factor; Egr-1, Proteinbindungsdomäne für das Protein early growth response 1; TATA, Proteinbindungsdomäne für das Protein TATA-binding protein, welches die DNA-bindende Untereinheit des TFIID darstellt; CAATbox, für eine erfolgreiche Transkription notwendige eukaryotische Promotersequenz; Oct, Proteinbindedomäne für Transkriptionsfaktoren mit POU Domänen; NF-1, Proteinbindungsdomäne für das Protein nuclear factor-1; MyoD, Proteinbindungsdomäne für das Protein myogenic differentiation 1 , welches in proliferierenden Myoblasten und differenzierten Muskelfasern exprimiert wird und als transkripioneller Aktivator von Muskel-spezifischen Genen agiert; AP-2, Proteinbindungsdomäne für das Protein activator protein 1; FKH, Proteinbindungsdomäne für fork head Transkriptionsfaktoren, die während der Entwicklung des frühen Embryogenese und im Nervensystem adulter Tiere exprimiert werden; TFIID, Proteinbindungsdomäne neben der TATA-Box für den Transkriptionsfaktor IID.

\subsubsection{In vitro Analyse des murinen Pax7 Promotors}

\subsection{Expression von Pax7 in der Zelllinie C2C12}

Für in vitro Analysen der klonierten Pax7 Promoter-Luziferase Reporterkonstrukte wurde die murine Zelllinie $\mathrm{C} 2 \mathrm{C} 12$ ausgewählt, die durch Kultivierung von murinen Myoblasten entstanden ist (Yaffe D und Saxel O, 1977). Die Zelllinie wurde auf endogene Expression von Pax7 durch RT-PCR-Analysen an cDNA überprüft (Murmann OV et al., 2000). Abbildung 50 zeigt, dass C2C12 Zellen vor allem bei niedrigen Serumkonzentrationen (2 \% FCS) und bei zusätzlicher hoher Zelldichte (Daten nicht gezeigt) eine starke Pax7 Expression aufweisen.

Soweit nicht anders erwähnt, wurden alle nachfolgenden in vitro Experimente an C2C12 Zellen bei hoher Zelldichte und niedrigen Serumkonzentrationen durchgeführt. Als negative Kontrollzelllinie wurden NIH/3T3 eingesetzt, da diese keine endogene Pax7 Expression zeigen (siehe Abbildung 50). 


\section{$\mathrm{C2C12}$}

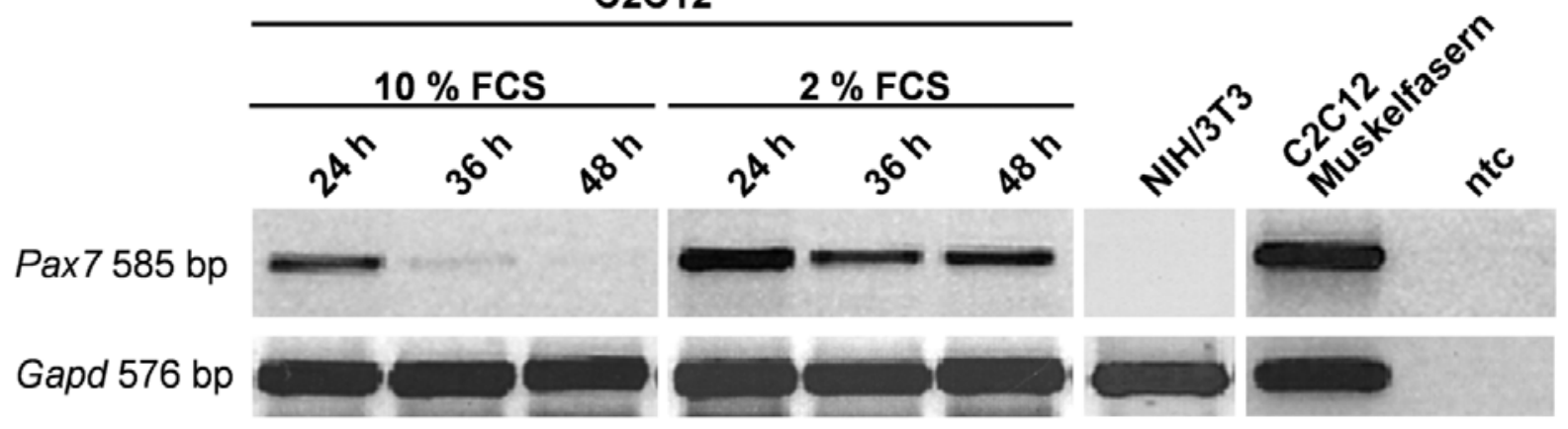

Abbildung 50: Pax7 Expression der myogenen Zellinie C2C12. RT-PCR-Analysen an CDNA von C2C12 Zellen bei hohen (10 \% FCS) und niedrigen (2 \% FCS) Serumkonzentrationen. Als Positivkontrolle wurde cDNA aus Muskelfasern von differenzierten $\mathrm{C} 2 \mathrm{C} 12$ Zellen eingesetzt. Außerdem wurde die Fibroblasten-Zelllinie NIH/3T3 auf Pax7 Expression untersucht. Für die Amplifikation der murinen Pax7 Transkripte wurde mit dem Oligonukleotidpaar mPax7-F1/mPax7-R1 gearbeitet. Als Kontrolle der cDNA-Matrizen diente die Amplifikation von Gapd Transkripten. Abkürzungen: FCS, fetal calf serum (fötales Kälberserum); ntc, no template control.

\subsection{In vitro Analyse der Pax7 Luziferase Reporterplasmide}

Zur in vitro Expressionsanalyse der Pax7 Luziferase Reporterkonstrukte ( $p G L 3$ Pax7prom 3,2; pGL3 Pax7prom 2,5, pGL3 Pax7prom 1,5; Abbildung 49) wurden diese zusammen mit dem Plasmid $p R L-C M V$ in die Zelllinien $\mathrm{C} 2 \mathrm{C} 12$ und NIH/3T3 cotransfiziert. $48 \mathrm{~h}$ nach erfolgter Transfektion wurden die Zellen abgeerntet und die Zelllysate mit dem Dualen-Luziferase-Assay analysiert.

Als Positivkontrolle wurde das Plasmid pGL MG-185 (Expression der Luziferase unter Kontrolle des Myogenin Minimalpromotors, aktiv in C2C12 Zellen) (Ohto $\mathrm{H}$ et al., 1999) und als Negativkontrolle der Leervektor pGL3-basic transfiziert. Abbildung 51 zeigt die Luziferasemessung aus 2 unabhängigen, jeweils in Tripletts durchgeführten Experimenten. Die gemessenen Werte wurden auf die Aktivität der Renilla Luziferase ( $p R L-C M V$ Vektor) normalisiert. Die Grundaktivität des $p G L 3-b a s i c$ Leervektors wurde subtrahiert. Alle analysierten Reporterplasmide exprimierten die Firefly Luziferase auf hohem, nahezu gleichem Niveau in C2C12 Zellen. Hingegen wurde fast keine Expression in den nicht-myogenen $\mathrm{NIH} / 3 \mathrm{~T} 3$ Zellen induziert. Ähnliche Ergebnisse wurden auch in anderen nicht-myogenen Zelllinien (A673; 10T1/2) erzielt (Daten nicht gezeigt). Aus den Ergebnissen wurde geschlossen, dass der klonierte Pax7 Promotor spezifisch im myogenen Zellen exprimiert wird. 


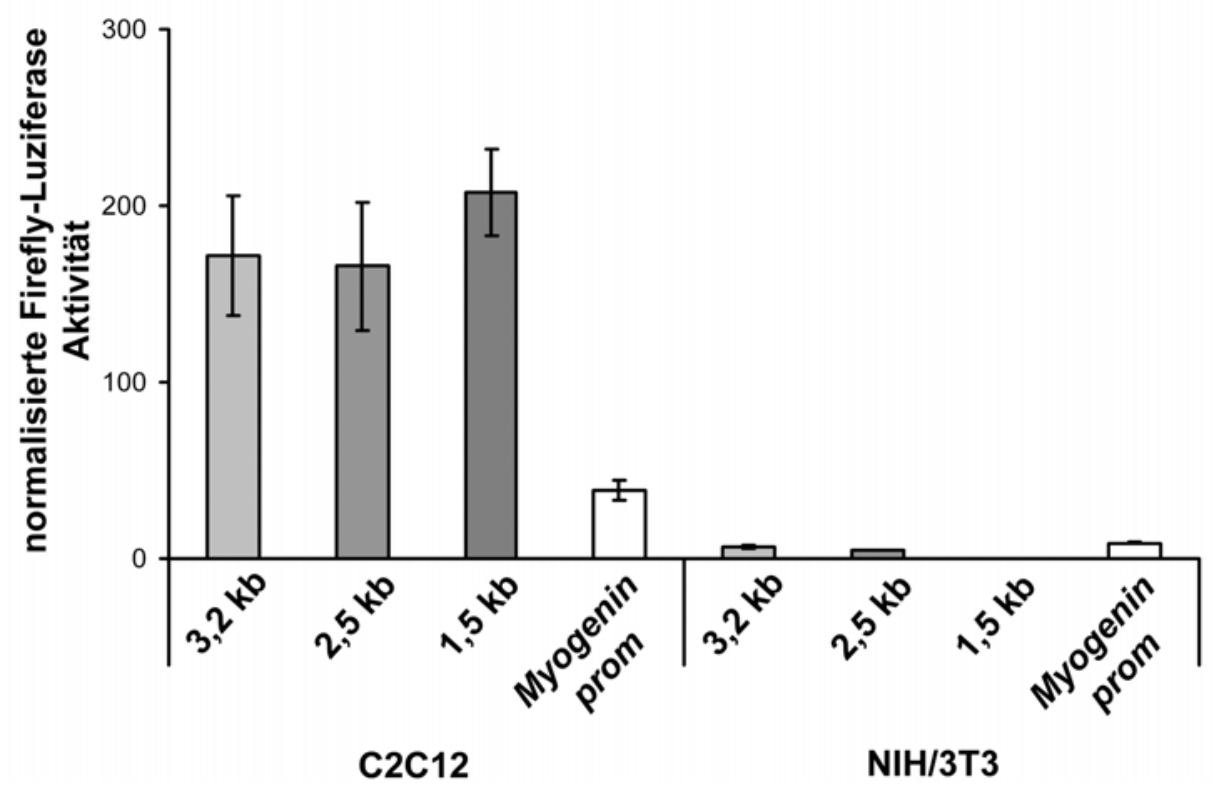

Abbildung 51: Dualer-Luziferase-Assay zur Analyse der Pax7 Luziferase Reporterplasmide. CoTransfektionen der Pax7 Luziferase Reporterplasmide (3,2 kb, pGL3 Pax7prom 3,2; 2,5 kb, pGL3 Pax7prom 2,5; 1,5 kb, pGL3 Pax7prom 1,5) mit pRL-CMV in die Zelllinien C2C12 und NIH/3T3. Als Positivkontrolle wurde das Plasmid pGL MG-185 (Myogenin prom) mit $p R L-C M V$ co-transfiziert. Die Mittelwerte wurden aus 2 unabhänigen Experimenten, die jeweils in Triplikaten durchgeführt wurden, errechnet. Die Expression wurde auf die Aktivität der Renilla Luziferase normalisiert. Die Grundaktivität des Leervektors $p G L 3-b a s i c$ wurde subtrahiert.

\subsection{In vitro Analyse des pPax7CreTM Plasmids}

Abbildung 49 zeigt die Struktur des linearisierten pPax7CreTM Plasmids. Es beinhaltet 3217 bp der 5'-Sequenz des murinen Pax7 Promotors. Daran schließt ein chimeres Intron an. Dann folgt das synthetische Gen der Tamoxifen-induzierbaren MerCreMer-Rekombinase (Verrou C et al., 1999). Hierbei entspricht die Position des endogenen Pax7 Translationsstartcodons der des MerCreMer Rekombinase Gens. Aus dem Expressionsplasmid pAN MerCreMer (zur Verfügung gestellt von M. Reth, Max-Planck-Institut für Immunobiologie, Freiburg) wurde die SV 40 Poly A Sequenz übernommen.

Die $p$ Pax7CreTM-vermittelte Rekombination des konditionellen $p P t c h^{N X}$ Zielvektors $^{2}$ (Abbildung 17) wurde zunächst in vitro auf DNA-Ebene durch Co-Transfektion beider Plasmide in $\mathrm{C} 2 \mathrm{C} 12$ Zellen dokumentiert. $24 \mathrm{~h}$ nach der Transfektion wurde die exprimierte MerCreMer-Rekombinase (im Weiteren als CreTM-Rekombinase bezeichnet) durch Zugabe von $10 \mu \mathrm{M}$ Tamoxifen (in DMSO) zum Medium induziert. Nach weiteren $24 \mathrm{~h}$ wurde die Gesamt-DNA der Zellen isoliert und durch PCR- 
Analysen mit dem Oligonukleotidpaar Exon7-F/Neo-R (Tabelle 10; Abbildung 17) analysiert. Abbildung 52 zeigt die Rekombination des $p P t c h^{N X}$ Zielvektors durch die induzierte CreTM-Rekombinase (Spur 1; pPtch ${ }^{\text {delNX }} 950$ bp). Durch Zugabe von reinem Lösungsmittel (DMSO) wurde dagegen keine Rekombination festgestellt (Spur 4; pPtch 2700 bp). Als Kontrolle wurde das pMC-Cre Plasmid mit dem $p P t c h^{N X}$ Zielvektor co-transfiziert (Abbildung 52; Spur 2 und 5).

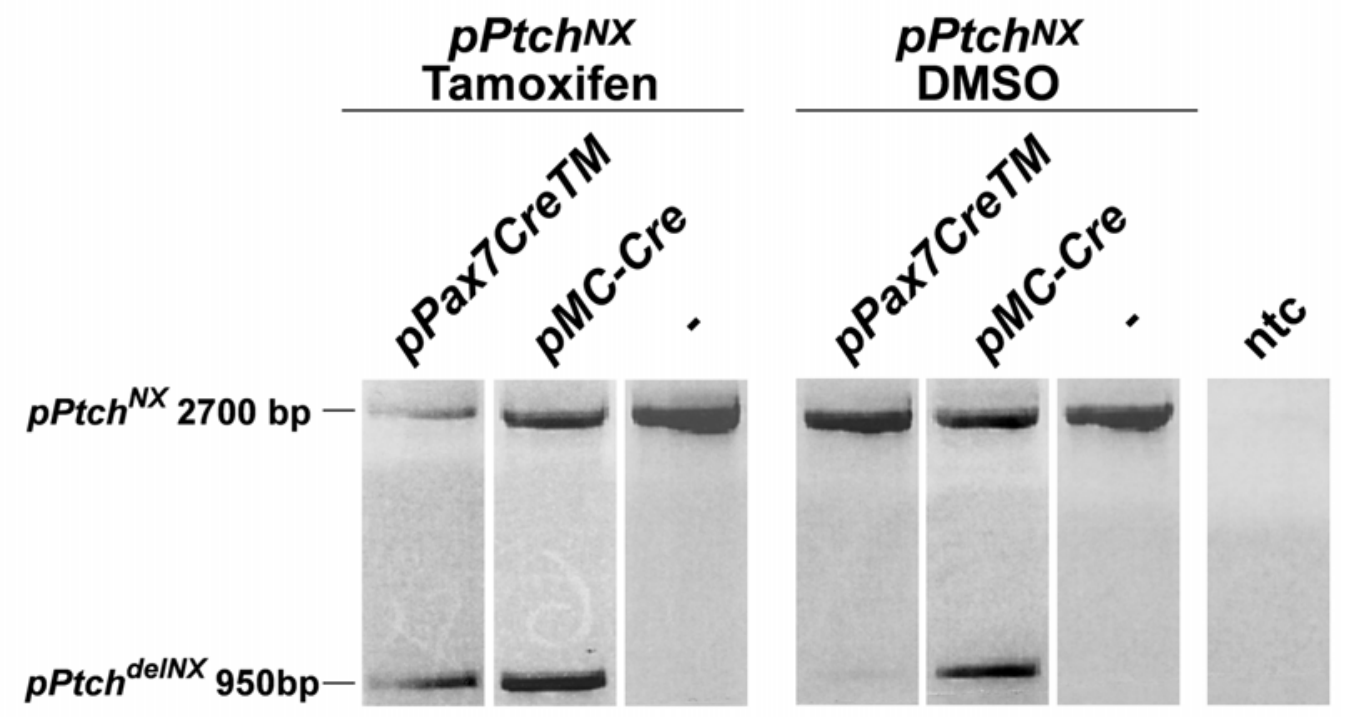

Abbildung 52: Tamoxifen-induzierte Rekombination des pPtch $^{N X}$ Zielvektors durch CoTransfektion mit dem pPax7CreTM Plasmid. Der $p$ Ptch ${ }^{N x}$ Zielvektor wurde mit dem Plasmid pPax7CreTM oder mit pMC-Cre in C2C12 Zellen co-transfiziert Die Zellen wurden mit $10 \mu \mathrm{M}$ Tamoxifen oder Lösungsmittel (DMSO) behandelt. Die Gesamt-DNA der Zellen wurde isoliert und mit dem Oligonukleotidpaar Exon7-F/Neo-R (Tabelle 10; Abbildung 17) mittels PCR analysiert. Abkürzungen: ntc, no template control.

Die Induzierbarkeit und die Grundaktivität („leakyness") der durch pPax7CreTM exprimierten CreTM-Rekombinase wurde des Weiteren auch durch die CoTransfektion mit dem Reporterplasmid ploxNeoloxßGal bestimmt. Die Transfektion wurde an $\mathrm{C} 2 \mathrm{C} 12$ Zellen durchgeführt. Als Kontrollplasmid wurde pAN MerCreMer eingesetzt. $24 \mathrm{~h}$ nach der Transfektion der Zellen wurde Tamoxifen $(10 \mu \mathrm{M})$ oder Lösungsmittel zum Medium gegeben. In Folge der Cre-vermittelten Rekombination des ploxNeoloxßGal Plasmids wurde $\beta$-Galaktosidase exprimiert, deren Enzymaktivität $24 \mathrm{~h}$ nach Zugabe von Tamoxifen durch X-Gal-Färbung nachgewiesen wurde. Das Experiment wurde in Triplikaten durchgeführt. Alle ßGalaktosidase positiven Zellen aus $1 \times 10^{5}$ ausgesähten Zellen pro Platte wurden 
ausgezählt. Nach alleiniger Transfektion des ploxNeoloxßGal Reporterplasmids wurde keine X-Gal-Färbung detektiert (Daten nicht gezeigt).

Abbildung 53 zeigt, dass die Grundaktivität der CreTM-Rekombinase sowohl in pPax7CreTM als auch in pAN MerCreMer transfizierten Zellen gering ist. Durch Zugabe von Tamoxifen wurde ein fast 7-facher Aktivitätsanstieg der vom pPax7CreTM Plasmid exprimierten CreTM-Rekombinase im Vergleich zur Lösungsmittelkontrolle erreicht. Die Induktion der Cre-Rekombinase des verwendeten Kontrollplasmids war dagegen geringer (4,2-fache Induktion durch Tamoxifen). Unspezifische Effekte durch die Tamoxifenzugabe zum Medium wurden durch Co-Transfektion einer konstitutiv aktiven Cre-Rekombinase ( $p M C$-Cre) mit dem Reporterplasmid ploxNeoloxßGal ausgeschlossen. Es wurde auch keine unspezifische Rekombination durch Tamoxifen induziert (Daten nicht gezeigt).

Zusammengefasst zeigen diese Ergebnisse, dass das pPax7CreTM Plasmid eine funktionelle, Tamoxifen-induzierbare CreTM-Rekombinase exprimiert, welche auch den Ptch $^{N X}$ Lokus effizient rekombiniert.

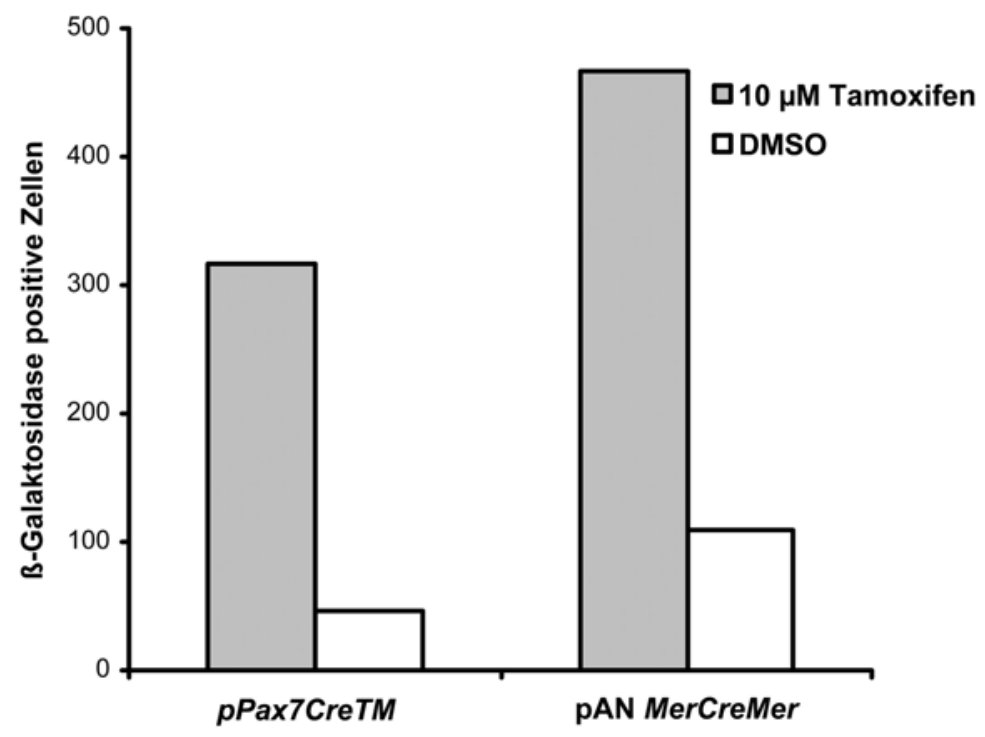

Abbildung 53: Tamoxifen-induzierte Rekombination des ploxNeoloxßGal Reporterplasmids durch Expression pPax7CreTM. Das ploxNeoloxßGal Reporterplasmid wurde mit $p$ Pax7CreTM oder pAN MerCreMer in $1 \times 10^{5} \mathrm{C} 2 \mathrm{C} 12$ Zellen co-transfiziert. Die transfizierten Zellen wurden mit $10 \mu \mathrm{M}$ Tamoxifen oder DMSO behandelt (die Zugabe erfolgte $24 \mathrm{~h}$ nach der Transfektion). $48 \mathrm{~h}$ nach der Transfektion wurden die Zellen fixiert und mit X-Gal gefärbt. Alle ß-Galaktosidase-positiven Zellen wurden ausgezählt. Die Daten repräsentieren die Summe aller ß-Galaktosidase positiven Zellen aus 3 unabhängigen Experimenten. 


\subsubsection{Herstellung von $\operatorname{Tg}(\operatorname{Pax} 7 \mathrm{CreTM})$ transgenen Mäusen}

Transgene Pax7CreTM Mäuse (Tg(Pax7CreTM)) wurden, wie unter 2.19.1.3 beschrieben, etabliert. In Kapitel 3.3.1.1.3 wird die Klonierungsstrategie des hierzu verwendeten Vektors beschrieben. Abbildung 49 zeigt die Struktur des linearisierten pPax7CreTM Zielvektors.

Aus der Injektion des Vektors in befruchtete FVB/N und C57BL/6N Oozyten gingen 7 Tiere hervor, bei welchen das Plasmid in das Genom integriert worden war. Durch die Verpaarung dieser "Founder" Tiere mit C57BL/6N wt Tieren konnten 4 unabhängige transgene $\mathrm{Tg}$ (Pax7CreTM) Linien etabliert werden (im Folgenden als Linien \#14, \#54, \#21, \#27 bezeichnet).

Die Integration des Pax7CreTM Transgens wurde durch PCR-Analysen mit dem Oligonukleotidpaar mPax7seqF4/MerSeqR1 an genomischer DNA aus Schwanzbiopsien überprüft (Tabelle 10; Abbildung 49).

Alle transgenen Linien wurden den im Folgenden beschriebenen Expressionsanalysen unterzogen. Als Kontrolle für die endogene Expression von Pax7 während der Embryonalentwicklung und im adulten Tier wurde mit der Mauslinie Pax7G4 gearbeitet. Diese Linie exprimiert unter dem endogenen Pax7 Promotor ß-Galaktosidase (Mansouri A et al., 1996).

\subsection{In vivo Analysen der CreTM-Rekombinaseexpression in Tg(Pax7CreTM) Mäusen}

Die Expression und Funktionalität der transgenen Linien wurden durch eine Verpaarung mit ROSA26- $R$ Reportermäusen (Soriano $\mathrm{P}$, 1999) überprüft. Bei dieser Mauslinie wird eine loxP-Sequenz-flankierte Neomycin-Resistenzkassette mit nachgeschaltetem ß-Galaktosidasegen vom endogenen ROSA26 Lokus aus exprimiert (Friedrich G und Soriano P, 1991). Nach Deletion der NeomycinResistenzkassette durch Cre-vermittelte Rekombination wird das ß-Galaktosidasegen ubiquitär exprimiert. 


\subsection{Keine Aktivität der CreTM-Rekombinase im Embryo}

Zur Analyse der Expression der CreTM-Rekombinase während der Embryonalentwicklung wurden männliche $T g(\operatorname{Pax} 7 \mathrm{CreTM})$ Tiere mit heterozygoten ROSA26- $R^{+/}$Weibchen verpaart (Soriano $\left.P, 1999\right)$. Befruchtete Weibchen wurden durch Vaginalplaques identifizert und von den Männchen isoliert. Die Induktion der CreTM-Rekombinase in den Embryonen erfolgte in utero durch zweimalige intraperitoneale Injektion der Mütter mit je $1 \mathrm{mg}$ Tamoxifen zum Zeitpunkt 8,5 dpc und 9,5 dpc oder 11,5dpc und 12,5dpc.

In einem Kontrollexperiment wurden auch Embryonen einer Kreuzung von männlichen heterozygoten ROSA26CreERT2 ${ }^{+-}\left(E R T 2^{+/}\right)$(siehe Kapitel 3.2.5.2) mit weiblichen heterozygoten ROSA26- $R^{+/}$untersucht. Am Tag 12,5 dpc (bei Induktion an den Tagen 8,5 $d p c$ und 9,5 $d p c$ ) bzw. am Tag 15,5 $d p c$ (bei Induktion an den Tagen 11,5 $d p c$ und 12,5 $d p c$ ) erfolgte die Isolierung, Fixierung und X-Gal-Färbung der Embryonen. Als weitere Kontrolle für die endogene Expression von Pax7 wurden Pax7G4 $^{+-}$Embryonen analysiert (Mansouri A et al., 1996). Der Genotyp der Embryonen wurde über PCR-Analysen an genomischer DNA aus den entsprechenden Dottersäcken bestimmt.

In keiner der untersuchten 4 transgenen $\mathrm{Tg}$ (Pax7CreTM) Linien konnte eine CreTMvermittelte Rekombination in dem Entwicklungsstadium zwischen Tag 8,5 $d p c$ bis 15,5 dpc detektiert werden (Abbildung 54; links). Von jeder Tg(Pax7CreTM) Linie wurde mindestens 2 Würfe für beide Induktionszeitpunkte untersucht. In den $R O S A 26-R^{+/} E R T 2^{+/}$Kontrollembryonen wurde dagegen eine nahezu vollständige Rekombination am ROSA26- $R$ Lokus durch die Gabe von $2 \mathrm{mg}$ Tamoxifen induziert (Abbildung 54; Mitte). Ebenso wurde die ß-Galaktosidaseexpression in den Pax7G4 ${ }^{+-}$Kontrollembryonen nachgewiesen (Abbildung 54; rechts) (Mansouri A et al., 1996). 

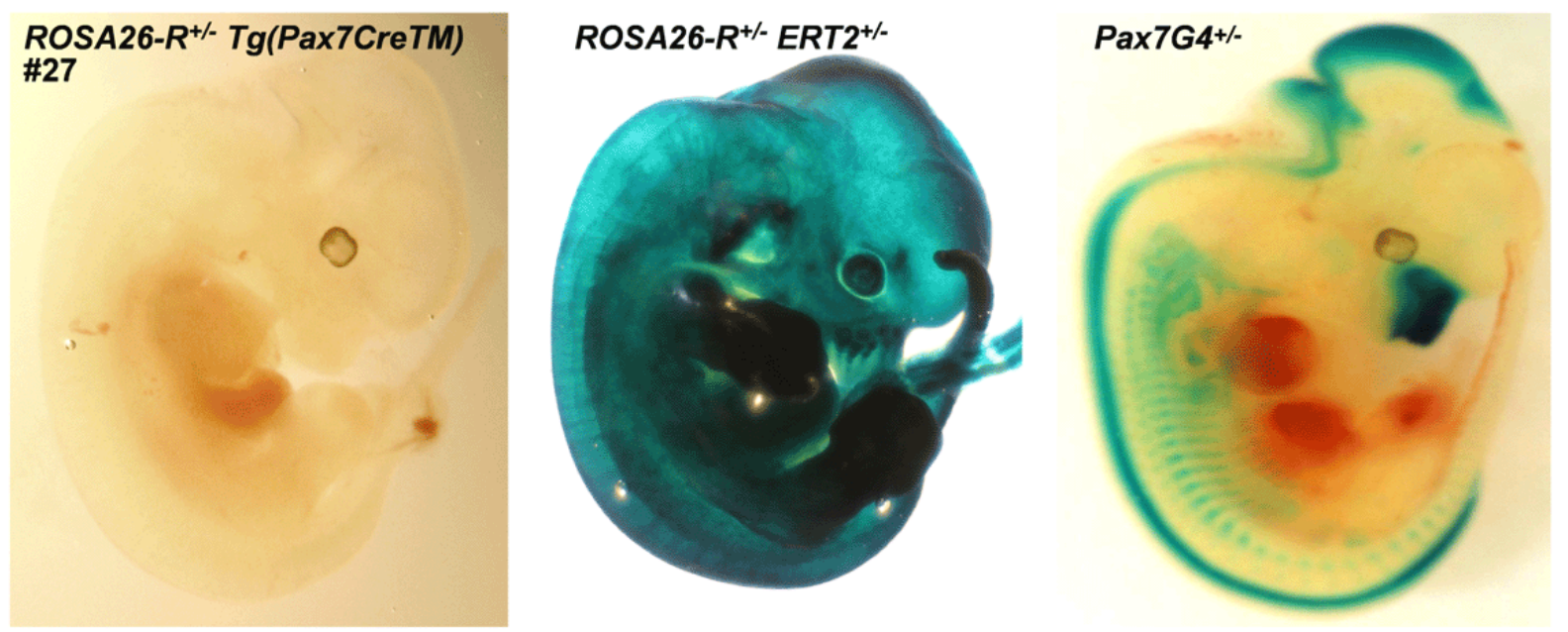

Abbildung 54: Keine Expression der CreTM-Rekombinase in Tg(Pax7CreTM) Mauslinien während der Embryonalentwicklung. Dargestellt ist ein mit X-Gal gefärbter ROSA26- $R^{+/-}$ $T g$ (Pax7CreTM) (links), ein ROSA26- ${ }^{+/-} E R T 2^{+/-}$(Mitte) und ein Pax7G4 ${ }^{+/}$(rechts) Embryo im Alter von 12,5 dpc. Die Induktion der entsprechenden Cre-Rekombinase erfolgte in utero an den Tagen 8,5 und 9,5 dpc durch Gabe von je $1 \mathrm{mg}$ Tamoxifen (kumulative Dosis $2 \mathrm{mg}$ ). Der abgebildete ROSA26$R^{+-} \mathrm{Tg}($ Pax7CreTM) Embryo stammt aus der Linie Tg(Pax7CreTM) \#27 und wurde repräsentativ für alle untersuchten Linien abgebildet.

\subsection{Die CreTM-Rekombinase wird im adulten Muskel exprimiert}

Zur Untersuchung der CreTM-Rekombinaseexpression in adulten $\mathrm{Tg}$ (Pax7CreTM) Tieren wurden doppelt heterozygote Nachkommen aus der Verpaarung von $T g(P a x 7 C r e T M) \times R O S A 26-R^{+/-}$(Soriano P, 1999) im Alter von 6 Wochen mit $100 \mu \mathrm{g}$ Tamoxifen, 4-Hydroxy-Tamoxifen (4-OHT) oder Lösungsmittel (Emulsion aus Ethanol und Sonnenblumenöl) intramuskulär injiziert.

10 Tage nach der Tamoxifen- bzw. 4-OHT-Gabe wurden die Tiere schmerzfrei getötet und der injizierte Skelettmuskel (musculus soleus) isoliert. Der Muskel wurde fixiert, $10 \mu \mathrm{m}$ Kryostatschnitte angefertigt und mit X-Gal angefärbt. In Kontrollexperimenten wurde die CreERT2-Rekombinase in ROSA26- $R^{+/} E R T 2^{+/-}$ Tieren mit Tamoxifen bzw. 4-OHT induziert (siehe Abbildung 45). Dieses Experiment sollte Aufschluss darüber geben, ob durch eine intramuskuläre Gabe von Tamoxifen bzw. 4-OHT tatsächlich eine Induktion der Rekombinaseaktivität erreicht werden kann. Des Weiteren sollte untersucht werden, ob mit beiden Medikamenten eine vergleichbare Induktion der ERT2- bzw. der CreTM-Rekombinase erzielt werden kann. Da durch die Gabe von 4-OHT eine zur Tamoxifengabe vergleichbare Induktion der Rekombination induziert wurde, erfolgte in weiterführenden 
Experimenten die Induktion der ERT2- als auch der CreTM-Rekombinase durch Gabe von Tamoxifen. Als Kontrolle für die endogene Expression von Pax7 wurden Muskeln aus Pax7G4 ${ }^{+/-}$Tieren analysiert. Alle Analysen wurden in 2 bis 3 unabhängigen Experimenten wiederholt.

In 3 von $4 \mathrm{Tg}($ Pax7CreTM) Linien wurde in unabhängigen Experimenten die Expression von B-Galaktosidase in spezifischen Bereichen der Skelettmuskeln detektiert (Abbildung 56). Hierbei handelt es sich höchstwahrscheinlich um Schwannsche Scheiden. Während 2 transgene Linien (\#21, \#27) eine vergleichbar starke Rekombination des ROSA26-R Lokus zeigten, wurde in der Linie Tg(Pax7CreTM) \#54 eine deutlich stärke Rekombinationsrate festgestellt. In den Muskeln der Kontrolltiere aller Linien wurde keine ß-Galaktosidaseaktivität beobachtet.

Bei Analysen von Muskelschnitten konnte bei keiner der untersuchten Tg(Pax7CreTM) Linien eine Expression der CreTM-Rekombinase in Satellitenzellen detektiert werden (Daten nicht gezeigt). Um dieses Ergebnis zu bestätigen, wurden einzelne Muskelfasern der jeweiligen Tiere präpariert, fixiert und mit X-Gal angefärbt. Auch bei dieser Analyse konnte bei keiner der 4 Linien eine ß-Galaktosidaseaktivität in den Satellitenzellen festgestellt werden (Daten nicht gezeigt). Die als Kontrolle mitgeführten Muskelfasern von heterozygoten $\mathrm{Pax} 7 \mathrm{G} 4^{+/}$Tieren gleichen Alters zeigten dagegen die beschriebene schwache ß-Galaktosidaseaktivität in den Satellitenzellen (Abbildung 55) (Oustanina $S$ et al., 2004).

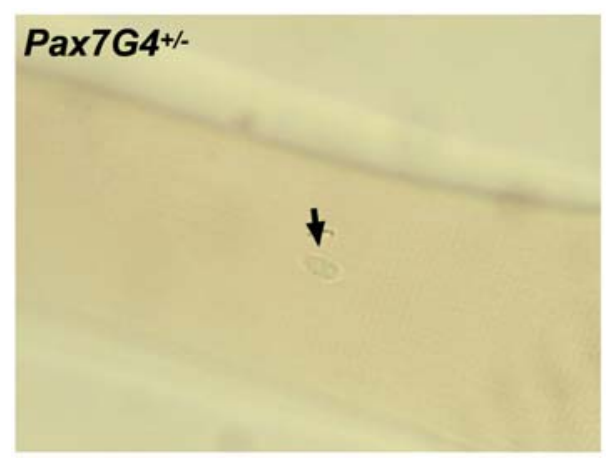

Abbildung 55: Satellitenzellen aus $\operatorname{Pax}_{\mathrm{GG}} 4^{+/}$Mäusen exprimieren ß-Galaktosidase. Muskelfasern einer Pax $7 G 4^{+-}$Maus wurde isoliert, fixiert und mit X-Gal angefärbt. Der Pfeil weist auf eine ß-Galaktosidase exprimierende Satellitenzelle (Oustanina $S$ et al., 2004).

Zusammengefasst lässt sich feststellen, dass in 3 von $4 \mathrm{Tg}$ (Pax7CreTM) Linien die Tamoxifen-induzierbare CreTM-Rekombinase im adulten Muskel exprimiert wird, 
wobei 2 der 4 Linien eine vergleichbar starke Expression aufweisen und eine Linie die CreTM-Rekombinase stärker exprimiert. Das CreTM-Expressionsprofil der 3 Linien unterscheidet sich nicht, was für eine Transgen-spezifische Expression spricht. Das $T g($ Pax7CreTM) Transgen wird jedoch nicht in Satellitenzellen exprimiert.

Die Expression der CreTM-Rekombinase beschränkt sich im Muskel möglicherweise auf die Schwannschen Scheiden von Nerven. In diesen Strukturen wurde die endogene Expression von Pax7 in der adulten Maus beschrieben (Rodger $\mathrm{J}$ et al., 1999).

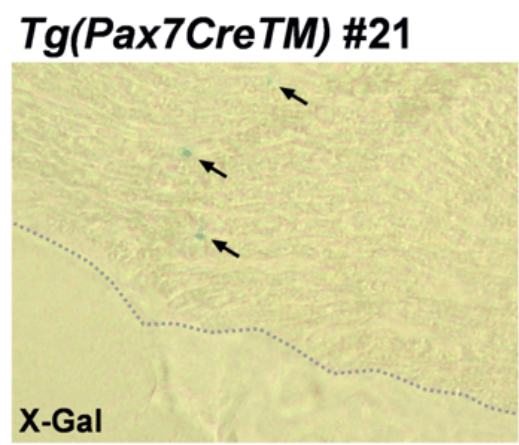

Tg(Pax7CreTM) \#27

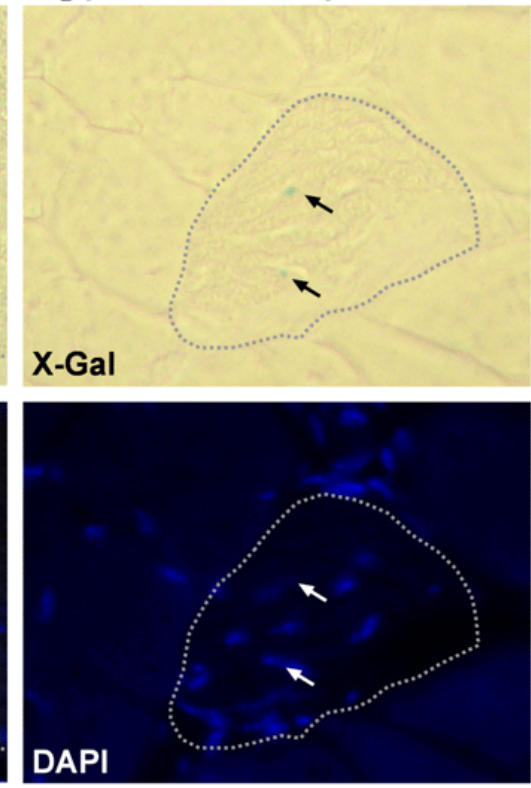

$\operatorname{Tg}($ Pax7CreTM) \#54

X-Gal

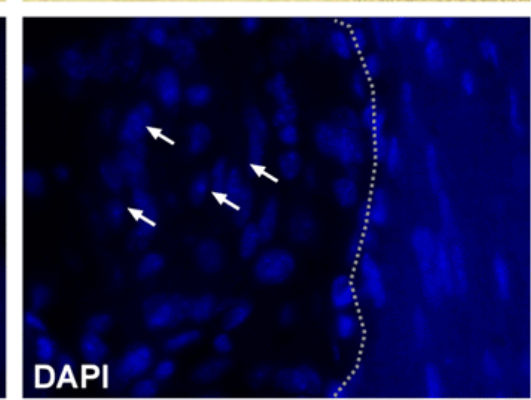

Abbildung 56: CreTM-Rekombinaseaktivität in Nervenstrukturen von $T$ (Pax7CreTM) Mäusen. Doppelt heterozygote ROSA26- $R^{+/} T g$ (Pax7CreTM) Nachkommen der Linien Tg(Pax7CreTM) \#21, \#27, \#54 wurden im Alter von 6 Wochen mit $100 \mu \mathrm{g}$ Tamoxifen intramuskulär injiziert. 10 Tage nach der Injektion wurden Kryostatschnitte des injizierten musculus soleus angefertigt und mit X-Gal gefärbt (oben). Die gefärbten Schnitte wurden mit einem DAPI-enthaltenden Montagemedium (unten) eingedeckt (unten). Die schwarzen Pfeile deuten auf ß-Galaktosidase-positive Zellen. Weiße Pfeile zeigen auf die entsprechenden Zellkerne in der DAPI-Färbung. Graue Linien markieren die NervenMuskelgrenzen. 


\section{Diskussion}

\subsection{Analysen zur Entstehung von Ptch-assoziierten RMS}

Das Tumorsuppressorgen PTCH ist mit der Entwicklung vieler humaner Tumore, unter anderem auch mit der von RMS, assoziiert (Bridge JA et al., 2000; Tostar $U$ et al., 2006). Über den Mechanismus der Entstehung von PTCH-assoziierten RMS ist jedoch bisher nicht viel bekannt (siehe Kapitel 1.4). Das Verständnis wird besonders dadurch erschwert, dass in humanen $\mathrm{PTCH}$-assoziierten Tumoren häufig nur eines der beiden PTCH Allele mutiert ist (Wetmore $C$, 2003) und $P T C H$ überexprimiert wird. Dies trifft auch auf RMS von $P t c h^{\text {neo67/+ }}$ Mäusen zu. So wurden in diesen Tumoren, die sich durch eine starke Expression von Ptch auszeichnen, weder LOH am Ptch Lokus noch Mutationen im wt Ptch Allel identifiziert (Calzada-Wack J et al., 2002).

Interessanterweise kommt die Überexpression von Ptch in RMS durch Ptch ${ }^{d 67}$ Transkripte zustande. Wt Transkripte sind im Tumor gegenüber dem Normalgewebe deutlich reduziert (siehe Abbildung 5). Dies konnte auch für das MB des Ptch ${ }^{\text {neo12 }}$ Mausmodells gezeigt werden (Wetmore $C$ et al., 2000). In den Organen der Ptch $^{\text {neo67/+ }}$ Tiere konnten dagegen keine Unterschiede der Ptch ${ }^{d 67}$ und wt Ptch Transkriptniveaus beobachtet werden (Uhmann A et al., 2005).

Um detailliertere Einblicke in die Entstehung von Ptch-assoziierten RMS zu erlangen, wurde im ersten Teil dieser Arbeit der Aufbau des überexprimierten mutanten Ptch $^{d 67}$ Transkripts und des daraus resultierenden Proteins untersucht.

Hierzu war es notwendig, sich zunächst einen Überblick über die verschiedenen Ptch Spleissvarianten zu verschaffen.

Humane PTCH Transkripte können 5 alternative erste Exone enthalten, die als Exon 1a, Exon 1b, Exon 1c, Exon 1d und Exon 1e bezeichnet werden (Kogerman P et al., 2002; Nagao $\mathrm{K}$ et al., 2005a; Nagao $\mathrm{K}$ et al., 2005b). Die genaue Funktion der unterschiedlichen Spleissvarianten ist bis jetzt jedoch nicht eindeutig geklärt.

Im Rahmen dieser Arbeit wurde zunächst gezeigt, dass sich der Aufbau des humanen Exon 1e PTCH Transkripts von seinem murinen Gegenstück unterscheidet. Im Gegensatz zum humanen Exon 1e wird das murine Exon 1e nicht in Exon 2 gespleisst, sondern umfasst den gesamten Sequenzbereich zwischen den beiden Exonen. 
Wie durch Kogerman et al. beschrieben, sind beim Menschen nur Exon 1B PTCH Transkripte zur vollständigen Hemmung von SMO in der Lage. Die Autoren stellen die Hypothese auf, dass die Exon 1b Spleissvariante bei der Aktivierung der Kaskade vermehrt exprimiert wird, um so die Aktivierung der Kaskade wieder auszubalancieren. Auch zeigen die Autoren, dass in humanen Basaliomen überwiegend Exon 1b PTCH Transkripte exprimiert werden. Da in diesen Tumoren trotz der Überexpression von Exon 1b Transkripten keine Inhibition von SMO hervorgerufen wird, postulieren Kogerman et al., dass die überexprimierten PTCH Transkripte mutanten Transkripten entsprechen müssen. Die Tatsache, dass Exon 1b Transkripte im Gegensatz zu den 4 weiteren Speissvarianten vermehrt im Tumor exprimiert werden, wurde durch die verstärkte Aktivierung des Exon 1b Promotors erklärt (Kogerman P et al., 2002).

Wie aus unseren Analysen nun hervorgeht, werden in RMS von Ptch ${ }^{\text {neo67/+ }}$ Mäusen neben Exon 1b Ptch Transkripten (die tatsächlich größtenteils vom mutanten Ptch ${ }^{d 67}$ Allel stammen) auch Exon 1a und Exon 1c Ptch Transkripte überexprimiert (Uhmann A et al., 2005). Diese Daten zeigen, dass die Überexpression von Ptch in RMS von Ptch $^{\text {neo67/+ }}$ Mäusen nicht ausschließlich durch einen hyperaktiven Exon $1 \mathrm{~b}$ Promotor zu erklären ist. Gegen einen solchen hyperaktiven Promotor spricht auch die Tatsache, dass man keine vermehrte Expression von wt Transkripten im Tumor detektieren kann. Da inzwischen bekannt ist, dass auch die Expression von Exon 1a Transkripten eine vollständige Hemmung des Signalweges bewirken kann (Shimokawa T et al., 2004; Nagao K et al., 2005a; Nagao K et al., 2005b) und da Exon 1a Transkripte auch in RMS von Ptch ${ }^{\text {neo67/+ }}$ Tieren verstärkt exprimiert werden (Uhmann A et al., 2005), kann sich die Theorie von Kogerman et al. nicht mehr halten.

\subsubsection{Shh/Ptch Signalwegsaktivierung durch Reduktion von wt Ptch Transkripten}

Die bisherigen Ergebnisse zeigen, dass a) eine monoallelische Ptch Mutation - nicht aber ein biallelischer Ausfall von Ptch - für die Entstehung von RMS notwendig ist, und b) die Tumorentstehung eher durch ein Ungleichgewicht der Expression des mutanten und wt Allels zustande kommt, wobei wt Ptch Transkripte im Tumor stark reduziert sind. 
Um zu prüfen, ob die alleinige Reduktion von wt Ptch Transkripten ausreichend ist, um die Shh/Ptch Signalkaskade zu aktivieren, wurde wt Ptch mRNA mit Hilfe von Ptch-spezifischer siRNA degradiert. Durch die Verminderung von wt Ptch Transkripten konnte tatsächlich eine erhöhte Expression und Aktivität von Gli1 induziert werden.

Diese Daten zeigen, dass eine Fehlregulation des Shh/Ptch Signalweges durch die verminderte Expression von wt Ptch ausgelöst werden kann und auch in Abwesenheit eines mutanten Ptch Proteins zustande kommt.

Im Organismus könnte die verminderte Expression von wt Ptch z. B. durch den veränderten Methylierungsstatus dieses Allels ausgelöst werden, wie dies für andere Tumorsuppressorgene bereits beschrieben worden ist (Wijermans $\mathrm{P}$ et al., 2000; Herman JG und Baylin SB, 2003). So konnte in unserem Labor auch gezeigt werden, dass durch Methylierung der Ptch Promotorsequenz eine vollständige Transkriptionsrepression induziert wird (Uhmann A et al., 2005). Da auch die Behandlung von MB Zelllinien mit DNA demethylierenden Agenzien (5-Azacytidin) zur Reaktivierung der Expression von wt Transkripten führt (Berman DM et al., 2002), ist eine Inaktivierung des wt Ptch Lokus in RMS durch Methylierung denkbar. Die daraus resultierende verminderte Expression des wt Allels könnte eine Aktivierung des Signalweges bewirken und damit die Genese von RMS induzieren.

\subsubsection{Das Ptch ${ }^{\mathrm{d} 67}$ Protein kann den Shh/Ptch Signalweg nicht mehr hemmen}

Vorarbeiten anhand von immunhistologischen Färbungen an RMS und embryonalen Ptch $^{\text {ne067/neo67 }}$ Fibroblasten unserer Arbeitsgruppe deuteten auf die Translation von Ptch $^{d 67}$ mRNA hin (Uhmann A et al., 2005). Da bei der Transkription des mutanten Ptch $^{d 67}$ Allels Exon 5 ohne Leserasterverschiebung in Exon 8 gespleisst wird (Hahn $\mathrm{H}$ et al., 1998), sollte das mutante Protein sowohl C- als auch N-terminal die Struktur des wt Äquivalents besitzen. Bisher war jedoch nicht geklärt, ob Ptch ${ }^{d 67}$ Transkripte translatiert werden und welche Funktion $\mathrm{Ptch}^{\mathrm{d} 67}$ Proteine besitzen.

In dieser Arbeit wurde gezeigt, dass durch die in vitro Expression von $\operatorname{Ptch}^{d 67}$ cDNA ein mutantes $\operatorname{Ptch}^{\mathrm{d} 67}$ Protein generiert wird. Das detektierte Ptch ${ }^{\mathrm{d} 67}$ Protein besitzt das theoretisch errechnete molekulare Gewicht. Sowohl der C- als auch der N- 
Terminus des mutanten Proteins wurden nachgewiesen. Hieraus wurde geschlossen, dass die C- und N-terminale Struktur des $\mathrm{Ptch}^{\mathrm{d} 67}$ Proteins der des wt Proteins entspricht. Das Ptch ${ }^{\mathrm{d} 67}$ Protein ist vergleichbar dem wt Protein intrazellulär lokalisiert. Dies läßt die Aussage zu, dass das Fehlen von Exon 6 und 7 von Ptch weder die vesikuläre Lokalisation noch den Transport des Proteins zur Zellmembran beeinflusst.

Die Funktionalität des $\operatorname{Ptch}^{\mathrm{d} 67}$ Proteins wurde anhand von in vitro Analysen untersucht. Es konnte gezeigt werden, dass der Shh/Ptch Signalweg durch die Expression von $\mathrm{Ptch}^{\mathrm{d} 67}$ nicht gehemmt werden kann. Dies zeigt, dass die Deletion von Exon 6 und 7 zu einem Funktionsverlust von Ptch führt.

Überraschenderweise wurde festgestellt, dass durch die gleichzeitige Expression von wt Ptch und Ptch ${ }^{\mathrm{d} 67}$ Protein die Signalkaskade im aktiven Zustand gehalten wird. Aufgrund dessen kann man annehmen, dass $\mathrm{Ptch}^{\mathrm{d} 67}$ die Wirkungweise des wt Proteins in einer dominant-negativen Art und Weise beeinflusst. Dies wird auch durch eine Publikation aus dem Jahr 2004 unterstützt, in der eine PTCH Mutation gezeigt wird, die in $D$. melanogaster aufgrund eines dominant-negativen Mechanismus zur Aktivierung von Smo führt (Hime GR et al., 2004).

Beim Vergleich der Expressionsstärken der beiden Ptch Expressionsplasmide im Western Blot (siehe Abbildung 15) fällt zunächst auf, dass das mutante Protein deutlich schwächer als das wt Protein exprimiert wird. Trotzdem scheint diese schwache Expression ausreichend zu sein, um die Hemmung der Signalkaskade durch das wt Protein zu blockieren. Dies könnte bedeuten, dass schon eine geringe Anzahl von $\operatorname{Ptch}^{\mathrm{d} 67}$ Molekülen ausreichend ist, um die hemmende Funktion von wt Proteinen aufzuheben und damit eine Fehlregulation des Shh/Ptch Signalweges zu bewirken. Da jedoch schon ein wt Ptch Molekül in der Lage ist, 45 Smo Moleküle in ihrer Aktivität zu hemmen (Taipale $\mathrm{J}$ et al., 2002), ist verwunderlich, warum das extrem überexprimierte wt Protein nicht in der Lage sein sollte, den Signalweg zu inaktivieren. Man könnte dies jedoch durch eine höhere Affinität von Ptch ${ }^{\mathrm{d} 67}$ Molekülen zu Smo erklären.

Wenn nun Ptch $^{\mathrm{d} 67}$ tatsächlich dominant-negativ auf wt Ptch wirken sollte, stellt sich weiterhin die Frage, warum es nicht auch in normalen Organen von Ptch ${ }^{\text {neo67/+ }}$ Mäusen zu einer generellen Aktivierung des Signalweges kommt, wo doch beide Transkripte gleich stark exprimiert werden. 
Hierzu ist zu sagen, dass unsere bisherigen Expressionsanalysen von Ptch ${ }^{\text {neo67/+ }}$ Organen nur auf transkriptioneller Ebene durchgeführt wurden und auch eine mögliche Instabilität des Ptch $^{d 67}$ Transkriptes nicht untersucht wurde. Daher kann zum jetzigen Zeitpunkt nicht ausgeschlossen werden, dass in Organen von $P_{t c h} h^{\text {neo67/+ }}$ Mäusen weniger $\operatorname{Ptch}^{\mathrm{d} 67}$ als wt Protein exprimiert wird.

\subsubsection{Ein modifiziertes Modell der Ptch-assoziierten Tumorigenese in Ptch $^{\text {neo67/+ }}$ Mäusen}

Basierend auf den oben dargestellten Daten lässt sich nun ein neues Modell zur Ptch-assoziierten Tumorigenese aufstellen.

Das Modell nach Uhmann et al. ist in Abbildung 57 dargestellt und besagt, dass die Ptch-assoziierte Tumorigenese durch die Inaktivierung eines Allels (z. B. durch Methylierung) und einer nachfolgenden inaktivierenden Mutation des zweiten Allels hervorgerufen wird. Die Inaktivierung eines der beiden wt Ptch Allele hat keine Auswirkung, da der Shh/Ptch Signalweg noch ausreichend reguliert werden kann. Wird jedoch dieses Allel durch Mutation inaktiviert, kann die Signalkaskade nicht mehr gehemmt werden. Gli wird verstärkt exprimiert und aktiviert die Expression seiner Zielgene im Zellkern. Ptch gehört zu diesen Zielgenen. Aufgrund der Methylierung des wt Ptch Allels, wird nur das nicht-methylierte, mutante Ptch Allel exprimiert. Da dieses die Signalkaskade nicht hemmen kann, kommt es zu einer „run-away" Aktivierung der Shh/Ptch Signalkaskade, was in einer starken Überexpression von Gli sowie auch Ptch und letztlich in Tumorigenese resultiert.

Weder die Mutation noch die Methylierung eines der beiden Ptch Allele besitzen in diesem Modell die Kompetenz, die Tumorigenese zu induzieren. Auch ist die Reihenfolge der Allel-Inaktivierungen in diesem Modell nicht ausschlaggebend. Bei den Ptch ${ }^{\text {neo67/+ }}$ Tieren liegt jedoch die Mutation zuerst vor.

Das in Abbildung 57 vorgeschlagene Modell berücksichtigt sowohl die Charakteristik eines Tumorsuppressorgens als auch die beobachtete Überexpression von mutantem Ptch Protein in Ptch-assoziierten Tumoren. Gleichzeitig stimmt dieses Modell mit der Beobachtung überein, dass die Behandlung von Ptch-assoziierten Tumorzelllinien mit demethylierenden Agenzien zur Wiederherstellung der wt Ptch Expression führt (Berman DM et al., 2002). 
Auch für andere Tumorsuppressorgene ist ein solcher Mechanismus, bestehend aus Mutation eines Allels und Methylierung des zweiten Allels, beschrieben worden (Jones PA und Baylin SB, 2002; Herman JG und Baylin SB, 2003) und einige dieser Tumore sprechen auf eine Behandlung mit demethylierenden Agenzien an (Wijermans P et al., 2000; Issa JP et al., 2004).
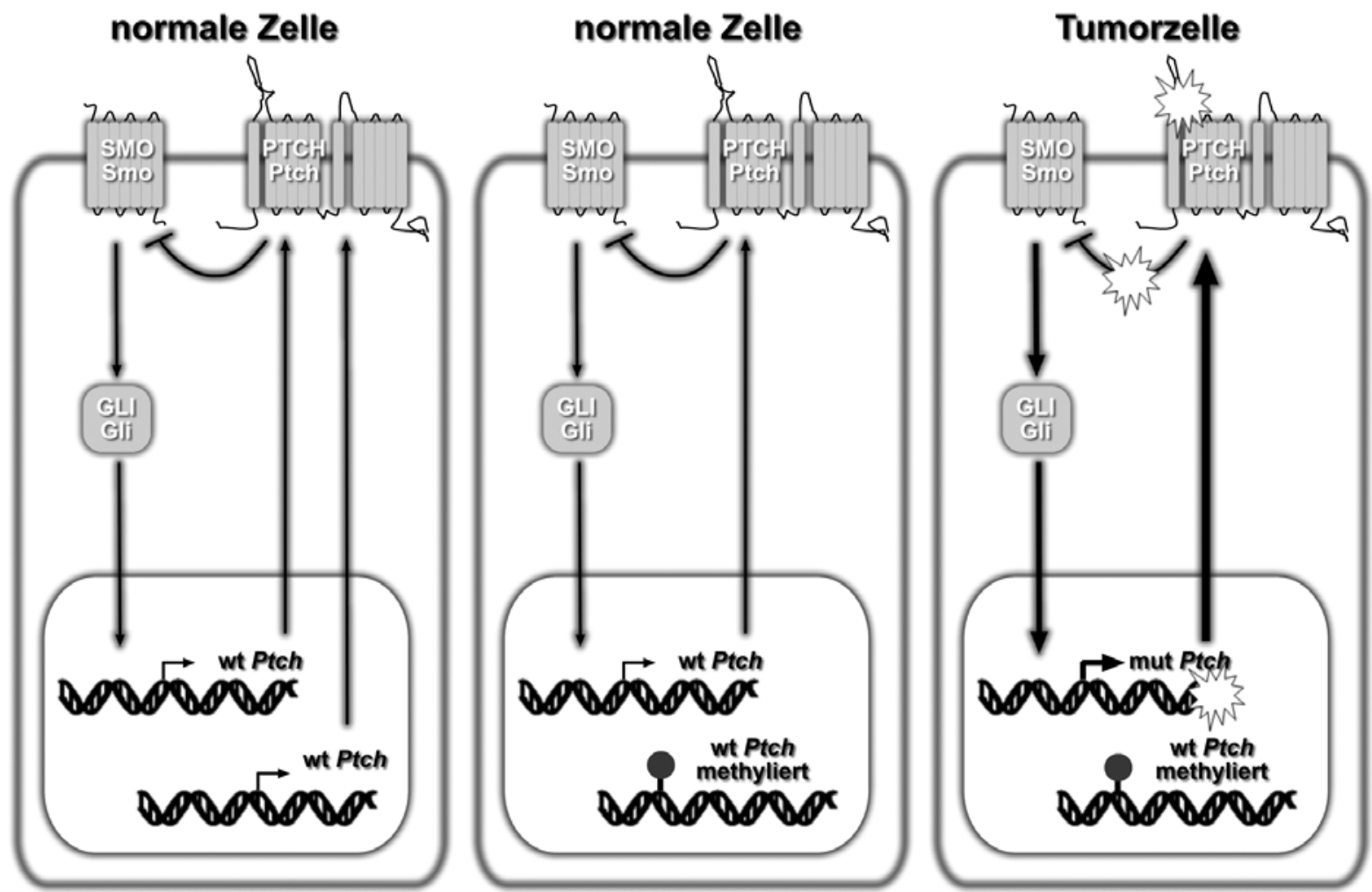

Abbildung 57: Schematische Darstellung eines Modells zur Entstehung von Ptch-assoziierten Tumoren. Dargestellt ist links eine normale somatische Zelle, in der der Signalweg auf niedrigem Niveau aktiviert ist. Durch die Inaktivierung eines Allels, hier durch Methylierung (Mitte), wird der Signalweg durch die monoallelische Ptch Expression trotzdem noch normal reguliert. Erst die Inaktivierung des zweiten Allels durch Mutation (rechts) bewirkt ein Ungleichgewicht des Signalweges und damit die Tumorigenese. Die Inaktivierung der Allele kann auch in umgekehrter Reihenfolge geschehen. Letzendlich resultiert ein solcher Mechanismus jedoch immer in der ungehinderten Überexpression des mutanten PTCH/Ptch Allels. In Großbuchstaben sind humane, in Kleinbuchstaben homologe murine Gene und Proteine markiert. Abkürzungen: Ptch, Patched; Smo, Smoothened. Stern, Mutation in PTCH/Ptch; Strich mit Köpfchen, Methylierung.

Aufgrund der in dieser Arbeit beschriebenen Ergebnisse kann dieses Modell noch erweitert werden. Neben der Reduktion von wt Ptch Transkripten könnte zusätzlich noch ein dominant-negativer Wirkmechanismus von $\mathrm{Ptch}^{\mathrm{d} 67}$ in Frage kommen. 
So kann postuliert werden, dass in gesunden Organen von Ptch ${ }^{\text {neo67/+ }}$ Mäusen ein ausreichendes Gleichgewicht zwischen wt und $\mathrm{Ptch}^{\mathrm{d} 67}$ Protein vorherrschend ist und der Signalweg normal reguliert werden kann. Im Tumor dagegen wird durch das Stummschalten des wt Allels, z. B. durch Methylierung, das mutante Allel exprimiert. Auch wenn das mutante Transkript instabil wäre, würde trotzdem genügend $\operatorname{Ptch}^{\mathrm{d} 67}$ Protein translatiert, um dominant-negativ die Aktivität von noch vorhandenem wt Ptch zu unterdrücken. Die daraus folgende Fehlregulation des Signalweges führt zur Überexpression des mutanten nicht-methylierten Allels und letztlich zur Entwicklung von Tumoren.

Ein dominant-negativer Mechanismus des $\operatorname{Ptch}^{\mathrm{d} 67}$ Proteins würde auch erklären, warum in RMS von Ptch ${ }^{\text {neo67/+ }}$ Mäusen trotz postulierter Methylierung des wt Allels noch wt Transkripte detektierbar sind.

Im Gegensatz zu Kogerman et al. wird jedoch in beiden Modellen der Expression von alternativen Ptch Transkripten keine spezifische Funktion während der Tumorentstehung zugestanden. 


\subsection{Induzierter konditioneller knock-out von Ptch}

Um die Entstehung von RMS zu induzieren und somit detaillierter analysieren zu können, wurde eine Mauslinie etabliert, welche den konditionellen knock-out von Ptch gewährleistet.

Durch die in vitro Analyse des pPtchNX Zielvektors wurde gezeigt, dass die Ptch Exone 8 und 9 durch die Expression einer Cre-Rekombinase effizient deletiert werden können.

Die daraufhin etablierte homozygote $\operatorname{Ptch}^{N X / N X}$ Mauslinie wurde über $1 \mathrm{Jahr}$ beobachtet, und es wurde gezeigt, dass homozygote $\operatorname{Ptch}^{N X / N X}$ Mäuse fertil sind, keine Tumoren entwickeln und wt Ptch Transkripte exprimieren.

Durch die heterozygote und homozygote Keimbahndeletion der Ptch Exone 8 und 9 konnte weiterhin gezeigt werden, dass durch die Ptch ${ }^{\text {delNX }}$ Mutation ein zu Ptch ${ }^{\text {neo67 }}$ und Ptch ${ }^{\text {neo12 }}$ Mäusen vergleichbarer Phänotyp erzeugt wird (Goodrich LV et al., 1997; Hahn $\mathrm{H}$ et al., 1998). Sowohl in Tumoren von $\operatorname{Ptch}^{\text {delNX/t+ }}$ Mäusen als auch in

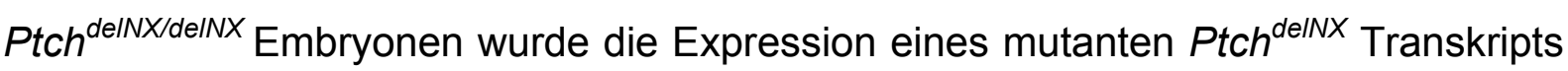
nachgewiesen, bei dem Exon 7 in Exon 10 gespleisst wird. Das Spleissen führt zu einer Verschiebung des Leserasters und zu einem vorzeitigen Stopcodon an der Aminosäure 349. Das aus der entsprechenden mRNA translatierte Protein sollte ein molekulares Gewicht von 38 kD haben. Durch die Deletion sollten wichtige funktionelle Ptch Domänen, wie die SSD und die zweite extrazelluläre Schleife, die für die Bindung von Shh notwendig ist, zerstört werden. Leider war es nicht möglich, ein $38 \mathrm{kD}$ großes Protein in Geweben von Ptch ${ }^{\text {delNX/+ }}$ oder in Ptch $^{\text {delNX/delNX }}$ nachzuweisen. Der Grund hierfür ist sehr wahrscheinlich die mangelnde Spezifität der für dieses Experiment verwendeten Antikörper.

Im Folgenden wurde dann der Phänotyp von Mäusen analysiert, bei denen die biallelische Inaktivierung von Ptch im Alter von 8 Wochen induziert wurde. Hierzu wurden Ptch $^{N X N X}$ Mäuse mit ROSA26CreERT2 ${ }^{+/-}$Mäusen, welche eine Tamoxifeninduzierbare Cre-Rekombinase exprimieren, gekreuzt. Diese Mäuse wurden nach der Induktion der ERT2-Rekombinase „tPtch ${ }^{-/-\varkappa}$ Mäuse genannt. Der hervorgerufene komplexe Phänotyp ließ die Beobachtung der Tiere über einen Zeitraum von mehr als 23 Tagen nicht zu. 


\subsubsection{Hyperproliferative Veränderungen in Ptch $^{-/}$Mäusen}

Die histologische Analyse der $\mathrm{APtch}^{-/}$Organe zeigte, dass durch die biallelische Inaktivierung von Ptch hyperproliferative, tumorartige Veränderungen der Haut, des Magens und der mesenterialen Zellen induziert werden. Obwohl der Beobachtungszeitraum von 23 Tagen zu kurz ist, um die Entstehung von Tumoren zu beobachten, kann vermutet werden, dass die biallelische Inaktivierung von Ptch im adulten Tier zur Entwicklung von Basaliomen, Magen- und mesenterialen Tumoren führt. Diese Vermutung wird auch durch Publikationen unterstützt, in denen gezeigt wird, dass die Fehlregulation des Shh/Ptch Signalweges zur Entwicklung von Basaliomen (Unden AB et al., 1996; Adolphe $C$ et al., 2006) und Magentumoren (Berman DM et al., 2003) führt.

\subsubsection{Gestörte Hämatopoese in Ptch $^{-/}$Mäusen}

Neben hyperproliverativen Organveränderungen wurde ein schwerer Immundefekt in der B und T Zellentwicklung im Thymus und im Knochenmark identifiziert. Außerdem wurde gezeigt, dass dieser Defekt schon in der frühen Entwicklung von hämatopoetischen Vorläuferzellen vorliegt.

\subsubsection{Gestörte T Zellentwicklung in $\mathbf{t P t c h}^{-/}$Mäusen}

Die stark verkleinerten Thymi der $t P t c h^{-/}$Tiere ließen zunächst einen Differenzierungsdefekt der T Zelllinie im Thymus vermuteten, und es wurde gezeigt, dass die T Zellentwicklung in Ptch $^{-/}$Tieren im frühen DN1-DN2 Übergangsstadium und nach dem DN4 Stadium blockiert ist. Das Fehlen der jeweils nachfolgenden Subpopulationen (DN2 und DN3 bzw. DP und SP) kann nicht durch ein Absterben derselben erklärt werden, da keine erhöhten Annexin V-Werte detektiert wurden.

Die frühen T Zellvorläuferzellen (early T cell progenitor, ETP) wurden bei der Analyse von $\mathrm{tPtch}^{-/}$Thymozyten nicht berücksichtigt, da die ETP Population, die durch einen Lin $^{\text {low }}$ c-kit ${ }^{\text {high }}$ CD25- Phänotyp charakterisiert ist, im murinem Thymus nur ca. 20000 Zellen groß und daher schwer zu isolieren ist (Bhandoola A und Sambandam A, 2006b).

Mit Hilfe der spezifischen Expression von Oberflächenproteinen ließen sich aber die einzelnen Stadien der Thymozytendifferenzierung verfolgen. Wie bereits ausführlich 
im Ergebnisteil beschrieben, durchlaufen Thymozyten im Verlauf ihrer Differenzierung die sogenannten DN Stadien (DN, doppelt negativ für CD4 und CD8 Oberflächenmoleküle), die wiederum über die Expression der Proteine CD44 und CD25 in 4 Stadien (DN1 bis DN4) unterschieden werden können (Rothenberg EV und Taghon T, 2005). Dabei sind die ETP teilweise auch in der DN1 Subpopulation des Thymus zu finden (siehe Abbildung 58).

In bisherigen in vitro und in vivo Studien wurde gezeigt, dass gerade während der DN Differenzierungsstadien der aktive Shh/Ptch Signalweg für die sich entwickelnden Thymozyten unerlässlich ist (Outram SV et al., 2000; Gutierrez-Frias C et al., 2004; Shah DK et al., 2004; Sacedon R et al., 2005; Andaloussi AE et al., 2006). Daher kann davon ausgegegangen werden, dass durch die Inaktivierung von Ptch das Gleichgewicht zwischen aktiviertem und inaktivem Shh/Ptch Signalweg gestört ist. Daraus könnte die Blockade der Thymozytenentwicklung zwischen dem DN1 und DN2 Stadium in Ptch $^{-/}$Mäusen resultieren. Zusätzlich könnte durch die Ptch Mutation auch die Proliferation der DN1 Subpopulation angeregt werden, was jedoch zunächst noch untersucht werden müsste.

Der Differenzierungsblock zwischen dem DN1 und DN2 Stadium resultierte in einer dramatischen Abnahme der DN2 und DN3 Zellpopulation. Interessanterweise blieb jedoch die relative Anzahl der DN4 Thymozyten in Ptch $^{-/}$Thymi unverändert. Dies könnte bedeuten, dass Ptch eine zusätzliche Rolle im oder nach dem DN4 Stadium spielen könnte, wobei in diesen Zellen durch die Ptch Mutation z. B. ein proliferativer Stimulus ausgelöst werden könnte, der aber die weitere Differenzierung der DN4 Zellen zu den DP und SP Stadien verhindert. Dadurch könnte auch das Fehlen der DP und SP Stadien erklärt werden.

Die Unterscheidung zwischen frühen DN Thymozyten und späten DP Thymozyten ist durch das Auftreten von CD4 und CD8 Oberflächenmolekülen möglich. Die Stadien der SP $\mathrm{CD} 4^{+}$oder SP $\mathrm{CD}^{+}$Thymozyten stellen die Enddifferenzierung der T Zellen dar, wobei SP CD4 ${ }^{+} \mathrm{T}$ Zellen die Population der T Helferzellen und SP CD8 ${ }^{+} \mathrm{T}$ Zellen die Population der zytotoxischen T Lymphozyten bilden (Rothenberg EV und Taghon $T$, 2005). Für diese späten Stadien ist bisher nicht bekannt, ob der Shh/Ptch Signalweg an der Regulierung der Entwicklung und/oder ihrer Funktion beteiligt ist. In unserem Modell konnte dies jedoch nicht untersucht werden, da die Entwicklung der 
T Zellen bereits im DN1 Stadium gestört war und daher die späteren T Zell Stadien vollständig fehlten.

Eine Zusammenfassung der T Zellentwicklungsdefekte in Ptch $^{-/}$Mäusen ist in Abbildung 58 gezeigt.

\subsubsection{Gestörte B Zellentwicklung in $\operatorname{tPtch}^{-/}$Mäusen}

Die Differenzierung der B Zellvorläufer vollzieht sich im Knochenmark und lässt sich durch Analyse von spezifischen Oberflächenproteinen, wie B220, CD43, CD19 und IgM, verfolgen. Erst späte unreife B Zellstadien werden aus dem Knochenmark über die Blutbahn in die Milz geschwemmt, wo sie zu reifen B Zellen ausdifferenzieren (Busslinger M, 2004).

Die Analyse von $t$ Ptch ${ }^{--}$Milzen zeigte, dass auch die B Zelldifferenzierung in Ptch $^{-/}$ Mäusen gestört verläuft. Vor allem die frühen Stadien peripherer B Zellen waren stark reduziert.

Über einen Einfluss des Shh/Ptch Signalwegs auf die Entwicklung von frühen B Zellen ist bisher nichts bekannt. Aufgrund der Daten kann nun geschlossen werden, dass Ptch essentiell für eine normale B Zellentwicklung ist.

Obwohl die Differenzierung von unreifen zu reifen B Zellen in der Milz Shh-abhängig verläuft (Sacedon $\mathrm{R}$ et al., 2005), wurde in den Ptch $^{-/}$Milzen kein Entwicklungsdefekt in späten Stadien der B Zellen beobachtet. Dies könnte mit der Langlebigkeit von reifen B Zellen und dem kleinen Zeitfenster von 23 Tagen zusammenhängen. Ein möglicher negativer Einfluß von PPtch $^{-/}$auf die reifen, rezirkulierenden B Zellen der Milz und des Knochenmarks könnte somit unentdeckt geblieben sein. Da reife, rezirkulierende B Zellen jedoch auch im Knochenmark der $\mathrm{tPtch}^{-/}$Tiere detektiert wurden, ist zumindest die Migration dieser Zellen in $\mathrm{tPtch}^{-/}$ Tieren nicht gestört.

Die B Zelldefekte von Ptch $^{-/}$Mäusen sind in Abbildung 58 zusammengefasst dargestellt. 


\subsubsection{Entwicklungsdefekt der lymphoiden Linie im Knochenmark von Ptch $^{-/-}$ Mäusen}

Die Details der Differenzierung der HSC zum gesamten hämatopoetischen System und vor allem zu lymphoiden und myeloischen Vorläuferzellen sind bisher noch unklar. Bislang wird ein Modell postuliert, welches auf dem von Akashi-KondoWeissmann (Kondo M et al., 1997) beruht. Dabei bilden die HSC des adulten Knochenmarks die ursprünglichste Population von Stammzellen, welche zur Entwicklung der lymphoiden Linien und aller anderen Blutzellen befähigt sind. Ausgehend von den HSC wird zuerst die Population der MPP gebildet, die sich in die MEP Linie und LMPP Linie verzweigt. Aus der LMPP Population entstehen die GMP sowie auch die CLP (siehe Abbildung 58) (Kondo $\mathrm{M}$ et al., 1997; Akashi $\mathrm{K}$ et al., 2000; Laiosa CV et al., 2006; Nagasawa T, 2006).

Bei der Untersuchung des Gesamtknochenmarks von $\operatorname{tPtch}^{-/}$Tieren konnte zunächst der Defekt der B Zellentwicklung bis zum frühen CLP Stadium verfolgt werden. Da für die Entwicklung von B Zellen aus CLP die Expression der $\alpha$-Kette des IL-7R und die Transkriptionsfaktoren EBF, Rag1/2 und Pax5 benötigt werden, wurde tPtch $^{-1}$ Gesamtknochenmark auf deren Expression untersucht. Es konnte gezeigt werden, dass der $\mathrm{Ptch}^{-/}$induzierte Entwicklungsdefekt auch durch die reduzierte Expression von IL-7R $\alpha, E B F$, Rag1/2 und Pax5 charakterisiert ist. Da auch die pro- und pre-B Zellpopulationen in Gesamtknochenmark stark reduziert waren, musste der Defekt bei den CLP zu suchen sein.

Wie bereits erwähnt, werden $\mathrm{T}$ und $\mathrm{B}$ Zellen des Immunsystems von den CLP gebildet. Neben den B Zellvorläufern und den ETP entstehen aus den CLP weiterhin die natürlichen Killerzellen (NK, natural killer cell). Hierzu ist jedoch noch festzuhalten, dass ETP nicht nur aus den CLP, sondern höchstwahrscheinlich auch aus HSC, den MPP und auch direkt aus den LMPP hervorgehen können (siehe Abbildung 58) (Bhandoola A und Sambandam A, 2006a).

Die Vorläuferpopulationen benötigen für die Differenzierung zur lymphoiden Linie die Expression der Transkriptionsfaktoren PU.1 und Ikaros, sowie die Expression des Rezeptors Flt3 und die $\alpha$-Kette des IL-7R. Mit Hilfe von Gesamtknochenmarksanalysen konnte gezeigt werden, dass sich weder die Expression von PU.1, Ikaros noch Flt3 in Ptch $^{-/}$Tieren von Kontrollknochenmark unterscheidet. Dagegen wurde eine verminderte Expression von IL-7R $\alpha$ in Ptch $^{-/}$Tieren detektiert. Da die 
Expression von IL-7R $\alpha$ essentiell für die Entwicklung von B und teilweise auch von T Zellvorläufern ist, wurde mittels durchflusszytometrischer Analysen die IL-7R $\alpha$ Expression der Lin $^{-}$Knochenmarksfraktionen untersucht. Dadurch konnte gezeigt werden, dass die IL-7R $\alpha$ exprimierende CLP Fraktion der Lin ${ }^{-}$c-kit ${ }^{\text {low }}$ Sca-1-1/low Knochenmarkspopulation in Ptch $^{-/}$Tieren stark reduziert ist (Kondo $\mathrm{M}$ et al., 1997; Orlic D et al., 1997).

Die normale Expression von PU.1, Ikaros und Flt3 im tPtch ${ }^{-/}$Knochenmark ließ dagegen vermuten, dass die Entwicklung der Vorläufer- und Stammzellen vor dem CLP Stadium nicht durch die Ptch beeinflusst wird. Diese Vermutung wurde anhand der durchflusszytometrischen Analysen der Lin` Knochenmarksfraktion bestätigt. Hier konnte gezeigt werden, dass sowohl die Lin ${ }^{-}$Sca- $1^{\text {high }}$ c-kit ${ }^{\text {high }}$ Fraktion, welche die HSC und MPP enthält, als auch die Lin ${ }^{-}$Sca- $1^{-}$c-kit ${ }^{\text {high }}$ Fraktion, die die myeloischen Vorläuferzellen enthält (Akashi K et al., 2000) in tPtch ${ }^{-/}$Mäusen keine Auffälligkeiten zeigten (siehe Abbildung 58).

\subsubsection{Normale Entwicklung der myeloischen Linie in Ptch $^{-/-}$Mäusen}

Die Vorläuferzellen, aus welchen sich die Zellen der myeloischen Linie entwickeln, sind die MEP und die GMP. Aus den MEP entwickeln sich sowohl Megakaryozyten als auch Erythrozyten, während die GMP zu Granulozyten oder Makrophagen differenzieren.

Weder im Differenzierungspotential von $\operatorname{Lin}^{-}$Knochenmarkszellen noch in Differentialblutbildern von $\mathrm{IPtch}^{-/}$Tieren wurden Abnormitäten der Abkömmlinge der myeloischen Linie festgestellt. So waren alle CFU Werte normal. Selbst die Anzahlen der kurzlebigen Granulozyten und Thrombozyten im peripheren Blut zeigten keine Abweichungen von der Norm auf. Die dabei detektierte erhöhte Zahl von neutrophilen Granulozyten in Ptch $^{-/}$Tieren kann mit der schlechten körperlichen Verfassung der Tiere begründet werden. Vergleichbar zu Bhardwaj et al. (Bhardwaj G et al., 2001) lassen diese Ergebnisse den Schluß zu, dass die Aktivierung des Shh/Ptch Signalweges (bei Bhardwaj et al. durch Hh Stimulierung, hier durch die Deletion von Ptch) keinen Effekt auf das Differenzierungspotential von HSC hat, aus denen alle Zellen des Immunsystems hervorgehen (Akashi K et al., 2000; Bhandoola A und Sambandam A, 2006b). 
Unsere Ergebnisse zeigen jedoch einen Defekt in der Erythrozytenentwicklung in tPtch $^{-1-}$ Mäusen an. So waren trotz normaler BFU-E Zahlen die pro-Erythroblasten in Knochenmarkausstrichen von Ptch $^{-1}$ Tieren erniedrigt. Erythrozyten entstehen zusammen mit Megakaryozyten aus den MEP. Da die Zahl der peripheren, extrem kurzlebigen Thrombozyten normal war, kann davon ausgegangen werden, dass sich die MEP von tPtch $^{-/}$Tieren normal entwickeln. Die allerersten Erythrozytenvorläufer werden durch BFU-E Zahlen angezeigt, die in $t \mathrm{Ptch}^{-/}$Tieren normal waren. Erst die pro-Erythroblasten waren vermindert. Diese Ergebnisse lassen vermuten, dass die Erythropoese in tPtch $^{-/}$Tieren erst nach dem BFU-E Stadium gestört ist (siehe Abbildung 58).

Diese Daten stehen zunächst in Kontrast zu denen von Detmer et al. (Detmer $\mathrm{K}$ et al., 2000). Hier wurde durch eine Behandlung von myeloischen Vorläuferzellen in vitro mit Cyclopamin eine Blockade der erythroiden Entwicklung ausgelöst. Im Gegensatz zu Ptch Mutationen inhibiert Cyclopamin die Hh Signalkaskade. Da aber sowohl ein „Zuviel“ als auch ein „Zuwenig“ der Aktivität der Shh/Ptch Signalkaskade die normale Entwicklung von Zellverbänden stört, können beide Zustände dieselben Defekte, d. h. in diesem Fall den Entwicklungsdefekt der Erythrozytenlinie, auslösen.

Abbildung 58: Schematische Darstellung der gestörten Hämatopoese von Ptch $^{-/}$Mäusen. Die Darstellung der Entwicklungsstadien der hämatopoetischen Vorläuferzellen ist von Nagasawa (Nagasawa T, 2006), die der DN Populationen der T Zelllinie von Bhandoola (Bhandoola A und Sambandam A, 2006b) und die der B Zellen von Busslinger (Busslinger M, 2004) übernommen worden. Abkürzungen: uv, unveränderte Population in $\mathrm{tPtch}^{-/}$Tieren; nach unten weisende Pfeile, reduzierte Population in tPtch $^{-1-}$ Tieren; nach unten weisende Pfeile in Klammern, anzunehmende reduzierte Population in Ptch $^{-\alpha}$ Tieren; n.a., nicht analysiert; HCS, hämatopoetische Stammzelle (hematopoietic stem cell); MPP, multipotentiale Vorläuferzelle (multipotential progenitor); LMPP, lymphoid-spezifische multipotente Vorläuferzelle (lymphoid-primed multipotential progenitor); CLP, allgemeine lymphoide Vorläuferzelle (common lymphoid progenitor); MEP, Megakaryozyt/Erythrozyt Vorläuferzelle (megakaryocyte/erythrocyte progenitor); GMP, Granulozyt/Makrophage Vorläuferzelle (granulocyte/macrophage progenitor); NK, natürliche Killerzelle (natural killer cell); ETP, früher T Zellvorläufer (early $\mathrm{T}$ cell progenitor); $\mathrm{DN}, \mathrm{CD}^{-} \mathrm{CD} 8^{-}$doppelt negative $\mathrm{T}$ Zelle (CD4 ${ }^{-} \mathrm{CD} 8^{-}$double negative T cell); DP, $\mathrm{CD} 4^{+} \mathrm{CD} 8^{+}$doppelt positive T Zelle $\left(\mathrm{CD} 4^{+} \mathrm{CD} 8^{+}\right.$double positive cell); SP, einfach positive T Zelle (single positive T cell). 


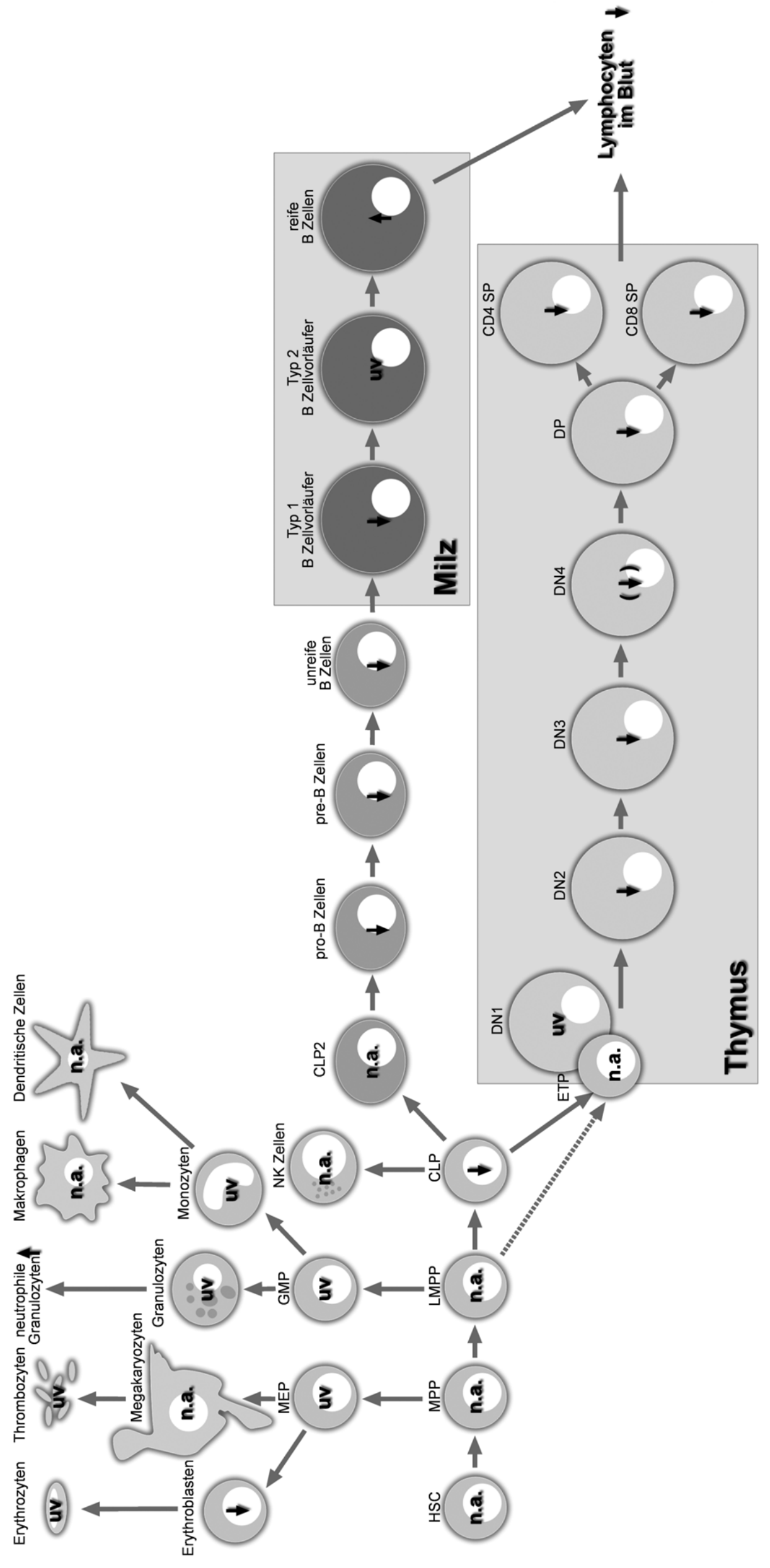




\subsubsection{Zusammenfassende Betrachtung der Funktion von Ptch bei der Lymphopoese}

Die genaue Funktion des Shh/Ptch Signalweges während der Hämatopoese ist bisher noch nicht vollständig geklärt. Aufgrund von in vitro Experimenten wird jedoch eine wichtige Rolle dieses Signalweges bei proliferativen Vorgängen von humanen hämatopoetischen Zellen des peripheren Blutes postuliert (Bhardwaj G et al., 2001; Kawai S und Sugiura T, 2001).

Unsere Ergebnisse zeigen erstmalig, dass Ptch eine essentielle Rolle bei der Entwicklung der lymphoiden Zelllinien im adulten Organismus spielt.

Der beobachtete Verlust von IL-7R $\alpha$ exprimierenden Lin $^{-}$c-kit ${ }^{\text {low }}$ Sca-1-1low Vorläuferzellen in $\mathrm{tPtch}^{-/}$Mäusen weist stark auf eine Blockade der Entwicklung von CLP im Knochenmark hin, was sich in dem daraus resultierenden Verlust von frühen B Zellen in Milz und Knochenmark widerspiegelt.

Außer B Zellen entwickeln sich auch die ETP aus der CLP Fraktion. Aufgrund des CLP Verlustes in tPtch $^{-/-}$Mäusen kann ein vermindertes Einwandern von ETP in den Thymus und ein damit verbundener Defekt der $\mathrm{T}$ Zellentwicklung angenommen werden. Jedoch ist eine ETP Differenzierung auch aus HSC, MPP oder LMPP möglich (Bhandoola A und Sambandam A, 2006b). Da die letzteren Zellpopulationen in PPtch $^{-/}$Tieren intakt erscheinen, ist eine normale CLP-unabhängige ETP Entwicklung in Ptch $^{-/}$Tieren anzunehmen. Aufgrund des enormen Proliferationspotentials dieser ETP sollte daher eine relativ normale T Zellentwicklung im Thymus von Ptch $^{-/}$Tieren möglich sein. Dies war jedoch nicht der Fall. Obwohl die relative Anzahl von DN1 Zellen in $\mathrm{tPtch}^{-/}$Thymi erhöht war, fehlten die DN2 und DN3 Stadien der Thymozyten vollständig, was auch durch den reduzierten Thymuskortex gezeigt wurde, in dem sich diese Populationen entwickeln (Palmer E, 2003). Hierbei sind DN3 Zellen der beste Indikator für eine normale T Zellentwicklung, da sich die Zellen ab diesem Stadium nur noch zu Thymozyten, nicht aber zu B Zellen entwickeln können (Bhandoola A und Sambandam A, 2006b). Die DN1 Fraktion dagegen sagt nichts über die in den Thymus eingewanderten ETP aus, da sich a) die in den Thymus eingewanderten ETP nicht alle in der DN1 Fraktion des Thymus befinden (Wu L et al., 1991; Bhandoola A und Sambandam A, 2006b) (siehe Abbildung 58) und b) da sich Zellen des DN1 Stadiums auch in andere Zelllinien (z. B. B Zellen) weiterentwickeln können. Somit muss nun angenommen 
werden, dass die Depletion der Thymozyten in $\mathrm{tPtch}^{-/-}$Mäusen entweder durch einen Migrationsdefekt der ETP zum Thymus hervorgerufen wird, oder aber durch ein defektes Thymusstroma ausgelöst wird, so dass sich die in den Thymus eingewanderten ETP nicht mehr weiterentwickeln können.

Obwohl nicht alle Fragen geklärt sind, wird offensichtlich, dass Ptch eine bedeutende Rolle bei der Entwicklung von T Zellen spielt.

Die hier vorgestellten Daten werden auch durch die Ergebnisse anderer Arbeitsgruppen untermauert. Aufgrund von bisherigen in vitro und in vivo Analysen ist bekannt, dass die Entwicklung von Thymozyten direkt von der Aktivität des Shh/Ptch Signalwegs abhängig ist (Outram SV et al., 2000; Gutierrez-Frias C et al., 2004; Shah DK et al., 2004; Sacedon R et al., 2005; Andaloussi AE et al., 2006). Des Weiteren ist bekannt, dass Ptch in DN Zellen exprimiert wird (Outram SV et al., 2000). Außerdem konnte durch Shah et al. gezeigt werden, dass der Shh/Ptch Signalweg eine wichtige Rolle während der Proliferation von DN1 Zellen, sowie bei der Entwicklung zum DN2 Stadium spielt (Shah DK et al., 2004). Dabei scheint vor allem die Regulierung der IL-7R $\alpha$ Expression durch die Shh/Ptch Signalkaskade wichtig zu sein (Gutierrez-Frias C et al., 2004). Dies unterstreicht ebenfalls unsere Ergebnisse aus Knochenmarksanalysen, in denen gezeigt wird, dass Ptch in der CLP-enthaltenen Lin $^{-}$Knochenmarksfraktion für die Expression von IL-7R $\alpha$ verantwortlich ist.

\subsubsection{Ausblick}

Zusammenfassend zeigen die Daten, dass die biallelische ubiquitäre Inaktivierung von Ptch im adulten Tier zu einem partiellen Defekt in der Entwicklung der erythroiden Linie und zu schweren Differenzierungsdefekten lymphoider Zellen führt. Dies spiegelt vor allem die Involution des Thymus wider.

Anhand der Daten kann jedoch momentan nicht ausgeschlossen werden, dass auch ein Defekt des Thymusstromas in $t P t c h^{-/-}$Mäusen die Entwicklung der Thymozyten beeinflusst und damit zum Verlust von späten Differenzierungsstadien der T Zellen führt. Ebenso könnte auch das Stroma des Knochenmarks durch die Inaktivierung von Ptch zu den Entwicklungsdefekten der B Zelllinie und der gesamten lymphoiden Vorläuferpopulation führen. Diese Annahme wird vor allem dadurch unterstützt, dass 
die aktive Shh/Ptch Signalkaskade auch die Expression von Bmp Genen im Knochenmarkstroma reguliert, welche wichtige regulatorische Funktionen während der Differenzierung der hämatopoetischen Vorläuferzellen im Knochenmarkstroma besitzen (Bhardwaj G et al., 2001).

Um dies zu untersuchen, könnten Repopulationsanalysen von immundefizienten Mäusen durchgeführt werden, die mit $t \mathrm{Ptch}^{-/} \mathrm{Lin}^{-}$Knochenmarkszellen transplantiert werden. Dadurch könnte untersucht werden, ob der T und B Zelldefekt in Ptch $^{-/-}$ Tieren tatsächlich zellautonom ist. Weiterhin könnte über Proliferationsstudien untersucht werden, ob außer dem $t P t c h^{-/}$induzierten Differenzierungsdefekt auch ein Proliferationsdefekt der entsprechenden Zellpopulationen (z. B. HSC, CLP, etc.) in tPtch $^{-/-}$Mäusen vorliegt.

Die bisherigen Knochenmarks- und Blutanalysen konnten keinen Anhaltspunkt auf die Entwicklung einer Leukämie in $t P t c h^{-/}$Mäusen liefern. Für einen definitiven Ausschluß eines leukämischen Potentials des $t$ tch ${ }^{-/}$Knochenmarks könnten die oben beschiebenen Proliferations- und Repopulationsanalysen ebenfalls nützlich sein.

Zuletzt weisen die bisherigen Daten darauf hin, dass in PPtch $^{-/}$Mäusen ein Immundefekt induziert wird, der dem „Severe Combined Immunodeficiency“ (SCID) Syndrom im Menschen entspricht. So führt SCID, ausgelöst durch IL-7R $\alpha$ Mutationen, zum kompletten Verlust von T Zellen und dem Verlust der adaptiven Immunität (Buckley RH, 2004). In ca. 15 \% der SCID Fälle sind die auslösenden Faktoren noch nicht bekannt. In dem hier beschriebenen Mausmodell führt die Inaktivierung von Ptch zu einer verminderten Zahl von IL-7R $\alpha^{+}$lymphoiden Vorläuferzellen, obwohl die Expression der Transkriptionsfaktoren PU.1 und Ikaros, die direkt die Expression von IL-7R $\alpha$ stimulieren (Lee HC et al., 2005), nicht beeinflusst ist. Da auch der Phänotyp der $t P t c h^{-/}$Mäuse mit dem von IL-7R $\alpha$ knockout Mäusen vergleichbar ist (Peschon JJ et al., 1994), besteht die Möglichkeit, dass eine Fehlregulation des Shh/Ptch Signalweges zur Entwicklung von SCID führen könnte. 


\subsubsection{Durch intramuskuläre Tamoxifengabe in 6 Wochen alte Ptch $^{N X / N X}$ $E T_{2}{ }^{+/}$Mäuse lassen sich keine RMS induzieren}

Wie schon mehrmals in dieser Arbeit dargestellt, sollte mit Hilfe der konditionellen Ptch knock-out Mäuse geklärt werden, ob eine biallelische Inaktivierung von Ptch tatsächlich notwendig ist, um die Entstehung von RMS auszulösen.

In der vorliegenden Arbeit wurde nun gezeigt, dass der biallelische Verlust von Ptch neben dem induzierten schweren Immundefekt auch zur Hyperproliferation einiger sich schnell teilender Gewebe führt. Die Ptch Inaktivierung, die durch die Gabe von $5 \mathrm{mg}$ Tamoxifen induziert wurde, ließ jedoch die Beobachtung der $\mathrm{tPtch}^{-/}$Tiere nicht über einen Zeitraum von mehr als 23 Tagen zu. Dieser Zeitraum war für die Entstehung von Tumoren, einschließlich der von RMS, zu kurz.

Daher wurde in einem zweiten experimentellen Ansatz die Rekombination des Ptch $^{N X}$ Lokus in Ptch $^{N X / N X}$ ERT2 ${ }^{+-}$Tieren durch die einmalige intramuskuläre Gabe von $100 \mu \mathrm{g}$ Tamoxifen induziert.

Durch die intramuskuläre Tamoxifengabe sollte die Rekombination am Ptch Lokus hauptsächlich im injizierten Muskel - hier vor allem in den adulten Stammzellen des Muskels, den Satellitenzellen (siehe Kapitel 4.3) induziert werden. Jedoch wurde bis zum Abschluss dieser Arbeit in keinem der analysierten $\mathrm{Ptch}^{N X / N X} E R T 2^{+/-}$Tiere die Entwicklung von RMS beobachtet. Da aber gezeigt wurde, dass eine Rekombination in Satellitenzellen von ROSA26- $R^{+/} E R T 2^{+/-}$Mäusen nach der Gabe von Tamoxifen stattfindet und auch im Muskelgewebe von tPtch $^{-/}$Mäusen Ptch ${ }^{\text {delNX }}$ Transkripte exprimiert werden, kann vermutet werden, dass durch die intramuskuläre Tamoxifengabe tatsächlich eine Rekombination des $\operatorname{Ptch}^{N X}$ Lokus im Muskel stattgefunden hat.

Nun gibt es mehrere Möglichkeiten, warum sich in diesen Tieren keine RMS entwickelten. So könnte das Alter der Tiere, bei dem die Ptch Inaktivierung stattfindet, ausschlaggebend sein. Außerdem wäre denkbar, dass sich die Entwicklung von RMS durch die Tamoxifengabe in den Muskel von sehr jungen Tieren in utero induzieren ließe, da pränatale und neugeborene Mäuse wesentlich mehr Satellitenzellen als 6 Wochen alte Tiere besitzen (Seale P et al., 2000; Oustanina S et al., 2004). Dadurch würde sich die Wahrscheinlichkeit einer biallelischen Inaktivierung von Ptch in Satellitenzellen erhöhen. 
Außerdem prädisponiert der gemischte genetische Hintergrund (129Sv x C57BL/6N) der Ptch $^{N X / N X}$ ERT2 $^{+/}$Mäuse nicht sehr stark zu RMS, wie auch im Rahmen dieser Arbeit gezeigt wurde (siehe Kapitel 3.2.4.1). Das Einkreuzen von Balb/c Allelen wäre eine Möglichkeit, um die Inzidenz für RMS in $\operatorname{Ptch}^{N X / N X} E R T 2^{+/-}$Mäusen zu erhöhen (Hahn H et al., 2004).

Des Weiteren könnte die verabreichte geringe Tamoxifendosis nicht ausreichend für die Induktion der Rekombination im Muskel sein. Diese Annahme ist jedoch eher unwahrscheinlich, da eine sehr effektive Rekombination in der unbehaarten Haut der Tiere stattgefunden hat (siehe Kapitel 4.2.4.1).

\subsubsection{Induktion von Basaliomen durch intramuskuläre Tamoxifengabe in 6

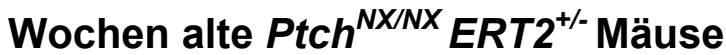

Obwohl sich nach intramuskulärer Gabe von $100 \mu \mathrm{g}$ Tamoxifen in den Ptch $^{N X / N X}$ $E R T 2^{+/-}$Mäusen keine RMS induzieren ließen, entwickelten sich Basaliome. Dabei waren vor allem unbehaarte Hautregionen betroffen, während stark behaarte Regionen wie die Bauchhaut erst 6 Monate nach der Tamoxifengabe hyperproliferative Areale aufwiesen. Erste Analysen der Tumoren an Ohren, Schwanz und der Plantarseiten der Pfoten zeigten dabei deutliche hyperproliferative tumorartige Veränderungen der Basalzellschicht sowie der äußeren Wurzelscheide.

Es gibt mehrere Möglichkeiten, warum die Basaliome schneller in unbehaarten als an der behaarten Haut auftraten. Unterschiedliche äußere Faktoren (z. B. Putztrieb und Reize durch Einstreu) wie auch interne Unterschiede zwischen den Hautarealen (z. B. unterschiedliche Dicke des Unterhautfettgewebes, Schnelligkeit des Haarzyklus etc.) könnten die schneller auftretenden hyperproliferativen Bereiche unbehaarter Haut erklären. Auch die vermehrte Exposition der unbehaarten Haut mit UV-Strahlung wäre ein denkbarer Faktor. Allerdings kann dies ausgeschlossen werden, da die Tiere in Plexiglaskäfigen gehalten wurden, die die ohnehin schon geringe UV-Lichtemissionen der Lampen im Tierstall auf eine minimale UVBestrahlung reduzieren.

Eine weitere Möglichkeit ist eine bessere Durchblutung der unbehaarten Haut, so dass das gespritze Tamoxifen hier besser anfluten kann und wirksamer ist. 
Die Möglichkeit zur Induktion von Basaliomen in den $\operatorname{Ptch}^{N X / N X} E R T 2^{+-}$Mäusen ist für die Erforschung dieser Tumoren und auch für die Entwicklung neuer Therapieansätze für den Menschen von großer Bedeutung.

$90 \%$ der sporadisch auftretenden humanen Hauttumore sind Basaliome und betreffen besonders häufig die weißhäutige Bevölkerung (Daya-Grosjean $L$ und Couve-Privat S, 2005). Dabei sind vor allem Menschen ab dem vierzigsten Lebensjahr oder mit defektem Immunsystem prädisponiert (Price MA et al., 1994). Auch spielt die Exposition mit UV-Licht eine übergeordnete Rolle bei der Induktion von Basaliomen (Crowson AN, 2006). Es ist bekannt, dass die heterozygote Keimbahnmutation von PTCH (neben der Prädisposition zu MB und RMS) auch zur Entwicklung von Basaliomen prädisponiert. Die Entstehung von Basaliomen sowohl in familiären als auch in sporadischen Fällen geht dabei häufig mit homozygot inaktivierenden Mutationen von PTCH einher (Gailani MR et al., 1996; Hahn $\mathrm{H}$ et al., 1996; Johnson RL et al., 1996; Wicking C und Bale AE, 1997).

In den bisher gängigen heterozygoten $P t c h^{\text {neo67/+ }}$ und $P t c h^{\text {neo12/+ }}$ Tiermodellen ist die Induktion von Basaliomen durch UV-Bestrahlung möglich (Aszterbaum $\mathrm{M}$ et al., 1999; Mancuso M et al., 2004; So PL et al., 2004). Es wird angenommen, dass die Bestrahlung zum biallelischen Verlust von Ptch führt, was die Entstehung dieser Tumore bewirkt. Obwohl jedoch die Exposition mit UV-Licht auch zu anderen molekularen Effekten führen kann, konnte bisher nicht eindeutig geklärt werden, ob eine zellautonome homozygote Inaktivierung von Ptch tatsächlich der Grund für die Entstehung von Basaliomen ist.

Nun wurde kürzlich durch Adolphe et al. ein weiteres konditionelles Ptch knock-out Mausmodell beschrieben. Die Autoren zeigen, dass sich auch in diesem Tiermodell durch die induzierte homozygote Deletion von Ptch in der Haut Basaliome induzieren ließen (Adolphe $C$ et al., 2006). Trotz der unterschiedlichen experimentellen Ansätze von Adolphe et al. und dieser Arbeit kann daher davon ausgegangen werden, dass die Entstehung von Basaliomen durch die homozygote Inaktivierung von Ptch ausgelöst wird. Ob sich diese Tumoren dabei aus Zellen der Basalzellschicht oder aber aus Zellen der äußeren Wurzelscheide entwickeln, ist bisher noch nicht eindeutig geklärt. Daher konnte die Frage nach der Urspungszelle des Basalioms noch nicht gelöst werden. Durch immunhistologische Antikörperfärbungen oder das 
Einkreuzen anderer Zell-spezifischer Cre-Rekombinasen in $\operatorname{Ptch}^{N X / N X}$ Mäuse könnte dies jedoch untersucht werden.

\subsubsection{Ausblick}

Das hier beschriebene Tiermodell kann ersten Analysen zufolge sehr gut für die Analyse von Basaliomen genutzt werden. Vor allem ist dabei hervorzuheben, dass nach intramuskulärer Gabe von Tamoxifen mit keinen größeren körperlichen Beeinträchtigungen der Tiere, selbst über einen Zeitraum von mehr als 6 Monaten, zu rechnen ist.

Ob sich die so behandelten $\operatorname{Ptch}^{N X / N X} E R T 2^{+/}$Mäuse tatsächlich für die Analyse von RMS eignen, muss noch geklärt werden. Wahrscheinlich muss der genetische Hintergrund durch das Einkreuzen von Balb/c Allelen, die für die Entwicklung von RMS prädisponieren (Hahn $\mathrm{H}$ et al., 2004), korrigiert werden. Des Weiteren muss wahrscheinlich die Ptch Inaktivierung zu einem früheren Zeitpunkt erfolgen. 


\subsection{Versuch des Nachweises der Urspungszellen von Ptch- assoziierten RMS mit Hilfe von transgenen Tg(Pax7CreTM) Mauslinien}

Im ersten Teil dieser Arbeit wurde ein neues Modell zur Entstehung von Ptchassoziierten RMS vorgeschlagen (Uhmann A et al., 2005) (siehe Kapitel 4.1.3). Die Ursprungszelle des RMS ist bisher jedoch nicht bekannt. Es wird aber angenommen, dass Muskelstammzellen an der Entwicklung von RMS beteiligt sind. Dabei werden sowohl die Satellitenzellen als auch die Zellen der "Side Population" des Muskels in der Literatur als Muskelstammzellen und potentielle Vorläuferzellen von RMS diskutiert (Tiffin N et al., 2003; Relaix $\mathrm{F}$ et al., 2005), doch fehlen momentan geeignete Modellsysteme zur Lösung dieser Frage.

Das Tiermodell zur induzierbaren biallelischen Inaktivierung von Ptch, welches im zweiten Teil dieser Arbeit vorgestellt wurde, könnte dabei neue Möglichkeiten zur detaillierten Analyse der Ptch-assoziierten Entwicklung von RMS bieten. Durch die intramuskuläre Injektion von Tamoxifen in $\operatorname{Ptch}^{N X / N X} E R T 2^{+/}$Mäuse ist es jedoch bislang nicht möglich gewesen, die Entwicklung von RMS zu induzieren (siehe Kapitel 4.2.4).

In dieser Arbeit sollte der Versuch unternommen werden, Ptch spezifisch in Satellitenzellen zu deaktivieren. Falls sich durch dieses Vorgehen RMS induzieren lassen sollten, wäre dies der direkte Nachweis dafür, dass diese Tumoren aus den Satellitenzellen entstehen. Um nun Ptch spezifisch in Satellitenzellen zu deletieren, wurden transgene Mauslinien zur Expression einer induzierbaren Cre-Rekombinase unter Kontrolle des murinen Pax7 Promotors etabliert.

Um diese Strategie besser verstehen zu können, sollen an dieser Stelle die bekannten Daten der Literatur zur Expression von Pax7 im Embryo und in adulten Geweben aufgelistet werden.

Die Expression von Pax 7 beschränkt sich nicht nur auf die Satellitenzellen im adulten Muskel. Der Transkriptionsfaktor wird auch im Verlauf der embryonalen Entwicklung exprimiert (Jostes B et al., 1990; Goulding MD et al., 1991; Mansouri A et al., 1994; Relaix $\mathrm{F}$ et al., 2006). So wird Pax7 während der Embryogenese im dorsalen Neuralrohr exprimiert und reguliert die Entwicklung von dorsalen ektodermalen Zellen während der Neurulation (Jostes B et al., 1990; Goulding MD et al., 1991). In 
späteren Entwicklungsstadien ist Pax7 zur regionalen Differenzierung des Neuralrohrs notwendig (Wada $\mathrm{H}$ et al., 1996). Seine Expression in den Zellen der Neuralleiste des Neuralrohrs (neural crest cells) führt zur Auswanderung der Zellen aus dem Neuralrohr in den sich entwickelnden Embryo, wo sie zu Neuronen, Gliazellen des peripheren Nervensystems und Melanozyten differenzieren (Stoykova A und Gruss P, 1994; Wada H et al., 1996). Pax7 wird auch während der Mesodermentwicklung im Dermatomyotom exprimiert (Stoykova A und Gruss P, 1994).

Die Pax7 Expression im jungen adulten Tier beschränkt sich auf abgegrenzte Hirnbereiche (Stoykova A und Gruss P, 1994), Bereiche des peripheren Nervensystems (Jostes B et al., 1990; Goulding MD et al., 1991), neuromuskuläre Spindeln (Rodger J et al., 1999) und auf einen Großteil der Satellitenzellen im Skelettmuskel (Seale P et al., 2000; Kuang S et al., 2006; Relaix F et al., 2006).

Mäuse mit einer homozygoten Pax7 Defizienz entwickeln Defekte in Zellen der anterioren Neuralleiste und sterben postnatal (Mansouri A et al., 1996). Des Weiteren besitzen diese Mäuse nur eine geringe Anzahl Satellitenzellen im Skelettmuskel, die während der weiteren postnatalen Entwicklung stark abnimmt (Seale P et al., 2000; Oustanina S et al., 2004). Die Muskelfasern dieser Tiere sind jedoch normal entwickelt. Daher wird angenommen, dass die Expression von Pax7 essentiell für die Erneuerung und Erhaltung der Satellitenzellpopulation im jungen Tier ist (Oustanina S et al., 2004; Relaix F et al., 2006).

Aufgrund dieser Daten ist der Pax7 Promotor hervorragend dafür geeignet, Gene in Satellitenzellen zu exprimieren. Daher sollte dieser Promotor genutzt werden, um eine Cre-Rekombinase in Satellitenzellen zu exprimieren. Obwohl sich die Expression von Pax7 im adulten Tier im Skelettmuskel auf die Satellitenzellen und auf Nervenstrukturen beschränkt (Jostes B et al., 1990; Goulding MD et al., 1991; Rodger J et al., 1999; Seale P et al., 2000; Kuang S et al., 2006; Relaix F et al., 2006), muss jedoch die Cre-Rekombinase induzierbar sein, um eine CreRekombinase-vermittelte Rekombination während der embryonalen Entwicklung zu vermeiden. Daher wurde eine Tamoxifen-induzierbare Cre-Rekombinase verwendet (MerCreMer-Rekombinase (Verrou C et al., 1999), im Folgenden als CreTMRekombinase bezeichnet). 
Mit Hilfe von in vitro Analysen in $\mathrm{C} 2 \mathrm{C} 12$ Zellen konnte gezeigt werden, dass das klonierte proximale murine Pax7 Promotorfragment in myogenen Vorläuferzellen aktiviert wird. Die Vorarbeiten zeigten weiterhin, dass auch die CreTM-Rekombinase, welche unter diesem Promotor exprimiert wurde, in myogenen Zellen gebildet wird und sich durch die Gabe von Tamoxifen induzieren läßt. Daher wurde damit gerechnet, dass die CreTM-Rekombinase auch in vivo in myogenen Vorläuferzellen aktiv sein sollte.

\subsubsection{Keine Expression von $T g(P a x 7 C r e T M)$ während der Embryonalentwicklung}

In keiner der 4 etablierten transgenen $T g(P a x 7 C r e T M)$ Mauslinien wurde eine Expression bzw. Aktivität der CreTM-Rekombinase während der embryonalen Entwicklung festgestellt. Hierzu wurden die $T$ (Pax7CreTM) Mäuse mit ROSA26- $R^{+/-}$ Reportermäusen gekreuzt und die CreTM-Rekombinase mit einer kumulativen Dosis von $2 \mathrm{mg}$ Tamoxifen in utero stimuliert. Die Embryonen wurden isoliert und mit X-Gal gefärbt. Es konnte jedoch keine ß-Galaktosidase-Aktivität in den Embryonen nachgewiesen werden.

Von Lang et al. wurde unabhängig von dieser Studie ein zu dem hier verwendeten 3,2 kb langes Pax7 Promotorfragment vergleichbar langes Pax7 Fragment (Pax7-4) benutzt, um die Aktivität dieses Fragments in transgenen Embryonen zu untersuchen. Hierzu haben Lang et al. das Promotorfragment vor das ß-Galaktosidasegen kloniert. Dann wurden transgene Mäuse hergestellt und Embryonen am Tag 10,5 dpc bis 13,5 dpc isoliert. Wie die Daten von Lang et al. zeigen, wurde das ß-Galaktosidasegen nur sehr schwach im Embryo exprimiert. Dabei beschränkte sich die Aktivität des Reportergens auf schmale Bereiche des Kleinhirns und der Mittelhirn-Hinterhirn-Grenze (Lang D et al., 2003).

Aufgrund des Vergleichs unserer Daten mit den Daten von Lang et al. könnte sich nun die fehlende X-Gal-Färbung in unserem Experiment durch mehrere Faktoren erklären lassen: 1) Zunächst könnte die eingesetzte Dosis von 2 mg Tamoxifen zu gering gewesen sein, um die CreTM-Rekombinase in ausreichender Weise zu aktivieren. Da jedoch auch in der Literatur mit solchen Dosen gearbeitet wird, kann dies ausgeschlossen werden. 2) Des Weiteren ist es möglich, dass sich die CreTMRekombinase nicht optimal durch Tamoxifen induzieren lässt. Laut Empfehlung von 
Prof. M. Reth (Max-Planck-Institut für Immunobiologie, Freiburg), aus dessen Labor diese Cre-Rekombinase stammt, sollte anstatt Tamoxifen das Analog 4-OHT benutzt werden. Unsere Experimente am adulten Tier haben jedoch gezeigt, dass sich durch 4-OHT und Tamoxifen derselbe Effekt auf die Induktion der CreTM-Rekombinase im Muskel erzielen läßt. Daher kann angenommen werden, dass 4-OHT keine bessere Induktion der CreTM-Rekombinase als Tamoxifen hervorruft. 3) Weiterhin ist es möglich, dass die CreTM-Rekombinase die loxP-Sequenz-flankierte Kassette am ROSA26 Lokus nicht optimal entfernt, was eine schwache oder keine X-Gal-Färbung nach sich ziehen könnte. Literaturangaben zufolge ist die hier eingesetzte ROSA26R Mauslinie nicht für alle Cre-Rekombinasen eine optimale Reportermaus. 4) Auch die Länge des Promotorfragments könnte bei der Expression eine Rolle spielen. Das Pax7 Promotorfragment von Tg(Pax7CreTM) ist in der 5'-Region um ca. 800 bp kürzer als das Promotorfragment von Lang et al. Innerhalb dieser 800 bp sind jedoch keine Bindungsstellen für Transkriptionsfaktoren gefunden worden, welche eine fehlende X-Gal-Färbung in ROSA26- $R^{+-} \operatorname{Tg}($ Pax7CreTM) Embryonen erklären könnte.

Nun enthält das in dieser Arbeit eingesetzte Promotorfragment im Gegensatz zu Pax7-4 nicht nur den Transkriptionsstart von Pax7, sondern auch die Sequenz vom Pax7 Transkriptionsstart bis hin zum Pax7 Translationsstart. Hierbei handelt es sich um 25 bp. Innerhalb dieser Sequenz sind noch zusätzlich zwei für die myogene Expression von Pax7 möglicherweise wichtige Proteinbindungsdomänen lokalisiert. Dies sind die Bindungsdomäne für „TEF1 releated muscle factor“ und eine „muscle initiator sequence" (Abbildung 49). Daher wurde nun überprüft, ob sich die CreTMRekombinase im adulten Muskel induzieren läßt. Gegebenfalls könnte sich dann die fehlende embryonale Aktivität von Tg(Pax7CreTM) sogar als vorteilhaft für die geplanten Studien erweisen, da dann keine „leakyness“ der CreTM-Rekombinase während der Embryonalentwicklung auftreten sollte.

\subsubsection{Tg(Pax7CreTM) wird im adulten Muskel in Nervenstrukturen, nicht aber in Satellitenzellen aktiviert}

Keine der 4 transgenen $T g(P a x 7 C r e T M)$ Linien zeigte eine induzierbare CreTMRekombinaseaktivität in Satellitenzellen des adulten Muskels. Auch nach 
intramuskulärer Gabe von 4-OHT (anstatt von Tamoxifen) konnte keine Aktivität in Satellitenzellen nachgewiesen werden.

Dies stimmt mit Daten der von Lang et al. beschriebenen transgenen Mauslinien überein, bei denen ebenfalls keine Reportergenaktivität in Satellitenzellen nachgewiesen werden konnte (persönliche Mitteilung Epstein JA, Universität Pennsylvenia, Philadelphia, USA).

Interessanterweise wurde aber die Expression und Aktivität der CreTM-Rekombinase in Nervenfasern der Skelettmuskeln adulter ROSA26- $R^{+/-} \operatorname{Tg}($ Pax7CreTM) Mäuse detektiert. Wahrscheinlich wird sie in den Schwannschen Scheiden exprimiert. Dies konnte in 3 der 4 untersuchten transgenen Linien nachgewiesen werden. Hierbei handelte es sich um die $T g(P a x 7 C r e T M)$ Linien \#21, \#27 und \#54. Dies zeigt, dass es sich nicht um eine unspezifische Transgenexpression aufgrund der Integration im Genom handelt. Außerdem konnte gezeigt werden, dass die Aktivität der CreTMRekombinase in diesen 3 Linien nur nach Tamoxifeninduktion nachweisenbar ist. Daraus kann geschlossen werden, dass die 3 Tg(Pax7CreTM) Linien nicht "leaky“ sind und sich sehr gut für induzierte Geninaktivierungen eignen.

Wie bereits beschrieben, enthält das klonierte murine Pax7 Promotorfragment mehrere putative Proteinbindungsdomänen für myogene Transkriptionsfaktoren (Abbildung 49). Die Bindungsdomänen für allgemeine Transkriptionsfaktoren entsprechen im analysierten murinen Pax7 Promotor denen des humanem Pax7 Promotors (Oct, NF1, TATA, TFIID, CAAT-box) (Murmann OV et al., 2000). Auch die Bindungsstellen für spezielle Transkriptionsfaktoren, wie Egr-1 (early growth response 1) und FKH (fork head), wurden im Vergleich zwischen humanem und murinem Pax7 Promotor bestätigt. Des Weiteren wurden Bindungsstellen für Muskelspezifische regulatorische Proteine im murinen Modell nachgewiesen. So sind sowohl eine „muscle initiator sequence“, eine Domäne für „TEF-1 related muscle factor“ als auch eine Domäne für den MyoD (myogenic differentiation 1) Transkriptionsfaktor, eine Domäne für SRF (serum response factor) und eine E-box Bindungsdomäne (Proteinbindungsdomäne für myogene Helix-Loop-Helix Transkriptionsfaktoren) in dem klonierten Promotorfragment enthalten. Dabei entsprechen sowohl die Lokalisation und die Sequenz der E-box als auch der MyoD Bindungsdomäne den von Murmann et al. beschriebenen Bindungsdomänen des humanen Pax7 Promotors (Murmann OV et al., 2000). 
Von Murmann et al. wurde die Expression des klonierten humanen Pax7 Promotors in der myogenen Zelllinie C2C12 nachgewiesen, was auch in dieser Arbeit für den murinen Pax7 Promotor gezeigt wurde. Jedoch sind die myogenen Proteinbindungsdomänen in vivo scheinbar nicht ausreichend, um eine Expression des Pax7 Promotorfragments in Satellitenzellen zu bewirken.

Zu FKH Proteinen ist festzuhalten, dass diese nicht nur Muskel-spezifisch sondern auch neuronal exprimiert werden (Fukunaga $\mathrm{K}$ et al., 2005). Daher könnten die beiden FKH Bindungsdomänen für die Expression des Transgens im peripheren adulten Nervengeweben genügen. Die Expression von endogenem murinem Pax7 in Schwannschen Scheiden von Nerven (Rodger J et al., 1999) und auch in Bereichen des adulten peripheren Nervensystems ist bekannt (Jostes B et al., 1990), doch bisher nicht näher untersucht worden.

\subsubsection{Ausblick}

\subsubsection{Sind Tg(Pax7CreTM) Mäuse für Studien zur Ursprungszelle des RMS geeignet?}

Wie die hier vorgestellten Daten zeigen, konnte mit den bisherigen Versuchsansätzen keine Aktivierung der CreTM-Rekombinase in Satellitenzellen erzielt werden. Daher wird man die $T g$ (Pax7CreTM) Mauslinien zum jetzigen Zeitpunkt für eine Satellitenzell-spezifische Ptch Inaktivierung zum Nachweis der Urspungszelle des RMS nicht nutzen können.

Da jedoch die verwendete Reportermaus Rosa26- $R$ nicht sehr sensitiv ist, sollte man eventuell noch eine weitere Reportermauslinie testen. Dafür wäre z. B. die R26REYFP Mauslinie verwendbar, da diese als sensitiver gegenüber der CreRekombinase-vermittelten Rekombination beschrieben wurde und auch durchflußzytometrische Analysen von EYFP-positiven Zellen zuläßt (Srinivas S et al., 2001).

Des Weiteren sollte man höhere Dosen von 4-OHT oder Tamoxifen zur Induktion des Transgens testen, bevor man die endgültige Aussage trifft, dass sich die hier generierten Mauslinien nicht für eine Ablation von Genen in Satellitenzellen eignen. 


\subsubsection{Sind $T g(\operatorname{Pax} 7 \mathrm{CreTM})$ Mäuse für Studien an adulten Nerven geeignet?}

Mit Hilfe des hier beschriebenen Tg(Pax7CreTM) Mausmodells ist nicht nur die genaue Analyse der Pax7 exprimierenden neuralen Zellen des Muskels möglich, sondern auch die Analyse nach induzierter Geninaktivierung in diesen Zellen. Natürlich sind hierfür zunächst weitere Untersuchungen nötig, wie z. B. die Präparation der betroffenen Nerven, um die Tg(Pax7CreTM) Transgenexpression genauer zu charakterisieren. Anhand des bisher untersuchten Materials besteht die Vermutung, dass das Transgen in Zellkernen der Schwannschen Scheiden, welche sich aus Oligodendrozyten entwickeln, exprimiert wird (persönliche Mitteilung Dr. W. Schulz-Schaeffer, Universitätsklinikum Göttingen, Abt. Neuropathologie). Sollte sich diese Annahme bestätigen, wäre auch die Expressionsanalyse von Gliazellen des Gehirns (Rodger J et al., 1999) interessant und es würde die Möglichkeit eröffnet, mit Hilfe dieses Tiermodells die Regeneration von peripheren Nerven und des Zentralnervensystems im Zusammenhang mit unterschiedlichen Geninaktivierungen zu untersuchen. 


\section{Zusammenfassung}

Heterozygote Keimbahnmutationen des Sonic Hedgehog (Shh) Rezeptors Patched (Ptch) sind im Gegensatz zu homozygoten Mutationen nicht letal und prädisponieren mit hoher Wahrscheinlichkeit zur Entstehung von Basaliomen, Medulloblastomen und Rhabdomyosarkomen (RMS). Heute wird angenommen, dass es sich bei Ptch um ein Tumorsuppressorgen handelt, da für die Entstehung von Basaliomen die biallelische Inaktivierung von Ptch auf somatischer Ebene notwendig ist. Dagegen konnte jedoch gezeigt werden, dass für die Entstehung von RMS und MB ein monoallelischer Ausfall von Ptch genügt.

Ziel dieser Arbeit war es, die Pathogenese von Ptch-assoziierten RMS besser zu verstehen. Des Weiteren sollte der Versuch unternommen werden, die Ausgangszelle dieser Tumoren zu identifizieren.

Im Rahmen dieser Arbeit wurde zunächst mit Hilfe anderer Labormitglieder demonstriert, dass die Entstehung von RMS in heterozygoten Ptch ${ }^{\text {neo67/+ }}$ Mäusen durch ein Ungleichgewicht der Expression des mutanten und des Wildtyp (wt) Ptch Allels zu erklären ist. Dabei wird in RMS das mutante Allel verstärkt, das wt Allel hingegen vermindert exprimiert. Um diese Beobachtung tiefergehend zu analysieren, wurden die verschiedenen Spleissvarianten von Ptch im RMS untersucht.

Des Weiteren wurde gezeigt, dass der Shh/Ptch Signalweg sowohl durch die Expression von mutantem Ptch Protein als auch durch die Reduktion von wt Ptch aktiviert wird. Aufgrund der Ergebnisse wurde ein Modell zur Entstehung von Ptchassoziierten RMS vorgeschlagen, in dem die Tumorentstehung durch mutationsbedingte Inaktivierung eines Ptch Allels und transkriptionelles Abschalten des anderen Allels induziert wird (Uhmann A et al., 2005).

Um die Entstehung von Ptch-assoziierten Tumoren im Detail untersuchen zu können, wurde eine mutante Mauslinie charakterisiert, die die konditionelle, biallelische Deletion von Ptch im adulten Organismus ermöglicht. Unter Verwendung einer induzierbaren Cre-Rekombinase wurde Ptch systemisch in adulten Mäusen inaktiviert. Innerhalb kürzester Zeit führte dies zu hyperproliferativen Veränderungen der Haut, des Gastrointestinaltrakts und des Mesenteriums. Des Weiteren wurde durch die Ptch Deletion ein schwerer Defekt der T und B Zellentwicklung im Thymus und im Knochenmark ausgelöst. Der Defekt resultiert in einem Verlust von unreifen, 
peripheren B Zellen und einem kompletten Verlust der T Zellen im Thymus (Uhmann A et al., 2006 eingereicht).

Zusätzlich wurde nach lokaler Induktion der Cre-Rekombinase im Muskel der Tiere nach 90 Tagen die Entstehung von Basaliomen, nicht aber die von RMS oder anderen Defekten induziert.

Weiterhin wurden im Rahmen dieser Arbeit transgene Mäuse, die eine induzierbare Cre-Rekombinase unter Kontrolle des murinen Pax7 Promotors exprimieren hergestellt und charakterisiert. Mit Hilfe dieser Mauslinie sollte Ptch in den konditionellen Ptch knock-out Mäusen spezifisch in Satellitenzellen (adulte Stammzellen des Skelettmuskels) deletiert werden. Dadurch sollte der Beweis erbracht werden, dass RMS aus Satellitenzellen entstehen. Bis zum Abschluss dieser Arbeit konnte die transgen exprimierte Cre-Rekombinase in Satellitenzellen nicht aktiviert werden. Dagegen fand sich eine Aktivierung der Cre-Rekombinase in den Nerven des Skelettmuskels, in dem der Pax7 Promotor ebenfalls aktiv ist. Daher könnten die generierten transgenen Mäuse ein neues Modell für die Untersuchung der Entwicklung und regenerativer Prozesse peripherer Nerven darstellen. 


\section{Abkürzungsverzeichnis}

\begin{tabular}{|c|c|}
\hline${ }^{32} \mathrm{P}$ & Radioaktives Phosphorisotop \\
\hline 6-FAM & 6-Carboxyfluoreszein \\
\hline AP-2 & Proteinbindedomäne für das Protein activator protein 1 \\
\hline APAAP & alkalische $\underline{P h o s p h a t a s e}$ anti-alkalische $\underline{P h o s p h a t a s e}$ \\
\hline APS & Ammoniumpersulfat \\
\hline $\mathrm{Bcl} 2$ & 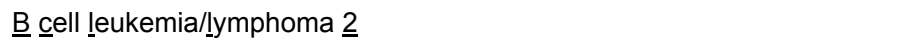 \\
\hline BFU-E & burst-forming unit erythroid \\
\hline Bil-T & Gesamt-Bilirubin \\
\hline$B M P / B m p$ & $\underline{\text { bone }}$ morphogenetic proteins \\
\hline $\mathrm{Bq}$ & Becquerel \\
\hline BSA & bovine serum albumine (Rinderserumalbumin) \\
\hline BUN & blood urea nitrogen (Blutharnstoff) \\
\hline $\mathrm{C}$ & Protein- bzw. Nukleinsäure-spezifischer Koeffizient \\
\hline$c$ & Konzentration von Proteinen bzw. Nukleinsäuren \\
\hline c & cortex (Kortex) \\
\hline CAAT-box & Proteinbindedomäne eukaryotischer Promotoren \\
\hline Cdh1 & E-çadherin \\
\hline cDNA & copyDNA \\
\hline CFU & colony-forming unit \\
\hline CFU-G & colony-forming unit granulocyte \\
\hline CFU-GEMM & 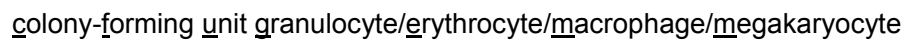 \\
\hline CFU-GM & colony-forming unit granulocyte/macrophage \\
\hline CFU-M & colony-forming unit macrophage \\
\hline Chol & $\underline{\text { Cholesterin }}$ \\
\hline $\mathrm{Ci}$ & CQubitus ịnteruptus (D. Melanogaster Gli-Homolog) \\
\hline$c-k i t$ & kit Onkogen \\
\hline CLP & common lymphiod progenitor (allgemeine lymphoide Vorläuferzelle) \\
\hline CMP & common myeloid progenitor (allgemeine myeloische Vorläuferzelle) \\
\hline CMV & 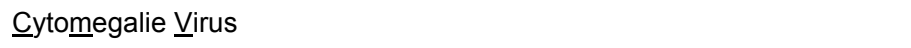 \\
\hline $\cos 2 / \cos 2$ & $\underline{\text { Costal }} \underline{2}$ \\
\hline CreTM & MerCreMer-Rekombinase \\
\hline C-terminal & carboxyteriminal \\
\hline Ct-Wert & cycle treshold (Schwellenwert) \\
\hline Су3, Су5, Су7 & Indodikarbocyanin-Derivate \\
\hline DAPI & 4'6-Diamino-2-phenylindiol \\
\hline Dhh & Desert hedgehog \\
\hline DISP/Disp & Dispatched \\
\hline DMEM & Dulbecco's Modified Éagle Medium \\
\hline DMSO & N.N.-Dimethyls $\underline{\text { slfoxid }}$ \\
\hline DN & double negative (Doppelt negative) \\
\hline dNTPs & Deoxyribonukleotidtriphosphate \\
\hline $\mathrm{DP}$ & double positive (doppelt positive) \\
\hline$d p c$ & days post coitum (Tage nach der Kopulation) \\
\hline
\end{tabular}




\begin{tabular}{|c|c|}
\hline Dpp & Decapentaplegic \\
\hline DTT & Dithiothreitol \\
\hline E & Extinktion \\
\hline$E B F$ & early $\underline{B}$ cell factor 1 \\
\hline E-box & Typische Proteinbindedomäne für myogene Helix-Loop-Helix Proteine \\
\hline EDTA & Éthylen-diamin-tetraa cetat \\
\hline Egr-1 & early growth response 1 \\
\hline EPO & Erythropoietin \\
\hline ERT2 & ROSA26CreERT2 \\
\hline ETP & early lymphiod progenitor (frühe T Zellvorläuferzelle) \\
\hline$f$ & Verdünnungsfaktor \\
\hline FACS & fluorescent-ạctivated cell sorting (durchflusszytometrische Analyse) \\
\hline FCS & fetal calf serum (fötales Kälberserum) \\
\hline FITC & Fluoresceinisothiocyanat \\
\hline FKHR & fork head box 01 \\
\hline FLPase & DNA-Rekombinationsenzym (bindet an flt DNA-Konsensussequenzen) \\
\hline flt & $\underline{\text { flt }}$ Sequenz (DNA-Konsensussequenz zur Bindung der FLPase) \\
\hline Flt3 & FMS-like tyrosine kinase 3 \\
\hline $\mathrm{Fu} / \mathrm{FU}$ & fused \\
\hline g & grandulärer, musköser Magen \\
\hline G418 & Geneticinsulfat \\
\hline Gadd $45 \alpha$ & growth arrest and DNA-damage-inducible $\underline{45}$ alpha \\
\hline Gapd & Glycerinaldehyd-3-phosphatase-dehydrogenase \\
\hline Gh & Großhirn \\
\hline Gli-BS & Gli-binding site (Gli-Proteinbindungsdomäne) \\
\hline Glu & Glukose \\
\hline GMP & granulocyte/macrophage progenitor (Granulozyt/Makrophage Vorläuferzelle) \\
\hline GSK-3 & glykogen sythetase kinase $\underline{3}$ \\
\hline $\mathrm{Ha}$ & Haut \\
\hline $\mathrm{He}$ & $\underline{\text { Herz }}$ \\
\hline$H h$ & $\underline{H}$ edgehog \\
\hline HMGCR & 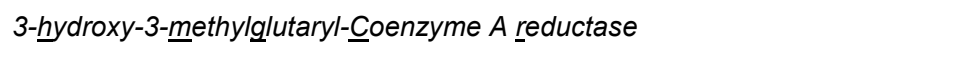 \\
\hline HRP & horseradish peroxidase (Meerrettich Peroxidase) \\
\hline HS & horse serum (Pferdeserum) \\
\hline HSC & hematopoietic stem cell (hämatopoetische Stammzelle) \\
\hline IF & Immunfluoreszenz \\
\hline $\operatorname{lgf2}$ & insulin-like growth factor $\underline{2}$ \\
\hline $\mathrm{IHC}$ & Immunhistochemie \\
\hline Ihh & Indian hedge $\underline{h} \circ g$ \\
\hline Ikaros (Zfpn1a1) & $\underline{\text { zinc }}$ finger protein, subfamily $\underline{1 A}, \underline{1}$ \\
\hline IL-3 & 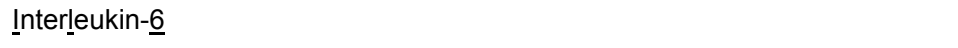 \\
\hline IL-6 & Interleukin- $\underline{3}$ \\
\hline IL-7Ra & 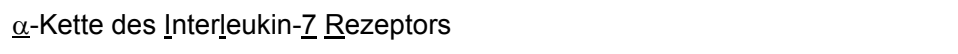 \\
\hline $\mathrm{Kh}$ & Kleinhirn \\
\hline LB & Luria -Bertani \\
\hline Le & Leber \\
\hline
\end{tabular}




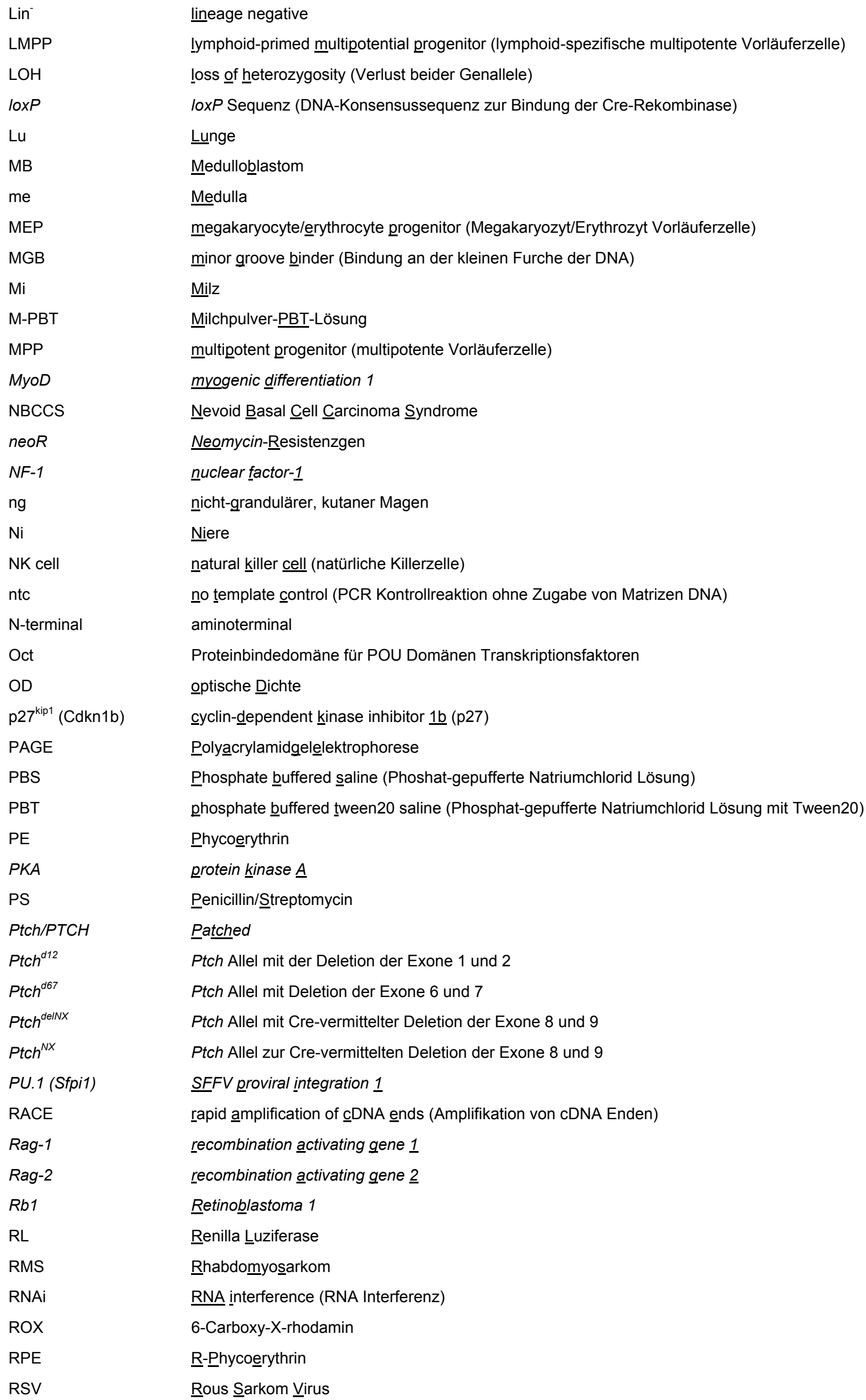




\begin{tabular}{|c|c|}
\hline Sca-1 (Ly6a) & Iymphocyte antigen $\underline{6}$ complex, locus $\underline{A}$ \\
\hline SCAP & $\underline{S} R E B P \underline{c}$ leavage activating protein \\
\hline SCF & stem cell factor \\
\hline SCID & 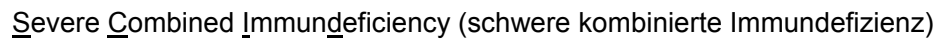 \\
\hline SDS & Natriumdodecylsulfat \\
\hline SGPT & Serum-Glutamat-Pyruvat-Transaminase \\
\hline $\mathrm{Shh} / \mathrm{SHH}$ & Sonic hedgehog \\
\hline siRNA & short interfering RNA \\
\hline SM & Skkelettmuskel \\
\hline Smo/SMO & Smoothened \\
\hline SP & single positive (einfach positive) \\
\hline SSC & standard saline citrate (Standard Natriumcitrat Lösung) \\
\hline SSC/FSC & 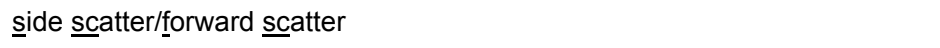 \\
\hline Sufu/SUFU & $\underline{\text { suppressor of fused }}$ \\
\hline SV40 & 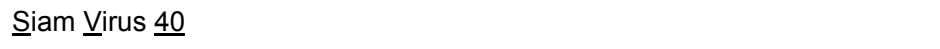 \\
\hline TATA & Proteinbindedomäne für TATA-binding Protein \\
\hline TBE & Iris-B̈orsäure-EEDTA Lösung \\
\hline TBS & tris-buffered saline (Tris-gepufferte Natriumchlorid Lösung) \\
\hline$T C R ß$ & $\underline{I} \underline{\text { cell }}$ receptor $\underline{\beta}$ \\
\hline TEMED & N,N,N',N'Tetramethylethylendiamin \\
\hline TFIID & Proteinbindedomäne neben TATA für den Iranskriptionsfaktor $\underline{\text { IID }}$ \\
\hline TG & Triglyceride \\
\hline Th & $\underline{\text { Thymus }}$ \\
\hline TK & Thymidin Kinase \\
\hline Tprot & Gesamt-Protein \\
\hline $\operatorname{tPtch}^{--}$ & Tamoxifen-induzierte $\operatorname{Ptch}^{\text {delNX}}$ Mutation \\
\hline TRC8 & translocation in renal cell carcinoma 8 \\
\hline $\operatorname{Trp53}(p 53)$ & transforming-related protein $\underline{53}$ \\
\hline$U$ & unit (Enzymaktivitätseinheit) \\
\hline UV-Licht & Ulltraviolettes Licht \\
\hline $\mathrm{v} / \mathrm{v}$ & volume/volume (Volumen/Volumen) \\
\hline $\mathrm{VIC} \circledast$ & Fluorochrom \\
\hline Vol & $\underline{\text { Volumen }}$ \\
\hline$w / v$ & weight/volume (Gewicht/Volumen) \\
\hline WB & $\underline{\text { Western } \text { Blot }}$ \\
\hline$W g / W n t / W N T$ & Wingless \\
\hline wt & Wildtyp \\
\hline xg & fache Erdbeschleunigung \\
\hline
\end{tabular}




\section{Literaturverzeichnis}

Adolphe C, Hetherington R, Ellis T und Wainwright B, 2006. 'Patched1 functions as a gatekeeper by promoting cell cycle progression.' Cancer Res 66(4): 2081-8.

Akashi K, Traver D, Miyamoto T und Weissman IL, 2000. 'A clonogenic common myeloid progenitor that gives rise to all myeloid lineages.' Nature 404(6774): 193-7.

Andaloussi AE, Graves S, Meng F, Mandal M, Mashayekhi M und Aifantis I, 2006. 'Hedgehog signaling controls thymocyte progenitor homeostasis and differentiation in the thymus.' Nat Immunol.

Ardavin C, Wu L, Li CL und Shortman K, 1993. 'Thymic dendritic cells and T cells develop simultaneously in the thymus from a common precursor population.' Nature 362(6422): 761-3.

Aszterbaum M, Beech J und Epstein EH, Jr., 1999. 'Ultraviolet radiation mutagenesis of hedgehog pathway genes in basal cell carcinomas.' J Investig Dermatol Symp Proc 4(1): 41-5.

Aza-Blanc P, Lin HY, Ruiz i Altaba A und Kornberg TB, 2000. 'Expression of the vertebrate Gli proteins in Drosophila reveals a distribution of activator and repressor activities.' Development 127(19): 4293-301.

Bai CB, Auerbach W, Lee JS, Stephen D und Joyner AL, 2002. 'Gli2, but not Gli1, is required for initial Shh signaling and ectopic activation of the Shh pathway.' Development 129(20): 4753-61.

Bai CB, Stephen D und Joyner AL, 2004. 'All mouse ventral spinal cord patterning by hedgehog is Gli dependent and involves an activator function of Gli3.' Dev Cell 6(1): 103-15.

Barnes EA, Kong M, Ollendorff V und Donoghue DJ, 2001. 'Patched1 interacts with cyclin B1 to regulate cell cycle progression.' Embo J 20(9): 2214-23.

Barr FG, 1999. 'The role of chimeric paired box transcription factors in the pathogenesis of pediatric rhabdomysarcoma.' Cancer Res 59(7 Suppl): 1711s-1715s.

Barr FG, 2001. 'Gene fusions involving PAX and FOX family members in alveolar rhabdomyosarcoma.' Oncogene 20(40): 5736-46.

Becker KF, Atkinson MJ, Reich U, Becker I, Nekarda H, Siewert JR und Hofler H, 1994. 'E-cadherin gene mutations provide clues to diffuse type gastric carcinomas.' Cancer Res 54(14): 3845-52.

Beer C, Buhr P, Hahn H, Laubner D und Wirth M, 2003. 'Gene expression analysis of murine cells producing amphotropic mouse leukaemia virus at a cultivation temperature of 32 and 37 degrees C.' J Gen Virol 84(Pt 7): 1677-86. 
Berman DM, Karhadkar SS, Hallahan AR, Pritchard JI, Eberhart CG, Watkins DN, Chen JK, Cooper MK, Taipale J, Olson JM und Beachy PA, 2002. 'Medulloblastoma growth inhibition by hedgehog pathway blockade.' Science 297(5586): 1559-61.

Berman DM, Karhadkar SS, Maitra A, Montes De Oca R, Gerstenblith MR, Briggs K, Parker AR, Shimada Y, Eshleman JR, Watkins DN und Beachy PA, 2003. 'Widespread requirement for Hedgehog ligand stimulation in growth of digestive tract tumours.' Nature 425(6960): 846-51.

Bhandoola A und Sambandam A, 2006a. 'From stem cell to $T$ cell: one route or many?' Nat Rev Immunol 6(2): 117-26.

Bhandoola A und Sambandam A, 2006b. 'From stem cell to $T$ cell: one route or many?' Nature Rev. Immunol. 6: 117-26.

Bhardwaj G, Murdoch B, Wu D, Baker DP, Williams KP, Chadwick K, Ling LE, Karanu FN und Bhatia M, 2001. 'Sonic hedgehog induces the proliferation of primitive human hematopoietic cells via BMP regulation.' Nat Immunol 2(2): 172-80.

Bishop JM, 1983. 'Cellular oncogenes and retroviruses.' Annu Rev Biochem 52: 30154.

Bridge JA, Liu J, Weibolt V, Baker KS, Perry D, Kruger R, Qualman S, Barr F, Sorensen P, Triche T und Suijkerbuijk R, 2000. 'Novel genomic imbalances in embryonal rhabdomyosarcoma revealed by comparative genomic hybridization and fluorescence in situ hybridization: an intergroup rhabdomyosarcoma study.' Genes Chromosomes Cancer 27(4): 337-44.

Briscoe J, Chen Y, Jessell TM und Struhl G, 2001. 'A hedgehog-insensitive form of patched provides evidence for direct long-range morphogen activity of sonic hedgehog in the neural tube.' Mol Cell 7(6): 1279-91.

Buckley RH, 2004. 'The multiple causes of human SCID.' J Clin Invest 114(10): 140911.

Burke R, Nellen D, Bellotto M, Hafen E, Senti KA, Dickson BJ und Basler K, 1999. 'Dispatched, a novel sterol-sensing domain protein dedicated to the release of cholesterol-modified hedgehog from signaling cells.' Cell 99(7): 803-15.

Busslinger M, 2004. 'Transcriptional control of early B cell development.' Annu Rev Immunol 22: 55-79.

Calzada-Wack J, Kappler R, Schnitzbauer U, Richter T, Nathrath M, Rosemann M, Wagner SN, Hein R und Hahn H, 2002. 'Unbalanced overexpression of the mutant allele in murine Patched mutants.' Carcinogenesis 23(5): 727-734.

Chamoun Z, Mann RK, Nellen D, von Kessler DP, Bellotto M, Beachy PA und Basler $\mathrm{K}, 2001$. 'Skinny hedgehog, an acyltransferase required for palmitoylation and activity of the hedgehog signal.' Science 293(5537): 2080-4. 
Chen $Y$ und Struhl G, 1996. 'Dual roles for patched in sequestering and transducing Hedgehog.' Cell 87(3): 553-63.

Cohen MM, Jr., 2003. 'The hedgehog signaling network.' Am J Med Genet A 123(1): 528.

Cooper GM, 1987. 'Cellular oncogenes and cancer.' Clin Physiol Biochem 5(3-4): 1229.

Cossu G und Borello U, 1999. 'Wnt signaling and the activation of myogenesis in mammals.' Embo J 18(24): 6867-72.

Crowson AN, 2006. 'Basal cell carcinoma: biology, morphology and clinical implications.' Mod Pathol 19 Suppl 2: S127-47.

Dagher R und Helman L, 1999. 'Rhabdomyosarcoma: an overview.' Oncologist 4(1): 34-44.

Dahmane N, Lee J, Robins P, Heller P und Ruiz i Altaba A, 1997. 'Activation of the transcription factor Gli1 and the Sonic hedgehog signalling pathway in skin tumours.' Nature 389(6653): 876-81.

Dai P, Akimaru H, Tanaka Y, Maekawa T, Nakafuku M und Ishii S, 1999. 'Sonic Hedgehog-induced activation of the Gli1 promoter is mediated by GLI3.' J Biol Chem 274(12): 8143-52.

Davis RJ und Barr FG, 1997. 'Fusion genes resulting from alternative chromosomal translocations are overexpressed by gene-specific mechanisms in alveolar rhabdomyosarcoma.' Proc Natl Acad Sci U S A 94(15): 8047-51.

Daya-Grosjean L und Couve-Privat S, 2005. 'Sonic hedgehog signaling in basal cell carcinomas.' Cancer Lett 225(2): 181-92.

DeKoter RP, Lee HJ und Singh H, 2002. 'PU.1 regulates expression of the interleukin-7 receptor in lymphoid progenitors.' Immunity 16(2): 297-309.

Denef N, Neubuser D, Perez L und Cohen SM, 2000. 'Hedgehog induces opposite changes in turnover and subcellular localization of patched and smoothened.' Cell 102(4): 521-31.

Detmer K, Walker AN, Jenkins TM, Steele TA und Dannawi H, 2000. 'Erythroid differentiation in vitro is blocked by cyclopamine, an inhibitor of hedgehog signaling.' Blood Cells Mol Dis 26(4): 360-72.

Duman-Scheel M, Weng L, Xin S und Du W, 2002. 'Hedgehog regulates cell growth and proliferation by inducing Cyclin D and Cyclin E.' Nature 417(6886): 299-304.

Ebers G, 1875. 'Papyros Ebers. Das Hermetische Buch über die Arzneimittel der alten Ägypter in hieratischer Schrift.' Leipzig (2 Bände). 
Elbashir SM, Harborth J, Weber K und Tuschl T, 2002. 'Analysis of gene function in somatic mammalian cells using small interfering RNAs.' Methods 26(2): 199-213.

Ellermann V und Bang O, 1908. 'Experimentelle Leukemie bei Hühnern.' Zenralbl. Bakteriol. Parasitenkd. Infectionskr. Hyg. Abt. Orig. 46: 595-609.

Fan H und Khavari PA, 1999. 'Sonic hedgehog opposes epithelial cell cycle arrest.' J Cell Biol 147(1): 71-6.

Fletcher CDM, 1995. 'Diagnostic Histopathology of Tumors.' Churchill Livingstone Vol2.

Friedrich G und Soriano P, 1991. 'Promoter traps in embryonic stem cells: a genetic screen to identify and mutate developmental genes in mice.' Genes Dev 5(9): 151323.

Fukunaga K, Ishigami T und Kawano T, 2005. 'Transcriptional regulation of neuronal genes and its effect on neural functions: expression and function of forkhead transcription factors in neurons.' J Pharmacol Sci 98(3): 205-11.

Gailani MR, Leffell DJ, Ziegler A, Gross EG, Brash DE und Bale AE, 1996. 'Relationship between sunlight exposure and a key genetic alteration in basal cell carcinoma [see comments].' J Natl Cancer Inst 88(6): 349-54.

Galili N, Davis RJ, Fredericks WJ, Mukhopadhyay S, Rauscher FJ, 3rd, Emanuel BS, Rovera G und Barr FG, 1993. 'Fusion of a fork head domain gene to PAX3 in the solid tumour alveolar rhabdomyosarcoma.' Nat Genet 5(3): 230-5.

Ghalioungui P, 1987. 'The Ebers Papyrus.' Kairo.

Godfrey DI, Kennedy J, Suda T und Zlotnik A, 1993. 'A developmental pathway involving four phenotypically and functionally distinct subsets of CD3-CD4-CD8triple-negative adult mouse thymocytes defined by CD44 and CD25 expression.' J Immunol 150(10): 4244-52.

Goodrich LV, Milenkovic L, Higgins KM und Scott MP, 1997. 'Altered neural cell fates and medulloblastoma in mouse patched mutants.' Science 277(5329): 1109-13.

Goodrich LV und Scott MP, 1998. 'Hedgehog and patched in neural development and disease.' Neuron 21(6): 1243-57.

Gorlin RJ, 1987. 'Nevoid basal-cell carcinoma syndrome.' Medicine (Baltimore) 66(2): 98-113.

Gorlin RJ und Goltz RW, 1960. 'Multiple nevoid basal-cell epithelioma, jaw cysts and bifid rib. A syndrome.' New Eng J Med 262: 908-12.

Goulding MD, Chalepakis G, Deutsch U, Erselius JR und Gruss P, 1991. 'Pax-3, a novel murine DNA binding protein expressed during early neurogenesis.' Embo J 10(5): 1135-47. 
Gu H, Zou YR und Rajewsky K, 1993. 'Independent control of immunoglobulin switch recombination at individual switch regions evidenced through Cre-loxP-mediated gene targeting.' Cell 73(6): 1155-64.

Gutierrez-Frias C, Sacedon R, Hernandez-Lopez C, Cejalvo T, Crompton T, Zapata AG, Varas A und Vicente A, 2004. 'Sonic hedgehog regulates early human thymocyte differentiation by counteracting the IL-7-induced development of CD34+ precursor cells.' J Immunol 173(8): 5046-53.

Hahn H, Nitzki F, Schorban T, Hemmerlein B, Threadgill D und Rosemann M, 2004. 'Genetic mapping of a Ptch1-associated rhabdomyosarcoma susceptibility locus on mouse chromosome 2.' Genomics 84(5): 853-8.

Hahn H, Wicking C, Zaphiropoulous PG, Gailani MR, Shanley S, Chidambaram A, Vorechovsky I, Holmberg E, Unden AB, Gillies S, Negus K, Smyth I, Pressman C, Leffell DJ, Gerrard B, Goldstein AM, Dean M, Toftgard R, Chenevix-Trench G, Wainwright $B$ und Bale AE, 1996. 'Mutations of the human homolog of Drosophila patched in the nevoid basal cell carcinoma syndrome.' Cell 85(6): 841-51.

Hahn H, Wojnowski L, Specht K, Kappler R, Calzada-Wack J, Potter D, Zimmer A, Muller U, Samson E und Quintanilla-Martinez L, 2000. 'Patched target Igf2 is indispensable for the formation of medulloblastoma and rhabdomyosarcoma.' J Biol Chem 275(37): 28341-4.

Hahn H, Wojnowski L, Zimmer AM, Hall J, Miller G und Zimmer A, 1998. 'Rhabdomyosarcomas and radiation hypersensitivity in a mouse model of Gorlin syndrome.' Nature Med 4: 619-622.

Hamed S, LaRue $\mathrm{H}$, Hovington $\mathrm{H}$, Girard J, Jeannotte L, Latulippe $\mathrm{E}$ und Fradet $\mathrm{Y}$, 2004. 'Accelerated induction of bladder cancer in patched heterozygous mutant mice.' Cancer Res 64(6): 1938-42.

Hanahan D und Weinberg RA, 2000. 'The hallmarks of cancer.' Cell 100(1): 57-70.

Herman JG und Baylin SB, 2003. 'Gene silencing in cancer in association with promoter hypermethylation.' N Engl J Med 349(21): 2042-54.

Hime GR, Lada H, Fietz MJ, Gillies S, Passmore A, Wicking C und Wainwright BJ, 2004. 'Functional analysis in Drosophila indicates that the NBCCS/PTCH1 mutation G509V results in activation of smoothened through a dominant-negative mechanism.' Dev Dyn 229(4): 780-90.

Hooper JE und Scott MP, 1989. 'The Drosophila patched gene encodes a putative membrane protein required for segmental patterning.' Cell 59(4): 751-65.

Huesmann M, Scott B, Kisielow P und von Boehmer H, 1991. 'Kinetics and efficacy of positive selection in the thymus of normal and $T$ cell receptor transgenic mice.' Cell 66(3): 533-40.

Imai T, Jiang M, Chambon $\mathrm{P}$ und Metzger D, 2001. 'Impaired adipogenesis and lipolysis in the mouse upon selective ablation of the retinoid $X$ receptor alpha 
mediated by a tamoxifen-inducible chimeric Cre recombinase (Cre-ERT2) in adipocytes.' Proc Natl Acad Sci U S A 98(1): 224-8.

Incardona JP, Lee JH, Robertson CP, Enga K, Kapur RP und Roelink H, 2000. 'Receptor-mediated endocytosis of soluble and membrane-tethered Sonic hedgehog by Patched-1.' Proc Natl Acad Sci U S A 97(22): 12044-9.

Ingham PW, 2000. 'How cholesterol modulates the signal.' Curr Biol 10(5): R180-3.

Ingham PW und McMahon AP, 2001. 'Hedgehog signaling in animal development: paradigms and principles.' Genes Dev 15(23): 3059-87.

Issa JP, Garcia-Manero G, Giles FJ, Mannari R, Thomas D, Faderl S, Bayar E, Lyons $\mathrm{J}$, Rosenfeld CS, Cortes J und Kantarjian HM, 2004. 'Phase 1 study of low-dose prolonged exposure schedules of the hypomethylating agent 5-aza-2'-deoxycytidine (decitabine) in hematopoietic malignancies.' Blood 103(5): 1635-40.

Jainchill JL, Aaronson SA und Todaro GJ, 1969. 'Murine sarcoma and leukemia viruses: assay using clonal lines of contact-inhibited mouse cells.' J Virol 4(5): 549-53.

Johnson RL, Milenkovic L und Scott MP, 2000. 'In vivo functions of the patched protein: requirement of the $C$ terminus for target gene inactivation but not Hedgehog sequestration.' Mol Cell 6(2): 467-78.

Johnson RL, Rothman AL, Xie J, Goodrich LV, Bare JW, Bonifas JM, Quinn AG, Myers RM, Cox DR, Epstein EH, Jr. und Scott MP, 1996. 'Human homolog of patched, a candidate gene for the basal cell nevus syndrome.' Science 272(5268): 1668-71.

Jones PA und Baylin SB, 2002. 'The fundamental role of epigenetic events in cancer.' Nat Rev Genet 3(6): 415-28.

Jostes B, Walther C und Gruss P, 1990. 'The murine paired box gene, Pax7, is expressed specifically during the development of the nervous and muscular system.' Mech Dev 33(1): 27-37.

Kappler R, Bauer R, Calzada-Wack J, Rosemann M, Hemmerlein B und Hahn H, 2004. 'Profiling the molecular difference between Patched- and p53-dependent rhabdomyosarcoma.' Oncogene 23(54): 8785-95.

Kappler R, Calzada-Wack J, Schnitzbauer U, Koleva M, Herwig A, Piontek G, Graedler F, Adamski J, Heinzmann U, Schlegel J, Hemmerlein B, QuintanillaMartinez L und Hahn H, 2003. 'Molecular characterization of Patched-associated rhabdomyosarcoma.' J Pathol 200(3): 348-56.

Katayama N, Shih JP, Nishikawa S, Kina T, Clark SC und Ogawa M, 1993. 'Stagespecific expression of c-kit protein by murine hematopoietic progenitors.' Blood 82(8): 2353-60. 
Kawai S und Sugiura T, 2001. 'Characterization of human bone morphogenetic protein (BMP)-4 and -7 gene promoters: activation of BMP promoters by Gli, a sonic hedgehog mediator.' Bone 29(1): 54-61.

Keller C, Hansen MS, Coffin CM und Capecchi MR, 2004. 'Pax3:Fkhr interferes with embryonic Pax3 and Pax7 function: implications for alveolar rhabdomyosarcoma cell of origin.' Genes Dev 18(21): 2608-13.

Kinzler KW, Bigner SH, Bigner DD, Trent JM, Law ML, O'Brien SJ, Wong AJ und Vogelstein B, 1987. 'Identification of an amplified, highly expressed gene in a human glioma.' Science 236(4797): 70-3.

Kinzler KW, Ruppert JM, Bigner SH und Vogelstein B, 1988. 'The GLI gene is a member of the Kruppel family of zinc finger proteins.' Nature 332(6162): 371-4.

Kinzler KW und Vogelstein B, 1990. 'The GLI gene encodes a nuclear protein which binds specific sequences in the human genome.' Mol Cell Biol 10(2): 634-42.

Knudson AG, Jr., 1971. 'Mutation and cancer: statistical study of retinoblastoma.' Proc Natl Acad Sci U S A 68(4): 820-3.

Kogerman P, Krause D, Rahnama F, Kogerman L, Unden AB, Zaphiropoulos PG und Toftgard R, 2002. 'Alternative first exons of PTCH1 are differentially regulated in vivo and may confer different functions to the PTCH1 protein.' Oncogene 21(39): 6007-16.

Kondo M, Weissman IL und Akashi K, 1997. 'Identification of clonogenic common lymphoid progenitors in mouse bone marrow.' Cell 91(5): 661-72.

Kuang S, Charge SB, Seale P, Huh M und Rudnicki MA, 2006. 'Distinct roles for Pax7 and Pax3 in adult regenerative myogenesis.' J Cell Biol 172(1): 103-13.

Kubo M, Nakamura M, Tasaki A, Yamanaka N, Nakashima H, Nomura M, Kuroki S und Katano M, 2004. 'Hedgehog signaling pathway is a new therapeutic target for patients with breast cancer.' Cancer Res 64(17): 6071-4.

Kuhl M, Sheldahl LC, Park M, Miller JR und Moon RT, 2000. 'The Wnt/Ca2+ pathway: a new vertebrate Wnt signaling pathway takes shape.' Trends Genet 16(7): 279-83.

Kuwabara PE und Labouesse M, 2002. 'The sterol-sensing domain: multiple families, a unique role?' Trends Genet 18(4): 193-201.

Laiosa CV, Stadtfeld M und Graf T, 2006. 'Determinants of Lymphoid-Myeloid Lineage Diversification.' Annu Rev Immunol.

Lakso M, Pichel JG, Gorman JR, Sauer B, Okamoto Y, Lee E, Alt FW und Westphal $\mathrm{H}$, 1996. 'Efficient in vivo manipulation of mouse genomic sequences at the zygote stage.' Proc Natl Acad Sci U S A 93(12): 5860-5.

Lam CW, Xie J, To KF, Ng HK, Lee KC, Yuen NW, Lim PL, Chan LY, Tong SF und McCormick F, 1999. 'A frequent activated smoothened mutation in sporadic basal cell carcinomas.' Oncogene 18(3): 833-6. 
Lang D, Brown CB, Milewski R, Jiang YQ, Lu MM und Epstein JA, 2003. 'Distinct enhancers regulate neural expression of Pax7.' Genomics 82(5): 553-60.

Lee HC, Shibata H, Ogawa S, Maki K und Ikuta K, 2005. 'Transcriptional regulation of the mouse IL-7 receptor alpha promoter by glucocorticoid receptor.' J Immunol 174(12): 7800-6.

Lewis PM, Dunn MP, McMahon JA, Logan M, Martin JF, St-Jacques B und McMahon AP, 2001. 'Cholesterol modification of sonic hedgehog is required for long-range signaling activity and effective modulation of signaling by Ptc1.' Cell 105(5): 599-612.

Loder F, Mutschler B, Ray RJ, Paige CJ, Sideras P, Torres R, Lamers MC und Carsetti $\mathrm{R}, 1999$. ' $B$ cell development in the spleen takes place in discrete steps and is determined by the quality of $B$ cell receptor-derived signals.' J Exp Med 190(1): 7589.

Mancuso M, Pazzaglia S, Tanori M, Hahn H, Merola P, Rebessi S, Atkinson MJ, Di Majo V, Covelli V und Saran A, 2004. 'Basal cell carcinoma and its development: insights from radiation-induced tumors in Ptch1-deficient mice.' Cancer Res 64(3): 934-41.

Mansour SL, Thomas KR und Capecchi MR, 1988. 'Disruption of the proto-oncogene int-2 in mouse embryo-derived stem cells: a general strategy for targeting mutations to non-selectable genes.' Nature 336(6197): 348-52.

Mansouri A, Stoykova A und Gruss P, 1994. 'Pax genes in development.' J Cell Sci Suppl 18: 35-42.

Mansouri A, Stoykova A, Torres M und Gruss P, 1996. 'Dysgenesis of cephalic neural crest derivatives in Pax7-/- mutant mice.' Development 122(3): 831-8.

Marigo V, Davey RA, Zuo Y, Cunningham JM und Tabin CJ, 1996a. 'Biochemical evidence that patched is the Hedgehog receptor [see comments].' Nature 384(6605): $176-9$.

Marigo V, Johnson RL, Vortkamp A und Tabin CJ, 1996b. 'Sonic hedgehog differentially regulates expression of GLI and GLI3 during limb development.' Dev Biol 180(1): 273-83.

Marigo V, Scott MP, Johnson RL, Goodrich LV und Tabin CJ, 1996c. 'Conservation in hedgehog signaling: induction of a chicken patched homolog by Sonic hedgehog in the developing limb.' Development 122(4): 1225-33.

Mehlen P und Bredesen DE, 2004. 'The dependence receptor hypothesis.' Apoptosis 9(1): 37-49.

Merlino G und Helman LJ, 1999. 'Rhabdomyosarcoma--working out the pathways.' Oncogene 18(38): 5340-8. 
Metcalf D, 1999. 'Stem cells, pre-progenitor cells and lineage-committed cells: are our dogmas correct?' Ann N Y Acad Sci 872: 289-303; discussion 303-4.

Mill P, Mo R, Fu H, Grachtchouk M, Kim PC, Dlugosz AA und Hui CC, 2003. 'Sonic hedgehog-dependent activation of Gli2 is essential for embryonic hair follicle development.' Genes Dev 17(2): 282-94.

Miller JR, Hocking AM, Brown JD und Moon RT, 1999. 'Mechanism and function of signal transduction by the Wnt/beta-catenin and Wnt/Ca2+ pathways.' Oncogene 18(55): 7860-72.

Monnier V, Dussillol F, Alves G, Lamour-Isnard C und Plessis A, 1998. 'Suppressor of fused links fused and Cubitus interruptus on the hedgehog signalling pathway.' Curr Biol 8(10): 583-6.

Moon RT, Brown JD und Torres M, 1997. 'WNTs modulate cell fate and behavior during vertebrate development.' Trends Genet 13(4): 157-62.

Mullor JL, Sanchez P und Altaba AR, 2002. 'Pathways and consequences: Hedgehog signaling in human disease.' Trends Cell Biol 12(12): 562-9.

Murmann OV, Niggli F und Schafer BW, 2000. 'Cloning and characterization of the human PAX7 promoter.' Biol Chem 381(4): 331-5.

Nagafuchi A, Shirayoshi Y, Okazaki K, Yasuda K und Takeichi M, 1987. 'Transformation of cell adhesion properties by exogenously introduced E-cadherin cDNA.' Nature 329(6137): 341-3.

Nagao K, Togawa N, Fujii K, Uchikawa H, Kohno Y, Yamada M und Miyashita T, 2005a. 'Detecting tissue-specific alternative splicing and disease-associated aberrant splicing of the PTCH gene with exon junction microarrays.' Hum Mol Genet 14(22): 3379-88.

Nagao K, Toyoda M, Takeuchi-Inoue K, Fujii K, Yamada M und Miyashita T, 2005b. 'Identification and characterization of multiple isoforms of a murine and human tumor suppressor, patched, having distinct first exons.' Genomics 85(4): 462-71.

Nagasawa T, 2006. 'Microenvironmental niches in the bone marrow required fro $B$ cell development.' Nature Rev. Immunol. 6: 107-16.

Nusslein-Volhard C und Wieschaus E, 1980. 'Mutations affecting segment number and polarity in Drosophila.' Nature 287(5785): 795-801.

Nybakken K und Perrimon N, 2002. 'Hedgehog signal transduction: recent findings.' Curr Opin Genet Dev 12(5): 503-11.

Oda T, Kanai Y, Oyama T, Yoshiura K, Shimoyama Y, Birchmeier W, Sugimura T und Hirohashi S, 1994. 'E-cadherin gene mutations in human gastric carcinoma cell lines.' Proc Natl Acad Sci U S A 91(5): 1858-62. 
Ohto H, Kamada S, Tago K, Tominaga SI, Ozaki H, Sato S und Kawakami K, 1999. 'Cooperation of six and eya in activation of their target genes through nuclear translocation of Eya.' Mol Cell Biol 19(10): 6815-24.

Okada S, Nakauchi H, Nagayoshi K, Nishikawa S, Miura Y und Suda T, 1992. 'In vivo and in vitro stem cell function of c-kit- and Sca-1-positive murine hematopoietic cells.' Blood 80(12): 3044-50.

Orlic D, Girard LJ, Lee D, Anderson SM, Puck JM und Bodine DM, 1997. 'Interleukin$7 R$ alpha mRNA expression increases as stem cells differentiate into $T$ and $B$ lymphocyte progenitors.' Exp Hematol 25(3): 217-22.

Oro AE, Higgins KM, Hu Z, Bonifas JM, Epstein EH, Jr. und Scott MP, 1997. 'Basal cell carcinomas in mice overexpressing sonic hedgehog.' Science 276(5313): 817-21.

Oustanina S, Hause G und Braun T, 2004. 'Pax7 directs postnatal renewal and propagation of myogenic satellite cells but not their specification.' Embo J 23(16): 3430-9.

Outram SV, Varas A, Pepicelli CV und Crompton T, 2000. 'Hedgehog signaling regulates differentiation from double-negative to double-positive thymocyte.' Immunity 13(2): 187-97.

Palmer E, 2003. 'Negative selection--clearing out the bad apples from the T-cell repertoire.' Nat Rev Immunol 3(5): 383-91.

Palmiter RD und Brinster RL, 1986. 'Germ-line transformation of mice.' Annu Rev Genet 20: 465-99.

Pepinsky RB, Zeng C, Wen D, Rayhorn P, Baker DP, Williams KP, Bixler SA, Ambrose CM, Garber EA, Miatkowski K, Taylor FR, Wang EA und Galdes A, 1998. 'Identification of a palmitic acid-modified form of human Sonic hedgehog.' J Biol Chem 273(22): 14037-45.

Peschon JJ, Morrissey PJ, Grabstein KH, Ramsdell FJ, Maraskovsky E, Gliniak BC, Park LS, Ziegler SF, Williams DE, Ware CB, Meyer JD und Davison BL, 1994. 'Early lymphocyte expansion is severely impaired in interleukin 7 receptor-deficient mice.' J Exp Med 180(5): 1955-60.

Pietsch T, Waha A, Koch A, Kraus J, Albrecht S, Tonn J, Sorensen N, Berthold F, Henk B, Schmandt N, Wolf HK, von Deimling A, Wainwright B, Chenevix-Trench G, Wiestler OD und Wicking C, 1997. 'Medulloblastomas of the desmoplastic variant carry mutations of the human homologue of Drosophila patched.' Cancer Res 57(11): 2085-8.

Podos SD und Ferguson EL, 1999. 'Morphogen gradients: new insights from DPP.' Trends Genet 15(10): 396-402.

Porse BT, Bryder D, Theilgaard-Monch K, Hasemann MS, Anderson K, Damgaard I, Jacobsen SE und Nerlov C, 2005. 'Loss of C/EBP alpha cell cycle control increases 
myeloid progenitor proliferation and transforms the neutrophil granulocyte lineage.' $\mathrm{J}$ Exp Med 202(1): 85-96.

Porter JA, Ekker SC, Park WJ, von Kessler DP, Young KE, Chen CH, Ma Y, Woods AS, Cotter RJ, Koonin EV und Beachy PA, 1996. 'Hedgehog patterning activity: role of a lipophilic modification mediated by the carboxy-terminal autoprocessing domain.' Cell 86(1): 21-34.

Price MA, Goldberg LH und Levy ML, 1994. 'Juvenile basal cell carcinoma.' Pediatr Dermatol 11(2): 176-7.

Relaix F, Montarras D, Zaffran S, Gayraud-Morel B, Rocancourt D, Tajbakhsh S, Mansouri A, Cumano A und Buckingham M, 2006. 'Pax3 and Pax7 have distinct and overlapping functions in adult muscle progenitor cells.' J Cell Biol 172(1): 91-102.

Relaix F, Rocancourt D, Mansouri A und Buckingham M, 2005. 'A Pax3/Pax7dependent population of skeletal muscle progenitor cells.' Nature.

Robbins DJ, Nybakken KE, Kobayashi R, Sisson JC, Bishop JM und Therond PP, 1997. 'Hedgehog elicits signal transduction by means of a large complex containing the kinesin-related protein costal2.' Cell 90(2): 225-34.

Roberts WM, Douglass EC, Peiper SC, Houghton PJ und Look AT, 1989. 'Amplification of the gli gene in childhood sarcomas.' Cancer Res 49(19): 5407-13.

Rodger J, Ziman MR, Papadimitriou JM und Kay PH, 1999. 'Pax7 is expressed in the capsules surrounding adult mouse neuromuscular spindles.' Biochem Cell Biol 77(2): 153-6.

Rodriguez Cl, Buchholz F, Galloway J, Sequerra R, Kasper J, Ayala R, Stewart AF und Dymecki SM, 2000. 'High-efficiency deleter mice show that FLPe is an alternative to Cre-loxP.' Nat Genet 25(2): 139-40.

Rosenblatt JD, Lunt AI, Parry DJ und Partridge TA, 1995. 'Culturing satellite cells from living single muscle fiber explants.' In Vitro Cell Dev Biol Anim 31(10): 773-9.

Rothenberg EV und Taghon T, 2005. 'Molecular genetics of T cell development.' Annu Rev Immunol 23: 601-49.

Rous $\mathrm{P}, 1911$. 'A sarcoma of the fowl transmissible by an agent separable from tumor cells.' J. Exp. Med. 13: 397-411.

Ruiz i Altaba A, 1997. 'Catching a Gli-mpse of Hedgehog.' Cell 90(2): 193-6.

Ruiz i Altaba A, 1999. 'Gli proteins and Hedgehog signaling: development and cancer.' Trends Genet 15(10): 418-25.

Ruiz i Altaba A, Sanchez P und Dahmane N, 2002. 'Gli and hedgehog in cancer: tumours, embryos and stem cells.' Nat Rev Cancer 2(5): 361-72. 
Ruppert JM, Kinzler KW, Wong AJ, Bigner SH, Kao FT, Law ML, Seuanez HN, O'Brien SJ und Vogelstein B, 1988. 'The GLI-Kruppel family of human genes.' Mol Cell Biol 8(8): 3104-13.

Sacedon R, Diez B, Nunez V, Hernandez-Lopez C, Gutierrez-Frias C, Cejalvo T, Outram SV, Crompton T, Zapata AG, Vicente A und Varas A, 2005. 'Sonic hedgehog is produced by follicular dendritic cells and protects germinal center $B$ cells from apoptosis.' J Immunol 174(3): 1456-61.

Sasaki H, Nishizaki Y, Hui C, Nakafuku M und Kondoh H, 1999. 'Regulation of Gli2 and Gli3 activities by an amino-terminal repression domain: implication of Gli2 and Gli3 as primary mediators of Shh signaling.' Development 126(17): 3915-24.

Schnutgen F, Doerflinger N, Calleja C, Wendling O, Chambon P und Ghyselinck NB, 2003. 'A directional strategy for monitoring Cre-mediated recombination at the cellular level in the mouse.' Nat Biotechnol 21(5): 562-5.

Scotting PJ, Thompson SL, Punt JA und Walker DA, 2000. 'Paediatric brain tumours: an embryological perspective.' Childs Nerv Syst 16(5): 261-7; discussion 268.

Seale P, Sabourin LA, Girgis-Gabardo A, Mansouri A, Gruss P und Rudnicki MA, 2000. 'Pax7 is required for the specification of myogenic satellite cells.' Cell 102(6): 777-86.

Shah DK, Hager-Theodorides AL, Outram SV, Ross SE, Varas A und Crompton T, 2004. 'Reduced thymocyte development in sonic hedgehog knockout embryos.' J Immunol 172(4): 2296-306.

Sharp R, Recio JA, Jhappan C, Otsuka T, Liu S, Yu Y, Liu W, Anver M, Navid F, Helman LJ, DePinho RA und Merlino G, 2002. 'Synergism between INK4a/ARF inactivation and aberrant HGF/SF signaling in rhabdomyosarcomagenesis.' Nat Med 8(11): 1276-80.

Shimokawa T, Rahnama F und Zaphiropoulos PG, 2004. 'A novel first exon of the Patched1 gene is upregulated by Hedgehog signaling resulting in a protein with pathway inhibitory functions.' FEBS Lett 578(1-2): 157-62.

Sidransky D, 1996. 'Is human patched the gatekeeper of common skin cancers? [news; comment].' Nat Genet 14(1): 7-8.

Sinn E, Muller W, Pattengale P, Tepler I, Wallace R und Leder P, 1987. 'Coexpression of MMTV/V-Ha-ras and MMTV/c-myc genes in transgenic mice: synergistic action of oncogenes in vivo.' Cell 49(4): 465-75.

So PL, Lee K, Hebert J, Walker P, Lu Y, Hwang J, Kopelovich L, Athar M, Bickers D, Aszterbaum M und Epstein EH, Jr., 2004. 'Topical tazarotene chemoprevention reduces Basal cell carcinoma number and size in Ptch1+/- mice exposed to ultraviolet or ionizing radiation.' Cancer Res 64(13): 4385-9.

Soriano P, 1999. 'Generalized lacZ expression with the ROSA26 Cre reporter strain.' Nat Genet 21(1): 70-1. 
Srinivas S, Watanabe T, Lin CS, William CM, Tanabe $\mathrm{Y}$, Jessell TM und Costantini $\mathrm{F}$, 2001. 'Cre reporter strains produced by targeted insertion of EYFP and ECFP into the ROSA26 locus.' BMC Dev Biol 1: 4.

Stehelin D, Varmus HE, Bishop JM und Vogt PK, 1976. 'DNA related to the transforming gene(s) of avian sarcoma viruses is present in normal avian DNA.' Nature 260(5547): 170-3.

Stone DM, Hynes M, Armanini M, Swanson TA, Gu Q, Johnson RL, Scott MP, Pennica D, Goddard A, Phillips H, Noll M, Hooper JE, de Sauvage F und Rosenthal A, 1996. 'The tumour-suppressor gene patched encodes a candidate receptor for Sonic hedgehog [see comments].' Nature 384(6605): 129-34.

Stone JC, Crosby JL, Kozak CA, Schievella AR, Bernards R und Nadeau JH, 1989. 'The murine retinoblastoma homolog maps to chromosome 14 near Es-10.' Genomics $5(1): 70-5$.

Stoykova A und Gruss P, 1994. 'Roles of Pax-genes in developing and adult brain as suggested by expression patterns.' J Neurosci 14(3 Pt 2): 1395-412.

Taipale $\mathrm{J}$ und Beachy PA, 2001. 'The Hedgehog and Wnt signalling pathways in cancer.' Nature 411(6835): 349-54.

Taipale J, Chen JK, Cooper MK, Wang B, Mann RK, Milenkovic L, Scott MP und Beachy PA, 2000a. 'Effects of oncogenic mutations in Smoothened and Patched can be reversed by cyclopamine.' Nature 406(6799): 1005-9.

Taipale J, Chen JK, Cooper MK, Wang B, Mann RK, Milenkovic L, Scott MP und Beachy PA, 2000b. 'Effects of oncogenic mutations in Smoothened and Patched can be reversed by cyclopamine.' Nature 406(6799): 1005-9.

Taipale J, Cooper MK, Maiti T und Beachy PA, 2002. 'Patched acts catalytically to suppress the activity of Smoothened.' Nature 418(6900): 892-7.

Thayer SP, di Magliano MP, Heiser PW, Nielsen CM, Roberts DJ, Lauwers GY, Qi YP, Gysin S, Fernandez-del Castillo C, Yajnik V, Antoniu B, McMahon M, Warshaw AL und Hebrok M, 2003. 'Hedgehog is an early and late mediator of pancreatic cancer tumorigenesis.' Nature 425(6960): 851-6.

Thibert C, Teillet MA, Lapointe F, Mazelin L, Le Douarin NM und Mehlen P, 2003. 'Inhibition of neuroepithelial patched-induced apoptosis by sonic hedgehog.' Science 301(5634): 843-6.

Tiffin N, Williams RD, Shipley J und Pritchard-Jones K, 2003. 'PAX7 expression in embryonal rhabdomyosarcoma suggests an origin in muscle satellite cells.' $\mathrm{Br} \mathrm{J}$ Cancer 89(2): 327-32.

Tostar U, Malm CJ, Meis-Kindblom JM, Kindblom LG, Toftgard R und Unden AB, 2006. 'Deregulation of the hedgehog signalling pathway: a possible role for the PTCH 
and SUFU genes in human rhabdomyoma and rhabdomyosarcoma development.' J Pathol 208(1): 17-25.

Uhmann A, Dittmann K, Nitzki F, Koleva M, Frommhold A, Zibat A, Binder C, Adham I, Heller T, Armstrong V, Schulz-Schaeffer W, Wienands J und Hahn H, 2006 eingereicht. 'Specification and differentiation defects of the lymphoid lineage in conditional patched mutant mice.'

Uhmann A, Ferch $U$, Bauer R, Tauber S, Arziman Z, Chen C, Hemmerlein B, Wojnowski L und Hahn $\mathrm{H}$, 2005. 'A model for PTCH1/Ptch1-associated tumors comprising mutational inactivation and gene silencing.' Int J Oncol 27(6): 1567-75.

Unden AB, Holmberg E, Lundh-Rozell B, Stahle-Backdahl M, Zaphiropoulos PG, Toftgard R und Vorechovsky I, 1996. 'Mutations in the human homologue of Drosophila patched (PTCH) in basal cell carcinomas and the Gorlin syndrome: different in vivo mechanisms of PTCH inactivation.' Cancer Res 56(20): 4562-5.

Verrou C, Zhang Y, Zurn C, Schamel WW und Reth M, 1999. 'Comparison of the tamoxifen regulated chimeric Cre recombinases MerCreMer and CreMer.' Biol Chem 380(12): 1435-8.

Vogelstein B und Kinzler KW, 1992. 'p53 function and dysfunction.' Cell 70(4): 523-6.

Wada H, Holland PW und Satoh N, 1996. 'Origin of patterning in neural tubes.' Nature 384(6605): 123.

Wang B, Fallon JF und Beachy PA, 2000. 'Hedgehog-regulated processing of Gli3 produces an anterior/posterior repressor gradient in the developing vertebrate limb.' Cell 100(4): 423-34.

Wang G, Amanai K, Wang B und Jiang J, 2000. 'Interactions with Costal2 and suppressor of fused regulate nuclear translocation and activity of cubitus interruptus.' Genes Dev 14(22): 2893-905.

Watkins DN, Berman DM, Burkholder SG, Wang B, Beachy PA und Baylin SB, 2003. 'Hedgehog signalling within airway epithelial progenitors and in small-cell lung cancer.' Nature 422(6929): 313-7.

Wetmore C, 2003. 'Sonic hedgehog in normal and neoplastic proliferation: insight gained from human tumors and animal models.' Curr Opin Genet Dev 13(1): 34-42.

Wetmore C, Eberhart DE und Curran T, 2000. 'The normal patched allele is expressed in medulloblastomas from mice with heterozygous germ-line mutation of patched.' Cancer Res 60(8): 2239-46.

Wicking $C$ und Bale AE, 1997. 'Molecular basis of the nevoid basal cell carcinoma syndrome.' Curr Opin Pediatr 9(6): 630-5.

Wijermans P, Lubbert M, Verhoef G, Bosly A, Ravoet C, Andre M und Ferrant A, 2000. 'Low-dose 5-aza-2'-deoxycytidine, a DNA hypomethylating agent, for the 
treatment of high-risk myelodysplastic syndrome: a multicenter phase II study in elderly patients.' J Clin Oncol 18(5): 956-62.

Wreszinski W, 1913. 'Der Papyrus Ebers: I. Teil, Umschrift, in: Medizin der alten Ägypter, Band III.' Leipzig (2 Bände).

Wu L, Li CL und Shortman K, 1996. 'Thymic dendritic cell precursors: relationship to the $T$ lymphocyte lineage and phenotype of the dendritic cell progeny.' J Exp Med 184(3): 903-11.

Wu L, Scollay R, Egerton M, Pearse M, Spangrude GJ und Shortman K, 1991. 'CD4 expressed on earliest T-lineage precursor cells in the adult murine thymus.' Nature 349(6304): 71-4.

Yaffe D und Saxel O, 1977. 'Serial passaging and differentiation of myogenic cells isolated from dystrophic mouse muscle.' Nature 270(5639): 725-7.

Zhang $Y$ und Kalderon D, 2001. 'Hedgehog acts as a somatic stem cell factor in the Drosophila ovary.' Nature 410(6828): 599-604. 


\section{Danksagung}

Die vorliegende Arbeit wurde am Institut für Humangenetik (Leitung Herr Proffessor Dr. W. Engel) der Universität Göttingen angefertigt.

Mein Dank gilt in erster Linie Frau Professor Dr. H. Hahn für die Bereitstellung des sehr interessanten und spannenden Themas, für ihre intensive wissenschaftliche Betreuung, ihre Diskussionsbereitschaft, ihren Humor und dafür, dass sie immer voll hinter ihren Mitarbeitern steht.

Bei Herrn Professor Dr. W. Engel (Institut für Humangenetik) bedanke ich mich herzlich für die Übernahme des Referates und bei Frau PD Dr. S. Hoyer-Fender (Institut für Zoologie, Anthropologie und Entwicklungsbiologie) für die Übernahme des Korreferates dieser Arbeit.

Ebenso möchte ich mich bei Herrn Professor Dr. J. Wienands (Institut für Zelluläre und Molekulare Immunologie) für die Kollaboration mit seinem Labor bedanken, ohne welche die immunologische Analyse der $t P t c h^{-/}$Mäuse nicht möglich gewesen wäre. Weiterhin danke ich Herrn Dr. W. Schulz-Schaeffer (Abt. für Neuropathologie) für sein Engagement und seine wertvolle Hilfe in Fragen der Immunhistologie.

Frau Professor Dr. C. Binder (Abt. für Onkologie), Frau Dr. T. Heller (Abt. für Klinische Chemie) und Frau G. Hindermann (Institut für Humangenetik) danke ich für inre große Hilfe bei den zytologischen Knochenmarks- und Blutanalysen.

Für die Bereitstellung des Expressionsplasmids pAN MerCreMer möchte ich mich bei Herrn Professor Dr. M. Reth (MPI für Immunobiologie, Freiburg) bedanken. Ebenso gilt mein Dank Herrn Professor Dr. A. Berns (Netherlands Cancer Institute, Amsterdam), der uns die Mauslinie ROSA26CreERT2 noch vor deren Publikation zur Verfügung stellte. Herrn Professor Dr. M. P. Scott (Howard Hughes Medical Institute, Chevy Chase, USA) danke ich für die Bereitstellung des Vektors $p B S S K^{+}$ mPtch(K)wt.

Frau Dr. M. Koleva (ehemals Institut für Humangenetik) danke ich für die Klonierung des Zielvektors $p P t c h^{N X}$ sowie des ES-Zellscreens und Dr. I. Adham (Institut für Humangenetik) für seine Hilfe beim der Keimbahntransmission des $p P t c h^{N X} V_{\text {Vektors. }}$

Dr. A. Zibat (Institut für Humangenetik) danke ich für seine Hilfe bei der Analyse der Rekombinationseffizienz des Ptch $^{N X}$ Lokus. 
Außerdem möchte ich mich beim gesamten Team des Tierstalls der Humangenetik bedanken, insbesondere Stefan Wolf, Alexandra Pahl und Kerstin Beyer.

Mein ganz herzlicher Dank gilt außerdem allen Labormitgliedern der Arbeitsgruppe von Prof. Dr. H. Hahn. Allen voran danke ich meiner lieben kleinen Frauke und der fast immer fröhlichen Anke. Nicht nur die gemeinsamen Raucherpausen und das entspannte Arbeiten werde ich ganz schrecklich vermissen, sondern auch alles drumherum. Es war super. Danke auch an Regine, Du hast immer ein offenes Ohr gehabt für große und kleine Problemchen, ob wissenschaftlicher oder privater Art. Astrid und Ina, danke ich für Sektchen und fröhliches Arbeiten. Danke auch an Ines, Arne und Frauke P. für Eure aufmunternden Worte.

Außerdem geht ein ganz großer Dank an Kai (Institut für Zelluläre und Molekulare Immunologie). Mit Dir zu Arbeiten ist fast wie Urlaub.

Natürlich möchte ich nicht vergessen allen zu danken, die dafür verantwortlich sind, dass ich immer noch fröhlich aus der Wäsche gucke. Danke Mama und Papa, was habe ich Euch vollgequatscht... aber keine Sorge, dass werde ich auch weiterhin tun. Danke mein lieber kleiner, großer Bruder Martin, Du bist mein ganzer Stolz. Danke Anne und nochmals Frauke, mit Euch zu telefonieren, läßt den Alltag vergessen. Außerdem danke an meine Lieblingskleinfamilie und Tatortgucker: Tina, Alf, Philip, Olivia und Balu. 


\section{Curriculum vitae}

Persönliche Angaben

geboren am 23. Dezember 1976 in Erfurt

Staatsangehörigkeit: deutsch

\section{Ausbildung}

Sommersemester 2006

Rigorosum und Abschluss der Dissertation (Dr. rer. nat.)

Sept 2002 bis April 2006 Promotion am Institut für Humangenetik, Abeitsgruppe Prof. Dr. H. Hahn, Universität Göttingen

,Der Hedgehog Rezeptor Patched bei der Tumorentstehung und in der Hämatopoese'

Jan 2002

Diplom in Biologie (Note: sehr gut)

2001-2002

Diplomarbeit am Institut für Genetik, Prof. Dr. C.F. Lehner, Universität Bayreuth 'Phänotypische und molekulare Untersuchungen der Funktion von I(3)85Aa'

Herbst 1998 Vordiplom in Biologie

$1996-2000$

Studium der Biologie, Universität Bayreuth

Juni 1996

Abitur (Note: sehr gut), Integrierte Gesamtschule Erfurt

Juni 1993

Realschulabschluß, Integrierte Gesamtschule Erfurt

\section{Berufserfahrung}

April-Juli 2002

Aug-Sept 2000

Herbst 1999/2000

Sept-Okt 1999

Wissenschaftliche Mitarbeiterin am Institut für Genetik, Prof. Dr. C.F. Lehner, Universität Bayreuth

Industriepraktikum, Abt. Antiinfectiva Forschung, Dr. R. Gahlmann, Bayer AG pharma research, Wuppertal

'Expression und Isolierung der humanen UMP-CMP-Kinase in E.coli'

Praktikum am Institut für Genetik, Prof. Dr. C.F. Lehner, Universität Bayreuth

'Klonierung des $D$. virilis Gens three rows im genomischen Kontext des $D$.

melanogaster three rows in den Tranformationsvektor pCasper4'

'Isolierung des in $E$. coli überexprimierten $\mathrm{N}$-terminalen Fragmentes des $D$.

melanogaster Esp1p zur Hestellung eines Antikörpers'

Praktikum am Thüringer Medzin-Lebensmittel-Veterinär-Untersuchungsamt, Abt. Mikrobiologie, Dr. U. Warweg, Erfurt

\section{Publikationen}

Uhmann A, Ferch U, Bauer R, Tauber S, Arzinam Z, Chen C, Hemmerlein B, Wojnowski L, Hahn H. A model for PTCH1/Ptch1-associated tumors comprising mutational inactivation and gene silencing. Int J Oncol, 2005 Dec; 27(6):1567-75.

Uhmann A, Dittmann K, Nitzki F, Kolova M, Frommhold A, Zibat A, Binder C, Adham I, Heller T, Armstrong V, Schulz-Schaeffer W, Wienands J, Hahn H. Specification and differentiation defects of the lymphoid lineage in conditional patched mutant mice. Nat. Immunol., 2006, eingereicht. 
